\title{
Artefactual, Environmental and Archaeological Evidence from the Holyrood Parliament Site Excavations
}

Holyrood Archaeology Project Team

Scottish Archaeological Internet Report 40, 2010 www.sair.org.uk 
Published by

the Society of Antiquaries of Scotland, www.socantscot.org.uk with Historic Scotland, www.historic-scotland.gov.uk and the Council for British Archaeology, www.britarch.ac.uk

Editor: Helen Bleck

Produced by Archetype Informatique SARL, www.archetype-it.com

ISBN: 9780903903660

ISSN: 1773-3803

Requests for permission to reproduce material from a SAIR report should be sent to the Director of the Society of Antiquaries of Scotland, as well as to the author, illustrator, photographer or other copyright holder.

Copyright in any of the Scottish Archaeological Internet Reports series rests with the SAIR Consortium and the individual authors.

The maps are reproduced from Ordnance Survey material with the permission of Ordnance Survey on behalf of The Controller of Her Majesty's Stationery Office. C Crown copyright 2001. Any unauthorised reproduction infringes Crown copyright and may lead to prosecution or civil proceedings. Historic Scotland Licence No. GD 03032G, 2002.

The consent does not extend to copying for general distribution, advertising or promotional purposes, the creation of new collective works or resale. 
List of Illustrations . . . . . . . . . . . . . . . . . . . . . . . . . . . . . vi

List of Tables. . . . . . . . . . . . . . . . . . . . . . . . . . . . . vii

Preface and Acknowledgements . . . . . . . . . . . . . . . . . . . . . . . . viii

PART 1 THE ARTEFACT REPORTS ................................ 1

1.1 Introduction (Adrian Cox) . . . . . . . . . . . . . . . . . . . . . . . . 3

1.1.1 Summary of the artefact and ceramic evidence (Adrian Cox \& Derek Hall) . . . . . . . . . . . . . . . 3

1.2 Pottery (Derek W Hall) . . . . . . . . . . . . . . . . . . . . . . . . . 6

1.2.1 Scottish and English fabrics . . . . . . . . . . . . . . . . . . . . . . . . . . . . .6

1.2.2 Fabrics imported from the Low Countries. . . . . . . . . . . . . . . . . . . . . . . . . . 8

1.2.3 Fabrics imported from France. . . . . . . . . . . . . . . . . . . . . . . . . . 8

1.2.4 Fabrics imported from Germany . . . . . . . . . . . . . . . . . . . . . . . . . . . . . . 12

1.2.5 Fabrics imported from Spain . . . . . . . . . . . . . . . . . . . . . . . . . . . . 12

1.2.6 Fabrics imported from unknown sources in Northern Europe . . . . . . . . . . . . . . . . . . . . . 12

1.2.7 Conclusion. . . . . . . . . . . . . . . . . . . . . . . . 13

1.2.8 Selected catalogue of pottery from the main Parliament Site . . . . . . . . . . . . . . . . . . . . 14

1.3 Metal objects (Adrian Cox). . . . . . . . . . . . . . . . . . . . . . . . 16

1.3.1 Copper alloy objects . . . . . . . . . . . . . . . . . . . . . . . . . . . . . . . 16

1.3.2 Lead alloy objects. . . . . . . . . . . . . . . . . . . . . . . . . . . . . . . . . . 21

1.3.3 Iron objects . . . . . . . . . . . . . . . . . . . . . . . . . . . . . 22

1.4 Iron-making and -working (Effie Photos-Jones) . . . . . . . . . . . . . . . . . . . . . 24

1.4.1 Introduction: setting the scene. . . . . . . . . . . . . . . . . . . . . . . . . . . 24

1.4.2 The Scottish bloomery . . . . . . . . . . . . . . . . . . . . . . . . . . 25

1.4.3 Energy sources and natural resources . . . . . . . . . . . . . . . . . . . . . . . . . . 26

1.4.4 Typology and distribution of the Holyrood metallurgical waste . . . . . . . . . . . . . . . . . . . . . 26

1.4.5 Holyrood fuel and metallurgical waste: slag morphology and slag analysis methodology . . . . . . . . . . 27

1.4.6 Discussion . . . . . . . . . . . . . . . . . . . . . . . 36

1.5 Glass (Robin Murdoch) . . . . . . . . . . . . . . . . . . . . . . . 37

1.6 Ceramic objects (Adrian Cox) . . . . . . . . . . . . . . . . . . . . . . . 42

1.7 Ceramic and stone building material (Julie Franklin) . . . . . . . . . . . . . . . . . 43

1.7.1 Introduction . . . . . . . . . . . . . . . . . . . . . . . . . . . . 43

1.7.2 Floor and wall tiles . . . . . . . . . . . . . . . . . . . . . . . . . . . . . . . 44

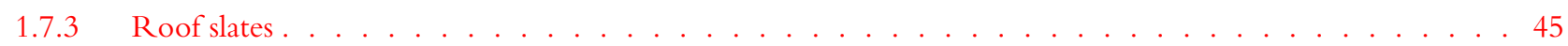

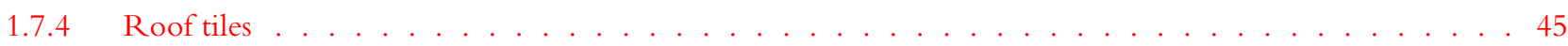

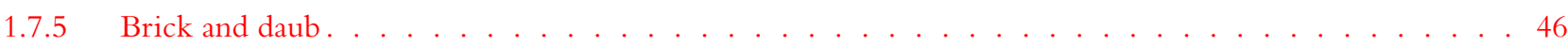


1.9 Flaked stone (Torben Bjarke Ballin) . . . . . . . . . . . . . . . . . . . . . . . . . 47

1.9 .1 Raw material. . . . . . . . . . . . . . . . . . . . . . . . . . . . . 47

1.9.2 Assemblage composition . . . . . . . . . . . . . . . . . . . . . . . 48

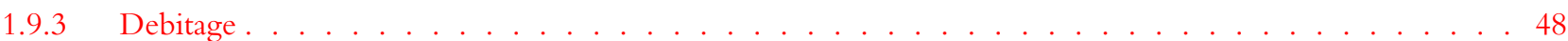

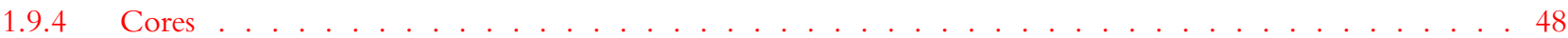

1.9 Tools. . . . . . . . . . . . . . . . . . . . . . . . . . 49

1.9.6 Possible ballast flint . . . . . . . . . . . . . . . . . . . . . . . . . . . 49

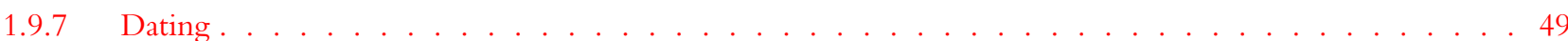

1.10 Bone and antler objects (Adrian Cox) . . . . . . . . . . . . . . . . . . . . . . 50

1.11 Leather objects . . . . . . . . . . . . . . . . . . . . . . . . . . . . 51

1.11.1 Leather-covered ball (Adrian Cox) . . . . . . . . . . . . . . . . . . . . . . . . . . . . . 51

1.11.2 Shoe and miscellaneous fragments (Clare Thomas) . . . . . . . . . . . . . . . . . . . . . 52

1.12 Coins and jetons (Nicholas Holmes). . . . . . . . . . . . . . . . . . . . . 52

1.13 Clay tobacco pipes (Dennis Gallagher) . . . . . . . . . . . . . . . . . . . . . . 53

1.13.1 Edinburgh makers . . . . . . . . . . . . . . . . . . . . . . . . . . . . 55

1.13.2 Imported and 19 th-century pipes . . . . . . . . . . . . . . . . . . . . . . . . . . . . 57

1.13.3 The pipes in relation to the site . . . . . . . . . . . . . . . . . . . . . . . . 57

1.14 Artefacts from Queensberry House . . . . . . . . . . . . . . . . . . . . . . 59

1.14.1 Pottery (Derek W Hall) . . . . . . . . . . . . . . . . . . . . . . . . . . . . . . . 59

1.14.2 Iron objects (Adrian Cox). . . . . . . . . . . . . . . . . . . . . . . . . . . . . . . 61

1.14.3 Industrial waste (Effie Photos-Jones). . . . . . . . . . . . . . . . . . . . . . . . . . . . . 61

1.14.4 Glass (Adrian Cox) . . . . . . . . . . . . . . . . . . . . . . . . . . 63

1.14 .5 Leather (Adrian Cox) . . . . . . . . . . . . . . . . . . . . . . . . . . . . . 64

1.14.6 Stone and ceramic building material (Adrian Cox) . . . . . . . . . . . . . . . . . . . . . . . . . . 64

1.14.7 Clay tobacco pipes (Dennis Gallagher). . . . . . . . . . . . . . . . . . . . . . . . . . . . 65

1.14.8 House of Refuge finds (Jo Dawson) . . . . . . . . . . . . . . . . . . . . . . . . . . . . . . 65

PART 2 THE ENVIRONMENTAL REMAINS ...........................69

2.1 Summary of results (Stephen Carter) . . . . . . . . . . . . . . . . . . . . . . . 71

2.2 Carbonised plant remains (Tim Holden \& Mhairi Hastie) . . . . . . . . . . . . . . . 71

2.2.1 Methodology. . . . . . . . . . . . . . . . . . . . . . . . . . 71

2.2.2 Main excavation site . . . . . . . . . . . . . . . . . . . . . . . . . . 71

2.2.3 Queensberry House . . . . . . . . . . . . . . . . . . . . . . . . . . . . . . . . 74

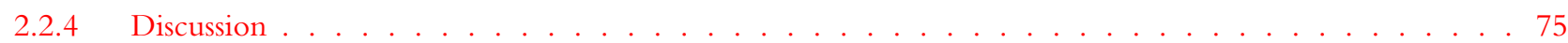

2.3 Mammalian, bird and molluscan remains (Catherine Smith) . . . . . . . . . . . . . . 76

2.3.1 Selection criteria for mammal bone samples . . . . . . . . . . . . . . . . . . . . . . . . . . 76

2.3.2 Summary of animal bone by period . . . . . . . . . . . . . . . . . . . . . . . . . . . 77 
2.3.3 The domestic livestock . . . . . . . . . . . . . . . . . . . . . . . . . . . . 81

2.3.4 Discussion of the mammalian and bird remains. . . . . . . . . . . . . . . . . . . . . . . 93

2.4 Fish remains (Ruby Cerón-Carrasco) . . . . . . . . . . . . . . . . . . . . . 105

2.4.1 Methodology. . . . . . . . . . . . . . . . . . . . . . 105

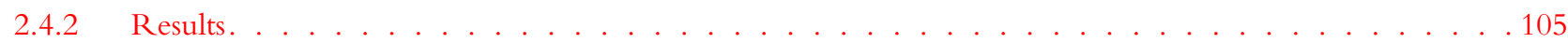

2.4.3 Discussion by period . . . . . . . . . . . . . . . . . . . . . . . . . . . . . . . . . .

2.5 Soils and sediments (Stephen Carter) . . . . . . . . . . . . . . . . . . . . 108

2.5.1 Sediment sources and processes of accumulation . . . . . . . . . . . . . . . . . . . . 108

2.5 .2 Soils . . . . . . . . . . . . . . . . . . . . . . . . . . . . . . . . . . . . . . . . . .

2.5.3 Materials and methodology . . . . . . . . . . . . . . . . . . . . . . . . 108

2.5.4 Results. . . . . . . . . . . . . . . . . . . . . . . . . . . . . . . . . . . . . . .

2.5.5 Sediment depth and distribution . . . . . . . . . . . . . . . . . . . . . . . . . . . 111

2.5.6 Discussion . . . . . . . . . . . . . . . . . . . . . . . . . 114

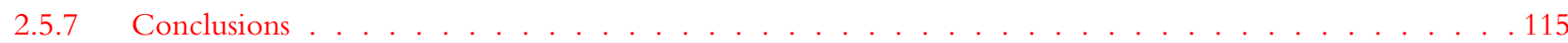

PART 3 THE ARCHAEOLOGICAL EVIDENCE FROM THE PARLIAMENT SITE (SIMON STRONACH). Reprinted from Scotland's Parliament and the Canongate: archaeology and history (HAPT 2008) . . . . . . . . . . . . . . . . . . . . . . 117

3.1 Introduction ....................................119

3.2 Summary of the archaeological evidence . . . . . . . . . . . . . . . . . . . . 119

3.3 Early features . . . . . . . . . . . . . . . . . . . . . . . 120

3.4 Period 1: 12th-14th-century ditch. . . . . . . . . . . . . . . . . . . . . . 121

3.5 Period 2: 14th-15th-century burgage plots . . . . . . . . . . . . . . . . . . . . 122

3.5.1 Medieval accumulation . . . . . . . . . . . . . . . . . . . . . . . . . . 122

3.5.2 Boundaries and backlands. . . . . . . . . . . . . . . . . . . . . . . . . . . . . 122

3.6 Period 3: 16th-17th-century tenements and gardens . . . . . . . . . . . . . . . . . 126

3.7 Period 4: 17th-18th-century townhouses and formal gardens . . . . . . . . . . . . . . 130

3.8 Period 5: 19th-century military barracks and modern features . . . . . . . . . . . . . . 135

3.9 Conclusions. . . . . . . . . . . . . . . . . . . . . . . . . . . 135

References........................................141 


\section{LIST OF ILLUSTRATIONS}

$1.1 \quad$ Pottery $($ Pot nos $1-30) \ldots \ldots \ldots \ldots \ldots$

1.2 Pottery $($ Pot nos $32-57) \ldots \ldots \ldots \ldots \ldots$

1.3 Pottery $($ Pot nos $58-87) \ldots \ldots \ldots \ldots \ldots \ldots$

1.4 Pottery $($ Pot nos $88-103) \ldots \ldots \ldots \ldots \ldots$

1.5 Copper-alloy and lead objects. . . . . . . . . . . . . . . . . . . . . . . . . . 17

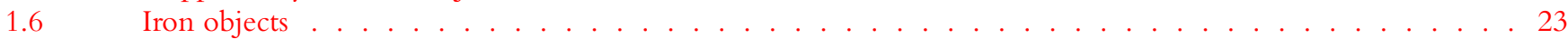

1.7 Iron-working . . . . . . . . . . . . . . . . . . . . . . . . . . . . . . 30

1.8 Iron-working . . . . . . . . . . . . . . . . . . . . . . . . . . . 31

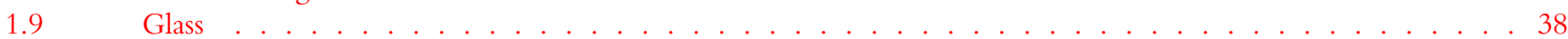

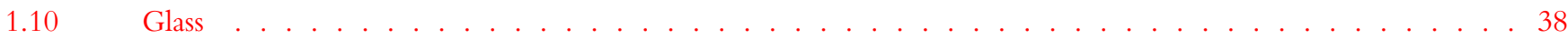

1.11 Glass . . . . . . . . . . . . . . . . . . . . . . . . . . . . . 38

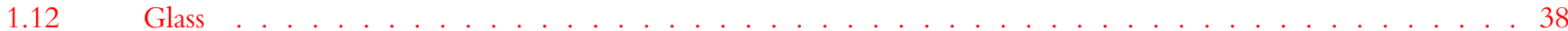

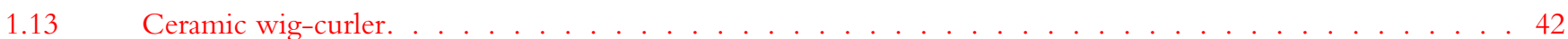

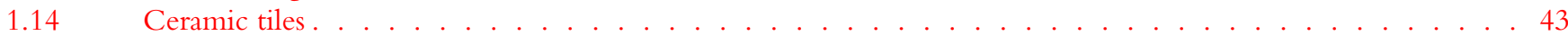

1.15 Ceramic tiles. . . . . . . . . . . . . . . . . . . . . . . . . . . . . . . 44

1.16 Stone discs . . . . . . . . . . . . . . . . . . . . . . . . . . . 46

1.17 Ceramic disc, stone whorls and bead . . . . . . . . . . . . . . . . . . . . . . . . . 47

1.18 Flaked stone artefacts . . . . . . . . . . . . . . . . . . . . . . . . . . . . . . 49

1.19 Expanded illustration of bone dice . . . . . . . . . . . . . . . . . . . . . . . . . . 50

1.20 Bone handle . . . . . . . . . . . . . . . . . . . . . . . . . . . . . . 51

$1.21 \quad$ Leather ball . . . . . . . . . . . . . . . . . . . . . . . . . . . . . . 52

1.22 Clay tobacco pipes . . . . . . . . . . . . . . . . . . . . . . 53

1.23 Clay tobacco pipes . . . . . . . . . . . . . . . . . . . . . . . . 54

1.24 Clay tobacco pipes . . . . . . . . . . . . . . . . . . . . . . . . . . . . 54

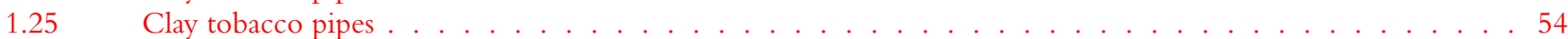

1.26 Clay tobacco pipes . . . . . . . . . . . . . . . . . . . . . . . 54

1.27 Clay tobacco pipes . . . . . . . . . . . . . . . . . . . . . . . . . . . 54

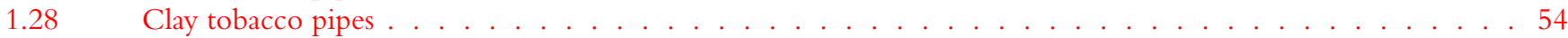

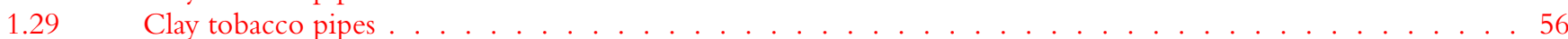

$1.30 \quad$ Clay tobacco pipes . . . . . . . . . . . . . . . . . . . . . . . . 56

1.31 Clay tobacco pipes . . . . . . . . . . . . . . . . . . . . . . . . . . . 56

1.32 Clay tobacco pipes . . . . . . . . . . . . . . . . . . . . . . . . . . 56

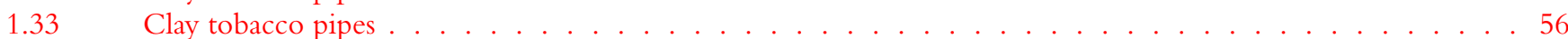

1.34 Clay tobacco pipes . . . . . . . . . . . . . . . . . . . . . . . 56

1.35 Clay tobacco pipes . . . . . . . . . . . . . . . . . . . . . . . . . . . . . 58

1.36 Clay tobacco pipes . . . . . . . . . . . . . . . . . . . . . . . 58

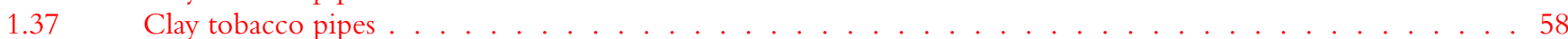

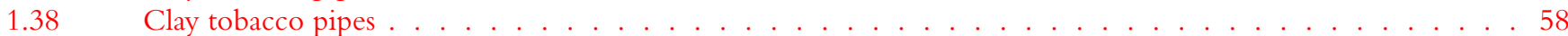

1.39 Clay tobacco pipes . . . . . . . . . . . . . . . . . . . . . . . . . . . . . . 58

1.40 Clay tobacco pipes . . . . . . . . . . . . . . . . . . . . . . . . 58

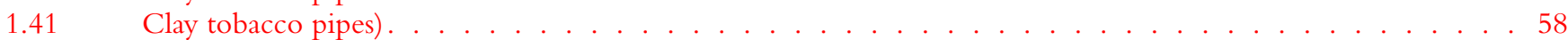

1.42 Pottery (QH Pot nos 1-17) from Queensberry House . . . . . . . . . . . . . . . . . . . . . . 59

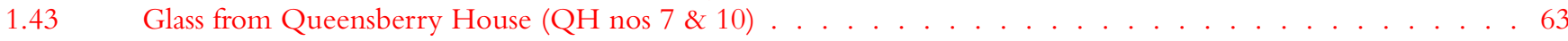

1.44 Tile from Queensberry House . . . . . . . . . . . . . . . . . . . . . . 65

2.1 Period 2: concentration of finds in bulk soil samples . . . . . . . . . . . . . . . . . . . . . . . 110

2.2 Period 3: concentration of finds in bulk soil samples . . . . . . . . . . . . . . . . . . . . . . . . . 112

2.3 Total depths of soil over subsoil . . . . . . . . . . . . . . . . . . . . . . . . . . . . . . 113 


\section{LIST OF TABLES}

1.1 Pottery: Scottish and English fabrics by period . . . . . . . . . . . . . . . . . . . . . . . 8

1.2 Pottery: European imported fabrics . . . . . . . . . . . . . . . . . . . . . . . . . . . . 9

1.3 Copper alloy pins. . . . . . . . . . . . . . . . . . . . . . . . . . . . . . . 20

1.4 Iron-working: distribution of charcoal/coal/coke from 12 th- to 19 th-century contexts . . . . . . . . . . . 27

1.5 Iron-working: the first ten contexts with the largest concentrations of fuel . . . . . . . . . . . . . . . . . . 27

1.6 Iron-working: the first ten contexts with the largest concentrations of slag . . . . . . . . . . . . . . . . . . 28

1.7 Iron-working: the first ten contexts with the largest concentrations of magnetic residues . . . . . . . . . . . 28

1.8 Iron-working: the first ten contexts with the largest concentrations of metal residues/ferruginous material . . . 28

1.9 Iron-working: list of samples . . . . . . . . . . . . . . . . . . . . . . . . . . . . . . . . . . . . . . 29

1.10 Iron-working: analyses of samples

1.10a SEM-EDAX analyses of Period $1 \mathrm{HMW}$. . . . . . . . . . . . . . . . . . . . . . . . . . . . . . . . . . 32

1.106 SEM-EDAX Analyses of Period $2 H M W$ (medieval period) . . . . . . . . . . . . . . . . . . . . . . . . . 33

1.10c SEM-EDAX Analyses of Period 3 HMW . . . . . . . . . . . . . . . . . . . . . . . . . . . . . . . 34

1.10d SEM-EDAX Analyses of Period 4 and Period 5 HMW . . . . . . . . . . . . . . . . . . . . . . . . . . . 35

1.11 Glass . . . . . . . . . . . . . . . . . . . . . . . . . . 4 41

1.12 The flaked stone assemblage . . . . . . . . . . . . . . . . . . . . . . . . . . . . . . . . . . . 4 48

1.13 Queensberry House: list of samples and results of SEM-EDAX and XRD analyses . . . . . . . . . . . . 62

2.1 Summary of carbonised plant remains by phase . . . . . . . . . . . . . . . . . . . . . . . 72

$2.2 \quad$ Waterlogged plant remains . . . . . . . . . . . . . . . . . . . . . . . . . 74

2.3 Total number of mammal bones. . . . . . . . . . . . . . . . . . . . . . . . . . . . . 77

2.4 Comparisons of numbers and percentages of food-forming mammals . . . . . . . . . . . . . . . . . . . . 78

2.5 Total number of bird bones . . . . . . . . . . . . . . . . . . . . . . . . . . . . . 79

2.6 Comparison of numbers and percentages of food-forming mammals from Scottish medieval

and post-medieval sites . . . . . . . . . . . . . . . . . . . . . . . . . . . . . . . . . . . . . . . . . . . 80

2.7 Total number of mammalian bones from Queensberry House . . . . . . . . . . . . . . . . . . . . . . 80

2.8 Total number of bird and amphibian bones from Queensberry House. . . . . . . . . . . . . . . . . . . . . 81

2.9 Cattle mandibles arranged by wear stages . . . . . . . . . . . . . . . . . . . . . . . . . . . . 81

$2.10 \quad$ Sheep/goat mandibles arranged by wear stages . . . . . . . . . . . . . . . . . . . . . . . . . . . . . 82

2.11 Age categories based on epiphyseal fusion of long bones . . . . . . . . . . . . . . . . . . . . . 82

2.12 Cattle long bones in each age category, by phase . . . . . . . . . . . . . . . . . . . . . . . . 83

2.13 Sheep/goat long bones arranged by age category. . . . . . . . . . . . . . . . . . . . . . . 83

$2.14 \quad$ Pig long bones by age category and phase . . . . . . . . . . . . . . . . . . . . . . . . . . 84

2.15 Catalogue of butchered horse bone . . . . . . . . . . . . . . . . . . . . . . . . . 84

2.16 Catalogue of butchered $\operatorname{dog}$ bone . . . . . . . . . . . . . . . . . . . . . . . . . . 84

2.17 Size range summary . . . . . . . . . . . . . . . . . . . . . . . . . . . . . 86

2.18 Catalogue of abnormal bone . . . . . . . . . . . . . . . . . . . . . . . . . . 92

2.19 Mollusc catalogue (hand-excavated) . . . . . . . . . . . . . . . . . . . . . . . . . . . . 94

2.20 Mollusc catalogue (retents) . . . . . . . . . . . . . . . . . . . . . . . . . . . . . . 98

2.21 Fish species represented in each period . . . . . . . . . . . . . . . . . . . . . . . . 106

2.22 Composition of the thin sections . . . . . . . . . . . . . . . . . . . . . . 109

2.23 Estimates of total accumulated soil depth . . . . . . . . . . . . . . . . . . . . . . . . . . . 114 


\section{PREFACE AND ACKNOWLEDGEMENTS}

A summary of these specialist reports (Parts 1 \& 2) was published in 2008 in the monograph on the Holyrood Parliament Site Project: Scotland's Parliament Site and the Canongate: Archaeology and History by the Holyrood Archaeology Project Team, Chapter $3.9 \& 3.10$ (HAPT 2008). Except for sections 3.9 and 3.10, Chapter 3 in that monograph has been repeated here as Part 3, in order to provide the archaeological context for the artefactual and environmental evidence alongside the specialist reports. The cross-references in Part 3 to other chapters refer to HAPT 2008.

We are grateful to the authors for their patience with this two-level process of publication and to Simon Stronach of Headland Archaeology Ltd, Catherine Smith of SUAT Ltd and Kevin MacLeod for their assistance.

Gordon G Barclay \& Anna Ritchie Editors 


\section{PART I}

สำ

The Artefact Reports 



\subsection{INTRODUCTION}

\section{ADRIAN COX}

The material from the main excavation encompasses a broad date range, mainly reflecting the site's occupation from the medieval period until recent times, although a lithic assemblage of prehistoric date was also present. The finds from the Queensberry House excavation provide additional insights, particularly into the later periods of activity on the site.

The full catalogue of the finds is deposited in the RCAHMS Archive, and a selective catalogue, including all the illustrated objects and most other diagnostic finds, is included here. There are separate catalogues for the finds and the pottery which are denoted here by the respective abbreviations no. 1, 2 etc and Pot no. 1, 2 etc. Since the main site excavation and much of the post-excavation work was completed before the Queensberry House work was commissioned, a second archive has been constructed for the Queensberry House material. In this, as for the main site, there are separate catalogues for the finds and the pottery. These are denoted here by the abbreviations QH no. 1,2 etc and QH Pot no. 1,2 etc. The pottery and finds from the main excavation are described first, followed by those from the excavation at Queensberry House.

\subsubsection{Summary of the artefact and ceramic evidence}

\section{ADRIAN COX AND DEREK HALL}

Although almost no major concentrations of artefacts strongly diagnostic of particular functions and activities occurred anywhere on the site, the evidence highlights changes in the nature of the site's occupation and use through time, and illuminates aspects of daily life. A large majority of the recovered artefacts came from deposits and features in the western half of the site, and many came from the extensive medieval and post-medieval 'garden' soils. Finds from the site's eastern end, formerly occupied by the Scottish \& Newcastle Breweries complex, were scarce.

In compiling this brief overview of the recovered evidence, reference has been made to the work of all the contributing specialists. For more detailed accounts of individual artefacts and material assemblages, the reader should refer to their detailed reports (below). Measurements in the catalogue are generally expressed to the nearest $1 \mathrm{~mm}$; where appropriate they have been expressed to the nearest $0.1 \mathrm{~mm}$.

\section{Period i (i2Th-I4Th Centuries)}

Few finds were associated with this period, although there was some evidence of metallurgical activity. Among the other artefacts recovered is a horseshoe nail (no. 58), of a form generally thought to have been in use until the 13th century, although finds from Perth indicate that similar nails may have remained in use into the 14 th century. The excavations yielded a total of 44 pieces of struck stone (mainly flint), although probably none was in a primary context. Two bipolar flakes of quartz (nos 143 \& 144) came from the natural silting in the boundary ditch 754 located along the southern edge of excavation, and a hard- hammer flake (no. 145) was found in a gravel deposit in this period.

This period produced a small amount of pottery $(24$ sherds in total), comprising jugs and cooking pots of Scottish White Gritty Ware, presumably of local production. Of most interest is the single sherd that is apparently from a local copy of a Yorkshire seal jug (756; Pot no. 13). If this identification is correct, the context that produced this sherd, namely backfill within the large boundary ditch 754 , can date no earlier than the 13 th or 14 th centuries.

Period 2 (I4TH-I5Th CeNturies)

\section{Period 2.1}

Even fewer finds were associated with Period 2.1, associated with the formal division of the site, than was the case in Period 1. Among those recovered was the earliest of a number of iron horseshoe fragments (no. 54). Other horseshoes were recovered from Periods 2.2 and 2.3.

\section{Period 2.2}

Associated with the accumulation of medieval 'garden soil' deposits and associated features in this period is a varied assemblage of artefacts, representing a diverse array of craft activities and domestic pursuits. As also in Period 1, a number of finds provide tentative evidence of the types of buildings which existed on or near the site. Among this evidence are two lead alloy window came fragments, indicating glazed windows. Found in the upper fills of the Period 1 boundary ditch 754, a fragment representing the edge of an inlaid floor tile (no. 122) probably came from a prestigious building, possibly with a religious function.

There is some limited artefactual evidence of non-ferrous metal-working. A fragment of lead alloy waste, rolled up and possibly intended for re-use (no. 51), came from one of the garden soil deposits, and a possible lead alloy offcut (no. 47) was found with the window came fragments referred to above. As well as being in demand to make cames, workers in lead would have been involved in the fabrication of roofs for ecclesiastical buildings and other large structures, and in the manufacture of pewter tableware, tokens and other artefacts (Ewan 1990, 34). Evidence for the cold working of sheet metal survives in the form of a riveted fragment of copper alloy sheet, probably representing a vessel repair patch (no. 35), which was found in the fill of the boundary ditch 810 on the east side of Plot 2.2. This may have been fabricated on the site, although the vessel may possibly have been brought to the site in its repaired condition.

Analysis of the industrial debris from the site revealed a sustained accumulation of iron smelting/smithing waste in an area to the south of Queensberry House in Periods 2.2-2.3 and Period 3, possibly indicating that metallurgical activities were concentrated in this area during the medieval and postmedieval periods.

Many town-dwellers probably produced much of their domestic requirements themselves. Indeed, documentary sources reveal that many people owned spinning wheels and other weaving equipment. Many would have clothed themselves with home-produced textiles. A decorated spindle whorl (no. 140), found in the fill of a well (1567, Plot 2.4) 
in this period, represents one of the artefact types associated with this kind of activity most likely to survive in the archaeological record. Generally only on waterlogged sites, where anaerobic conditions occur, are textiles and organic components of weaving equipment preserved. No. 140 is paralleled by finds from 13th- to 15th-century contexts elsewhere in Scotland. Spindle whorls were used in the production of fairly small quantities of yarn by the drop-spinning method. As Peter Yeoman $(1995,75)$ notes, the evidence recovered from Scottish urban excavations, in terms of spinning and weaving equipment, and of textiles, suggests that most domestic cloth production was simple and small-scale.

Limited evidence of costume survives in the form of dress accessories, such as a double-looped buckle from this period (no. 3), again recovered from a cultivated soil deposit, and dating from the mid 14 th century or later. This buckle may have been used in conjunction with a spur. The individual who wore it may therefore have been someone of at least moderate means, and perhaps the same can be said of the person who owned a copper alloy mount of cruciform shape (no. 16), which may have been worn on leather or textile clothing.

Alongside subsistence and any commercial activities, the site's inhabitants must have found time for leisure pursuits. The smallest of four stone discs from the site (no. 136), again recovered from a cultivated soil deposit, may represent a gaming counter. The earlier of two bone dice (no. 189) was also found in Period 2.2. Dice could be used in different ways, either by themselves in games of chance, or to determine the movement of pieces on a gaming board.

This period marks the first appearance of sizeable quantities of pottery on the site (1979 sherds). Scottish White Gritty Ware is the most common fabric, with smaller elements of the later local fabrics, Reduced Gritty Ware and Oxidised Redware. The largest number of sherds of Yorkshire-type Ware was recovered from this period, including sherds from the fill of a slot (333, Plot 2.1) and a pit (746, Plot 2.2) which were located in the property running adjacent to Reid's Close. Rhenish Stoneware (14th/15th centuries) first appears in this period, with sherds from Raeren and Siegburg vessels from industrial feature 1520 (Plot 2.4) and sump or feeder channel (767, Plot 2.2) respectively. Industrial feature 1520 also produced a single sherd of 16th/17th-century Weser Slipware which would place the backfilling of this feature towards the end of this period. The only sherd of green-glazed stoneware (15th century) from the excavation was found in the fill of a well (1567, Plot 2.4). It is of interest that even at this early stage the imported pottery present includes high-status stoneware and slipware.

\section{Period 2.3}

Scottish White Gritty continues to be the most common fabric in this period, with Reduced Gritty Ware and Oxidised Redware also well represented. The proximity of high-status buildings is suggested by a single sherd of Beauvais Double Sgraffito Ware from the backfill of a stone tank 843 in Plot 2.1 and four sherds from Spanish olive jars from surface 1104 on the Canongate frontage in Plot 2.4.

Based on the diagnostic fragments recovered, the glass assemblage from Periods 1 to 2.2 dates from the 15 th century or earlier, whereas that from Period 2.3 dates from the late 15 th to early 16 th centuries. The evidence from documentary sources indicates that, by the late 15 th century, there were some wealthy and substantial dwellings bordering the Canongate's main street.

Finds of costume accessories become more numerous in this period. Two copper alloy lace tags (nos 11 \& 12), designed to prevent the ends of clothing and shoe laces and thongs from fraying, came from ditch 913 on the west side of Plot 2.3. The same feature produced a small, copper-alloy, D-shaped buckle of 15th- or 16th-century date (no. 4).

Documentary records reveal that workshops, wells and gardens were situated to the rear of many burgage plots. Skinners, tanners, shoemakers, cutlers, masons and brewers all held property on the south side of the Canongate. The frontages of the plots offered opportunities for commercial enterprises, with booths serving as retail outlets. Some recovered artefacts may have been associated with industrial or craft-working activities, although there were no diagnostic concentrations of artefact types. Clay-lined stone tank 775 (in Plot 2.2), thought to have been used in a tanning process, contained a possible knife blade (no. 61) in its fill. The primary fill of stone-lined tank 843, also in Plot 2.2, contained the heavily corroded iron head of a large, three-pronged fork (no. 60). The fork may simply represent a component of discarded waste material, thrown into the feature once it had gone out of use. However, given its location in the primary fill, a connection with the feature's primary function is a possibility. Perhaps the fork was used to agitate the contents of the tank On the boundary between Plots 2.1 and 2.2, a possible hone fragment (no. 142) was found in the fill of rubbish pit 722.

Documentary evidence points to an abundance of gardens and orchards in the medieval burgh, and many people kept their own livestock. Artefactual evidence for the keeping of animals is scarce, although the only complete horseshoe recovered from the site (no. 56) was found in clay surface 1104, located near to the frontage in Plot 2.4.

\section{Period 3 (i6th-i7th Centuries)}

During the 16th century, the Canongate may have gained in prestige due to the presence of royalty, although it suffered at the hands of the Earl of Hertford's expeditionary forces in the years after James V's death in 1542. Artefact evidence, such as the different types of decorated floor tiles recovered, indicates the presence of prestigious buildings in the vicinity of the site during the medieval and post-medieval periods. The floor tiles were not concentrated in a particular area, but found in different parts of the site, and therefore are difficult to relate to particular buildings.

There is still a large group of Scottish White Gritty Ware present in this period, which must suggest that a lot of the features and deposits producing it are more likely to date to the earlier end of the medieval period. Imported wares are represented by sherds of Low Countries Tin-glazed Earthenware from the fill of drain 757 , located on the west side of Plot 3.3, and a sherd of Siegburg Stoneware from drain 1524 (Plot 3.4). All these sherds are from features associated with the burgage plots that run back from the Canongate. Of most interest in this period is the piece of 16th-century ceramic stove tile from the fill of garden feature 1683 (Plot 3.5, Pot no. 74, fig. 18.3). This feature lies in the part of the Parlia- 
ment site that may originally have been part of the monastic precinct of Holyrood Abbey and as these ceramic stoves are more commonly found related to religious buildings this may imply the proximity of such a building on this part of the site.

Documentary sources reveal that young men from all parts of Scotland were sent to the Canongate in the 16th century to serve as apprentices among the burgh's hammermen, who included blacksmiths, cutlers, lorimers, braziers and jewellers. Merchants and craftsmen would have derived benefits from living close to Holyrood Palace, where they could readily have found outlets for their various skills. Among the assemblage of copper alloy artefacts there appears to be some evidence of tailoring activity. Such finds include a thimble of open form (no. 20); a type used for specialised tasks such as sewing canvas and in tailoring, and generally preferred by tailors for heavier work. Copper alloy pins were also found in this period, as was a probable needle fragment, although a greater concentration of pins appeared in Period 4.1.

Although 16th-century Edinburgh suffered from overcrowding, the burgh of Canongate was not so built-up, and fine private residences were being constructed at that time (Turner Simpson \& Holmes 1981, 49). The presence of two Nuremburg jetons, one of late 15 th to mid 16th-century date, the other of late 16 th to early 17 th-century date, lends support to the notion of at least moderately wealthy residents on the site at this time.

Along with increasing evidence of wealth, there is increasing evidence of recreational activity. Part of a disc or counter, derived from a sherd of Reduced Greyware pottery (no. 120), found in rubble overlying stone-capped culvert 757 in Plot 3.3, was probably used as a gaming counter. The fabric of this object indicates that it dates from the 15th or 16th century, and it was found with window glass of a similar date. A small bone die (no. 188) was also found in this period.

The earliest clay pipes from the excavation date from the period c 1620-40, and can be compared with examples found in a pre-1637 context beneath Edinburgh's Tron Kirk (Gallagher 1987a). One of the stratigraphically earliest is a polished bowl from a garden soil deposit in this period (no. 225). Other early examples come from Period 4.1. Of over 900 pipe fragments recovered from the site, the majority were manufactured between $c 1630$ and 1680, a period in which there was a rapid growth in the fashion for pipe-smoking in Edinburgh.

\section{Period 4 (i7Th-i8Th Centuries)}

\section{Period 4.1}

The amounts of Reduced Gritty Ware and Oxidised Redware finally overtake Scottish White Gritty Ware in this period. Interestingly, the most common ceramic cooking vessel represented in the Oxidised Redware fabric is the handled skillet (Pot nos 37-41). A wide variety of imported wares are present in this period largely dating to the 16th or 17 th centuries; many of these are from cultivation features and soils within the formal gardens of Queensberry House, Plot 4.2, and Haddington House (Plot 4.1).

These fabrics include a second sherd of Beauvais Double Sgraffito Ware, sherds of Frechen Stoneware and a small group of slipwares that may be locally produced.The garden features
(1610, 1616) associated with Lothian Hut, Plot 4.3, contain sherds from Loire jugs. This period produced the only two sherds of Mediterranean Green and Brown Redware and Saintonge Palissy-type Ware from a levelling deposit within a terrace (643, Plot 4.2), and the backfill of boundary ditch 661 (Plot 4.2). Both sherds are from very ornate pottery vessels and it is tempting to suggest that they both originate from Queensberry House itself. A unique vessel in an unidentified fabric, present in the backfill of a stone-lined industrial tank (1637, Plot 3.6), appears to be an apothecary's cup, presumably used for measuring small quantities of liquid into the tank.

The Confession of Faith, signed in 1638 by a large number of Canongate's residents, indicates a broad cross-section of craftsmen living locally. For example, more than 50 tailors signed, along with 32 wrights, 25 weavers, 15 dyers and 8 saddlers (Turner Simpson \& Holmes 1981, 50). There is tentative artefactual evidence from the excavation to support the presence of craftsmen, and also evidence of increasing wealth and sophistication, although many poorer and less fortunate residents would have lived alongside the wealthier members of society.

Of the 11 copper alloy pins recovered from the site, all but two are from Period 4.1. Their form indicates a probable 17 th-century date. Four of the pins came from the fill of a stone-capped culvert 919 (Plot 4.2) likely to have led from the kitchens of a house fronting on to the Canongate. Other pins came from the underlying and overlying deposits. This concentration of pins would appear to be significant, and may indicate tailoring activities, either in the house from which this drain led, or in a property occupying the vicinity of the drain, probably in the second half of the 17th century. Part of a small pair of iron shears (no. 62), from a garden soil deposit, may have performed a variety of household functions or been used by a tailor working on or near the site.

Among the coins recovered from the site, the largest group is of 17th-century copper coinage. The burgh's location, on the main routes from the port of Leith to both Holyrood and Edinburgh, encouraged thriving commercial activity.

Finds from the Period 4.1 garden soils include a fragment of a copper alloy rumbler bell (no. 1), probably of 16th- or 17 th-century date, which may have been worn as a costume accessory, on horse harness or on the collar of an animal. A decorative buckle (no. 2), dating from the mid 17th to 18th centuries, was also recovered, along with numerous clay pipe fragments dating from the second half of the 17th century, and glass of similar date. Overall, the glass assemblage from Periods 3 and 4.1 dates from the early 16th to early 18th centuries. One of the garden soil deposits produced a ceramic wig curler of probable 18th-century date (no. 121).

Two decorative copper alloy mounts of domed form were found in this period. No. 14 was found in a garden soil deposit, while no. 15 came from a levelling deposit for a terrace (Plot 4.2). Two copper alloy studs of the kind used on furnishings in the 16th and 17th centuries were also found.

The earliest clay pipes from this period date from the period 1630-50 (eg nos 226 and 228). One of these (no. 226) came from a garden soil deposit under Haddington House (Plot 4.1). Closely-dated clay pipes from primary contexts provide particularly useful dating evidence, for example, a pipe bowl dating from $c$ 1660-1700, found in the packing for terrace wall 629 (Plot 4.2). 
Numbers of artefacts decline in Period 4.2, possibly as a result of changes in the use of the site at this time. Despite being present throughout Periods 2, 3 and 4.1, almost all evidence of the deposition of iron-working waste disappears at this point.

The glass recovered from Period 4.2 dates from the later 18 th to the 19th centuries. There is a surprising scarcity of glass (both vessel and window) of 18th-century date in the assemblage. Wine bottles, in particular, were manufactured and used in very large numbers in the middle of the 18th century, yet a relative lack of fragments of this date has been noted from this site, possibly indicating a change of site usage after the 17 th century.

Very few clay pipes from the site post-dated 1700 . Snufftaking appears to have replaced pipe smoking as the usual method of tobacco consumption after $c 1730$, and pipes dating from the remainder of the 18 th century are uncommon in much of Scotland. Twenty pipe bowls dating from c 1640-80 were found in a make-up deposit inside Haddington House (Plot 4.1) in this period.

By this period the amount of pottery present has begun to decline, possibly reflecting a change in the rubbish-disposal pattern and the use of the southern part of the site as gardens. Of most significance are the sherds from Loire jugs in a feature associated with the construction of the Lothian Hut in Plot 4.3 (1785) and a rimsherd from a late 16th-/early 17th-century Weser Ware dish from drain 601 (Plot 4.2).

Period 5 (i8Th-2OTh Centuries)

Period 5.1

In Period 5 the pottery assemblage is dominated by 18thand 19th-century china, possibly associated with the military occupation of the site. Apart from a small group of Low Countries Tin-glazed Earthenware from the floor make-up of the Quartermaster's store (536), all the remaining pottery is liable to be residual.

Among the finds from Period 5.1 were two conjoining fragments of a glazed ceramic carpet bowl (no. 119). These were found in the fill of a shallow pit within Haddington House. This represents further evidence of leisure pursuits on the site, which appears to be a continuing small-scale theme throughout its occupation since medieval times. Parlour games such as carpet bowls would have been popular in wealthierVictorian households.

The carpet bowl fragments were accompanied in the pit fill by a flat-bottomed, iron hanging vessel (no. 67), probably of 19th-century date, which may have served a partly ornamental function. Also found in this fill was a leather shoe of riveted construction, probably dating from the 1850s or later. Boots or shoes of riveted construction usually had front lacing, and three further leather fragments with lace-holes from this period are from footwear of a similar style and construction method.

Smaller quantities of clay pipes came from make-up deposits in this period, as compared with Period 4.2. Pipes from the make-up of the floor of the Quartermaster's store have a date range of $c$ 1680-1710. The glass assemblage from Period 5 dates from the 19th and 20th centuries.
The Canongate's fortunes had declined through the 17th and 18th centuries, and by the 19th century the burgh contained derelict and overcrowded slums (Turner Simpson \& Holmes 1981, 50). Nevertheless, one particular find from this phase may be an indicator of the presence of a prestigious household: this is a German porcelain tobacco pipe bowl, of 19th-century date, depicting a young woman reading a book while resting on a plinth (no. 348). This find came from the backfill of a Period 4 well to the rear of Haddington House (231, Plot 4.1), which also contained two copper alloy buttons and a ceramic alley (no. 116).

Alleys such as no. 116 formed components of the closure mechanisms for glass bottles in the 19th century, but they were also often claimed as marbles by children, once the bottles had been used. Many manufactured items by this time bore the maker's or seller's name. A stoneware bottle top (no. 118) bearing the mark of J Stewart \& Sons, a firm based on the Canongate, was found in a service trench in this period. Among the finds from the kitchen of Queensberry House is the body of a mineral water bottle embossed with a legend indicating a connection with Dr Struve's mineral waters business (QH no. 10).

Physical evidence for the nature of structures on the site in this latest phase of its occupation includes an iron strap hinge, of 19th-century date, from a cupboard or shutter (no. 59). This too, came from the fill of a service trench.

\subsection{POTTERY}

\section{DEREK W HALL}

The excavations produced 4,873 sherds of pottery ranging in date from the 12th to the 19th centuries (figs 1.1-1.4). This material has been examined by eye and where possible assigned to a recognised fabric name. Thin sectioning and ICPS analysis were undertaken on selected sherds of Scottish White Gritty Ware (Jones et al 2003).

\section{I.2.I SCOTtish AND ENGlish Fabrics (TABle I.I)}

\section{Scottish White Gritty Ware (Pot nos I-30, fig. I. I)}

Recent work has identified three potential production centres for this fabric in Lothian, Borders and Fife regions (Haggarty 1984; Hall 1997). However, a programme of chemical sourcing is beginning to suggest that kilns producing this fabric may have been more widespread than had previously been thought (Jones et al 2003). It has been found in Perth in association with 12th-century fabrics and appears to predate the Scottish East Coast Redware industry. It may no longer have been made by the 15th century (Hall 1996a, 127). It is usually highly fired to a white or grey colour and contains quartz inclusions. This fabric is the most common pottery type from the Holyrood excavations $(2,658$ sherds; $54 \%$ of the total), and is present in all phases of the site. The most common vessel type present is the glazed jug, and there is a bodysherd from context 756, the backfill of Period 1 boundary ditch 754, which has the remains of a seal on it. This device is bordered by a raised 

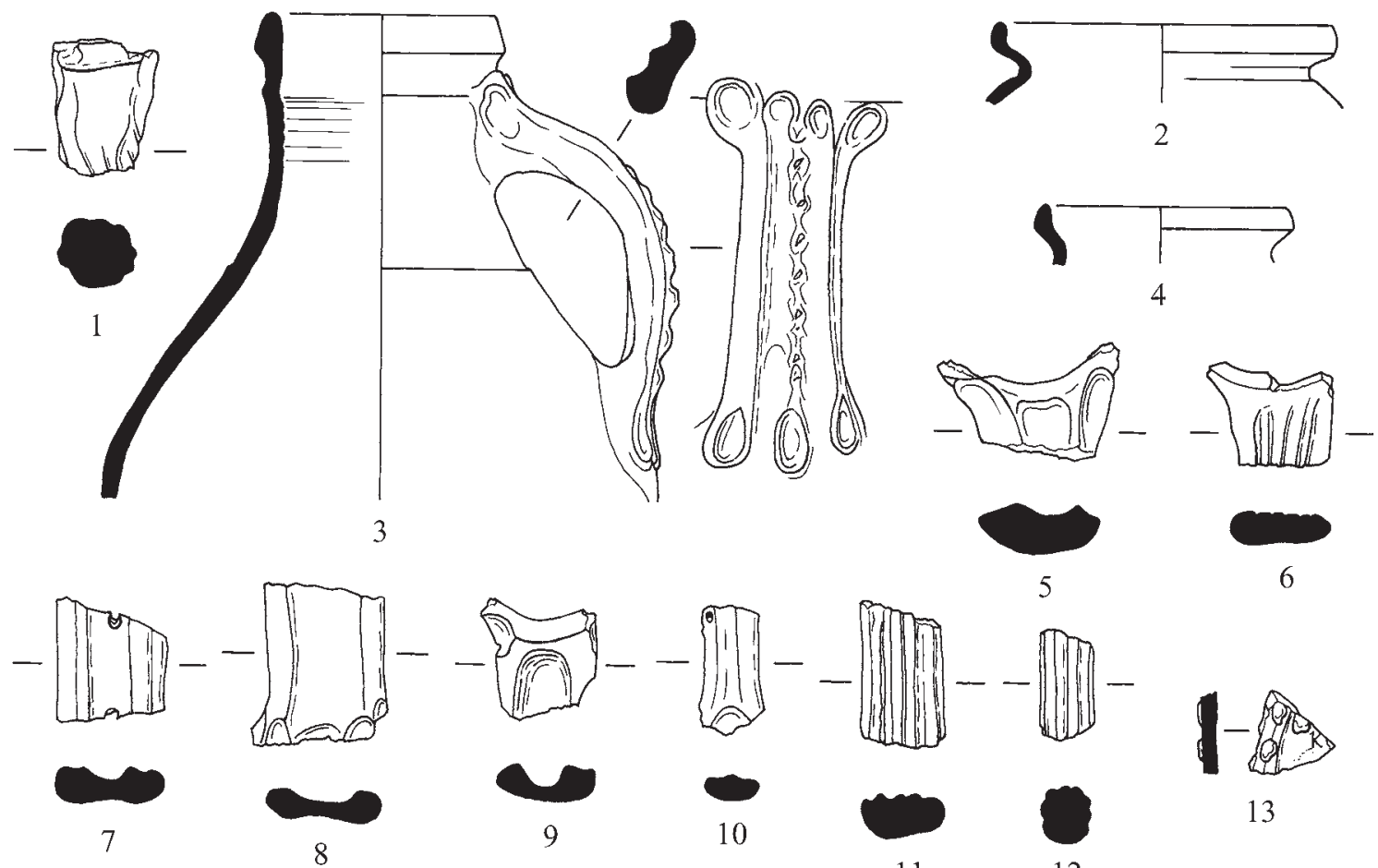

7

8

11

13

- -4

14

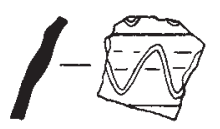

15
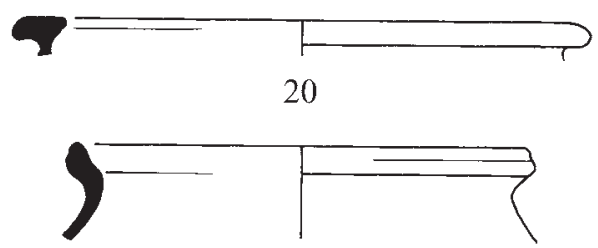

21

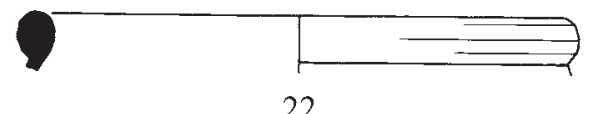

22

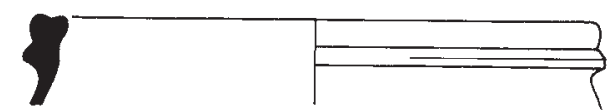

23

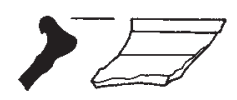

24

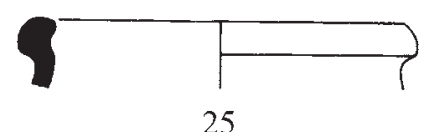

25

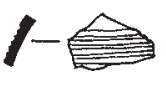

16

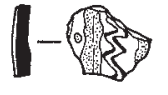

17

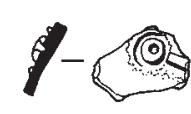

18
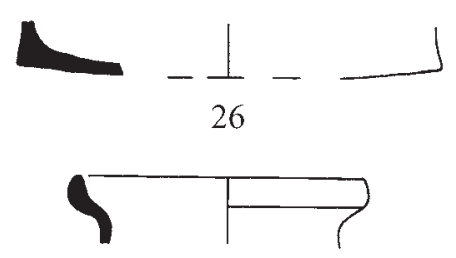

27

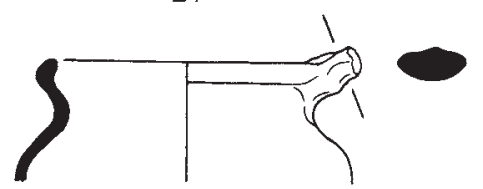

28

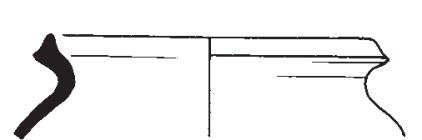

29

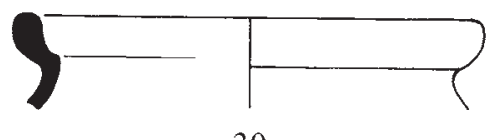

30

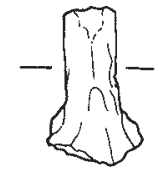

31

Fig. 1.1 Pottery (Pot nos 1-30) (scale 1:2)

line and pellets and surrounds an incised letter ' $\mathrm{K}$ ' (Pot no. 13). This is presumably the remains of an inscription and may suggest that this vessel is an attempt to copy Yorkshiretype Ware seal jugs of the 13th/14th centuries (McCarthy \& Brooks 1988, 235).
Scottish Post-Medieval Reduced Greyware (Pot nos 47-54, FIG. I.2)

This fabric type was first identified in excavations at Stirling Castle in the late 1970s (Haggarty 1980). It represents a late 
Table 1.1 Pottery: Scottish and English fabrics by period

\begin{tabular}{lrccc}
\hline Period & Wg & SPMRG & SPM Oxr & Yo \\
\hline 1 & 24 & 0 & 0 & 0 \\
2.1 & 142 & 2 & 0 & 0 \\
2.2 & 914 & 85 & 71 & 13 \\
2.3 & 476 & 185 & 88 & 3 \\
3 & 658 & 161 & 70 & 5 \\
4.1 & 349 & 378 & 381 & 1 \\
4.2 & 77 & 92 & 0 \\
5.1 & 11 & 32 & 23 & 0 \\
5.2 & 7 & 34 & 21 & 0 \\
\hline
\end{tabular}

Wg: Scottish White Gritty Ware; SPMRG: Scottish Post-Medieval Reduced Greyware; SPM Oxr: Scottish Post-Medieval Oxidised Redware;Yo:Yorkshire-type Ware

medieval transition from the Scottish East Coast Redware tradition and dates from the mid 15th to mid 18th centuries. It is the second most common fabric from these excavations, with 969 sherds from Periods 2.2 to 5.2. The most common vessel form in this fabric is the green-glazed jug.

\section{Scottish post-medieval Oxidised Redware (Pot nos} 3I-46, FIGS I.I \& I.2)

This later Redware tradition dates from the 15th to 18th centuries and is often called 'Throsk-type Ware' as it resembles the material being produced by the Throsk kiln site, near Stirling, in the 17th and 18th centuries (Caldwell \& Dean 1992). It is represented by 748 sherds from Periods 2.3 to 5.2. The most common vessel form represented in this fabric is the handled skillet. These cooking vessels are internally glazed and have very distinctive folded handles.

Yorkshire-Type Ware (Pot NOS 55-57, Fig. I.2)

Vessels in these distinctively glazed fabrics are the most common imports in the east coast burghs in the 13th and 14th centuries (McCarthy \& Brooks 1988, 227-52). There are only 22 sherds from this whole assemblage, with the largest group being from Period 2.2. The sherds from this period come from the fills of a slot (333, Plot 2.1), a pit (746, Plot 2.2) and two deposits of garden soil 298 and 612. The sherds from Periods 2.3, 3 and 4.1 are liable to be residual in context.

\subsubsection{Fabrics imported from the Low Countries (table 1.2)}

\section{Low Countries Greyware (Pot No. 66, Fig. I.3)}

It is now becoming clear that vessels in this fabric were amongst the most popular of the imported wares in 12thcentury Scotland. Previous work in Perth has suggested that their dominance of some assemblages may reflect the nationality of the site's inhabitants (Hall 1996b, 952-9). It has been argued that although Greyware vessels were arriving in Scotland in the 12th century, they were scarce and did not really start appearing in quantity until the 13 th century
(Verhaege 1983). There are only seven sherds of this fabric in the Holyrood assemblage from a deposit on the frontage of Plot 4.2 (Context 187, Period 4.2). These sherds are distinguished by being very smoke-blackened and may belong with the 'blackware' variant of this pottery which is dated to the late 13th/early 14th centuries (Janssen 1981, 172). This material was mixed with fabrics of post-medieval date and is therefore residual.

Low Countries highly decorated Redware (Pot no. 67, FIG. I.3)

This very distinctive fabric (formerly known as Aardenburg Type) has a white slip under its glaze. There is a single sherd from one of these distinctive vessels, which are thought to date to the early 14th century, from pit fill 859 in Period 4.1 (Pit 935, Plot 4.2). It seems likely that the white slip that is often applied to some of the Scottish East Coast Redwares may be an attempt to copy this decorative style (see above).

\section{Low Countries Tin-glazed Earthenware (Pot nos} 68-73, FIG. I.3)

There is a small group of Tin-glazed Earthenware of AngloNetherlandish origin from culvert 757 (Plot 3.3), cultivation slot 557 in Plot 4.2 and the make-up for the Quartermaster's store floor 536 in Period 5.1 (five sherds), which dates to the 17 th century. There is another small group that is unprovenanced and of 18th-century date from Periods 4.1 and 4.2 (four sherds).

\subsubsection{Fabrics imported from France}

\section{Beauvais EARTHenWARE}

In the late 15th and 16th centuries the Beauvais potters of northern France were producing very fine white wares of a superior quality to most other fabrics being produced in north-west Europe at the time. Essentially there are two types of this fabric: lead-glazed wares with a single overall glaze, or glazed inside one colour and outside another, and Sgraffito forms (Hurst et al 1986, 106). 


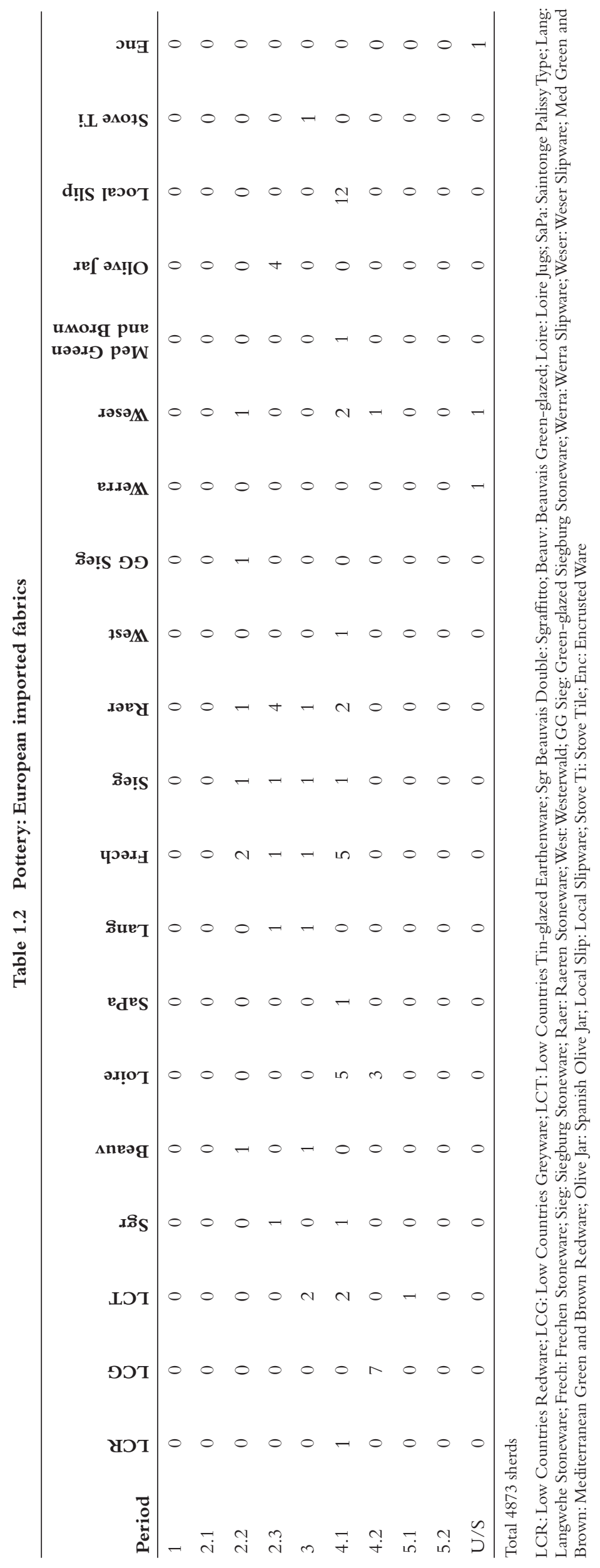



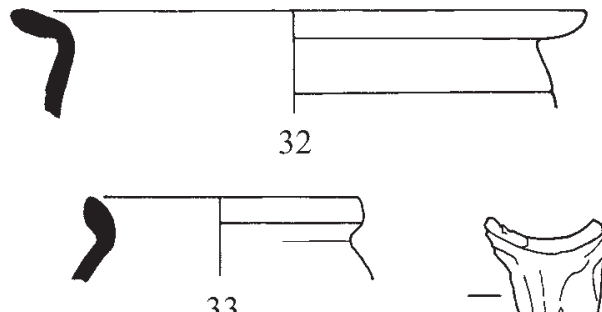

33

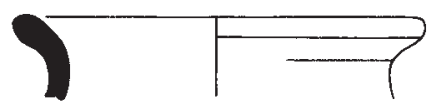

34

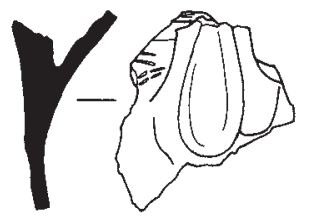

36
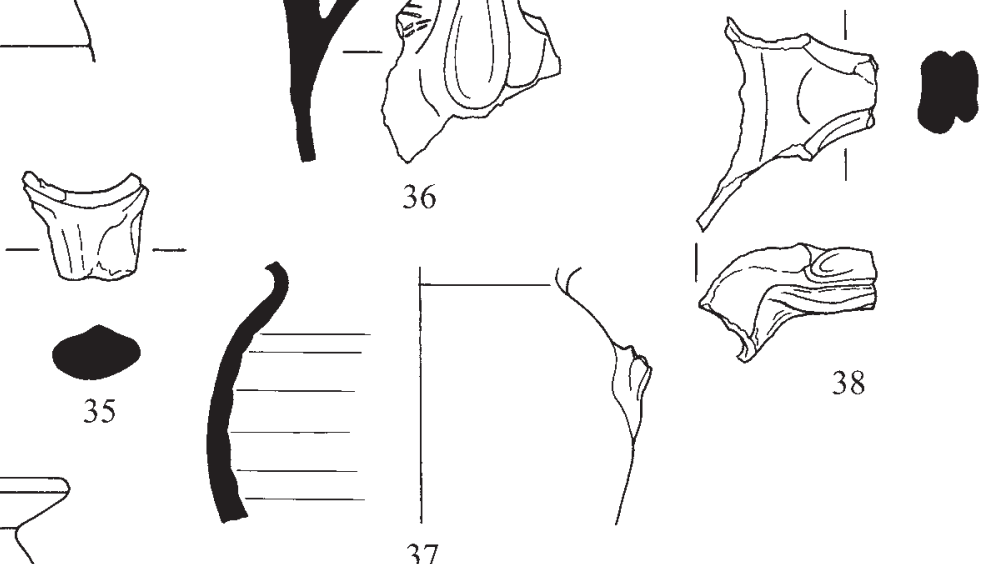

38

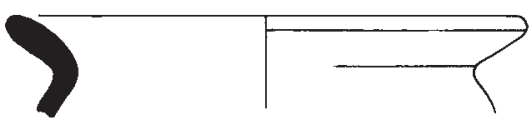

40
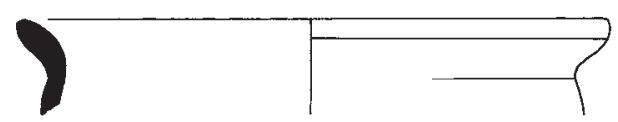

41

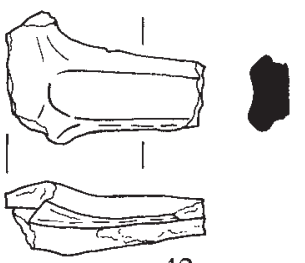

42

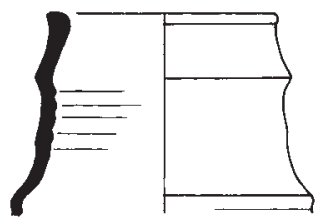

47

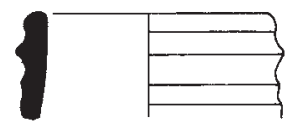

48

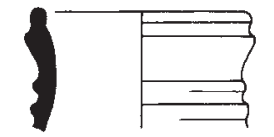

49

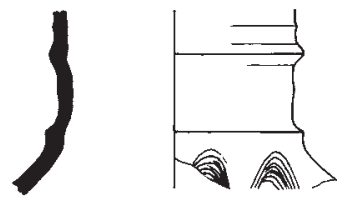

50

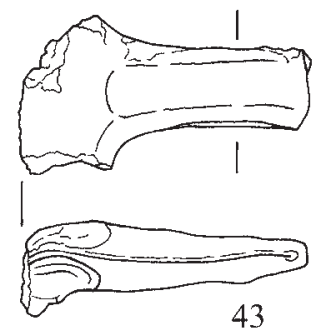

43

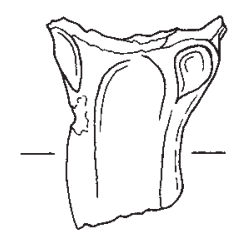

51

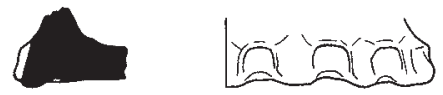

52
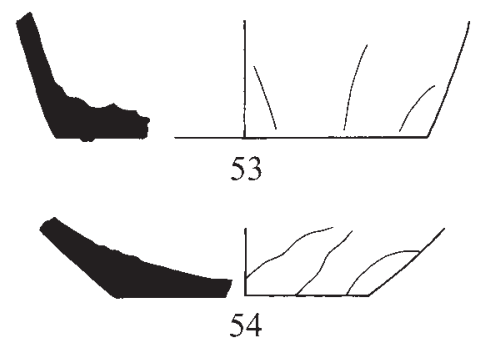

$-$
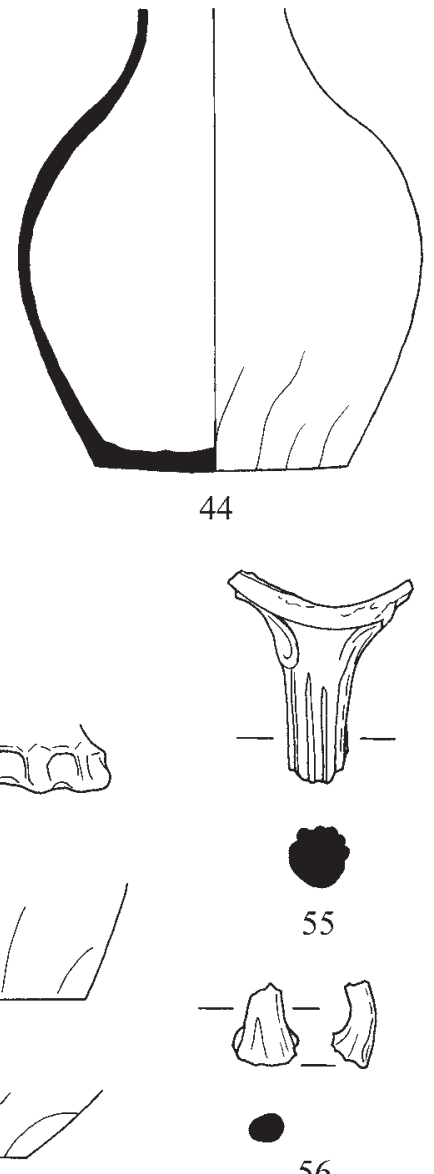

56
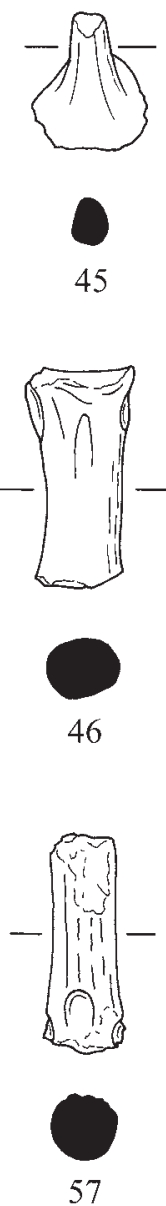

Fig. 1.2 Pottery (Pot nos 32-57) (scale 1:2)

Beauvais Overall Green-glazed (Pot nos 6o-62, fig. I.3)

There are two sherds from a narrow-necked vessel in this Beauvais fabric from the fill of the construction trench for a wall (190, Period 3) and another sherd from medieval garden soil 612 (Period 2.2).
Beauvais Double Sgraffito (Pot nos 58-59, Fig. I.3)

This pottery was manufactured in large quantities at Beauvais in the 16th century (Hurst et al 1986, 108). It has a very fine white fabric which is first covered with a red slip and subsequently with a white slip. Decoration is then scored 


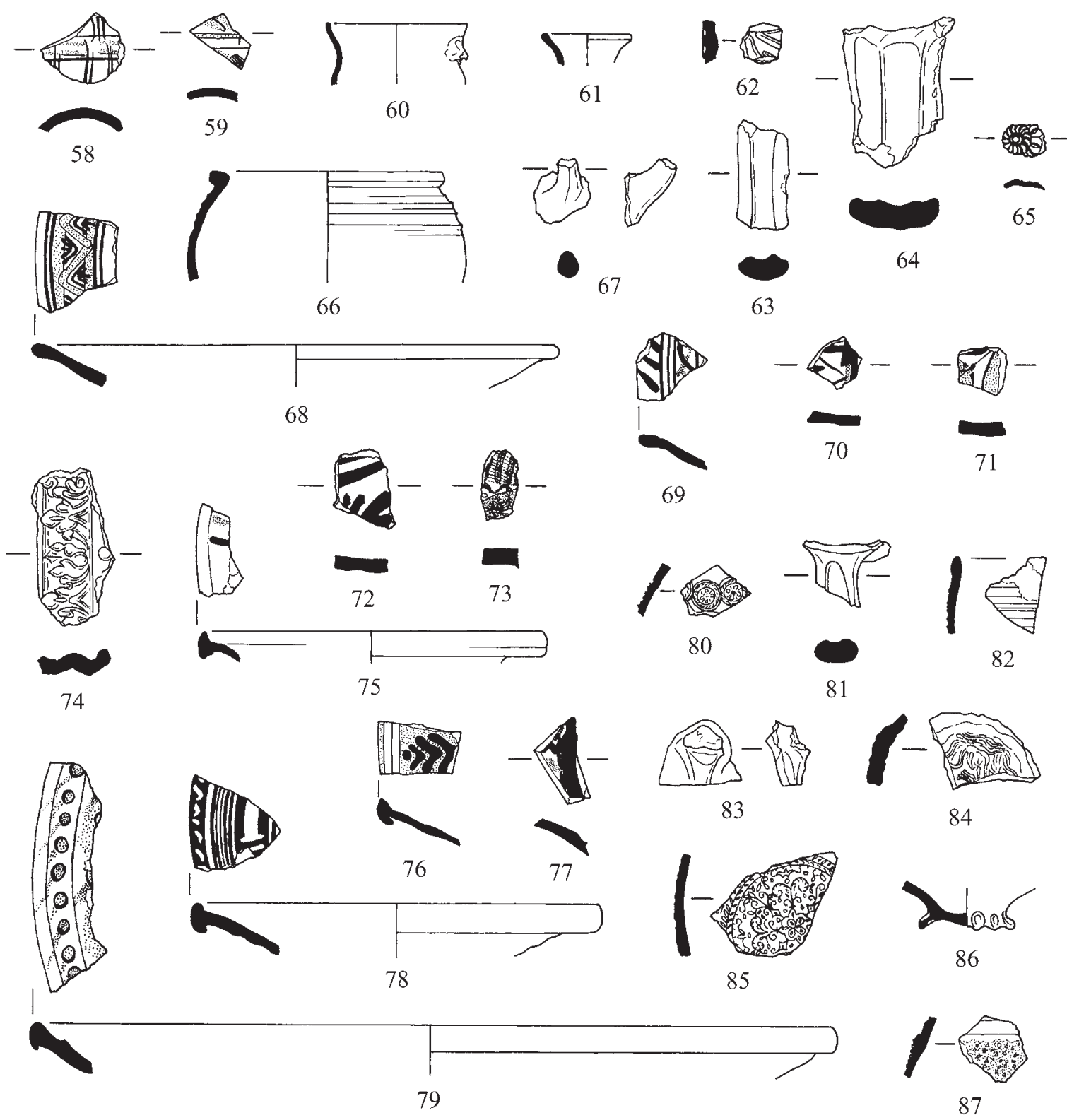

Fig. 1.3 Pottery (Pot nos 58-87) (scale 1:2)

through the white slip to expose the red and it is finally glazed green. The two sherds from Holyrood are amongst the only examples of this vessel type in this fabric from Scotland and may be from albarelli (drug jars). One of these comes from the fill of a stone tank (843) in Plot 2.2 and the other from garden soil within the formal gardens of Queensberry House (540, Period 4.1).

Loire Jugs (Pot NO. 63, Fig. I.3)

There are five sherds from these vessels in contexts 1610 and 1616, the fills of Plot 4.3 garden features and a further three from the fill of a feature possibly related to the construction of Lothian Hut in the same plot (1783). They are manufactured in a very fine off-white fabric with occasional patches of yellow glaze and are a very common find from 16th-century archaeological deposits in Scotland (Hurst et al 1986, 100; Haggarty 2006, file 32).
Saintonge Plain (Pot no. 64, Fig. I.3)

These plainer types of vessels were traded along with the fine-glazed decorated wares and are more common in the second half of the 15th and first half of the 16th centuries (Hurst et al 1986, 76, 77). The single piece from these excavations is a strap handle from a jug or pegau and comes from an unstratified context.

\section{Saintonge Palissy Type (Pot no. 65, Fig. I.3)}

There is a single tiny sherd from the fill of a Cowgate boundary ditch (661, Plot 4.2) which may be from one of these very ornate vessels which date to the late 16th/ mid 17 th centuries. The sherd appears to be a decorative rosette from a scalloped bowl, similar to an example published in the Rotterdam Papers (Hurst et al 1986, 91, Fig. 40). 


\subsubsection{Fabrics imported from Germany}

\section{Rhenish Stonewares (Рot nos 80-86, Fig. I.3)}

These distinctive, very hard-fired imported fabrics began to be imported into Scotland in the 14th and 15th centuries (Hurst et al 1986). They originate from the production centres of Langerwehe, Siegburg, Frechen and Raeren. The earliest appearance of these fabrics on site is in Period 2.2, where there are two sherds of Frechen Stoneware from cultivation layers 671 and 612 and single sherds of Siegburg and Raeren Stoneware from the fill of sump 767 (Plot 2.2) and industrial feature 1520 (Plot 2.4). Period 2.3 contains four sherds of Raeren Stoneware from two pits on the boundary between Plots 2.1 and 2.2 (669 and 728), the fill of tank 843 (Plot 2.2), and a cultivation soil (652). This period also contains single sherds of Frechen, Siegburg and Langerwehe Stonewares from stone tank 775 (Plot 2.2), boundary wall 653 (on the east side of the possible vennel) and pit 722 (on the boundary between Plots 2.1 and 2.2) Period 3 contains a sherd of Siegburg from the fill of a drain (1524, Plot 3.4), a sherd of Raeren Stoneware from midden 1620, a sherd of Frechen Stoneware from garden soil 215 and a sherd of Langerwehe Stoneware from garden soil 563. Period 4.1 contains five sherds of Frechen Stoneware from features associated with the construction of the formal gardens of Queensberry House (540, 888, 558, \& 643; Plot 4.2) and Haddington House (307, Plot 4.1). There are also two sherds of Raeren Stoneware from the fill of a drain in the garden of Lothian Hut (1604, Plot 4.3) and the fill of a pit below the terrace of Queensberry House (935, Plot 4.2). This period also produced the only sherd of ornately decorated Westerwald Stoneware from garden soil 242 and a single sherd of Siegburg Stoneware from cut 1786 (Plot 4.3).

\section{Green-Glazed Siegburg Stoneware}

There is a single sherd of this distinctive fabric from the fill of a well (1567, Plot 2.4). It dates to the 15th century (Hurst et al 1986, 129) and is a rare find from Scotland; the only other sherds are from Linlithgow Palace, Kildrummy Castle (Gaimster 1997, 87), Virginia Street, Aberdeen (Cameron \& Evans 2001, 162) and Deer Abbey, Aberdeenshire. These vessels were fired twice to produce a glossy green-glazed stoneware fabric which was impervious to liquids.

Weser and Werra Slipwares (eastern Germany) (Pot nos $75-78$, FIG. I.3)

Werra Ware has a red-brown sandy fabric and was manufactured at a number of sites in the valley of the River Weser in the 16th and 17th centuries. The two sherds from this excavation come from an unstratified deposit and modern backfill (104). The unstratified sherd is a rimsherd from a dish which is glazed brown with white slipped lines and decoration glazed light green. These vessels often have dates on them and the sherd from Holyrood is very like a published dish of 1597 from the Netherlands (Hurst et al 1986, Plate XIV).The stratified sherd is from a dish with a central incised anthropomorphic figure (J Hurst pers comm).

Weser Ware has an off-white to buff-brown fabric and was manufactured in the area between the Weser and Leine rivers between 1580 and 1630 . There are four sherds in the Holyrood assemblage from Periods 2.2, 4.1 and 4.2 and one piece is unstratified. The sherd from the fill of an industrial feature (1520) in Plot 2.4 is from a Weser Wavy Bands Dish similar to a published example from the Netherlands (Hurst et al 1986, Colour Plate XV). The sherd from the fill of a drain (601, Plot 4.2) is from a similar vessel with a different design.

Mediterranean Green and Brown Redware (Pot no. 79, FIG. I.3)

The provenance of this ware is uncertain but a Mediterranean origin is preferred by John Hurst (Hurst et al 1986, 74). It has a red-brown sandy fabric and is glazed yellow-brown on a white slip. The single piece from Holyrood is from a Period 4.1 levelling deposit (643, Plot 4.2) and is from the rim of a bowl that is decorated with brown and green-glazed blobs in its stepped flange. This vessel is another example of a rare high-quality import found at Holyrood (J Hurst pers comm).

\subsubsection{Fabrics imported from Spain}

\section{Seville Coarse Wares (olive jars)}

These distinctive amphora-like vessels were manufactured in Seville in Spain from the 13th century onwards (Gerrard et al 1995, 284). The sherds from Holyrood are later 16th-century Middle and Late Style olive jars, which reflect the increase in the export of olive oil to north-west Europe during this period. They were found in a charcoal and clay deposit associated with a blacksmith's property on the Canongate frontage (1104, Plot 2.4).

\subsubsection{Fabrics imported from unknown sources in northern Europe}

Stove tile (Pot NO. 74, Fig. I.3)

Holyrood is only the fourth site in Scotland to produce a piece from one of these ornately decorated medieval central heating systems which are dated to the 15th, 16th and 17th centuries (Gaimster 1990,4). The other pieces were found from excavations at St Nicholas leper hospital, St Andrews (Haggarty 1999), an excavation at Calton Road, Edinburgh (Haggarty forthcoming) and excavations inside St Giles Cathedral, Edinburgh (Hall \& Haggarty 2006). The sherd from Holyrood is from the decorated border of an imported smokeless ceramic stove, a type of central heating that was popular among elite society in Britain in the 16th century (Gaimster \& Hughes 1999, 185). It comes from the backfill of a pit in Plot 3.5 (1682, not illustrated). This single fragment may originate in the Baltic (D Gaimster pers comm).

\section{EnCrusted Ware (Pot nO. 87, Fig. I.3)}

There is a single sherd from an unstratified context in this very distinctive fabric which is essentially a whiteware that 


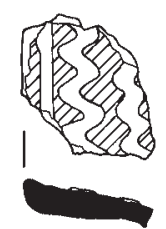

88

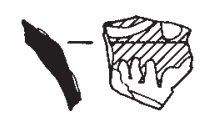

90

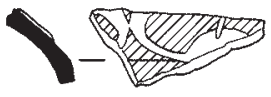

91

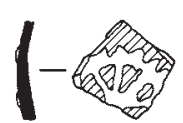

92

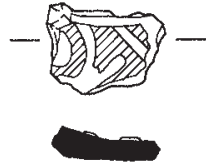

93

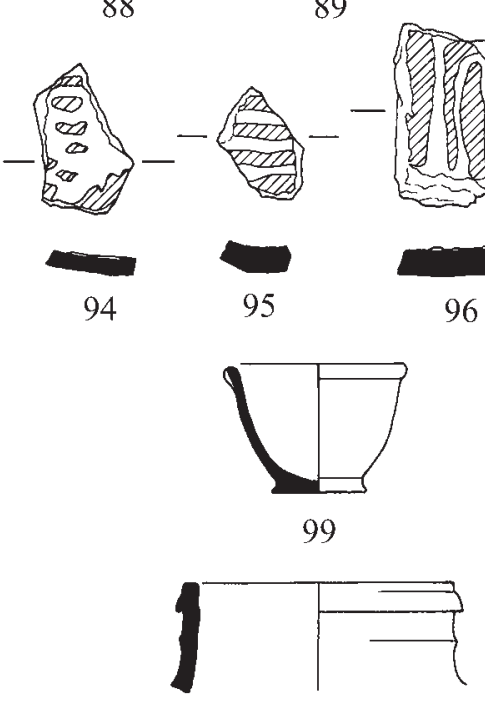

100

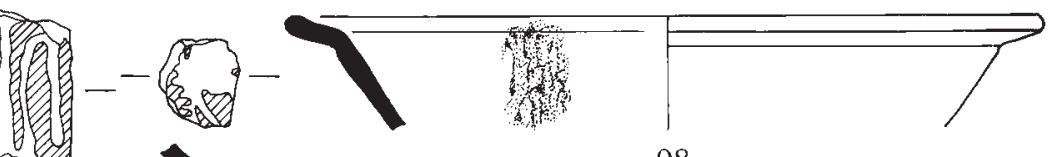

98
96

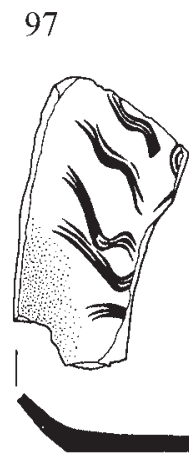

$>$

101

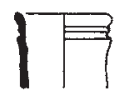

102

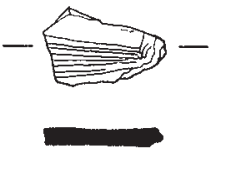

104

Fig. 1.4 Pottery (Pot nos 88-103) (scale 1:2)

has been decorated with stone chippings. This style was widespread in Germany in the late 16th and early 17th centuries and was copied in England in the 17th century, which makes it almost impossible to identify the source (Hurst et al 1986, 237). It has been suggested to the author that the quality of the manufacture of this piece makes it more likely to be of Rhenish production (J Hurst pers comm).

\section{SLIPWARES (Pot NOS 88-98, Fig. I.4)}

There is a small group of decorated slipwares from Period 4.1 which may be of either Dutch or local origin (12 sherds). All these sherds are associated with the garden features in this period. These sherds are all made in an orange-red fabric with purple-red outer surfaces and are glazed red-brown with yellow-glazed decorative strips on a white slipped background. They all come from open dishes or bowls. The absence of any green colouring on these sherds makes a Dutch provenance unlikely (J Hurst pers comm).

\section{Unidentified (Pot NO. 99, Fig. I.4)}

Of most interest amongst this small group of material is a complete vessel from the fill of industrial tank 1637 (Plot 3.6). This small vessel $(5 \mathrm{~cm}$ in diameter and $5 \mathrm{~cm}$ high) is unglazed and has a small pulled spout on its rim. It would appear to have been used in some process that involved the careful measuring of a liquid. This vessel was found in association with both Oxidised Redware and Scottish White Gritty Wares and the absence of later material would seem to imply that a date of the 15 th or 16 th centuries should be assigned to the backfilling of this tank.

\subsubsection{Conclusion}

Perhaps the most striking feature of the ceramic assemblage from the excavations at Holyrood is the importance of the information provided by the later medieval and post-medieval wares. Such assemblages are rare discoveries in the Scottish burghs simply because deposits of that date have rarely survived the development boom of the 19th century, when digging of cellars removed earlier deposits. Of the few other excavations in Edinburgh, John Schofield's work on the south side of the High Street in the mid 1970s is the only work to have produced a sizeable assemblage of imported wares; intriguingly, that site only produced a large group of Rhenish Stonewares of late 15th-century date (Clarke \& Hurst 1978, 206-11). The excavations inside St Giles Cathedral in 1981 produced a small group of imported material from Yorkshire, the Low Countries, Spain and Germany (Hall \& Haggarty 2006).

The quality of the later medieval and post-medieval wares in the Holyrood assemblage is very high and presumably can be used as an indicator of the status of the inhabitants of the buildings on the Canongate frontage and Queensberry House. This is particularly true of objects such as the sherds from a stove tile, an encrusted vessel and the tiny sherd of Palissy-type Ware. The excavations inside Queensberry House found sherds of Westerwald Stoneware which come from a very ornate drinking vessel (Pot no. 16) dating to the late 16th century and pieces of Netherlands Maiolica dating to the 16 th or 17 th centuries (Pot no. 14). It may also be argued that the presence of Spanish olive jars in the main site assemblage indicates the culinary preferences of the site's occupants. From the ceramic specialist's point of view, the 
most frustrating aspect of this assemblage is that, although it is possible to identify some rare Scottish examples of highstatus European imports, the sherds of these vessels recovered from the site are very small. From the point of view of the local pottery industry the presence of a group of potential local slipwares from Period 4.1 is of interest and this possibility will hopefully be tested in a future sourcing programme. These excavations have demonstrated that archaeological deposits survive at this end of the Canongate which contain important material evidence of the 16th, 17th and 18th centuries.

\subsubsection{Selected catalogue of pottery from the main Parliament site (figs 1.1-1.4)}

\section{Scottish White Gritty Ware}

1) Rim and twisted rod handle junction with traces of green glaze. Context 809; Period 2.2.

2) Rimsherd from small vessel internally glazed green with traces of external smoke-blackening. Context 814; Period 2.3.

3) Joining bodysherds from green-glazed jug with complete strap handle decorated with notched central strip. Context 1638; Period 4.1.

4) Rimsherd from jug with patches of green glaze on interior surface. Context 859; Period 4.1.

5) Rimsherd and strap handle junction from jug with patch of dark green glaze. Context 992; Period 4.1.

6) Rimsherd and ribbed strap handle junction from unglazed jug. Context 1000; Unstratified.

7) Strap handle fragment glazed green with deep central groove and two drilled holes. Context 745; Period 2.1.

8) Fragment of strap handle externally glazed yellow green. Context 778; Period 2.1.

9) Strap handle junction from unglazed vessel. Context 652; Period 2.3.

10) Narrow strap handle with patches of green glaze. Context 1648; Period 4.1.

11) Narrow ribbed strap handle glazed green. Context 794 ; Period 2.3.

12) Fragment of ribbed rod handle with traces of green glaze. Context 735; Period 2.3.

13) Bodysherd from green-glazed jug with remains of applied seal including incised letter ' $\mathrm{K}$ '. Context 756; Period 1.

14) Bodysherd from green-glazed jug decorated with incised line decoration. Context 612; Period 2.2.

15) Bodysherd from green-glazed jug decorated with incised wavy line. Context 704; Period 2.2.

16) Bodysherd from yellow-green glazed vessel with incised line decoration. Context 681; Period 2.3.

17) Bodysherd from green-glazed jug decorated with wavy incised line and applied strips glazed green. Context 345; Period 3.

18) Bodysherd from green-glazed jug decorated with applied line and ring and dot circle glazed brown. Context 667; Period 2.2.

19) Bodysherd from green-glazed jug decorated with applied line and ring and dot circle glazed brown. Context 794; Period 2.3.
20) Rimsherd from jar with slight traces of external smokeblackening. Context 734; Period 2.1.

21) Rimsherd from jar with patches of green glaze. Context 612; Period 2.2.

22) Rolled rimsherd from jar. Context 059; Period 3.

23) Ribbed rimsherd from jar. Context 330; Period 3.

24) Rimsherd from jar. Context 348; Period 3.

25) Rimsherd from jar. Context 888; Period 4.1.

26) Basesherd from jar with external smoke-blackening. Context 682; Period 3.

27) Rimsherd from skillet internally glazed green with traces of external smoke-blackening. Context 911; Period 3.

28) Rimsherd and handle junction from skillet internally glazed green and externally smoke-blackened. Context 129; Period 4.1.

29) Rimsherd and handle junction from skillet internally glazed green and externally smoke-blackened. Context 1612; Period 4.1.

30) Rimsherd from skillet internally glazed green with traces of external smoke-blackening. Context 617; Period 4.2.

\section{East Coast Redware}

31) Rod handle junction from jug with patches of brown glaze. Context 992; Period 4.1.

\section{Scottish Post-Medieval Oxidised Redware}

32) Rimsherd from vessel glazed brown internally and externally. Context 298; Period 2.2.

33) Rimsherd from vessel with patches of green-brown glaze internally and externally. Context 835; Period 2.3.

34) Rimsherd from vessel glazed green internally and externally. Context 859; Period 4.1.

35) Rim and strap handle junction from narrow-necked green-glazed jug. Context 859; Period 4.1.

36) Sidewalls and handle junction from green-glazed jug. Context 133; Period 4.1.

37) Sidewalls and handle junction from skillet internally glazed green and externally smoke-blackened. Context 807; Period 2.3.

38) Rimsherd and handle junction from skillet internally glazed green-brown and externally smoke-blackened. Context 215; Period 3.

39) Rimsherd and handle junction from skillet glazed green internally with traces of external smoke-blackening. Context 129; Period 4.1.

40) Rimsherd from skillet internally glazed brown with patch of external brown glaze and smoke-blackening. Context 222; Period 4.2.

41) Rimsherd from skillet glazed brown internally and externally smoke-blackened. Context 1572; Unphased.

42) Folded skillet handle glazed green. Context 617; Period 4.2.

43) Complete folded skillet handle and rim junction glazed green. Context 1000; Unstratified.

44) Neck to base profile of green-glazed jug with flat base. Context 1638; Period 4.1.

45) Rod handle junction from pipkin with external smokeblackening. Context 563; Period 3.

46) Narrow strap handle with traces of brown glaze from jug. Context 1000; Unstratified. 
47) Rim and neck from green-glazed jug with external raised cordons. Context 814; Period 2.3.

48) Rimsherd from jug glazed green-brown with external cordons. Context 540; Period 4.1.

49) Rimsherd from green-glazed jug with external raised cordons. Context 509; Period 5.2.

50) Neck and sidewall from green-glazed jug decorated with incised wavy lines. Context 1000; Unstratified.

51) Strap handle junction from green-glazed jug. Context 859; Period 4.1.

52) Frilled basal angle from green-glazed jug. Context 794; Period 2.3.

53) Basal angle from green-glazed jug with kiln stacking scar on base. Context 845; Period 2.3.

54) Basal angle from internally green-glazed vessel. Context 643; Period 4.1.

\section{YORKSHIRE-TYPE WARE}

55) Rim and ribbed rod handle junction from jug glazed lustrous green. Context 740; Period 2.2.

56) Decorative handle from vessel glazed lustrous green. Context 612; Period 2.2.

57) Abraded rod handle from jug glazed lustrous greenbrown. Context 334; Period 3.

\section{Beauvais Double Sgraffito}

58) Bodysherd from albarello slipped white on red and glazed lustrous green with Sgraffito decoration. Context 811; Period 2.3.

59) Bodysherd vessel slipped white on red and glazed lustrous green with Sgraffito decoration. Context 540; Period 4.1.

\section{Beauvais Green-GLazed}

60) Rimsherd from narrow-necked vessel glazed green internally and externally. Context 190; Period 3.

61) Rimsherd from narrow-necked vessel glazed light-green externally and green-white internally. Context 283; Period 5.1.

62) Bodysherd from open vessel form decorated with internal raised strips and glazed green. Context 888; Period 4.1.

LOIRE JUG

63) Handle and rim junction from Loire jug. Context 974; Period 4.1.

Saintonge Plain

64) Strap handle and rim junction from Saintonge Plain jug. Context 1000; Unstratified.

\section{Saintonge Palissy Type}

65) Fragment of applied rosette decoration glazed yellow with green border from scalloped bowl. Context 634; Period 4.1.

\section{Low Countries Greyware}

66) Rim and sidewalls from smoke-blackened vessel with externally rilled surface. Context 187; Period 4.2.

\section{Low Countries Highly Decorated Redware}

67) Decorative arm or handle from vessel glazed speckled green on a white slip. Context 859; Period 4.1.

\section{Low Countries Tin-glazed Earthenware}

68) Rimsherd from bowl or dish externally glazed greybrown and internally glazed white with blue and yellow decoration. Context 558; Period 4.1.

69) Rimsherd from bowl or dish glazed white internally and externally with blue decoration. Context 590; Period 4.1.

70) Bodysherd from Maiolica dish or plate externally glazed grey-brown with internal dark blue glazed decoration. Context 911; Period 3.

71) Bodysherd from Maiolica dish or plate externally glazed grey-brown with internal dark blue and light green decoration. Context 307; Period 4.1.

72) Bodysherd from Maiolica dish or plate externally glazed grey-brown with internal dark blue glazed decoration. Context 1000; Unstratified.

73) Basesherd from Maiolica dish or plate externally glazed grey-brown with internal dark blue glazed decoration. Context 557; Period 4.1.

STOVE TILE

74) Border fragment decorated with floral pattern and glazed brown. Context 1682; Period 3.

\section{Weser Slipware}

75) Rimsherd from bowl or dish glazed yellow and decorated with green and brown stripes. Context 617; Period 4.2.

76) Rimsherd from bowl or dish glazed brown decorated with yellow border and green 'tree' decoration. Context 1000; Unstratified.

77) Bodysherd from 'wavy bands' dish glazed brown with yellow and green decoration on a white slip background. Context 1500; Period 2.2.

\section{Werra SLIPWARE}

78) Rimsherd from bowl or dish glazed brown and decorated with light green glazed stripes on a white slip background. Context 1000; Unstratified.

\section{Mediterranean Green and Brown Redware}

79) Rimsherds from bowl or dish glazed light yellow and decorated with brown and green glazed 'blobs'. Context 643; Period 4.1.

\section{Westerwald Stoneware}

80) Bodysherd from vessel decorated with stamped pads, 
glazed dark blue externally and light grey-blue internally. Context 242; Period 4.1.

\section{RAeren StOneware}

81) Handle junction from vessel externally glazed grey and internally glazed brown. Context 668; Period 2.3.

\section{Frechen Stoneware}

82) Rimsherd from vessel glazed grey-brown internally and externally with external rilling. Context 799; Period 2.3.

83) Bodysherd and handle junction from vessel glazed light grey with brown patches. Context 643; Period 4.1.

84) Bodysherd from 'Bartmann' jug with remains of lower half of bearded face. Context 685; Unphased.

\section{Cologne/Frechen Stoneware}

85) Bodysherd from brown glazed Bartmann jug decorated with a medallion. Context 540; Period 4.1.

\section{Siegburg StOneware}

86) Frilled base from small unglazed vessel. Context 763; Period 2.2.

\section{ENCRUSTED WARE}

87) Bodysherd from vessel internally and externally glazed light green with stone chippings embedded in glaze surface. Context 1000; Unstratified.

\section{Local/Dutch SLIPWARES}

88) Rim and bodysherd from bowl or dish glazed brown with yellow-glazed white slipped lines. Context 558; Period 4.1.

89) Rimsherd from bowl or dish glazed green-brown with yellow-glazed white slipped decoration. Context 512; Period 4.1.

90) Bodysherd from bowl or dish glazed brown with yellowglazed white slipped decoration. Context 540; Period 4.1.

91) Bodysherd from bowl or dish glazed brown with yellowglazed white slipped lines. Context 558; Period 4.1.

92) Bodysherd from vessel glazed brown internally and externally and decorated with yellow-glazed white slipped decoration. Context 1000; Unstratified.

93) Basesherd from bowl or dish glazed brown with yellowglazed white slipped lines. Context 558; Period 4.1.

94) Basesherd from bowl or dish glazed brown with yellowglazed white slipped decoration. Context 690; Period 4.1.

95) Basesherd from bowl or dish glazed brown with yellowglazed white slipped decoration. Context 558; Period 4.1

96) Basesherd from dish glazed brown with yellow-glazed white slip lines and externally smoke-blackened.Context 1000; Unstratified.

97) Basesherd from bowl or dish glazed green-brown and decorated with yellow-glazed white slipped decoration. Context 1000; Unstratified.

\section{SLIPWARE}

98) Rimsherd from bowl glazed cream white on a white slip with remains of brown glazed tree decoration. Context 540; Period 4.1.

\section{UNIDENTIFIED}

99) Complete unglazed measuring vessel or crucible. Context 1638; Period 4.1.

100) Rimsherd from unidentified unglazed vessel form. Context 696; Period 2.3.

101) Rimsherd from small vessel white-slipped internally and externally. Context 345; Period 3.

102) Rim and sidewalls from very small vessel internally glazed light brown with occasional patches of external brown glaze. Context 145; Period 4.1.

103) Basesherd from open vessel glazed light yellow on a white slip with brown glazed Sgraffito decoration. Context 540; Period 4.1.

104) Basesherd from open vessel glazed light green on a white slip with incised lines forming part of unidentified design. Context; Unstratified.

\subsection{METAL OBJECTS}

\section{ADRIAN COX}

\subsubsection{Copper alloy objects (fig. 1.5)}

A range of activities is represented by the copper alloy artefact assemblage. The objects include costume fittings such as buckles, buttons, lace tags and mounts, textile equipment such as needles and thimbles, and a moderately large group of pins. The assemblage is discussed below within functional groupings.

\section{Costume FitTings}

Rumbler bells like no. 1 were made from two pieces of sheet copper alloy, joined together along projecting flanges. They contained a loose 'pea', often of iron, and were particularly common in the medieval period. There is little to distinguish rumbler bells worn as costume accessories from those attached to horse harness or the collars of animals (Egan \& Pritchard 1991, 337). Medieval horse harness straps could be ornamented with a wide variety of fittings such as mounts, suspended pendants and bells, as the representation of a horseman in the Hereford Cathedral Mappa Mundi (c 1300) illustrates (Griffiths 1995, 62).

No. 1, recovered from a post-medieval garden soil deposit, represents a single hemisphere from a rumbler bell, having broken along its flanged edge. It includes the characteristic dumbbell-shaped perforation, which appears to be a long-lived feature, appearing, for example, on bells of both late 13thcentury and 1-6th-century date from Southampton (Harvey 1975, 255, 262). On many excavated examples, a suspension loop also survives, as it does on a slightly smaller rumbler bell recovered from a late medieval context at Mill Street, Perth 


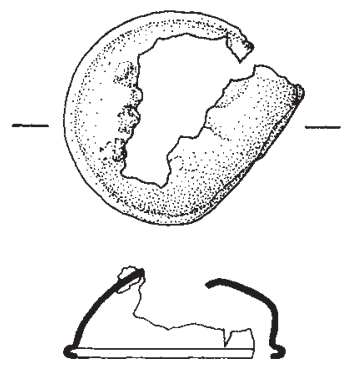

1

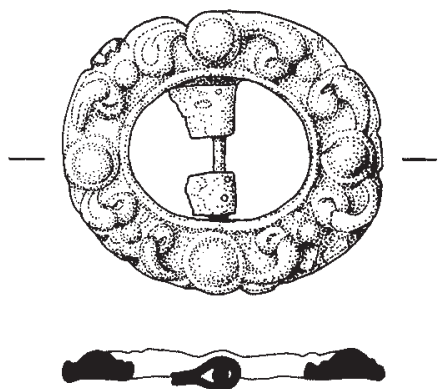

2

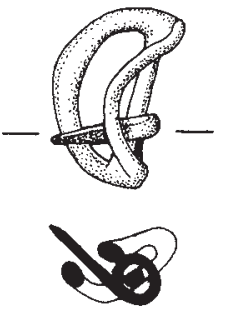

3

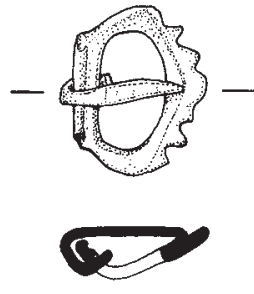

4

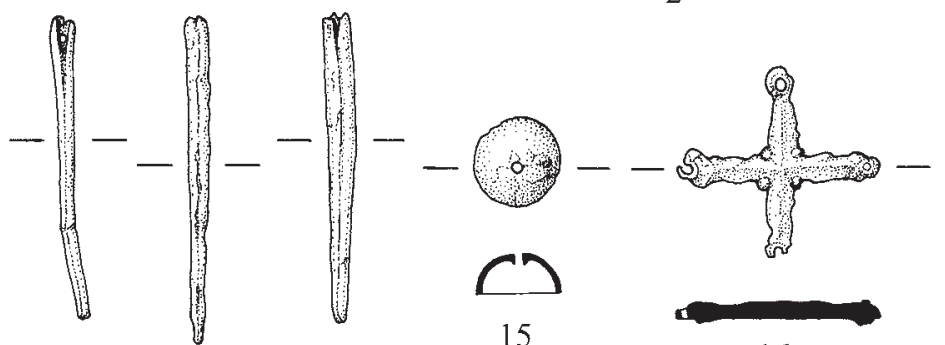

13

16

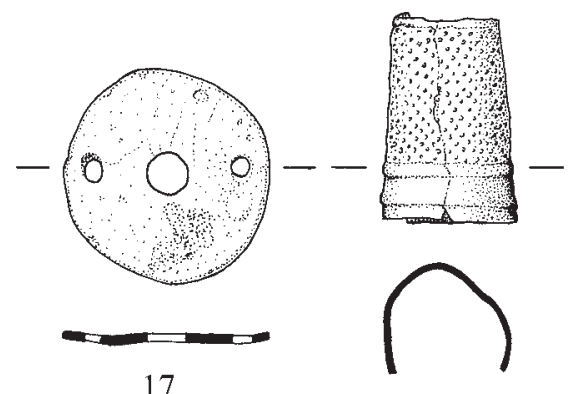

17

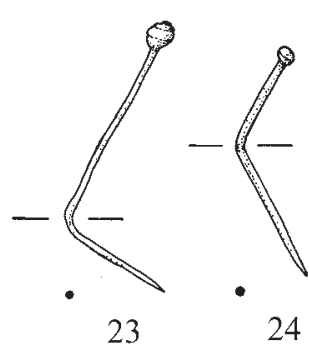

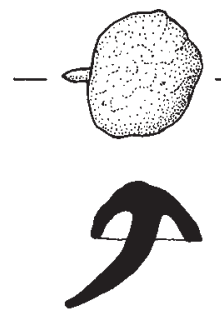

26

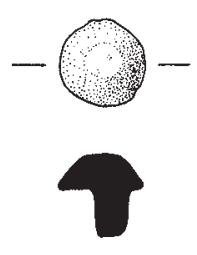

29
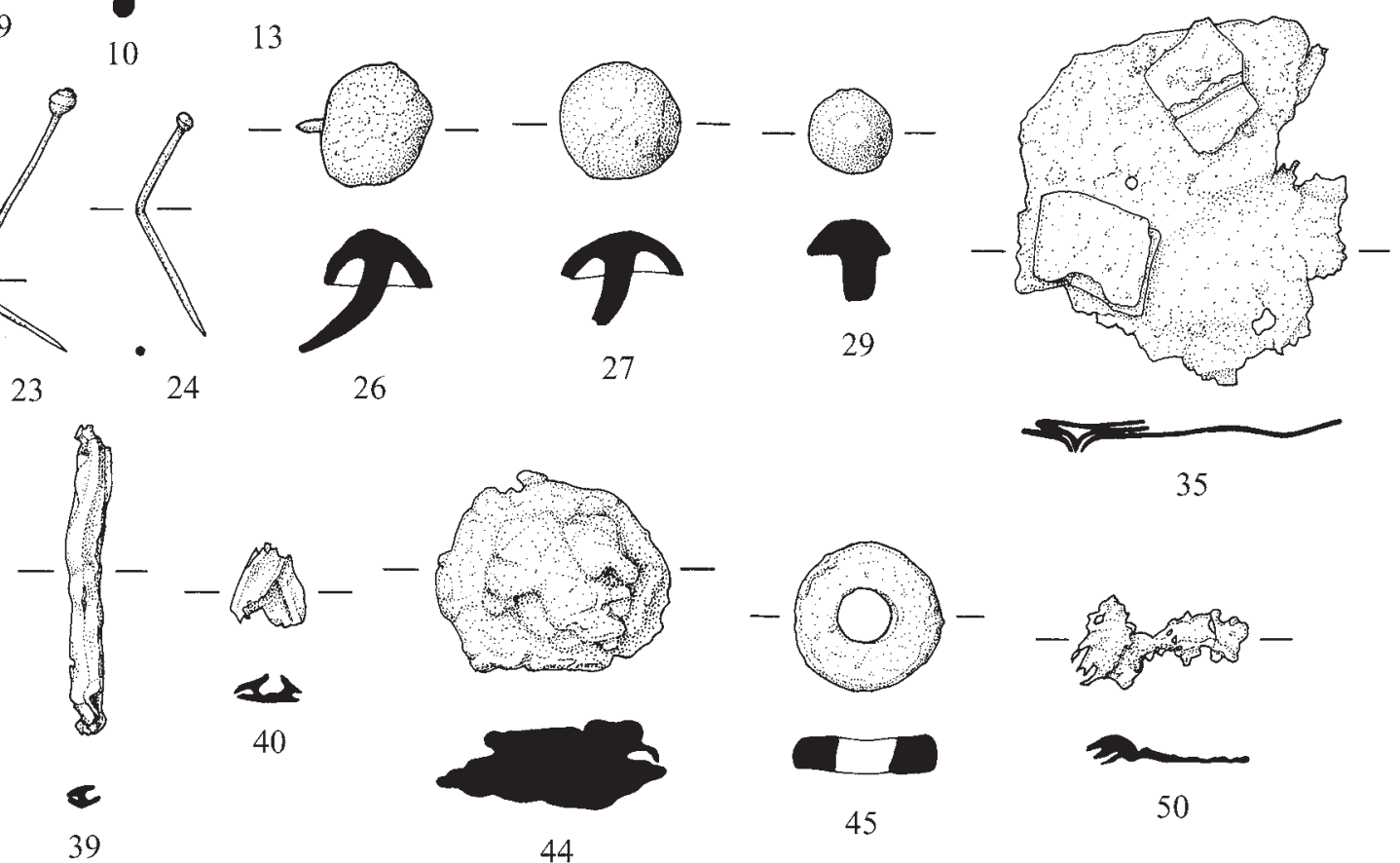

Fig. 1.5 Copper-alloy and lead objects (scale 1:1)

(Ford 1995, 959, Fig. 19, No. 1). No. 1 is likely to be of 16th- or 17th-century date.

1) Bell fragment. Original diameter $c 21 \mathrm{~mm}$; thickness of wall $1 \mathrm{~mm}$.

Fragment of a rumbler bell, representing a single hemisphere, roughly broken at the flanged edge and around the originally dumbbell-shaped perforation. Traces of ferrous corrosion products adhering to the interior surface may represent a remnant of an iron pea. The exterior surface is undecorated. Heavily corroded. Context 242; IADB 558; Period 4.1.
No. 2 is a two-piece buckle with a broad, oval frame. Decorative buckles with oval frames were fashionable from around the middle of the 17 th century into the 18 th century, and were worn as jewellery as well as being functional. The frame of this example is decoratively moulded, and appears to have traces of gilding in one area. The buckle came from a garden soil deposit in Period 4.1, and associated clay pipe evidence indicates a date range of 1640-1700, while glass from this context dates from the late 17 th to mid 18 th centuries.

Found in a cultivated soil deposit in Period 2.2, no. 3 is a small buckle with a circular frame, bisected by a pin bar. This type of buckle is not closely dateable, as similar forms 
were in use over a long period, and possibly had a variety of functions. The type occurs in representational art from around the middle of the 14th century, and was still in use in the 17 th century. It is suggested that a buckle from London, very similar to no. 3, may have been used on a spur (Egan \& Pritchard 1991, 65, Fig. 40, No. 214), and an example from Goltho, also interpreted as a spur buckle (Goodall 1975, 91, No. 7), has a plate around the central pin bar for attachment to a strap. Two similar buckles were found near Lindores Abbey in Fife (Cox \& King 1997, 195-7, Fig. 4, No. 12).

A small buckle from the fill of a linear cut in Period 2.3 (no. 4) has a serrated edge and a pin of very simple form, made from a tapering strip. D-shaped buckles with serrated and scalloped edges are generally dated to the 15th and 16th centuries. This example was found in association with two lace tags (see nos 11-12, below). Its frame is slightly distorted.

2) Buckle. Length $37 \mathrm{~mm}$; width $29 \mathrm{~mm}$; thickness $3 \mathrm{~mm}$. Two-piece buckle with a broad oval frame, bisected by a slender pin bar of trapezoidal cross-section. Fragments of a buckle plate survive where they were looped around the pin bar, although no trace of a pin survives. The frame is decoratively moulded, with circular bosses at the ends of the pin bar and the ends of the frame, with smaller bosses between these, interspersed with foliate or scrolling ornament, all in relief. Traces of gilding survive between the raised elements on one part of the frame. Context 227; IADB 1243; Period 4.1.

3) Buckle. Diameter $18 \mathrm{~mm}$; thickness $2 \mathrm{~mm}$.

Double-looped annular buckle, bisected symmetrically by the pin bar. The frame is plain, with sub-rectangular cross-sectioned edges. The pin is in the form of a plain, rectangular cross-sectioned, tapering strip, simply looped around the central bar. Distorted.

Context 667 (Sample 1106); IADB 3636; Period 2.2.

4) Buckle. Length (including pin) $15 \mathrm{~mm}$; width $17 \mathrm{~mm}$; thickness $3 \mathrm{~mm}$.

Small buckle of approximately D-shaped form, with a serrated outer edge and a narrow flange along the pin bar. The pin is in the form of a plain, rectangular crosssectioned, tapering strip, simply looped around the buckle frame. Slightly distorted.

Context 912 (Sample 2789); IADB 2855; Period 2.3.

The four buttons found on the site (nos 5-8) are all associated with the later phases of its occupation. Nos 5 and 6 both came from the fill of a well in Period 5.2. No. 5 is a decorative button, bearing the arms of Seton of Touch (the Lord Lyon King of Arms pers comm), surmounted by a ship in full sail. This example was manufactured by Kirkwood of Edinburgh. No. 6 is of plainer design, incorporating four thread holes. No. 7 was found on a possible slate floor within Haddington House and is part of a two- or three-piece button. Also from a button of multi-piece construction is no. 8 , representing only the face. These buttons are all probably of 19th- or early 20th-century date, possibly with the exception of no. 7 , which could be a little earlier.

Lace tags such as nos 9-13 were used to terminate laces or thongs, to prevent their ends from fraying and to facilitate threading. They were used on a wide variety of clothing throughout the late medieval period and into the 17 th century. It was common for numbers of tags to be used even in a single costume: the number used on an individual doublet and hose, for example, varied between two and twelve pairs (Cunnington \& Cunnington 1969, 108). Examples have been recovered from excavations throughout Scotland (Cox 1996a, 56). The tags recovered here are associated with medieval activity on the site.

Each tag was made from copper alloy sheet, rolled tightly around the end of the lace or thong. In a study of a large group of lace tags from Northampton, Oakley $(1979,262)$ identified two types of seams. Oakley's Type 1 tags have edgeto-edge seams, while the later Type 2 tags have their edges folded inwards along their length. Both types are represented here. The shape of the sheet from which a tag is fabricated can have a bearing on the nature of the seam, with tapering sheets leading to overlapping seams, examples of which are also represented here.

No. 9 has an edge-to-edge seam, but also incorporates a small, copper alloy rivet, hammered into its upper end, securing the lace or thong within the tag. The rivet has been hammered between the edges of the sheet, parting them, so that the enclosed remnant of the lace or thong is exposed. The rivet does not fully pierce the tag, penetrating only one side. Riveted tags were also found in Northampton (Oakley 1979, 262) and Scottish examples come from excavations at the Abbot's House, Dunfermline (Cox 1996b, 92, Fig. 15, No. 9). Two tags (nos $11 \& 12$, not illustrated) were found in the same context, a linear feature in the northern part of the site. No. 13 appears to have a finished narrower end, with the end of the sheet neatly bent inwards. This may have been achieved by filing around the end of the tag, or by rotating it under pressure while the tag was held at an angle against a flat surface.

9) Lace tag. Length $31 \mathrm{~mm}$; max. diameter $2 \mathrm{~mm}$.

Complete lace tag, made from thin sheet, with an edgeto-edge seam. A small, circular cross-sectioned copper alloy rivet has been hammered through the tag near the upper end, exposing a remnant of the enclosed lace or thong. There is a break in the tag near its lower end but all parts survive. Undecorated.

Context 140; IADB 83; Unphased.

10) Lace tag. Length $33 \mathrm{~mm}$; max. diameter $2 \mathrm{~mm}$.

Almost complete lace tag, made from thin sheet, with an edge-to-edge seam. A possible remnant survives of the lace or thong it enclosed. There is slight breakage at both ends and the tag is corroded. Undecorated.

Context 612; IADB 2463; Period 2.2.

13) Lace tag. Length $32 \mathrm{~mm}$; max. diameter $2 \mathrm{~mm}$.

Complete lace tag, made from thin sheet. The edges are folded inwards along the entire length of the tag, and the narrower end appears to have been finished. Undecorated.

Context 1536; IADB 3872; Period 2.3

The four mounts recovered (nos 14-17, 14 not illustrated) represent a range of forms. It is likely that mounts such as these performed a mainly decorative function, although it can be argued that no. 17 also served to protect the edges of a perforation in a leather strap. Small mounts were used on leather girdles and straps, and probably also on harness equipment. Some would also have been worn on textile garments. Their overall decorative effect may have depended 
on groups of mounts being used together, spaced along a strap for example. On sites where leather straps decorated with mounts survive, the excavated evidence also indicates that mounts of different forms were sometimes used alongside each other, in repeating patterns. Although less apparent from the archaeological record, mounts may also have been used on book covers, wooden furniture, boxes, caskets and other items.

Nos 14 and 15, although of different sizes and slightly different forms, probably served similar functions. Both are of domed form, with a perforation at or near the apex to accommodate a pin or rivet for attachment. No. 14, from a garden soil deposit, is the larger of the two, and appears to be of oval outline with a projecting flange. This type of mount is not closely datable. Examples of medieval date have been found in Perth (eg Cox 1996c, 761, Fig. 17, No. 2), but similar mounts may have been in use over a long period. No. 15, from a levelling deposit for the Hatton House terrace, is a smaller mount, of circular outline. A similar mount was found in a topsoil deposit at Castlecliffe, St Andrews (Caldwell 1996a, 638, Fig. 27, No. 17). Clay pipes associated with both nos 14 and 15 indicate possible 17 th-century dates, although both could be residual finds.

Recovered from a medieval garden soil deposit, no. 16 is a mount in the form of an equal-armed cross, with rounded, expanded terminals, through which rivets were inserted. This object may have been attached to leather, textile or possibly wood. Unusually, iron rather than copper alloy rivets were used for its attachment. The method of its attachment, by small rivets through terminal lobes, resembles that of some of the bar mounts from medieval London (Egan \& Pritchard 1991, 213-4), although no similar cruciform mounts were found. Bar mounts were attached transversely to leather straps in rows. They are depicted on men's waist belts and sword belts in contemporary illustrations (ibid, 209). Cruciform pendants have been recovered from excavations in Perth (Cox 1996c, 767, Fig. 18, No. 90) and at Urquhart Castle (Samson 1982, 472, Fig. 6, No. 77).

No. 17 is a circular mount with a central perforation and two smaller ones to accommodate rivets for its attachment, probably to a leather strap or belt. Similar mounts have been recovered from medieval contexts in London, where they are interpreted as possible surrounds for holes for buckle pins in straps (Egan \& Pritchard 1991, 167, Fig. 107, Nos 795-6).

15) Mount. Height 4mm; diameter $9 \mathrm{~mm}$.

Plain, circular mount of hollow, domed form, with a circular perforation (diameter $1 \mathrm{~mm}$ ) at the apex.

Context 888; IADB 3160; Period 4.1.

16) Mount. Length $20 \mathrm{~mm}$; surviving width $19 \mathrm{~mm}$; thickness $1 \mathrm{~mm}$.

Mount in the form of an equal-armed cross, with arms of approximately D-shaped cross-section and small pellets in the angles between the arms. The object was formerly secured by iron rivets through small perforations $(<1 \mathrm{~mm})$ through the rounded, expanded terminals. A remnant of one of the rivets survives and another two are attested by the presence of corrosion products. Parts of all four terminals survive, although two are broken across their rivet holes. The rear of the mount is flat. Corroded.

Context 612 (Sample 1615); IADB 3627; Period 2.2.
17) Mount. Diameter $21 \mathrm{~mm}$; diameter of central hole $4 \mathrm{~mm}$; thickness $0.8 \mathrm{~mm}$.

Circular mount with a central, circular perforation and two smaller ones (diameter $2 \mathrm{~mm}$ ) at either side of it. Context 660; IADB 1313; Period 3.

\section{TeXTILE EQUipMent}

Two fragments probably representing the points of needles (nos $18 \& 19$ ) came from Periods 2.1 and 3 respectively. Longitudinal seams are visible on both objects, indicating that they were fabricated from tightly rolled sheets.

The two thimbles recovered (nos $20 \& 21$ ) are of different forms, reflecting their different functions. No. 20 is an open or ring form. Using this type of thimble leaves the end of the finger free, and the needle is pushed with the side of the finger. Open thimbles were used for specialised tasks such as sewing canvas, and in tailoring. They were generally preferred by tailors for heavier work (Holmes 1988,1). Complete open thimbles are not commonly found in archaeological contexts and undistorted examples, such as those from King's Lynn and Exeter (Geddes \& Carter 1977, 289, Fig. 130, No. 31; Goodall 1984, 345, Fig. 194, Nos 214 \& 216), are rare. This thimble bears closely-spaced, machine-made indentations, indicating a probable 17 th-century date. The machine-knurling of indentations was first practised in the Netherlands in the early 17 th century (Holmes 1988, 3). Some post-medieval thimbles continued to be made by hand, using a bow-drill. This technique was illustrated in the early 15th century in the Mendelschen Hausbuch (c 1425).

No. 21, in contrast, is a thimble of closed or domed type. Using this type of thimble entails pushing the needle with the tip of the finger, the indentations serving to guide and control the head of the needle. This example has been crushed and is heavily corroded. Furthermore, the upper part of the thimble is largely missing, although a detached fragment from near its apex survives. The indentations on this thimble are more broadly spaced and less regular than those on no. 21, and were punched by hand.

20) Thimble. Height 20mm; original max. diameter c $15 \mathrm{~mm}$.

Tapering thimble of open form, with machine-knurled indentations on the upper $60-70 \%$ of the body, with a plain band below. The object is distorted and part of the wall is missing.

Context 660; IADB 1184; Period 3.

21) Thimble. Surviving height $18 \mathrm{~mm}$; original max. diameter c $15 \mathrm{~mm}$.

Thimble of slightly tapering, domed form, with broadly spaced, possibly punched indentations on the surviving upper part of the body, with a plain band below. The top of the thimble is largely missing, although a small, detached fragment survives and appears to bear indentations. The object has been crushed almost flat and is heavily corroded.

Context 812; IADB 2282; Period 2.3.

\section{Pins}

Eleven pins were recovered, and their details are presented in table 1.3. All appear to be of the same general type, made 
Table 1.3 Copper alloy pins

\begin{tabular}{|c|c|c|c|c|c|c|c|c|c|}
\hline No. & Context & IADB & Period & Completeness & Length & $\begin{array}{l}\text { Head } \\
\text { Type }\end{array}$ & $\begin{array}{l}\text { Head } \\
\text { Width }\end{array}$ & $\begin{array}{c}\text { Shaft } \\
\text { Diameter }\end{array}$ & Bent \\
\hline- & 130 & 3602 & - & shaft only & $12 \mathrm{~mm}$ & - & - & $0.5 \mathrm{~mm}$ & no \\
\hline- & 562 & 3619 & 4.1 & shaft only & $18 \mathrm{~mm}$ & - & - & $0.5 \mathrm{~mm}$ & yes \\
\hline 22 & 643 & 2755 & 4.1 & complete & $23 \mathrm{~mm}$ & $\mathrm{w}-\mathrm{w}$ & $1 \mathrm{~mm}$ & $0.6 \mathrm{~mm}$ & yes \\
\hline- & 643 & 2983 & 4.1 & complete & $34 \mathrm{~mm}$ & $\mathrm{w}-\mathrm{w}$ & $2 \mathrm{~mm}$ & $0.9 \mathrm{~mm}$ & yes \\
\hline 23 & 738 & 1711 & 3 & complete & $35 \mathrm{~mm}$ & $\mathrm{w}-\mathrm{w}$ & $2 \mathrm{~mm}$ & $0.6 \mathrm{~mm}$ & yes \\
\hline- & 888 & 4543 & 4.1 & tip missing & $8 \mathrm{~mm}$ & $\mathrm{w}-\mathrm{w}$ & $1 \mathrm{~mm}$ & $0.6 \mathrm{~mm}$ & no \\
\hline- & 888 & 4544 & 4.1 & tip missing & $11 \mathrm{~mm}$ & $\mathrm{w}-\mathrm{w}$ & $2 \mathrm{~mm}$ & $0.5 \mathrm{~mm}$ & no \\
\hline 24 & 921 & 4724 & 4.1 & complete & $25 \mathrm{~mm}$ & $\mathrm{w}-\mathrm{w}$ & $1 \mathrm{~mm}$ & $0.7 \mathrm{~mm}$ & yes \\
\hline 25 & 921 & 4725 & 4.1 & complete & $23 \mathrm{~mm}$ & $\mathrm{w}-\mathrm{w}$ & $1 \mathrm{~mm}$ & $0.6 \mathrm{~mm}$ & no \\
\hline- & 921 & 4726 & 4.1 & complete & $22 \mathrm{~mm}$ & $\mathrm{w}-\mathrm{w}$ & $1 \mathrm{~mm}$ & $0.5 \mathrm{~mm}$ & no \\
\hline- & 921 & 4727 & 4.1 & tip missing & $13 \mathrm{~mm}$ & $\mathrm{w}-\mathrm{w}$ & $1 \mathrm{~mm}$ & $0.7 \mathrm{~mm}$ & no \\
\hline
\end{tabular}

Notes: pins are listed in context order, and within contexts in IADB number order; w-w = wound-wire head.

from drawn wire, with the head formed by winding a small coil of wire around the top of the shaft, and secured by either an adhesive substance or by soldering. On some excavated examples, a white metal (probably tin) plating survives, as in the case of no. 25. Pins of this type have been recovered from medieval and post-medieval contexts across Scotland (Cox 1996a, 57).

At Holyrood, all but two examples are from Period 4.1, and are associated with activity of 16th- to 17 th-century date. The form of these pins indicates a date in the latter part of that range, probably in the second half of the 17 th century. Four pins came from the fill of a stone-capped drain, likely to have led from the kitchens of a house fronting onto the Canongate. Another two pins came from a levelling deposit into which this drain was cut, and another example was from the deposit overlying its stone capping. This represents a significant concentration of pins in and around a single feature, which may provide clues regarding the function of the building from which the drain led. Small pins of this type were used in large numbers by tailors, essentially as dress pins, although they performed a range of other functions involving securing textiles, for example in shroud burials. A connection with tailoring activities on the site is a possibility in this case.

23) Pin. Length if straightened $35 \mathrm{~mm}$; width of head $2 \mathrm{~mm}$; diameter of shaft $0.6 \mathrm{~mm}$.

Pin with an almost spherical, wound-wire head and a circular cross-sectioned shaft, the top of which stands slightly proud of the head. The shaft is bent to an acute angle. Corroded.

Context 738; IADB 1711; Period 3.

24) Pin. Length if straightened $25 \mathrm{~mm}$; width of head $1 \mathrm{~mm}$; diameter of shaft $0.7 \mathrm{~mm}$.

Pin with a pinched, wound-wire head and a circular crosssectioned shaft, which is bent just above mid-shaft.

Context 921 (Sample 2825); IADB 4724; Period 4.1.

\section{STUDS}

Three studs (nos 26-28, 28 not illustrated) and a possible stud or rivet (no. 29) were found. Nos 26 and 27, both from Period 4.1, are of a similar type, with a hollow, domed, circular or slightly oval head and a square cross-sectioned shank. They are both probably of 17th-century date. A good parallel for this form was excavated at Niddry Castle in West Lothian (Aliaga-Kelly 1997, 827, Fig. 27, No. 1035). Cast studs like these, with broad heads and relatively short shanks, were probably used on furnishings, attaching leather or fabric upholstery to wooden frames. Upholstered furniture became more common in the 16th and 17th centuries, as did textile wall-hangings, which may also have been secured using studs. No. 28, from an earlier context, is of a slightly different form with a smaller head and a broader, longer shank. This example was probably also driven into wood. No. 29 represents a stud or a rivet, with a small, solid head and a circular crosssectioned shank. Objects like this may have had a variety of uses. Small studs were sometimes used on leather straps and horse harness equipment.

26) Stud. Length $12 \mathrm{~mm}$; max. width of head $13 \mathrm{~mm}$. Stud with a domed, roughly oval head and a slightly bent, central, square cross-sectioned shank.

Context 232; Sample 262 (retent); Period 4.1.

27) Stud. Length $9 \mathrm{~mm}$; diameter $13 \mathrm{~mm}$.

Plain, circular stud of hollow, domed form, with a flat rim and a tapering, square cross-sectioned shank, which is broken and slightly misaligned.

Context 307; Sample 777 (retent); IADB 1541; Period 4.1.

29) Stud or rivet. Length $8 \mathrm{~mm}$; diameter $8 \mathrm{~mm}$.

Plain, circular stud with a solid head of domed form and an off-centre, circular cross-sectioned shank. The shank is blunt-ended, possibly its original form.

Context 1750; Sample 4402 (retent); Period 4.1.

\section{Miscellaneous}

A curved strip fragment recovered from an extensive medieval garden soil deposit (no. 30) may be part of a loop or chain attachment. Fittings of this size appear, for example, on strap-distributors used on horse harness. No. 31 is a ferrule or a chape, possibly used on the tip of a wooden cane or to terminate a scabbard. Recovered from the fill of a well in 
Period 5.2, it is probably of post-medieval or early modern date. No. 32, from an unstratified context, is also of postmedieval date. This smaller, faceted ferrule was probably used on a walking cane or similar object.

Recovered from an infill deposit in Haddington's Entry, no. 33 appears to be a fragment from a cast vessel. Cast copper alloy cooking pots only became common in late medieval times, and were frequently repaired or the metal reused (le Patourel 1973, 91). Fragments of cast copper alloy vessels have been found in medieval contexts in Perth (Ford 1987a, 127-9; Cox 1996c, 770, Fig. 20, No. 205). From an unphased context, no. 34 is possibly part of a buckle plate. There is no trace of surface decoration on this fragment. Glass of early 18th-century date was found in association with it.

A riveted sheet fragment, found in the fill of a medieval boundary ditch in Period 2.2 (no. 35, fig. 1.5) is probably from a repair patch, possibly used on a vessel. Two sheet metal rivets, often referred to as 'paperclip' rivets, made from lozenge-shaped sheets, perforate this fragment and would have secured it to the repaired object. Sheet metal repair patches for vessels have previously been excavated at Mill Street and at Meal Vennel, Perth (Ford 1995, 961; Cox 1996c, 768-70), in St Andrews (Caldwell 1996a, 636; Maxwell 1997a, 73) and at Castle Park, Dunbar (Cox 2000a, 121). Part of a heavily patched bowl was found at Linlithgow (Stones 1989, 160). All of these examples include paperclip rivets in situ.

Part of an elongated staple, with its surviving arm tapering to a point (no. 36) was found in a stone-capped drain in Period 3. This type of staple was probably used to secure items to structural timbers or fencing. No copper-alloy sheet offcuts, the presence of which would indicate the cold working of copper alloy, were found. Lengths of circular cross-sectioned wire were used in the fabrication of a variety of artefact types, including pins and wire loops. Concentrations of wire in medieval contexts can be indicative of manufacturing activity and of metal-workers' stock, but only two very small pieces of wire were recovered here.

\subsubsection{Lead alloy objects}

The small assemblage of lead alloy objects comes from Periods 2.2 to 4.1. Some (for example the window cames and an object representing caulking) may be associated with building construction and repair work, although the small quantity of this material present suggests that lead alloy construction materials were not fabricated in large quantities on the site. Lead alloy waste was easily and routinely reused, and among the assemblage are two objects, a came fragment (no. 42) and a piece of waste sheet (no. 51), that have been rolled up, probably with the intention of reusing.

Window cames like nos 39-42 (fig. 1.5) were used to join and support individual pieces of glass within a window, and they have a characteristic H-shaped cross-section. Two cames were recovered from Period 2.2 and two from Period 4.1. Three individual panes of glass would have been in contact with No. 40 (fig. 1.5), which represents a corner join. The angle of the corner is consistent with the insertion of a diamond-shaped pane. At least five pieces of glass, at least some of them diamond-shaped, were in contact with no. 42 when it was in use. Diamond-shaped or 'quarry'-shaped pieces of glass characterise domestic glazing in the 16th and 17th centuries, with triangular pieces used at the edges of window frames. Examples of both were recovered from the excavation (see Part 1.5). A lattice of cames was used to join pieces of glass together within a window, but the diamond lattice construction was generally replaced by paned sash windows in the 18 th century.

The came fragments also provide evidence of the thicknesses of the panes of glass they supported. No. 42 held panes of $c 5 \mathrm{~mm}$ in thickness, and no. 41 a pane of $c 4-5 \mathrm{~mm}$. The two later fragments (nos 39-40), however, supported thinner pieces of glass, with thicknesses of $c 3 \mathrm{~mm}$ in both cases.

39) Came. Length $66 \mathrm{~mm}$; width $7 \mathrm{~mm}$; thickness $3 \mathrm{~mm}$.

Window came fragment with an $\mathrm{H}$-shaped cross-section, broken at both ends and flattened.

Context 1654; IADB 4823a; Period 4.1.

40) Came. Length $18 \mathrm{~mm}$; width $16 \mathrm{~mm}$; thickness $5 \mathrm{~mm}$.

Window came fragment representing a corner join.

Context 1654; IADB 4823b; Period 4.1.

An object with a central, rectangular recess (no. 43) was probably used as caulking around an iron object such as a masonry cramp, a hinge pivot or a candlestick, to secure it within a rebate in stonework. The use of lead alloy caulking in this way helped to prevent the iron from rusting and splitting the stone into which it was inserted. Another example was found during recent excavations at Murraygate, Dundee (Cox 2000b, 53).

43) Caulking or plug. Length $33 \mathrm{~mm}$; width $19 \mathrm{~mm}$; thickness 20mm.

Possible caulking, with an open, rectangular recess at its centre and a strip projecting from the base of this recess. Regular, rectangular indentations (length $c 4 \mathrm{~mm}$ ) appear on the flat surface of the object.

IADB 268; Unstratified.

No. 44 (fig. 1.5) represents a vessel repair patch, used on a pottery vessel with a wall thickness of $c 6 \mathrm{~mm}$ where the patch was applied. Both the exterior and interior surfaces of the patch are present and, although crude, it appears to have been worked on from both sides. The interior surface has been more carefully finished. This surface is broader and slightly convex, and is thinned at the edges, possibly in order to prevent it from standing proud of the interior of the vessel wall. With a weight of $137 \mathrm{~g}$, this represents a substantial repair patch and the repaired vessel is also likely to have been substantial. A surviving remnant of the vessel wall, held in position within the repair patch, is of medieval East Coast White Gritty Ware fabric (D Hall pers comm), indicating that this object is possibly residual in Period 3.

44) Vessel repair patch. Length 50mm; width 41mm; max. thickness $8 \mathrm{~mm}$. Weight $137 \mathrm{~g}$.

Roughly oval repair patch, with a small sherd of East Coast White Gritty Ware held in position.

Context 348; IADB 1939; Period 3.

A perforated, discoid object (no. 45, fig. 1.5), found in the bedding deposits for a cobbled surface in Period 3, may have functioned as a weight (eg a loomweight) or as a spindle whorl. The former interpretation may be the more likely, as 
the object is rather crudely finished. However, no wear marks diagnostic of either function are present. A very similar, although slightly larger, object was associated with a 15 thto 16th-century phase of activity at Blackfriars House, Perth (Ford 1995, 961, Fig. 20, No. 170). No. 45 was found in association with a clay pipe bowl of late 17 th-century date.

45) Weight or spindle whorl. Diameter 30mm; thickness $7 \mathrm{~mm}$.

Plain, circular weight or spindle whorl with a central, circular hole (diameter 12mm). Weight 42g.

Context 1514; IADB 3865; Period 3.

The only evidence of the cutting of lead alloy sheet on the site survives in the form of two small, tapering offcuts (nos $46 \& 47)$. No. 46 has certainly been trimmed, whereas this is less clear in the case of no. 47, which was found in association with two window came fragments (nos $41 \& 42$, above) in the backfill of a rectilinear feature in Period 2.2. No. 46 is from an unphased context containing clay pipe fragments of 17th-century date.

No. 48, a curved strip fragment terminating in an irregular flange, was possibly part of a decorative strip pattern, for example on a window or mounted on a wooden object. It may represent a discarded waste piece from the casting of such decorative strips. The flanged end has the appearance of having been melted, possibly in a fire. Nos 49 and 50 (fig. 1.5) represent pieces of once-molten waste, produced either during the melting or casting of lead alloy objects, or accidentally in a fire. No. 49 incorporates a convex face with a pitted appearance, possibly indicating that the molten lead alloy solidified upon a rough, sandy or sanded surface. No. 50 , associated with clay pipe evidence of mid 17 th- to early 18 thcentury date, is a thin piece that also appears to have resulted from molten lead alloy landing upon an uneven surface and solidifying. No. 51, from a medieval garden soil deposit, is a rolled and slightly flattened sheet fragment, possibly intended for re-use. Artefactual evidence of the re-use of lead alloy has been recovered from medieval contexts elsewhere, for example at Urquhart Castle (Cox 1999).

50) Waste. Length $32 \mathrm{~mm}$; width $20 \mathrm{~mm}$; thickness $5 \mathrm{~mm}$. Waste piece of irregular form.

Context 540; IADB 644; Period 4.1.

\subsubsection{Iron objects (fig. 1.6)}

The iron artefacts recovered from this site are generally in poor condition, possibly due to the well-aerated, damp soil conditions. However, a range of functional categories is represented, including horse equipment, structural ironwork and tools. A large part of the assemblage came from the medieval and post-medieval garden soils. In addition to the items discussed below, a number of small fragments of corroded iron objects was recovered.

\section{HORSE EQUIPMENT}

Parts of horseshoes (nos 52-56) were recovered from Periods 2.1-2.3 and 4.1, although, with the exception of no. 56, all are small fragments and their details have mostly been recorded with the assistance of X-radiography. Horses' hooves grow continually and they need to be regularly trimmed and reshoed, particularly if the horse is taken on hard surfaces. This involves the periodic removal of horseshoes, whether worn or not. Frequent re-shoeing may account for numbers of discarded horseshoes, and in addition to this, shoes could have been accidentally lost as horses crossed muddy ground. Although the evidence from this site is fragmentary, a number of features of the horseshoes can be briefly discussed.

No. 52 represents the terminal of a branch of a shoe, with a rectangular nail hole set within a fullered groove. This feature, a groove around the ground surface of the shoe in which the nails sit, is a post-medieval innovation (Clark 1986, 1), occurring, for example, on a group of 17th-century horseshoes from Sandal Castle (Goodall 1983, 251).

No. 56, from a charcoal and clay deposit in Period 2.3, is the only complete horseshoe recovered. This example has an asymmetrical arrangement of nail holes, with four on one branch and three on the other. The shoe also has a pronounced calkin on one branch. Calkins, thickened or downturned terminals, can provide an improved foothold on soft ground and uneven roads. They are not in use today, and their benefits were being questioned even in the 17th century (Clark 1995, 82). An examination of the large collection of medieval horseshoes from London (ibid) revealed that the use of calkins declined fairly steadily from the 13th century through the 14 th and 15 th centuries, although most shoes in the 13th century included them. Calkins could be used on either both branches of the shoe, or just one, as in no. 56. The other fragments on which the terminal survives (nos 53 \& 55) do not have calkins. No. 54, stratigraphically the earliest shoe in this group, survives only as a fragment, with few diagnostic features. No. 55 was found in association with a group of late 17 th-century clay pipes.

52) Horseshoe. Length $74 \mathrm{~mm}$; max. width $23 \mathrm{~mm}$; thickness $7 \mathrm{~mm}$.

Horseshoe fragment representing the terminal of one branch, broken across a single sub-rectangular nail hole, set within a fullered groove. Heavily corroded. X-radiography reveals no additional nail holes in this fragment. Context 540; IADB 447; Period 4.1.

53) Horseshoe. Length $54 \mathrm{~mm}$; max. width $24 \mathrm{~mm}$; thickness $4 \mathrm{~mm}$.

Horseshoe fragment representing part of one branch, including the terminal. X-radiography reveals that the object has broken across a rectangular nail hole. Context 612; IADB 2635; Period 2.2.

54) Horseshoe. Length $58 \mathrm{~mm}$; max. width $24 \mathrm{~mm}$; thickness $3 \mathrm{~mm}$.

Horseshoe fragment representing part of one branch, heavily corroded, and with part of the outer edge missing. Parts of three rectangular nail holes survive. Context 760; IADB 2680; Period 2.1.

55) Horseshoe. Length $73 \mathrm{~mm}$; max. width $24 \mathrm{~mm}$; thickness (not including nail) $5 \mathrm{~mm}$.

Horseshoe fragment representing part of one branch, including the terminal. A single rectangular nail hole is visible, and is occupied by part of a nail with a rectangular head. A second nail hole can be discerned only by X-radiography.

Context 888; IADB 3294; Period 4.1. 


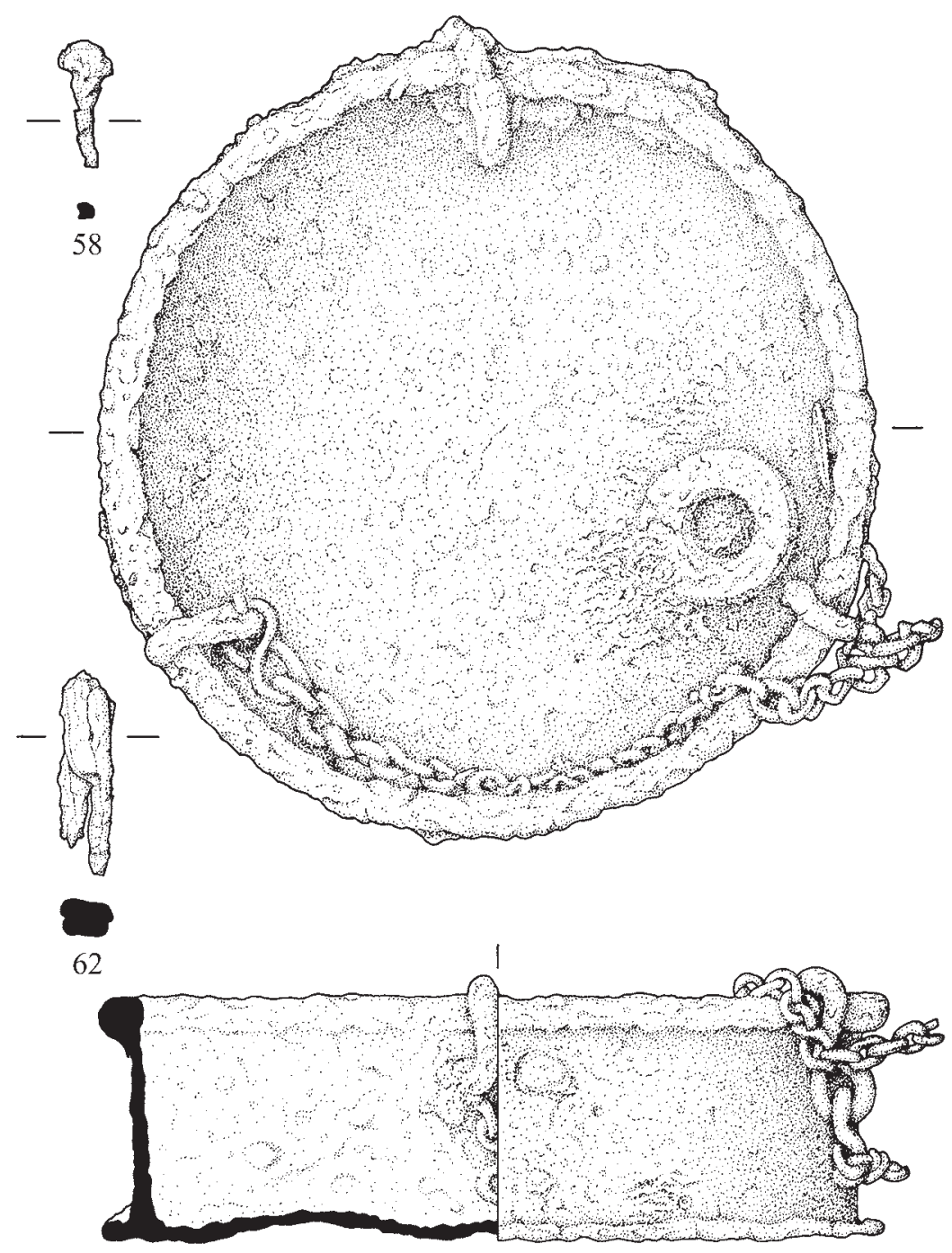

67

Fig. 1.6 Iron objects (scale 1:3)

56) Horseshoe. Length $121 \mathrm{~mm}$; max. width $30 \mathrm{~mm}$; thickness $7 \mathrm{~mm}$.

Complete horseshoe. X-radiography reveals seven rectangular nail holes, arranged asymmetrically. There is a calkin on one branch only. Heavily corroded.

Context 1104; IADB 3427; Period 2.3.

Four complete or almost complete horseshoe nails, and several fragments of such nails, were recovered from Periods 1-4.1. The two examples described below (nos 57 \& 58) have contrasting head forms. That of no. 57 is approximately trapezoidal, and has a flat top, whereas no. 58 has a more semi-circular head (fig 1.6). No. 58 is an example of a type generally thought to have been used from as early as the 9 th century until around the middle of the 13th century (Clark 1986, 2), although the dating of three examples from Perth, based on associated pottery, indicates that the type was still in use in the 14th century (Ford \& Walsh 1987, 137). No. 57, along with the other recovered examples, is a later form.
57) Horseshoe nail. Length $29 \mathrm{~mm}$; width of head $10 \mathrm{~mm}$; thickness $7 \mathrm{~mm}$.

Almost complete horseshoe nail, missing only its tip. The head is of approximately trapezoidal form.

Context 681; IADB 2270; Period 2.3.

58) Horseshoe nail. Length $29 \mathrm{~mm}$; width of head $13 \mathrm{~mm}$; thickness $4 \mathrm{~mm}$.

Almost complete horseshoe nail, missing only its tip, in three conjoining pieces. The head is of lobed, semicircular form. X-radiography indicates that the nail tip was clenched.

Context 790; IADB 2325; Period 1.

\section{Structural FitTing}

No. 59 is a strap hinge, probably from a shutter or a cupboard. The hinge arm narrows and is then broken across the beginnings of an expansion, hence it may have incorporated a decorative terminal. Found in the fill of a service trench in Period 5.2, this object probably dates from the 19th century. 
59) Strap hinge. Length $153 \mathrm{~mm}$; width $77 \mathrm{~mm}$; max. thickness $6 \mathrm{~mm}$.

Strap hinge with a tapering arm, with three nail holes, one of which it has broken across. The arm narrows and then is broken across the beginnings of an expansion. Context 1042; IADB 2941; Period 5.2.

Tools

The head of a large fork (no. 60) was found in the primary fill of a stone-lined tank in Period 2.3. Whether the fork is related to the function of this feature is uncertain. A large fork such as this may have been used for horticultural work or in digging or clearing pits and ditches, although it could also have been used to mix or agitate the contents of a tank, for example. The fork is very heavily corroded, hence the measurements below are approximate.

No. 61 appears to be a blade from a whittle tang knife. The term whittle tang denotes a tang inserted into a solid handle (whereas scale tang denotes one onto which plates or scales are riveted, forming a composite handle). This example was recovered from the backfill of a clay-lined, stone structure in Period 2.3, possibly used in a dyeing or tanning process.

A fragment representing part of a pair of shears (no. 62, fig. 1.6) was recovered from a post-medieval garden soil deposit in Period 4.1. The object includes the upper parts of both blades, overlapping in the closed position and corroded together. Parts of both handle arms also survive. The basic components of a pair of shears are two blades, joined by handle arms to a sprung bow. Whereas the junction of scissor blades incorporates a rivet, about which the blades pivot, $\mathrm{X}$-radiography confirms that this fragment consists of overlapping blades unconnected by a rivet.

No. 62 is from a fairly small pair of shears, and, in common with many excavated examples from the medieval period, they could have served a variety of domestic purposes, including hair-cutting and thread-trimming, although examples with relatively long blades could have been used for cloth-cutting and sheep-shearing. The relative proportions of the blades and handle arms of no. 62 are uncertain, but this reflected the use to which shears were put. Proportionately longer handles than blades meant that greater leverage could be achieved, and more pressure exerted in the cutting action. Long, slender blades were preferred for accurate and continuous cutting. Small shears that could only be held in the palm of the hand were not suitable for continuous cutting, but were suitable for single cuts, such as in cutting thread (de Neergaard 1987, 58). This pair of shears, probably dating from the 17th century on the basis of associated clay pipe evidence, may have been used in a domestic context or by a tailor working in the vicinity of the site.

60) Fork. Length c 420mm; max. width c 205mm; max. thickness $c 65 \mathrm{~mm}$.

Head of a large fork, with three parallel prongs of equal length, rounded shoulders and an approximately circularcross-sectioned handle. One of the prongs is broken but all parts survive. Very heavily corroded. Context 837; IADB 2373; Period 2.3.

62) Shears fragment. Length $46 \mathrm{~mm}$; max. width $14 \mathrm{~mm}$; thickness $7 \mathrm{~mm}$.

Fragment representing overlapping parts of the blades of a pair of shears, along with parts of the handle arms. The latter are of approximately circular cross-section.

Context 540; IADB 674; Period 4.1.

\section{Miscellaneous}

No. 63 possibly represents part of the frame of a rectangular buckle, although from these surviving fragments alone, this identification is uncertain. Associated clay pipe evidence indicates a late 17th-century date. No. 64 is a heavily corroded bar, broken at both ends. X-radiography of no. 65, a fragmentary buckle or strap fitting, reveals that it may have included a pronged arrangement on the central bar, rather than a pin. It would have been used on a fairly broad strap $(c 40-45 \mathrm{~mm}$ in width). No. 66 possibly functioned as a point or ferrule on the end of a wooden rod. X-radiography reveals that it is of hollow form, possibly containing mineralised wood remains. Associated clay pipes indicate a late 17th-century date.

Recovered from the fill of a shallow pit in Period 5.1, no. 67 (fig. 1.6) is a circular, flat-bottomed vessel, which had been suspended by chains attached at equal intervals around its rim. A flat-bottomed vessel like this may have held an oil lamp or supported a candle-holder. Alternatively, it may have served an ornamental function. It is probably of 19th-century date.

65) Buckle or strap fitting. Length c 49mm; width 27mm; thickness $3 \mathrm{~mm}$.

Five fragments from an elongated, rectangular buckle or strap fitting, including one side of the frame and the central bar. Heavily corroded.

Context 540 (Sample 2548); IADB 2710; Period 4.1.

67) Vessel. Diameter at rim $171 \mathrm{~mm}$; diameter at base $176 \mathrm{~mm}$; depth $56 \mathrm{~mm}$.

Circular, flat-bottomed vessel with approximately vertical sides and a rounded rim. The base appears to have been separately made and its edge projects from the vessel sides in the form of a narrow flange. At equal intervals around the rim, chains are secured by means of broad, S-shaped links. Several detached chain links were found in close association with this vessel, and recorded as IADB 714.

Context 294; IADB 718; Period 5.1.

\subsection{IRON-MAKING AND -WORKING}

\section{EFFIE PHOTOS-JONES}

\subsubsection{Introduction: setting the scene}

The present section aims to assess the nature, composition and distribution of the metallurgical debris derived from the excavations at Holyrood as a means of understanding iron-making and -working practices in the east of Scotland, within the urban confines of the Canongate and the capital as a whole. Given the chronological span of the deposits (12th-19th centuries), the amount of slag and associated fuel waste recovered was relatively small (c 35kg). Most of the Holyrood metallurgical waste originated from garden soils and was often found in association with metal artefacts. Its presence raises interesting questions. What does the waste 
represent? Does it reflect smelting or smithing practices, or both, and at which periods? Was it produced locally or was it brought from elsewhere, in either case as part of a smith's midden deposit? Assuming that there is evidence for primary smelting practices, what is to be learnt regarding the procurement of raw materials and energy resources available?

In order to set the metallurgical waste in its proper historical context it is important to give a brief overview of Scottish bloomery practices. Scotland is richly endowed with iron deposits and most of them were exploited in one way or another by the 19th century. Historically, it is the 'chance discovery' of clayband and blackband iron ores, the iron carbonates of the Lanarkshire, Ayrshire, Fife and Lothian fields in the 18th and 19th centuries respectively, which is thought to have contributed to Scotland's participation as a major player in the development of the British iron and steel industry in the early part of the 19th century. The importance of the metallurgical waste from Holyrood lies in the fact that it reveals, for the first time, that from the medieval and post-medieval periods the east coast urban centres were already using these locally available but complex ores, in which coal was an integral part of the ore rather than merely being added as a fuel. As Schubert $(1957,333)$ has written, 'the transition from charcoal to mineral coal and coke was closely connected with the rise of the clayband iron ores'. The evidence for the use of these ores at Holyrood raises two interesting points. First, the presence of coal in the bloomery must have been problematic since it introduced sulphur into the metal. Second, with the appearance of the hitherto scarcely visible medieval manufacturer of iron, vis à vis the ubiquitous smith, were the smith and the smelter the same person? And did these people work for the abbey or the burgh? We are fortunate that the metallurgical waste gives the opportunity to address both points. The diachronic distribution of metalworking waste over roughly the same area from the medieval to the post-medieval period suggests that production must have been local and in all likelihood, at least in the early periods, associated with the abbey.

The following sections present the archaeological background, the location and availability of local resources, and the distribution and analysis of the metallurgical waste from Holyrood.

\subsubsection{The Scottish bloomery}

Presently, the earliest bloomery furnace in Scotland is thought to be the one excavated at Tarras Farm, Forres, near Inverness, dated to cal $198 \mathrm{BC}-\mathrm{cal} \mathrm{AD} 49$ and cal $378 \mathrm{BC}-\mathrm{cal}$ AD 17 (Will 1999; Photos-Jones 1999a). It was a simple bowltype furnace dug into the ground and lined with stone slabs, and probably covered with a clay/charcoal superstructure, to ensure prevalence of oxygen-poor conditions, leading to the effective smelting of the ore. The product was workable lowcarbon iron for most uses.

Despite its antiquity, the bloomery is a chemically complex process involving the reaction of a solid lump of ore (iron oxide) with carbon monoxide from the burning of the fuel (charcoal). The process is difficult to control, yields are uncertain, and furthermore, a large amount of iron is lost in making slag, the non-metallic component or waste.

Metal artefacts in the form of raw metal or finished objects are a rare occurrence at bloomery sites, but occasional finds do shed light into what the end product, the bloom, might have been; essentially a low-carbon malleable iron (wrought iron), which could be shaped into tools, weapons or decorative artefacts. A complete $5 \mathrm{~kg}$ bloom from Stiddrigg, Dumfriesshire (Photos-Jones 1997), fragments of a bloom from Rothesay Castle, Isle of Bute (Photos-Jones 2000), a billet (shaped bloom) from Caerlaverock Castle, Dumfriesshire (Photos-Jones 2001), a currency bar from the Isle of Arran, and a forge-welded bar of iron from Woodend, Dumfriesshire (Atkinson \& Photos-Jones 2000, Fig. 8) testify to metal-working practices widely available and often of great technical expertise. These metallurgical wastes and artefacts from Scotland from the second century BC onwards suggest prolonged experience with the making of iron and a widespread availability of a variety of both energy resources and raw materials.

Regarding actual bloomeries, or the workshops where iron was produced, there are those associated with the small but ubiquitous bloomery mounds of the Scottish Highlands (Photos-Jones et al 1998; Atkinson \& Photos-Jones 2000), the medieval and post-medieval 'smithies' of burghs like Perth (Photos-Jones \& Atkinson 1998), and those attached to abbeys like Arbroath or castles like Rothesay and Caerlaverock (Photos-Jones 2000; 2001). Most date to the post-medieval period.

Conventional thinking trends might argue that most metallurgical debris within urban contexts must be of the smithing type. This is primarily because the methodological approach traditionally used, namely classification based on typology, does not lend itself to the testing of different hypotheses (Spearman 1988). In other words, the question of whether urban ironsmiths were also manufacturers of the raw metal is a complex one to address and the answer must be sought in the technical examination of industrial waste.

In reference to medieval Perth, Photos-Jones and Atkinson (1998), argued that there would be little need for dependency of the medieval smiths on their Highland counterparts for the procurement of the raw metal in that burgh, since bog-iron ore would have been readily available in the Perth countryside. Given the limited technical requirements of the bloomery, at least in its pre-waterpower-driven phase, and the abundance of the raw materials, most Scottish medieval ironsmiths living in urban centres would have been capable of making their own iron. Dennison's description of 'the rural atmosphere in the medieval town' where there is little pressure on space and potentially with direct access to the source of raw materials, supports this argument (HAPT, Chapter 4.5).

We must therefore ask, is there smelting slag amongst the metallurgical waste, and, who was producing it and where? Craft specialisation within the medieval town has been well documented. For 15th-century London, 'almost a quarter of the crafts ... were concerned primarily with metal' (Keene 1996, 96). An insight into this specialisation can also be glimpsed by the archives for medieval Nottingham (Egan 1996; MacCormick 1996). Among the ironsmiths, there are included armourers, arrowsmiths, blacksmiths and bladesmiths and farriers, all listed as forging iron and steel. On the other hand, locksmiths, lorimers and some blacksmiths are thought to have simply hot-and cold-worked iron and steel (MacCormick 1996, table 1). In addition to these crafts, there 
were cutlers and grinders who would be simply grinding and polishing blades without necessarily the need for a hearth installation. Most of these craftsmen would have belonged to an incorporation of hammermen, a guild for those working in both ferrous and non-ferrous metals. In reference to the hierarchy within the metal-working occupations, Keene $(1996,95)$ has argued, on the basis of London tax assessments, that ironmongers (merchants in iron), had a status second only to goldsmiths, while smiths and other metal manufacturers were at the bottom of the 'pecking order'. Did that include manufacturers of the raw metal as well? To our knowledge, there is no reference to makers of iron as living and working together with any of the above specialised ironmaking occupations.

\subsubsection{Energy sources and natural resources}

Scotland is richly endowed with iron ore deposits which have been considered both from a geological (McGreggor et al 1920) as well as an archaeological perspective (Hall \& Photos-Jones 1998). Prior to the early 17 th century, exploitation was small-scale and associated with iron seepages or encrustations (bog-iron ores) characterised by the presence of manganese and phosphorus and low potassium and calcium contents (Hall \& Photos-Jones 1998). The use of these regenerative sources of iron ore (they can re-form at a considerable thickness over a period of about 30 years) was first studied in association with the post-medieval bloomery mounds of the Scottish Highlands (Photos-Jones et al 1998, table 1).

Another type of ore used in the early bloomeries was siderite or carbonate ore which, when pure, contains $48.3 \%$ $\mathrm{Fe}$ (iron). Within this group there exist two types of ores, ironstones of the Carboniferous Age, found within the Limestone Coal Group, and are from the claybands and blackbands of Lanarkshire and Ayrshire, Fife and the Lothians. The clayband ores have a considerable amount of clayey material or shale, the ore ranging in colour from white to black. The blackband ores contain little clay and a considerable amount of coal. They are fossiliferrous and contain up to $30 \% \mathrm{Fe}$. Analyses of both types of ores used in the 19th century have been well documented in Sexton (1902) and MacGregor (1982).

The first documented workers of coal were supposed to have been the monks of Newbattle Abbey. In 1291 a charter was granted to the abbot and convent of Dunfermline giving them privilege to dig for coal in the lands of Pittencrieff (Macadam 1887, 95), whether for domestic or industrial applications is not certain. Domestic use is demonstrated by Eneas Sylvius, of Scotland, in the 14th century, who wrote that people who begged at the church doors received for alms "pieces of stone with which they went away contented ... whether with sulphur or whatever inflammable substance it may be impregnated, they burn it in place of wood' (ibid, 95). Therefore the domestic use of coal, assuming proximity to resources, must in principle and not necessarily in practice have preceded its use in iron-making by far.

Coal, although used extensively in smithing from the Roman period (Dearn \& Branigan 1995, 82), has always been considered inappropriate for smelting; large amounts of sulphur, when absorbed into the iron, render it hot-short (it fractures when hot hammered). Coking does not necessarily remove great amounts of sulphur, but low-sulphur coals can be used (Tylecote 1986, 225). Slag can also act as a desulphuriser in the blast furnace.

Turning to the sources that could have supplied Holyrood, the Midlothian coalfield extends to the west of the city of Edinburgh, between the Pentland Hills and a lower-lying ridge to the east. It runs in a NE/SW direction from the Firth of Forth, gently rising southwards to Auchencorth Moss. A number of collieries have been worked there until recently, extracting coal from the two great coal ring groups of Scotland, the Limestone Coal Group and the Productive Coal Measures. Within these coal measures, ironstone, both blackband and clayband, is found (especially at Loanhead Collieries 1, 2 and 3). The distance of Loanhead from Arthur's Seat is an obviously relatively short one, only about 4 miles $(6 \mathrm{~km})$ away. We can see therefore that both coal and ironstone would have been available close to the Canongate. While there is no direct evidence, it is likely that the calorific value of these fuels would have been evident well before the medieval period. Is it possible that in the medieval period the procurement of the ore could have been organised by the abbey in the manner that the monks of Newbattle Abbey had acquired a charter giving them privileges to dig for coal?

\subsubsection{Typology and distribution of the Holyrood metallurgical waste}

Examination of the material with a low-powered stereomicroscope revealed four categories:

- Fuel: any type of combustible material, be it charcoal, coal or coke, whether untreated, charred or partly ashed.

- Slag: any type of metallurgical waste of siliceous and/or iron-silicate base of any date, shape or form.

- Magnetic residues: small magnetically active fine particles of slag, 'ore' or fragments of metal, magnetically separated from their contexts.

- Ferruginous (also referred to as metal/metallic fragment): usually small, unidentifiable fragments of any material, which is either naturally or artificially iron-rich.

The largest single category by weight was coal/charcoal $(c$ $20.8 \mathrm{~kg})$, followed by slag $(9.3 \mathrm{~kg})$, magnetic residues $(3.6 \mathrm{~kg})$, and ferruginous materials $(0.5 \mathrm{~kg})$. Therefore the total amount of iron-working material and fuel recovered from the site weighed no more than $c 35 \mathrm{~kg}$, a relatively small amount considering that the site spans nearly 800 years of habitation.

Fuel constitutes the majority of the waste recovered. It could have derived either from domestic or industrial activities. At the start of the investigation, it was not clear how much of the fuel was charcoal, coal or something else. A number of contexts were therefore examined in detail with the stereomicroscope and four groups were identified: coal, charcoal, coke or porous and unidentified material (non-fuel). Some basic criteria were applied: charcoal was identified on the basis of its plantlike texture; coal on the basis of compactness and a platy structure; and 'coke' on the basis of porosity. The results (table 1.4) clearly suggest an overwhelming evidence for the use of coal. It should be noted here that by 'coke' we imply not the product of coking furnaces but rather the reduction of coal within the furnace and its localised-withinthe-furnace-conversion to coke. 
Table 1.4 Iron-working: distribution of charcoal/coal/coke from 12th- to 19th-century contexts

\begin{tabular}{lcccc}
\hline Context & Charcoal & Coal & Coke & Other \\
\hline 1109: Period 2.1/Formal division of site with establishment of burgh & 0 & 0.5 & 3.5 & 0.5 \\
332: Period 2.2/Accumulation of medieval garden soil and associated features & 0 & 9 & 4 & 1 \\
612: Period 2.2/Accumulation of medieval garden soil and associated features & 0 & 77 & 16 & 40 \\
330: Period 3/Accumulation of post-medieval garden soil and associated features & 0 & 8 & 1.5 & 0.5 \\
563: Period 3/Accumulation of post-medieval garden soil and associated features & 2 & 110 & 27 & 67.5 \\
1513: Period 3/Accumulation of post-medieval garden soil and associated features & 1 & 19 & 4 & 8 \\
540: Period 4.1/Post-medieval features & 0 & 86 & 36 & 30 \\
\hline
\end{tabular}

Table 1.5 Iron-working: the first ten contexts with the largest concentrations of fuel

\begin{tabular}{lllc}
\hline Context & Period & Description & Fuel weight (g) \\
\hline 563 & 3 & Post-medieval garden soil covering most of the site with a depth of 0.25m in thickness. & 2069.5 \\
540 & 4.1 & Stone wall and culvert 0.5m to 0.9m in height, unknown length. & 1520.7 \\
612 & 2.2 & Medieval garden soil. Extensive and fairly homogeneous deposit. & 1334 \\
558 & 4.1 & Cultivation slot fill, cut 566. N-S aligned feature, 6m long and 1m wide. & 1110.9 \\
215 & 3 & Post-medieval garden soil. Extensive layer stretching across much of trench 22. & 847.1 \\
888 & 4.1 & Levelling layer of Hutton House terrace, lay to N of terrace wall 635. & 675.7 \\
187 & 4.2 & Surface of occupation detritus 0.03m. & 539 \\
307 & 4.1 & Garden soil under Haddington House 0.5m thick. & 511.6 \\
667 & 2.2 & Cultivation layer, N of 629. A spread of garden soil in N of area, 7.3m N-S. & 443.6 \\
912 & 2.3 & Fill of linear cut 913. Extends N-S for 3.2m with a width of 0.6m. & 416.9 \\
& & TOTAL & 9469 \\
\hline
\end{tabular}

Table 1.5 summarises the first ten contexts which gave the largest concentrations of fuel, table 1.6 those of slag, table 1.7 the ten largest concentrations of magnetic residues and table 1.8 those of ferruginous materials. Overall the contexts that have produced the largest collection of materials are the following: 563 (Period 3), 612 (Period 2.2), 558 (Period 4.1), 307 (Period 4.1), 222 (Period 4.2), 807 (Period 2.3), 888 (Period 4.1), 187 (Period 4.2), 667 (Period 2.2) and 912 (Period 2.3).

In the examination of this material the following assumptions were made: contexts which contained a combined accumulation of slag, magnetic residues and coal were thought to reflect smelting activities (light-grey shade) (fig. 1.7). Contexts which contained magnetic residues in association with coal were assumed to reflect smithing activities (medium-grey shade). No definite assumptions could be made about contexts containing fuel only (dark-grey shade). In other words, these contexts can reflect either domestic or industrial activities. Roughly equal amounts of smithing/ smelting and domestic waste are recorded for the medieval and post-medieval periods, or about $14 \mathrm{~kg}: 12 \mathrm{~kg}$ respectively.

The distribution of the fuel and metallurgical waste throughout the excavated site points to most of the debris/ activities concentrating to the south of Queensberry House, in the garden soil at the corner between Reid's Close and Holyrood Road. The relative distribution of these contexts suggests that there was a sustained accumulation of smelting/ smithing waste from Periods 2, 3 and 4 (14th-18th centuries) in the same general area. Can these contexts be representing the dumping ground (midden deposits) of metal-working waste over a prolonged period of time (medieval-postmedieval)? Furthermore, there seems to be a typological difference between metallurgical waste from the medieval and post-medieval periods.

\subsubsection{Holyrood fuel and metallurgical waste: slag morphology and slag analysis methodology}

A number of samples were chosen for analysis from the main chronological periods, Period 1 (12th-14th centuries), Period 2 (14th-15th centuries), Period 3 (transition between medieval and post-medieval, 16th-17th centuries), Period 4 (post-medieval, 17th-18th centuries) and Period 5 (19th century). The samples have been prepared as polished blocks for examination with the optical microscope and with the SEM-EDAX (table 1.9).

All samples have been mounted on metallographic resin. They were ground and polished with $6 \mu \mathrm{m}$ and $3 \mu \mathrm{m}$ diamond paste and subsequently carbon-coated. Bloomery slags, whether smelting or smithing, are characterised by a number of distinct mineralogical phases. These include dendrites of wustite $(\mathrm{FeO})$, long or broken-up needles of fayalite (2FeO. $\left.\mathrm{SiO}_{2}\right)$, angular grains of hercynite $\left(\mathrm{FeO} \cdot \mathrm{Al}_{2} \mathrm{O}_{3}\right)$ and a glassy phase, which grows interstitially within the other phases. Smithing slags are dominated by wustite and magnetite as well as fayalite. The mineralogy of modern/industrial period slags is quite different. The slags are glassy rather than crystalline and they contain relatively little iron oxide (less than 10\% 
Table 1.6 Iron-working: the first ten contexts with the largest concentrations of slag

\begin{tabular}{lllc}
\hline Context & Period & Description & Slag weight (g) \\
\hline 222 & 4.2 & Infill/makeup in Haddington's Entry, 0.4m thick; homogeneous infill. & 837.4 \\
612 & 2.2 & Medieval garden soil. Extensive and fairly homogeneous deposit. & 819.1 \\
563 & 3 & Post-medieval garden soil covering most of the site with a depth of 0.25m in thickness. & 700.3 \\
540 & 4.1 & Stone wall and culvert 0.5m to 0.9m in height, unknown length. & 576.9 \\
215 & 3 & Post-medieval garden soil. Extensive layer stretching across much of trench 22. & 430.5 \\
807 & 2.3 & & 411.4 \\
307 & 4.1 & Garden soil under Haddington House, 0.5m thick. & 379.6 \\
652 & 2.2 & Cultivation soil. Garden soil spread 665. Loose sandstone rubble with silting; $10.07 \mathrm{~m}$ long. & 307 \\
298 & 2.2 & Medieval garden soil. An extensive deposit identified over most of the trench. & 222 \\
794 & 2.3 & Fill of waste pit cut 796. Diameter of approximately 2m and a depth of 1.05m. & 186.5 \\
& & TOTAL & 4870 \\
\hline
\end{tabular}

Table 1.7 Iron-working: the first ten contexts with the largest concentrations of magnetic residues

\begin{tabular}{|c|c|c|c|}
\hline Context & Period & Description & $\begin{array}{l}\text { Magnetic residue } \\
\text { weight }(\mathrm{g})\end{array}$ \\
\hline 612 & 2.2 & Medieval garden soil. Extensive and fairly homogeneous deposit. & 229.1 \\
\hline 187 & 4.2 & Surface of occupation detritus, $0.03 \mathrm{~m}$. & 131.3 \\
\hline 215 & 3 & Post-medieval garden soil. Extensive layer stretching across much of trench 22 . & 98.8 \\
\hline 853 & 2.1 & Accumulation in drain 768 . Dimensions $12 \mathrm{~m} \mathrm{~N}-\mathrm{S}, 0.15 \mathrm{~m}$ wide and $0.08 \mathrm{~m}$ deep. & 82 \\
\hline 559 & 4.1 & Cultivation slot fill, cut 567 . Linear feature; $2.7 \mathrm{~m} \mathrm{~N}-\mathrm{S}, 1.15 \mathrm{~m} \mathrm{E}-\mathrm{W}$ and $0.22 \mathrm{~m}$ thick. & 79.3 \\
\hline 734 & 2.1 & Fill of ditch, cut 759 . Dimensions: $30 \mathrm{~m} \mathrm{~N}-\mathrm{S}, 1.3 \mathrm{~m} \mathrm{E}-\mathrm{W}$ and $0.47 \mathrm{~m}$ deep. & 79.3 \\
\hline 312 & 4.1 & Fill of cultivation slot. Depth $0.5 \mathrm{~m}$. Feature damaged during the matching out. & 66.3 \\
\hline 763 & 2.1 & Fill of sumps. Fill $1.05 \mathrm{~m}$ deep. The top $0.2 \mathrm{~m}$ was predominantly a silty clay. & 62.5 \\
\hline 681 & 2.3 & Fill of pit cut $680.1 .8 \mathrm{~m}$ in diameter and $0.2 \mathrm{~m}$ in depth, very mottled deposit. & 60.8 \\
\hline \multirow[t]{2}{*}{269} & 5.1 & Fill of drain $2650.18 \mathrm{~m}$ thick homogeneous fill. & 60.4 \\
\hline & & TOTAL & 949 \\
\hline
\end{tabular}

Table 1.8 Iron-working: the first ten contexts with the largest concentrations of metal residues/ferruginous material

\begin{tabular}{lllc}
\hline Context & Period & Description & $\begin{array}{c}\text { Metal/ferruginous } \\
\text { material weight (g) }\end{array}$ \\
\hline 2 & 3 & Garden soil/midden type deposit. This is a dark deposit containing charcoal. & 239.6 \\
236 & 4.1 & Fill of cultivation slot. 2m wide and 0.4m deep. & 74.3 \\
1000 & - & U/S or overburden. & 56.6 \\
187 & 4.2 & Surface of occupation detritus 0.03m. & 15.4 \\
540 & 4.1 & Stone wall and culvert 0.5m to 0.9m in height, unknown length. & 13.5 \\
1766 & 3 & Dark brown garden soil with midden material fill in rectangular cut 1765. & 7.7 \\
219 & 4.1 & Fill of cultivation slot. & 6 \\
7 & 3 & Fine ash deposit filling pit 006. Contains charcoal, bone and shell. & 4.2 \\
912 & 2.3 & Fill of linear cut 913. Extends N-S for 3.2m with a width of 0.6m. & 3.6 \\
269 & 5.1 & Fill of drain 265 0.18m thick homogeneous fill. & 421 \\
\hline
\end{tabular}


Table 1.9 Iron-working: list of samples

\begin{tabular}{|c|c|c|c|c|c|c|}
\hline $\begin{array}{l}\text { Sample } \\
\text { No. }\end{array}$ & Typology & Context & Plot No. & IADB & Period & Description \\
\hline PST1 & Fragment of heavy dense slag. & 811 & 2.2 & 2510 & 2.3 & $\begin{array}{l}\text { Backfill of twin tank cut } 843 \text {. Sub- } \\
\text { rectangular spread of silt and rubble. }\end{array}$ \\
\hline PST2 & Single fragment of dense heavy slag. & 811 & 2.2 & 2516 & 2.3 & $\begin{array}{l}\text { Backfill of twin tank cut } 843 \text {. Sub- } \\
\text { rectangular spread of silt and rubble. }\end{array}$ \\
\hline PST3 & Large lump of heavy dense slag. & 682 & 3.2 & 2258 & 3 & $\begin{array}{l}\text { Construction backfill over drain } 692 . \\
\text { Fill of drain cut. }\end{array}$ \\
\hline PST5 & Single fragment of heavy dense slag. & 563 & - & 1858 & 3 & Post medieval garden soil. \\
\hline PST6 & Single fragment of heavy dense slag. & 612 & - & 3314 & 2.2 & Medieval garden soil. \\
\hline PST8 & Many fragments of heavy dense slag. & 280 & 4.1 & 2616 & 2.3 & Domestic refuse fill of pit 290. \\
\hline PST9 & $\begin{array}{l}\text { Fragment of coal with 'envelope' of } \\
\text { slag, result of reaction with slag. }\end{array}$ & 819 & 2.2 & 4044 & 2.3 & Fill of pit cut 815 . \\
\hline PST10 & & 809 & 2.2 & 4036 & 2.2 & Fill of ditch cut 810. \\
\hline PST13 & $\begin{array}{l}\text { Slag }+ \text { coal, with lumps of trapped coal } \\
\text { and iron. }\end{array}$ & 215 & 4.1 & 762 & 3 & Post-medieval garden soil. \\
\hline PST14 & Slag/clinker? (Bag identification). & 2 & - & 216 & 3 & $\begin{array}{l}\text { Garden soil/midden type deposit. This } \\
\text { is a dark deposit containing charcoal. }\end{array}$ \\
\hline PST16 & $\begin{array}{l}\text { Slag and coal with lumps of trapped } \\
\text { coal and iron. }\end{array}$ & 1657 & 3.6 & 4683 & 4.1 & $\begin{array}{l}\text { Compact clayey silt located beneath } \\
\text { capping } 1665 \text { in a stone-lined tank } \\
\text { structure. }\end{array}$ \\
\hline PST17 & $\begin{array}{l}\text { Slag and coal adhering onto } \\
\text { conglomerate stone. }\end{array}$ & 280 & 4.1 & 838 & 4.2 & Domestic refuse fill of pit 290. \\
\hline PST21 & Charcoal/coal & 612 & - & 2813 & 2.2 & Medieval garden soil. \\
\hline PST23 & Charcoal/coal & 563 & - & & 3 & Post-medieval garden soil. \\
\hline PST24 & Slag & 790 & N/A & 2437 & 1 & Natural silting in early boundary ditch. \\
\hline PST25 & Slag & 892 & N/A & 2871 & 1 & Fill of sub-circular feature cut 893. \\
\hline PST26 & Slag & 1109 & 2.4 & 4686 & 2.1 & Fill of hearth 1110. \\
\hline PST27 & Slag & 54 & - & 234 & 2.1 & $\begin{array}{l}\text { Upper fill of medieval feature. 'Greasy' } \\
\text { type fill with small stones. }\end{array}$ \\
\hline PST28 & Slag & 612 & - & 2157 & 2.2 & Medieval garden soil. \\
\hline PST29 & Slag & 814 & 2.2 & 2281 & 2.3 & Fill of pit 815 . Midden backfill. \\
\hline PST30 & Slag & 206 & 2.4 & 57 & 2.3 & Hearth fill \\
\hline PST31 & Slag & 1552 & 3.4 & 3943 & 3 & $\begin{array}{l}\text { Primary fill of pit } 1553 \text {. Midden-like } \\
\text { fill. }\end{array}$ \\
\hline PST34 & Slag & 187 & 4.2 & 3973 & 4.2 & Surface of occupation debris \\
\hline PST35a & Slag & 222 & - & 392 & 4.2 & Infill/makeup in Haddington's Entry. \\
\hline PST35b & Slag & 222 & - & 392 & 4.2 & Infill/makeup in Haddington's Entry. \\
\hline PST38 & Slag & 807 & $\begin{array}{l}\text { Possible } \\
\text { vennel, } \\
\text { Period } 2\end{array}$ & 2427 & 2.3 & Fill of cut 808. \\
\hline PST39 & Slag & 807 & $\begin{array}{l}\text { Possible } \\
\text { vennel, } \\
\text { Period } 2\end{array}$ & 2403 & 2.3 & Fill of cut 808 . \\
\hline PST40 & Slag & 215 & - & 1056 & 3 & Post-medieval garden soil. \\
\hline PST42 & Slag & 222 & - & 392 & 4.2 & Infill/makeup in Haddington's Entry. \\
\hline PST43 & Slag & 752 & 2.2 & 2209 & 2.2 & Primary pit (753) fill. \\
\hline
\end{tabular}



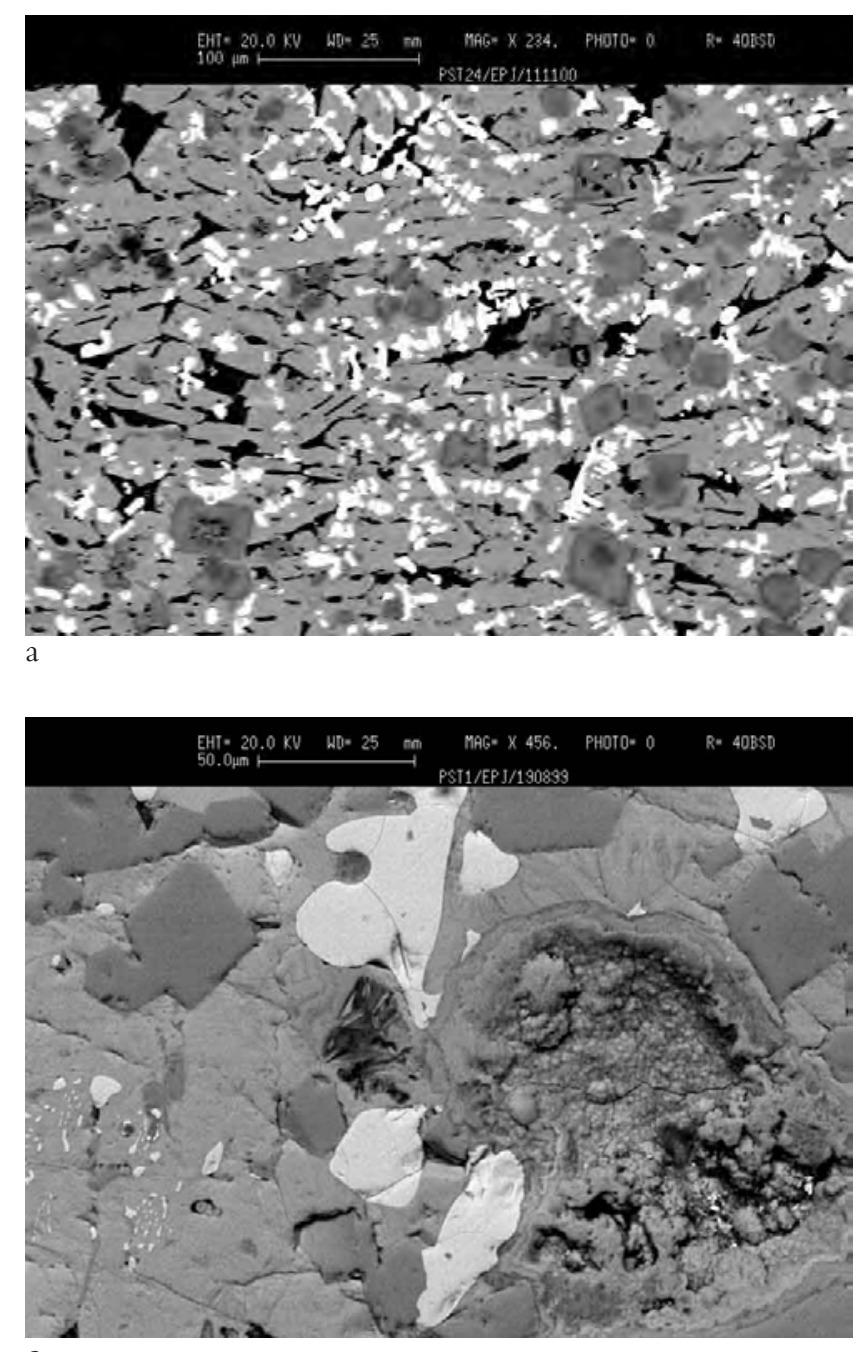
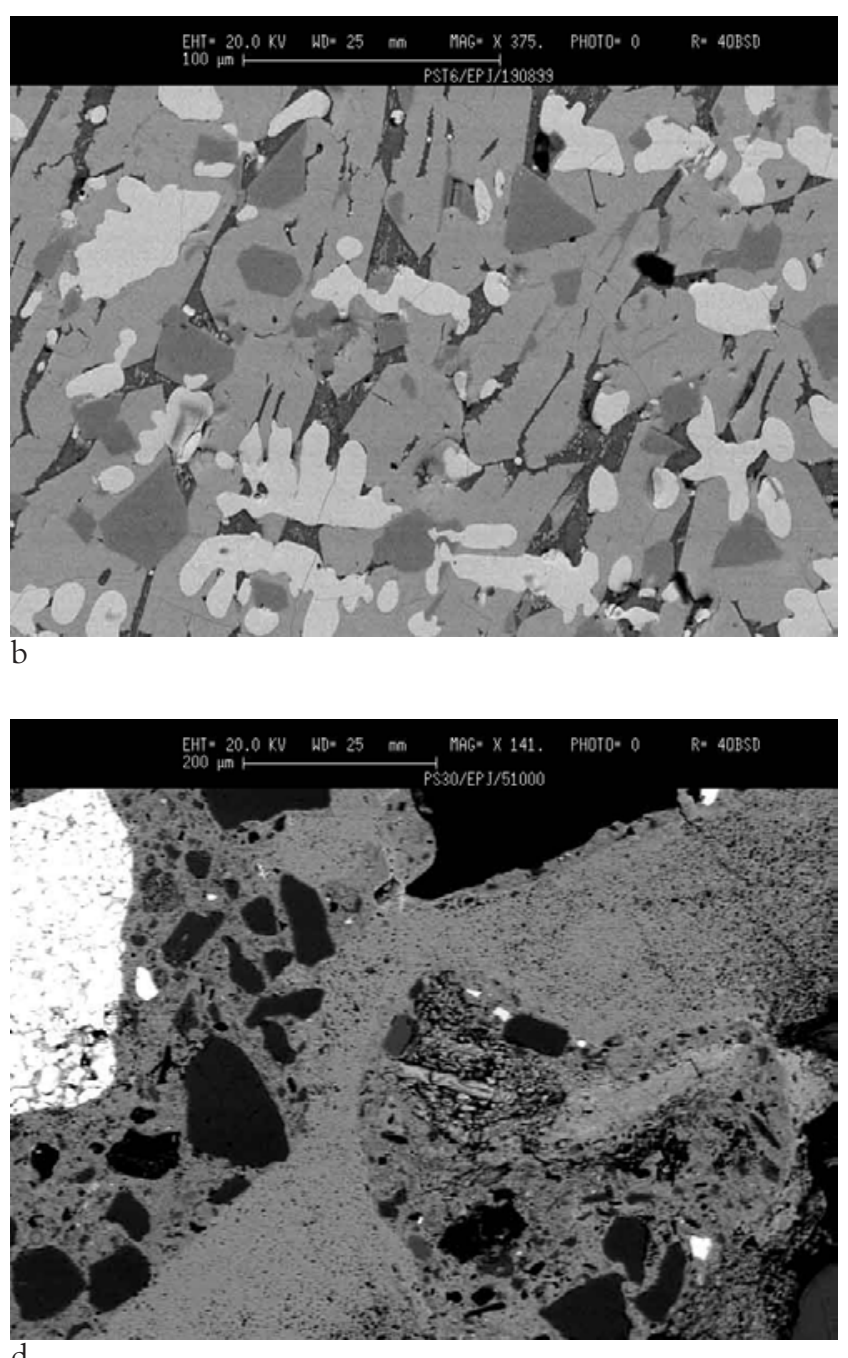

Fig 1.7 Iron-working: a, SEM-BS image of PST24 showing dendrites of wustite, well defined needles of fayalite, angular grains of hercynite in an intestitial glassy phase (bar $=100 \mu m ; \times 234) ; b$, SEM-BS image of PST6 revealing an alumino-silicate slag consisting of the four mineralogically distinct phases shown, finger-like fayalite (medium grey), globular wustite (light grey) and angular hercynite (dark grey) and an interstitial glassy matrix which consists of two phases (bar $=100 \mu \mathrm{m} ; \times 375)$; c, SEM-BS image of PST1 with the four characteristic phases of shiny wustite, angular hercynite, fayalite and the interstitial glass. In addition; also a fragment of partially reduced ore (bar $=50 \mu m ; \times 456)$; $d$, SEM-BS image of sample PST30 highlighting the co-existence of fragments or charcoal (centre of the picture) and coal, corroborating the observation made in the discussion that charcoal must have been used as fuel in the medieval bloomery but coal found itself in the furnace accidentally as part of the clayband iron stone (bar $=200 \mu m ; \times 141)$

$\mathrm{FeO}$ as opposed $60-70 \% \mathrm{FeO}$ in the bloomery). Within the glassy matrix, usually round metallic iron prills are trapped, indicating that the iron had melted.

The metallurgical waste can be divided into two morphologically distinct groups which correspond roughly to the two major chronological subdivisions, the medieval and the post-medieval slags. The former are bloomery slags, spongylooking, black and dense with charcoal imprints or fragments of charcoal trapped within. The post-medieval and later material consists primarily of porous and dense slag with large inclusions of coal, and patches of yellow mineralisation originating either from sulphur-rich precipitations or non-crystalline iron oxides, or a combination of both. There are examples of the first group (bloomery) within contexts dating to the post-medieval period but not the other way around. Some samples show 'dripping', as if they have locally melted. The embedded chunks of coal are large $(1-2 \mathrm{~cm}$ or more), suggesting partial heating.
Period 1 (12th-14th century) produced little metallurgical waste. Two samples were analysed with the SEM-EDAX (PST24 and PST25) (see table 1.10a). The samples originated from the fill of the ditch 754 and from the fill of cut 893 respectively. The samples point to a fayalitic type of slag with wustite and considerable amounts of aluminium so as to form a distinct mineralogical phase, hercynite (see fig. 1.7a) Alkali and alkaline earths derived from fuel ash while sulphur and titanium derived from the coal and the ore respectively Sulphur occurs as small metallic iron sulphide inclusions of less than $1-2 \mu \mathrm{m}$ in diameter. PST24 is most certainly a fragment of smelting slag on account of the hercynite pointing to a clayrich ore like a clayband ironstone. It was mentioned earlier that clayband ores have a considerable amount of clayey material or shale. Analysis of PST25 also dating to this period points to a wustitic slag, but with no hercynite. It is possible that it has derived from a smithing hearth. The argillaceous iron ores would have been the only ones locally available. If iron-making 

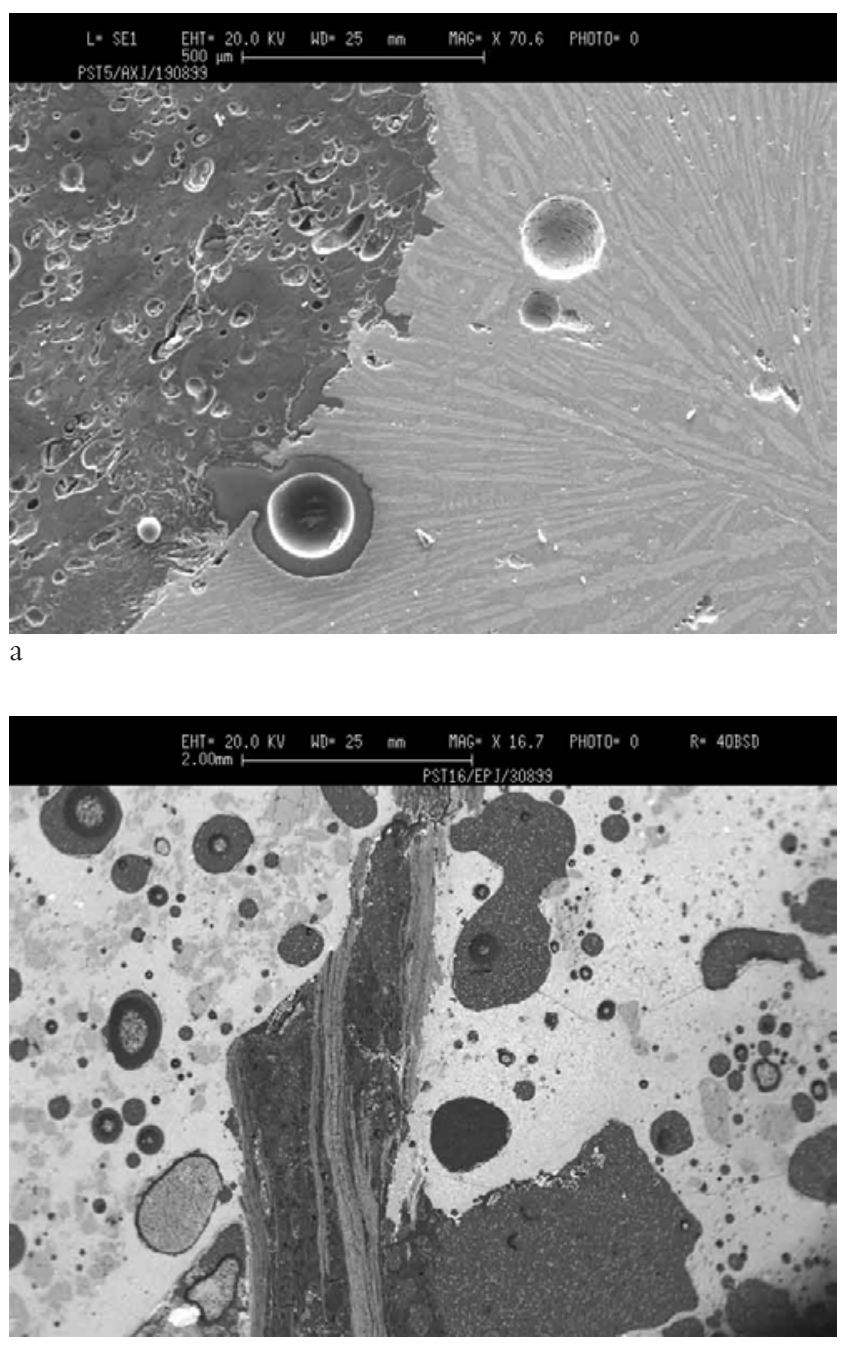

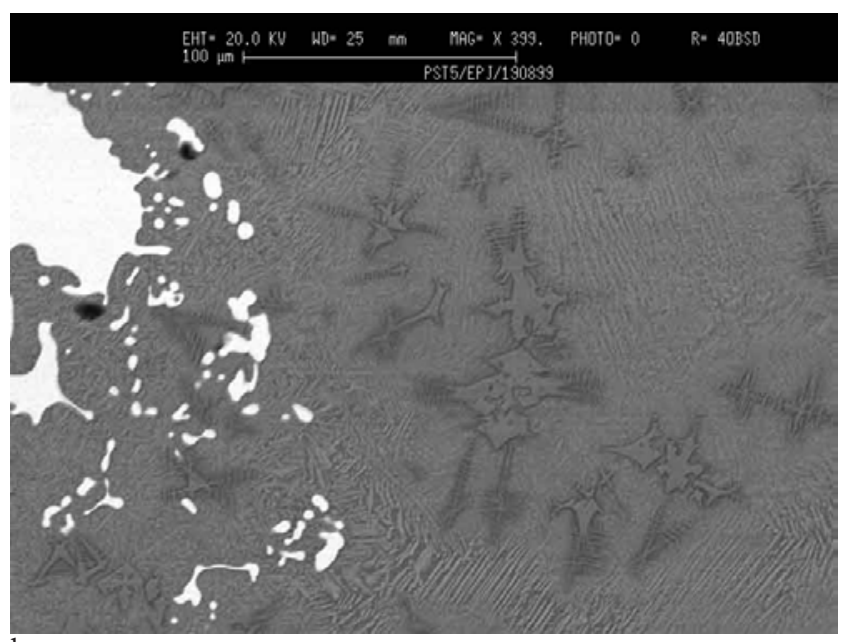

$\mathrm{b}$

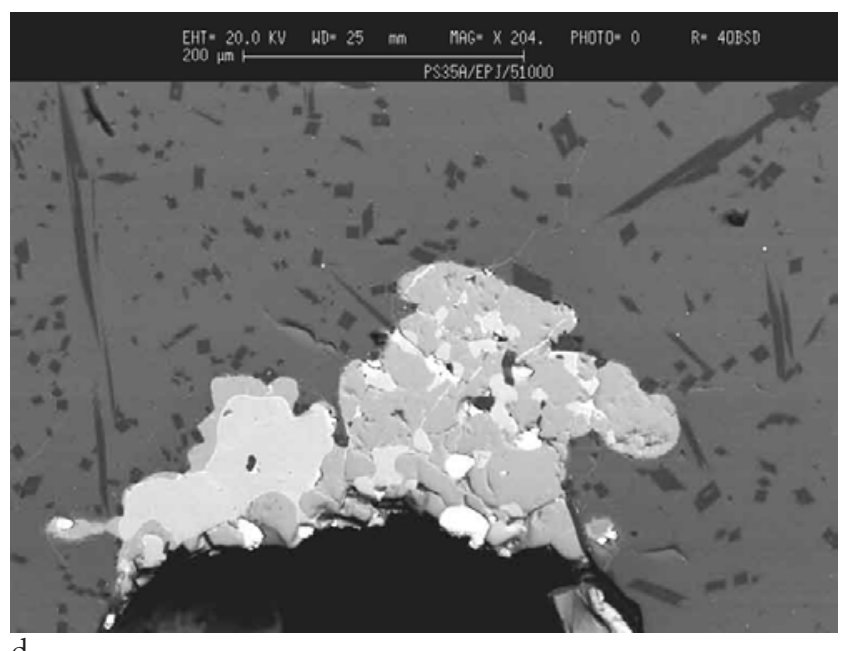

Fig. 1.8 Iron-working: a, SEM-BS image of PST5. The sample contains needles of fayalite growing at right angles to a fragment of coal (bar $=500 \mu m ; \times 70) ; b$, SEM-BS image of PST5. Vanadium and chromium-rich phases, snowflake-like phases are seen in elsewhere within the same sample. A considerable degree of unhomogeneity characterises this sample most likely originating from the smelting of blackband ironstone (bar=100 $\mu m ; \times=399) ; c$, SEM-BS image of PST16 consisting of coal trapped within an iron-rich alumino-silicate matrix; unreacted quartz grains. Needles of fayalite with very small iron sulphide inclusions (bar $=2 \mathrm{~mm} ; \times 17) ; d$, SEM-BS image of PST35A consisting of an aluminosilicate matrix with metallic inclusions of iron, vanadium and chromium (bar $=200 \mu m ; \times 204)$

was carried out locally at the time - as it clearly was - then this would be the type of deposit exploited.

In Period 2 (14th-16th century), the bulk chemical composition of a number of samples deriving from medieval garden soil and medieval features confirmed the observation that the same type of clayband ores appears to have been used locally. SEM-EDAX examination and analysis of slags from the medieval period (Periods 2.1, 2.2, 2.3 and perhaps some of Period 3) samples PST1, PST6 and PST30 (see fig. 1.7b for PST6, fig. 1.7c for PST1 and fig. 1.7d for PST30) also revealed a fayalitic-type slag. Just as in PST24, samples PST1 and PST26 consist of finger-like fayalite (medium grey), globular wustite (light grey), angular hercynite (dark grey) and an interstitial glassy matrix. The high sulphur content - in terms of bloomery slags - testifies to the accidental presence of coal in the charge. Figure $1.7 \mathrm{c}$ shows the partially reduced fragment of clayband ore.

SEM-EDAX examination of PST30 (fig. 1.7d, table 1.10b) highlights the co-existence of fragments of charcoal (the beehive structure in the centre of the image) and coal, corroborating the observation made earlier in this discussion. It is possible that, given the absence of grains of hercynite, this sample could have originated either in the smelting furnace or a smithing hearth.

Although of the bloomery type, the Holyrood samples differ from their post-medieval Scottish Highland counterparts in both types of ore (on account of the high aluminium content) and furnace operating conditions (Hall \& PhotosJones 1998; Photos-Jones et al 1998). The relatively high aluminium content must have made the Holyrood slags rather viscous. Highland ores/slags are rich in manganese and phosphorus. Manganese substitutes iron in the slag and manganese-rich slags melt at relatively low temperatures. Normally higher temperatures would have been required to make the Holyrood slags free-running, but the presence of coal in the ore may have provided that extra energy.

For Period 2 there is evidence for both metal-making and metal-working activity. Although PST30 might be a fragment 


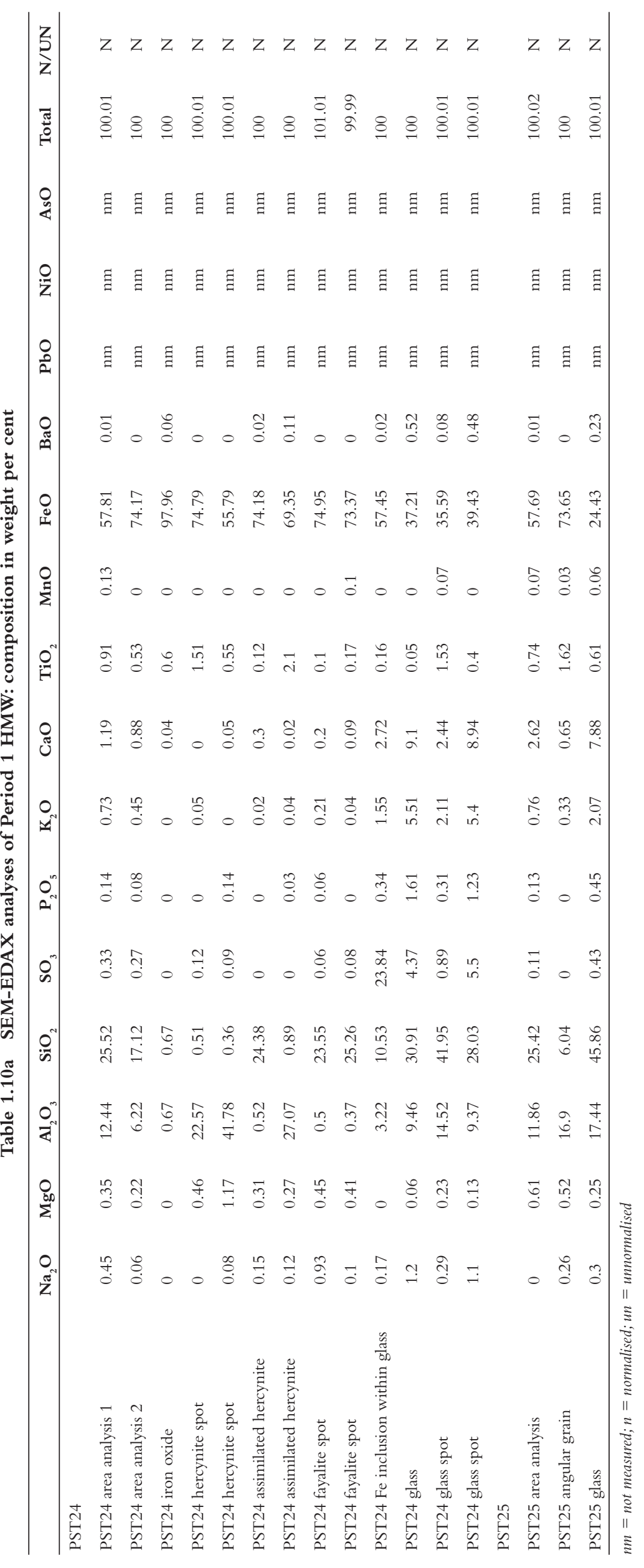




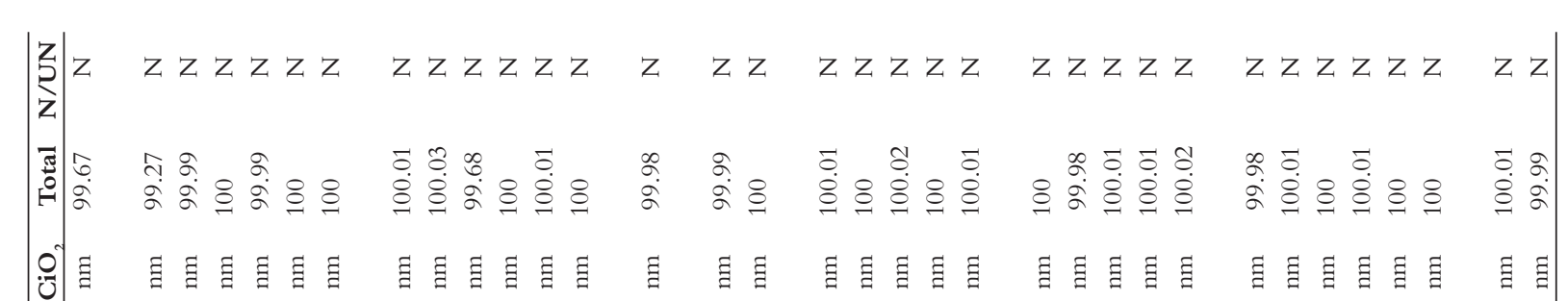
○

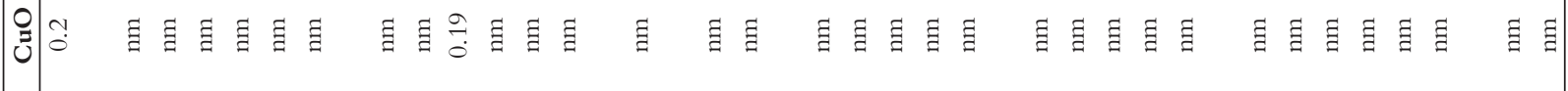

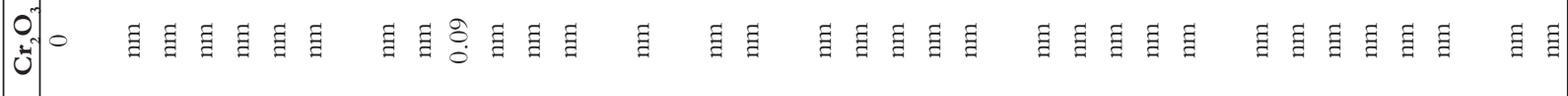

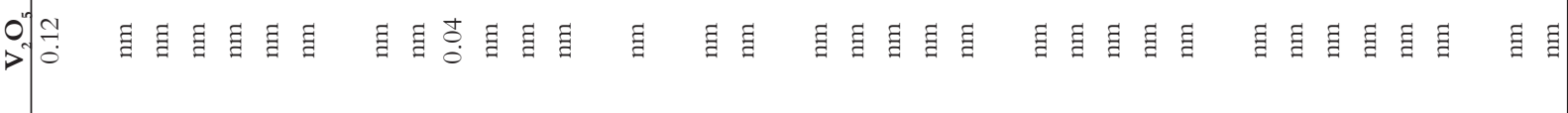

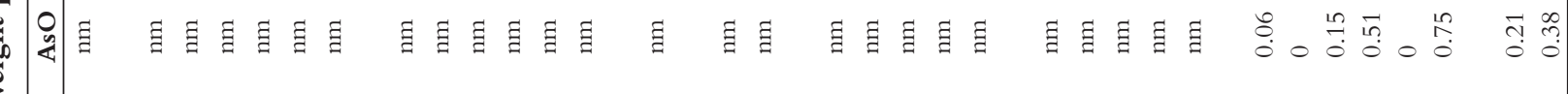

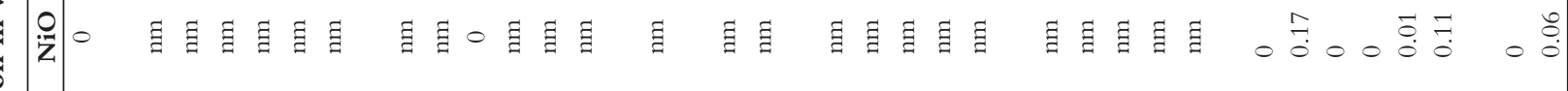

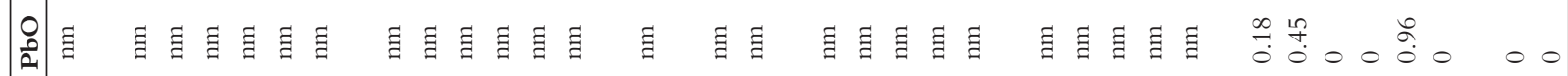

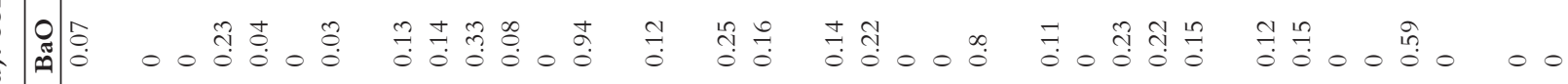

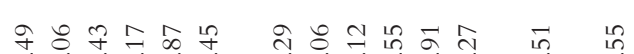

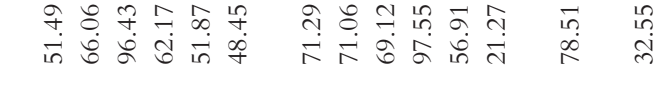

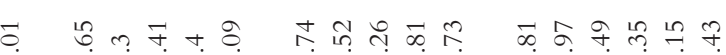

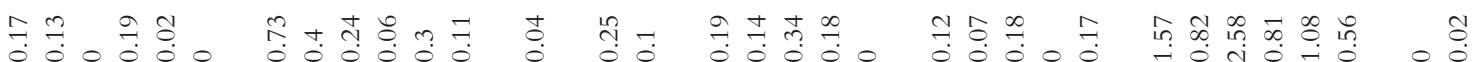

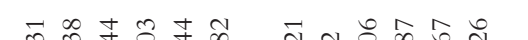

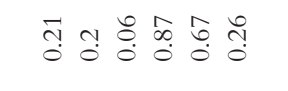

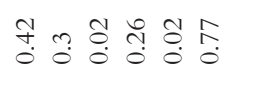

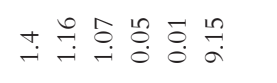

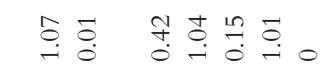
के के ․ㅛ용

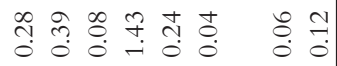

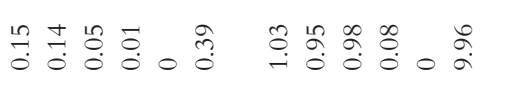
年告

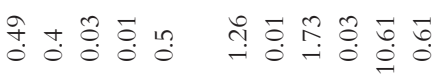
- $\stackrel{9}{\rightarrow}$ 낭 तु

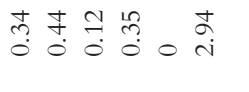

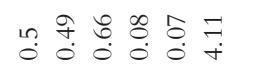
ते 


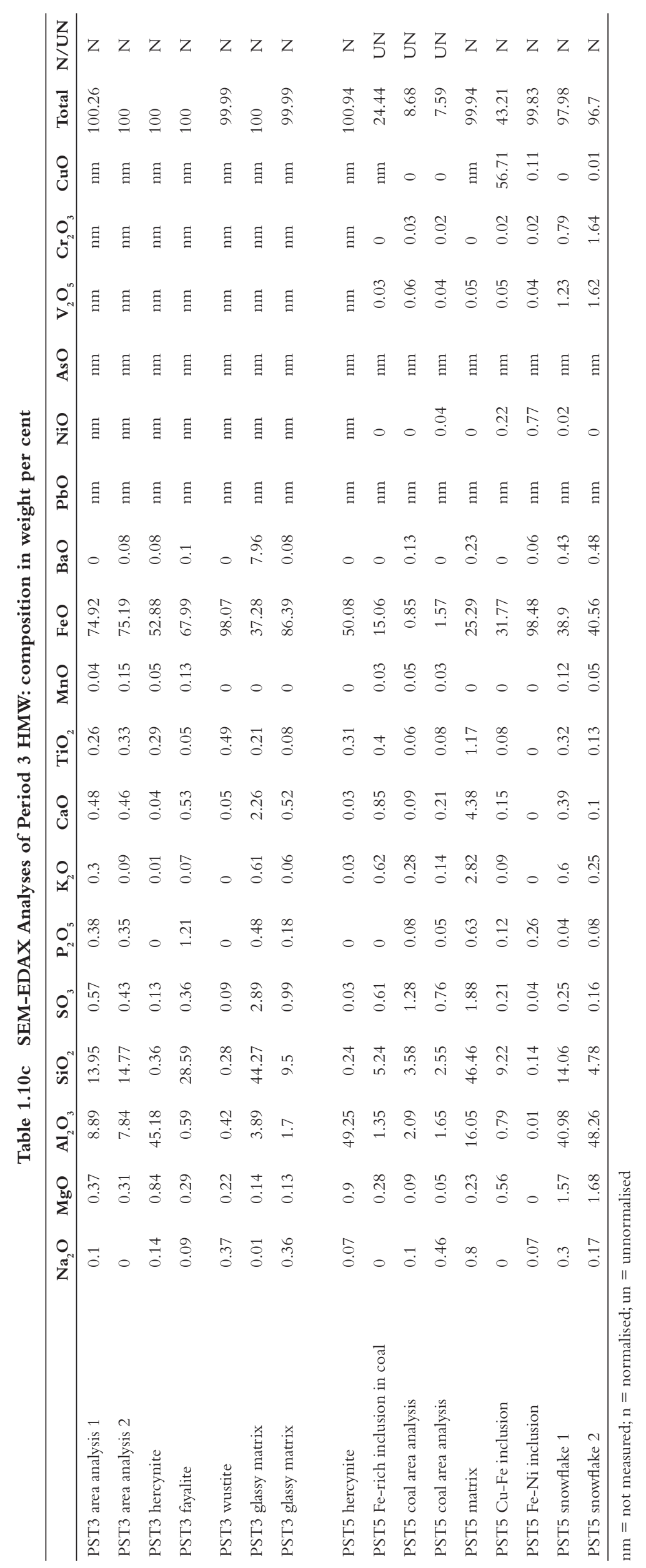




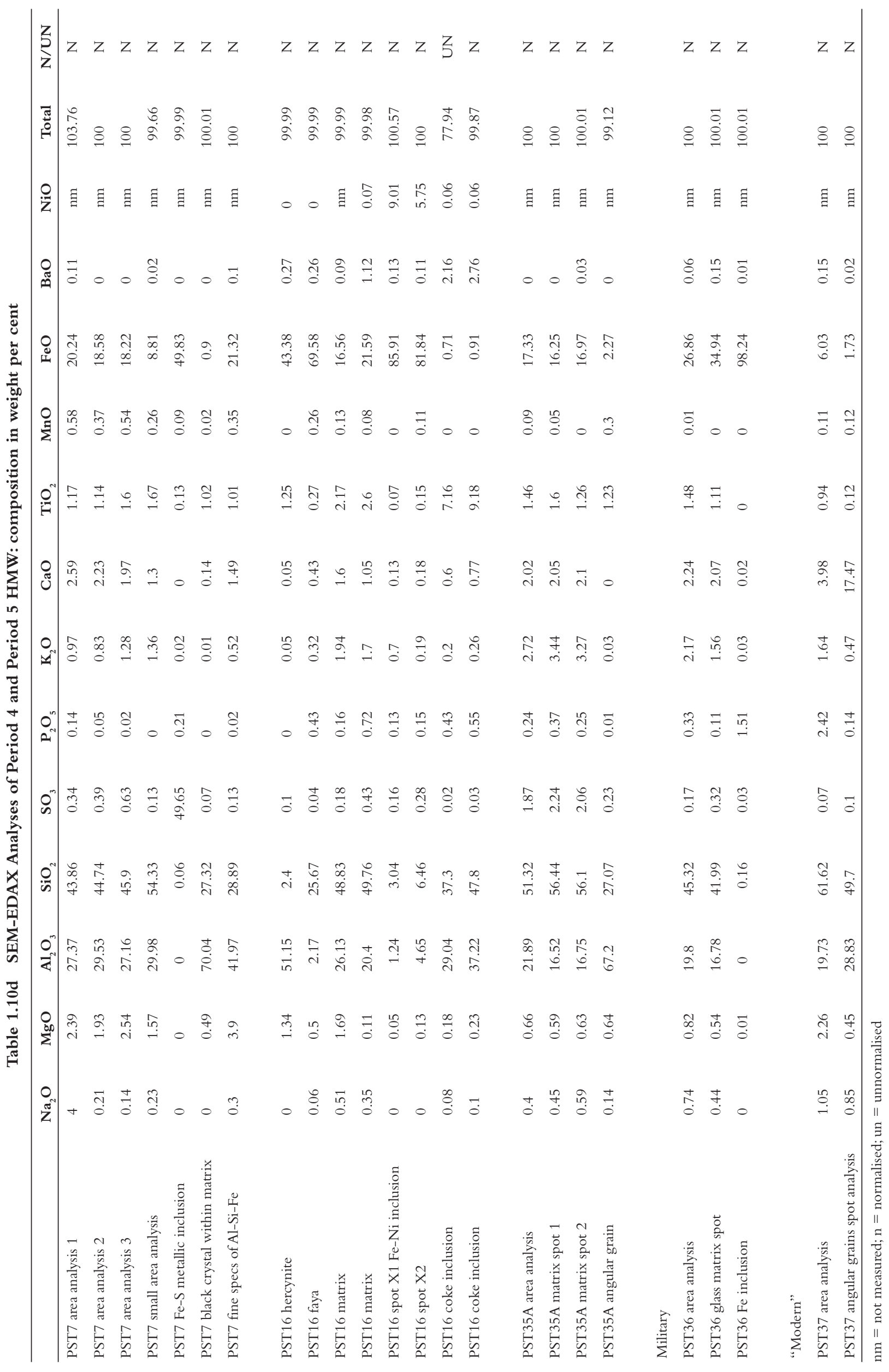


of smithing slag, PST26 (from Plot 2.4) as well as PST6 and others are undoubtedly fragments of smelting slag. These activities concentrate on two plots, the back of Plot 2.2 and the front of Plot 2.4. Plot 2.4 contained, 'the only preserved area of Canongate frontage exposed during the excavation'. However, preservation was poor because of later building activity. 'Several other features including hearths (206, 1110 \& 1115) were also recorded' (Part 3).Artefactual evidence like a horseshoe and features like hearths suggest that a combined workshop may have been in operation in Plot 2.4. There is no reason, other than our own preconceived ideas, why the two activities would not take place under the same roof and on a street frontage.

From Period 3 (16th-17th centuries) two samples (PST3, PST5) originating from the fill of drain 392 (Plot 3.2) and post-medieval garden soil appear to derive from a different type of metallurgical practice, distinguished by the lack of microcrystallinity in the slags. The SEM-EDAX image of sample PST5 (fig. 1.7a) contains needles of fayalite growing at rightangles to a fragment of coal as well as metallic inclusions of different composition ( $\mathrm{Fe}-\mathrm{Cu}$ and $\mathrm{Fe}-\mathrm{Ni}$ ) trapped within the matrix (fig. 1.7b) reflecting the type of ore used.Vanadium and chromium-rich phases form 'snowflake'-type micro-phases within the same sample. PST5 suggests the use of blackband ironstones which contain, apart from low levels of alumina and silica, vanadium, nickel and chromium (table 1.10c).

The presence of the last three elements has been observed in slags from the large-scale 19th-century ironworks at Calderbank, North Lanarkshire, where local ores were charged in the blast furnaces (Photos-Jones 1999c) for the production of pig iron.

From Period 4 (17th-18th century) sample PST16 (fig. $1.8 \mathrm{c}$; tables 1.9 and $1.10 \mathrm{~d}$ ) contains fragments of coal (centre of the image) set in a glassy matrix (light grey) with subangular, unreacted quartz grains scattered around the matrix, the whole sample being very vesicular. Very small metallic iron prills are also evident. PST35A, a highly siliceous slag, is potentially the waste product from the use of blackband ironstone, since it shows an aluminosilicate with metallic inclusions or iron, vanadium and chromium (see fig. $1.8 \mathrm{~d}$ and table 1.10d).

What are the processes that generated these slags, which consist roughly of $15-20 \% \mathrm{Al}_{2} \mathrm{O}_{3}, 45-50 \% \mathrm{SiO}_{2}$ and $15-20 \%$ $\mathrm{FeO}$ (table 1.10d)? In Perth, Photos-Jones and Atkinson (1998) suggested that similar types of materials may have derived from the high bloomery or a smelting process somewhere in between the bloomery and the blast furnace, given the iron alumino-silicate nature of the glassy slag. It should be emphasised that these materials are definitely slags and cannot be confused with high-fired ceramics, which contain only a small amount of iron (c 5\% FeO).

At present there is no evidence for urban bloomeries, in the sense of actual workshops. Furthermore, it is not possible to gauge the extent of the use of blackband ironstones in that period. The influence of the abbey must have waned and some private initiatives must have been set in place. In any case, this is the time when major initiatives are beginning to be established, such as the Carron Ironworks (1756) where clayband ores were being co-smelted with coke. Overall, the evidence for local production is not conclusive but is strongly suggested.

There was only a single find from Period 5 (18th-20th centuries), which bears many similarities with those derived from the post-medieval. Sample PST37 (see table 1.10d) is a fragment of argillaceous material which has been heated to high temperature. It contains unreacted fragments of coal (long needle-like fragments), also unreacted angular quartz inclusions, cracked and partly heated lumps of 'clay' within a glassy matrix, with unreacted clay on the left-hand side of the picture.

\subsubsection{Discussion}

There is no evidence for metal-working in the pre-burghal period, in other words, prior to the establishment of Holyrood Abbey by David I in 1128. With regard to the medieval period (Periods 1 and 2; 12th-16th centuries), could the metallurgical evidence assist in establishing a relationship between the abbey and the burgh? In reference to the post-medieval period, 1580-1707, what can the contents of the garden soils tell us about the urban precinct that developed around the Palace of Holyrood House? Finally regarding the early modern period, 1707-1825, could the metallurgical waste shed a little light on the activities at the Canongate?

In the medieval periods most of the metallurgical waste is associated with garden soils (Context 612), but medieval features as well.Very few can be strictly interpreted as metallurgical in nature. Activities were concentrated in the back of Plot 2.2 and the street frontage in Plot 2.4. In Plot 2.4, the associated presence of hearths with metallurgical waste may point to a combined workshop. PST26 is clearly a smelting slag and PST30 a smithing one, therefore there is no reason why the two activities, smelting and smithing, could not have taken place one next to the other under the same roof.

To what extent were the activities in these two plots carried out under the auspices of the abbey? We can only surmise. The abbey precincts are located only $50-100 \mathrm{~m}$ to the east and the raw materials (both ore and fuel) could have been procured by the abbey. It is possible that the abbey had interests in the manufacture of the raw metal, selling it in the market together with other goods. Given that the medieval or later documentary sources do not appear to encompass (at least in an obvious way) makers of iron, it is not possible to place this group of people, visible in the archaeological record only by the waste they produced, in their proper context. Given the 'silence' of burghal documents, their activities are more likely to be associated with Holyrood Abbey, since it is only as 'servants to the abbey', or as part of the large infrastructure of an ecclesiastical establishment, that their invisibility can be explained.

In the post-medieval period (Period 3), analysis suggests that another type of ore is used where coal is an integral part of the ore and the fuel. These are the blackband ironstones which are characterised by fingerprinting elements such as vanadium, chromium and nickel. These elements have previously been encountered in the industrial waste from the 19th-century blast furnace installations at Calderbank, North Lanarkshire. The early smelting of these ores would perhaps require more elaborate facilities and perhaps also the use of water power for the driving of the bellows. There is no evidence of these activities within the excavated area of the Parliament site. It should be borne in mind that by the early 1600s Scotland had seen the introduction of charcoal-operated blast furnace in the Highlands, at Letterewe in Wester Ross (Donnelly et al 1999) and, in the 1750s, of a coke-operated blast furnace in the Lowlands, at Carron Ironworks in Falkirk (Watters 1998). This 
is a period of technological transition and major innovation in iron-making, initiated by private enterprise, and the social and economic implications of the iron-making industry within the Canongate, if indeed there was any in situ, must be examined within this larger framework.

The Canongate was, and remains, a place separate and very different from Edinburgh. In the medieval period it acquired and maintained a status first as a marketplace for the financial survival of the abbey and secondly as a place for the royal court. The building of town houses with large gardens for the wealthy in the 17th and 18th centuries, their soils enriched metaphorically and literally by the ferruginous metallurgical waste of the local workshops of that and earlier periods, bears testimony to a close link between the abbey and its burgh. An unexpected bonus of this work turned out to be the evidence for the use of clayband and blackband iron ores - both closely associated with Scotland's industrialisation - considerably earlier than has previously been thought. The continuous exposure in the usage of local raw materials and energy resources can only reflect the long continuity of settlement at the Canongate from the early medieval period to modern times.

\subsection{GLASS}

\section{ROBIN MURDOCH}

Glass, until the beginning of the 18th century, was expensive and little used compared with pottery, and only sites of the very highest status are liable to yield glass dating to before around 1500. The range of types of glass from Holyrood is fairly typical for an urban site and consists of window glass, wine bottles, drinking vessels, medicine bottles and a few miscellaneous items (figs 1.9-1.12). Most of the shards are small and occur singly.Very few items are represented by more than one shard. This is not unusual and may be related to the fact that much broken glass was reused in historic times. In fact, this practice may be giving a falsely low impression of just how much glass was in general use.

In the analysis of a glass assemblage, especially when fragments are very small or do not retain manufacturing detail, condition can be helpful in giving a very rough assessment of date. Glass can, and does, decay, but the rate at which this happens is related to the chemistry of the glass itself, and that of its buried environment (Frank 1982).

Very briefly, when glass is made, a fluxing alkali is added to lower the temperature at which the batch will vitrify and can be worked. Historically, in simple terms, this alkali was either soda or potash, although each could (and generally did) contain a percentage of the other. Soda was derived from natural mineral sources or marine plants, potash from inland plants such as trees or ferns. For reasons which are still unclear, potash-fluxed glass is generally less durable than soda glass and the denaturing products have a different appearance. However, care must be taken when interpreting condition, since batch constituents other than the fluxing alkali can have a significant effect on durability.

The condition of the shards from Holyrood is typical of what is retrieved from Scottish sites where lime-mortared buildings have been present. An alkaline environment is generally more detrimental to glass than acidic. However, care must be taken not to assume consistent decay rates across the whole site.
Moisture plays a large part in the decaying process and a shard that has lain in the basement of a building will generally survive much better than one in damper garden ground outside.

\section{WINE BOTTLES}

Note: The term 'wine bottle' is generally used to describe a particular type of container as defined below. However, it is known that beer and ale bottles were made in forms virtually indistinguishable from these and the term is therefore used to describe all.

This category is considered first because it has good diagnostic dating characteristics and occurs almost universally on sites, especially post $c 1700$. Initially made on the Continent, production started in England in the 1630s. These strongly made bottles gained in popularity and by the middle of the 18th century easily outnumbered all other forms of glass vessel put together. Initially expensive, these bottles often had seals attached to them giving details of ownership, contents etc and frequently carried dates. The dated items have allowed accurate typologies to be generated which follow the shape evolution of these bottles through to the advent of semi-automatic mouldblowing technology in the early 19th century (see eg Hume 1961). Although Hume's typology is derived from material recovered from American colonial sites, virtually everything found there dating to before the middle of the 18th century will have been imported from Britain. The relative purity of the contexts allowed accurate validation of the dating. The small numbers available and their expense led to limited usage in the 17th century. J P Allan comments that the valuation of glass bottles was four times greater than that of earthenware in the Exeter port books of the late 16th and early 17th centuries (Allan 1984, 263). Even in the mid and later 17th century glass bottles were relatively scarce and the presence of several from Holyrood dating to before 1680, and possibly as early as the $1660 \mathrm{~s}$, is interesting and an indication of a site of some status. A glasshouse for the manufacture of bottles was set up in the Cromwellian citadel of Leith in 1663 by English settlers (Kingdom's Intelligencer 1663) and there is no reason why the Holyrood examples could not have been made there. Other 17th-century glass production sites in Scotland existed at Wemyss in Fife and Morrison's Haven and West Pans, East Lothian. What is surprising in the Holyrood assemblage however, is the relative lack of diagnostic pieces from 18thcentury wine bottles. This situation is reflected even more clearly in the vessel glass and also the window, although in the latter case, dating is far less precise. Given the enormous usage of wine bottles in the middle of the 18th century, their low numbers here are an indication of change of site usage from the 17 th century. A study of the dates for the clay tobacco pipes also reveals a dearth of 18th-century material.

The five fragments of wine bottle illustrated (fig. 1.9) demonstrate some of the evolutionary characteristics of these containers. The neck and lip (no. 70) are of heavy construction and well made, with a rounded-section string ring mounted some way below the lip, a feature only found on wine bottles pre $c 1680$. No. 71, another neck and lip, is slightly less substantial; the string ring is thinner in section and is mounted closer to the lip. This bottle is slightly later than no. 70 but nevertheless is unlikely to be later than 1680 . The base (no. 72) has the typical low kick and small pontil scar which would be found on bottles represented by necks 


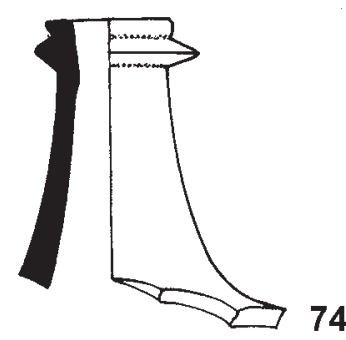

74

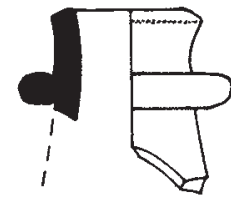

70

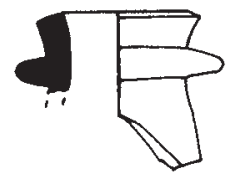

73

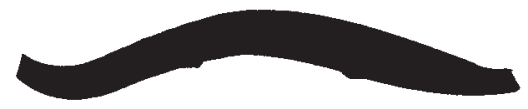

76

Fig. 1.9 Glass (scale 1:2)

1 and 2 . These bottles had a relatively narrow diameter base ring and the sidewalls extended outwards to reach maximum diameter at shoulder level. The neck and lip (no. 73) are of much lighter (weight) construction and have a neatly tooled triangular-section string ring $2-3 \mathrm{~mm}$ below the lip. The neck is short at $56 \mathrm{~mm}$ and has a curving outward splay towards the body. All these criteria are characteristic of bottles $c 1700$. Finally, neck and lip (no. 74), in contrast to the others, is poorly finished, with the string ring obviously reworked for half its circumference. The lip has either been enhanced by the addition of more glass or tooled into a broad, downwardsloping profile not seen before $c 1760$.

\section{BOTTLES OTHER THAN WINE}

Several bottles other than wine were recovered and six of those, with reasonable antiquity, are illustrated (fig. 1.10). Nos 84, 85 and 86 are of definite pharmaceutical use and nos 82 and 83 are of probable pharmaceutical use. The bases of nos 84 and 85 are typical small pharmaceutical bottles/phials which would have had everted lips as does no. 86 (Thompson et al 1984, 86; Gooder 1984, 221). No. 84, with its darker colour, is probably late 17 th century and no. 85 , early 18 th. By the middle of the 18th century many of these items were being made in clear glass and have narrower diameters with less chunky necks and lips. The neck (no. 82), with its flared lip, is a profile with a long-term usage but, the style tends to fade out about the middle of the 17th century (Crossley 1987,358 Figs 6.21 \& 22; Vose 1994, 25, Fig. 8.4 and Crossley \& Aberg 1972, 132, Fig. 60.3). A similar situation exists with the hexagonal base (no. 83). Polygonal shapes were popular until the middle of the 17 th century and, while not disappearing completely, were made

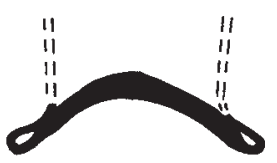

77

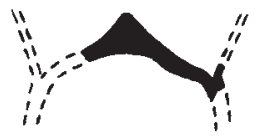

82

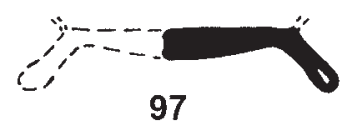

97

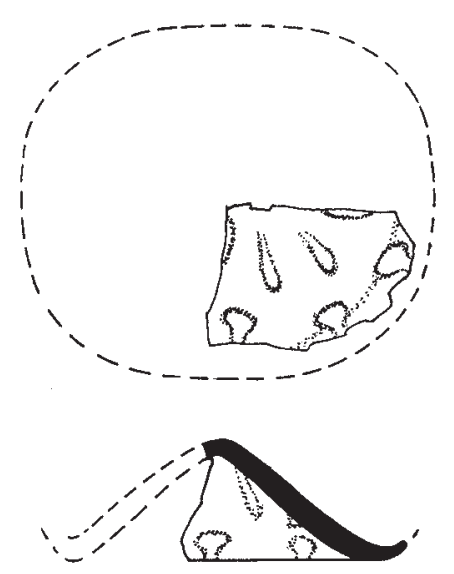

78
Fig. 1.10 Glass (scale 1:2)

in greatly reduced numbers. No. 87 has been a fine quality bottle, oval in plan and blown in a decorative mould. Although nothing remains of the outer wall, it is extremely likely that it would also have been decorated with relief moulding similar to what is visible in the kick. No direct parallels were found but the Venetians frequently made bottles and flasks where the moulding was carried into the kick in such a manner. The light weathering on the shard might also favourVenetian manufacture, possibly a perfume or scented water bottle, or for some high-status culinary item.

\section{VesSel gLASS}

The situation with the vessel glass is similar to that of the wine bottles, with 18th-century types very poorly represented. Fragments were generally very small and many did not retain enough form to allow identification of probable vessel shape. However, several fragments of pushed-in base were present. This feature is found on the majority of fine drinking-glass tableware up to the middle of the 17 th century. One reason for this was to increase the mechanical strength of the edge of the most vulnerable part of generally thin-blown vessels. The expense of glass and an attempt to improve clarity and to decolour were the main reasons for the thin blowing in the first place.

The pushed-in base took two basic forms. The first was where the push-in was considerable and formed a pedestal base of double thickness where the base rim itself was left hollow, and the second form was where the base was pushed in only slightly but the hollow base rim was retained. Both forms are present in the Holyrood glass. The pushed-in base is known as far back as the fourth century $\mathrm{AD}$ and was particularly common in English forest glasshouse production from the 14th to 16th centuries (Wood 1982, 30). The style continued into the period of rapid expansion of the glass industry, par- 


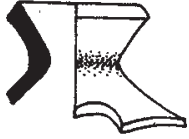

79

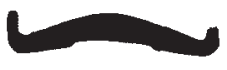

81

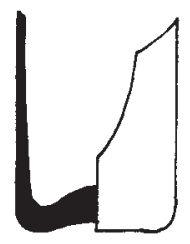

80

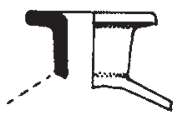

77

Fig. 1.11 Glass (scale 1:2)

ticularly in England, in the second half of the 16th and first half of the 17th centuries. Examples of pushed-in bases have been recovered from many glasshouse sites of late 16th- to early 17 th-century date. They include Hutton and Rosedale in Yorkshire (Crossley \& Aberg 1972), Haughton Green, Manchester (Vose 1994), Knightons, Surrey (Wood 1982) and Kimmeridge, Dorset (Crossley 1987). In the latter half of the 17 th century, with the preference for thinner stem forms, the doubling over became restricted to the rim itself and is known as the folded foot. This technique in turn phased out of common use about 1760. The Holyrood assemblage only contained one example of the later type of folded foot, but six of the earlier pushed-in base. Vessel glass was made in two different basic codes, green or crystal (clear). The presence of iron in the batch, either in the raw materials or leached from the clay of the manufacturing pots, gave almost all glass a tinge, most commonly green, unless specific attempts were made to clarify it. Generally speaking the green glass vessels were at the lower end of market quality. Green glass was a forest glasshouse tradition, where little or no attempt was made to remove colouration from the glass, in fact some preferred this colour and added more iron to enhance it.

For many centuries glassmakers also strove to make clear, colourless glass and from time to time managed it, sometimes more by luck than judgement. Around 1450 the Venetians developed 'cristallo', simply Italian for clear, a term which became corrupted to crystal and is used to the present day. Although probably clearer and less tinted than what went before, this early Venetian glass still generally had a slight tinge, usually ginger-brown or grey. By the first half of the 16th century a thriving industry had been set up in the Low Countries by emigrants from the Italian glass-making centres of Venice and Altare, near

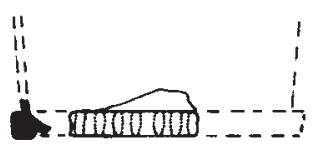

98
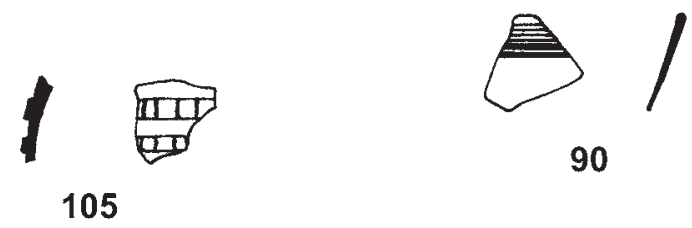

90

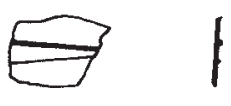

99

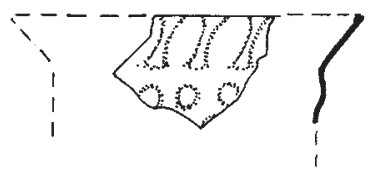

87
Fig. 1.12 Glass (scale 1:2)

Genoa. The output of these new works was imitative of the original sources and earned the title of Façon de Venise; apparently even the experts could not discriminate between the genuine article and the copy (Godfrey 1975, 8). As already mentioned, it was not until about 1720 that a consistent method of decolourising glass was perfected. Only one drinking vessel (not surprisingly the later one with folded foot, no. 81) from the Holyrood assemblage appears to be made from colourless glass.

Among the fragments of vessels with a pushed-in base were those from tall, relatively cylindrical, beakers generally believed to have been for beer or ale. They were common throughout the 16th and the first half of the 17th century. No. 76 is a typical example (fig. 1.9), and parallels are numerous (Crossley \& Aberg 1972, Figs 66.93 \& 97). This type of glassware was frequently 'decorated', either by mould-blowing to give an overall pattern or by the addition of thin surface trails of glass. However, it would appear that the trailing often only consisted of a couple of turns approximately half way up the vessel and may have been for grip improvement rather than decoration. The small fragments nos 91 and 92 may be examples of such trailing although the former shard seems to have come from just above the foot. No. 91 has been notched by a rigaree (a bit like a pastry wheel). These tall beakers also occur in another form where the base is plain (ie not significantly pushed-in), but where a thin cordon of glass has been wrapped round the circumference of the vessel at the junction of base and sidewall. This, again, is probably part decoration and part mechanical strengthening of a vulnerable area. These applied cordons are frequently notched with the rigaree (see no. 90).

This technique is also found on some of the goblet-type glasses where the rigaree cordon is applied round the base of a bucket bowl. Given the sharp angle between base and 
sidewall in these bowls, again strengthening may be a significant factor. Because there is so little left it is not possible to say whether no. 90 came from a beaker or a goblet. No close parallels for the flaring rim (no. 88) were found but the moulding would suggest an ale beaker or tumbler.

Pushed-in bases are also found on goblets, bowls and tazzas, especially those late 15 th- to early 17 th-century forms which had broad pedestal stems or bases. Although there is only a tiny fragment of side and base wall surviving on no. 75 , this could be a goblet with pushed-in base. Interestingly, the good condition of the glass and its bright blue-green colour have reasonable parallels in material recovered from Rosedale, in Yorkshire (Crossley \& Aberg 1972). This comment also applies to no. 90 .

The pushed-in base (no. 77) is intriguing. It is made from lattimo (opaque white) glass, often used for decoration but less for complete vessels. Unfortunately nothing of the sidewall remains to give an idea of its angle with respect to the base and hence its possible shape and function. Charleston comments that the London glass-seller John Greene imported lattimo vessels from Venice around 1670 (Charleston 1984, 262) but by then taste in drinking-glass shape had moved to types not suited to the pushed-in base method of manufacture. It seems likely that no. 77 predates the English Civil War.

No. 93 is probably a fragment of a 'beker op voet', or footed beaker, made in Holland around 1600. This external ribbing is common on Dutch and North German vessels of that period (Henkes 1994, 187, 44.3).

With only the rim folded and its bright colourless metal, the folded foot (no. 81) can be confidently dated to the 18th century and probably to $1730-60$.

The piece of rim, no. 89 , is particularly interesting, since this type of decoration, where several horizontal, thin, parallel bands of white lattimo glass have been marvered in just below the rim, has begun to turn up with some regularity on Scottish sites. Find spots include Fast Castle, Berwickshire, which yielded two fragments from 16th-century contexts (Murdoch 2001, Fig. 38.9 \& 11). Niddry Castle, West Lothian, yielded another two (Murdoch 1997, Fig. 22.1) and another, possibly from a tazza, was found at Spynie Palace, near Elgin (Murdoch 2002, Fig. 96.16). This type of decoration is paralleled in England, where an example from Exeter is dated to 1500-50 (Charleston 1984, 269 G.52). However, English parallels are infrequent and this style seems to have appealed particularly to Scottish taste. Interestingly, in the relatively brief glass report on finds from the Edinburgh Niddry Street/Blackfriars Street excavations of the early 1970s, comment is made on a pushed-in foot with vertical applied threads of lattimo. While suggesting that the conventional dating for this type of decoration is early 16th century, Charleston does not rule out a late 15th-century date (Schofield $1976,214)$. However, another interesting factor is that all of the shards seen with horizontal banded decoration appear to have very similar weathering products, suggesting a similar if not common origin. The weathering seems excessive for Venetian glass and a northern European source is more likely, which would make a 16th-century date more likely.

Three other shards of pushed-in base were recovered but are too small for comment except that they are probably 16th/17th-century.

Several other small fragments of vessel glass, not illustrated, are likely to be from ale beakers since many are lightly moulded and most appear to be made from green rather than crystal glass.

The short length of tube (no. 94) is probably a piece of chemical apparatus, its changing thickness perhaps indicating the spout of an alembic, a piece of distilling equipment (Wood 1982,32). Alembics were made over a long period of time and the weathering on this piece would suggest 17th century at the latest.

\section{WINDOW GLASS}

Window glass, particularly plain, is much more difficult to assess for date than vessel or bottle glass, because of a lack of shape. Added to this we have the problem of assessing whether the shard came from a completed window or was debris from the common practice of glazing on site. Needless to say, the timespan between the creation of a window and its destruction can be considerable. Decay can sometimes provide the answer to the glazing or waste question since the process can start while the window is in use. Quite often lead came or wooden astragal shadows can be seen at the edge of window shards where there has been differential weathering.

An enforced change in technology at the beginning of the 17 th century can also provide a clue as to date. In 1614 a ban was imposed on the use of wood for firing glass furnaces in Britain and coal had to be used instead. The changeover took some time to effect, since the old open pot furnaces allowed contamination of the glass from the coal fumes. Once a suitable closed pot system was perfected, however, the much higher temperatures achievable with coal led to a rapid improvement in the quality of British glass. The higher the temperature, the more liquid the glass becomes and small gas bubbles can be purged more efficiently, giving a much clearer product. There was also a subtle side-effect of this change in technology which particularly affected window glass. During the wood-firing era, almost all of the domestically produced window glass was potash fluxed and the potash was frequently recovered from the ashes of the wood used to fire the furnace (Godfrey 1975, 196). The ashes of coal, however, were of no use as a fluxing alkali, and another convenient and cheap source had to be found to replace costly importation.

Sir Robert Mansell, the major player in the English glass industry in the early 17 th century, used native kelp or 'seaoare' for his ordinary glass, which included window-glass, and imported alkali for his crystal glass (ibid). Most of the imported alkali was soda, as was the kelp, since it was a marine plant. Whether or not the glassmakers realised it, they ended up making a more durable product. As already mentioned, potashand soda-fluxed glasses have denaturing products which are markedly different in appearance. Potash normally results in a very dark brown to black surface and frequently denatures right through the entire thickness of the glass. In the worst cases this can result in total disintegration of the shard into small crystals or powder. Much medieval glass is thought to have disappeared in this manner. Conversely, soda glass decays at a much slower rate and the surface products are generally paler. In very simple terms, what this means is that window shards with a very dark decayed surface are liable to date to before $c 1650$.

However, as already indicated, other constituents in the glass can affect durability, and a lack of weathering cannot be assumed to mean a lack of antiquity. Window glass was made 
by two different techniques: crown (disc) or broad (cylinder or muff) and, if the shards are large enough, it is sometimes possible to tell which. This can also give a rough clue as to date. Unfortunately the great majority of the window shards from Holyrood were too small for comment on likely technique. Earlier glass tends to be broad and later glass tends to be crown, although this rule is not hard and fast. Most of the window glass used in Scotland before the early 17 th century would have been imported from the Continent. The type of glass would depend on the source of these imports. For instance, the Lorraine glassmakers favoured broad glass, which was normally potash fluxed, and the Normandy glassmakers made soda-fluxed crown. Historical references can also create some confusion since, in the 16th century, most window glass was referred to as broad, simply to differentiate it from vessel, rather than an indication of the technique of manufacture (Godfrey 1975, 5) and there is inherent danger in interpreting the term too literally.

Sir George Hay of Nethercliff obtained a patent for the manufacture of glass in Scotland in 1610 but Godfrey (1975, 97) suggests that it remained dormant until 1618. Certainly, the works at Wemyss, in Fife, were up and running by 1621 according to the records of the Privy Council of Scotland. Apparently the quality of the Wemyss window glass was good but that of the vessel glass was not, and English specimens were to be lodged in Edinburgh Castle to serve as patterns for quality (Chambers 1858, 428).

Shard shape and thickness are also pertinent when considering a rough date for window glass. Examples recovered from Scottish sites so far indicate that window glass made up to the end of the 15 th century was generally quite thick, anything from $2.5 \mathrm{~mm}$ upwards. The $16 \mathrm{th}$ - and 17 th-century material is generally thin: less than $2 \mathrm{~mm}$ and sometimes less than $1 \mathrm{~mm}$. Early on very thin glass was usually a sign of broad glass, however as the skills and techniques improved it became possible to make crown glass even thinner. This probably reached its extreme during the Napoleonic Wars, when taxation on glass was at its most punitive. However, thicker varieties were produced to accommodate sufficient mechanical strength for the much larger pane size of the case window, which became the preferred option in many larger houses from c 1680 onwards. Poorer dwellings, where they had glazing at all, had small windows. Before the middle of the 16th century, windows in Scotland would have been made up from small panes, quite often of irregular shape, in leaded surrounds. In larger windows the lead 'cames' were in turn attached to metal glazing bars and the mechanical strength of the glass was of little importance. After the Reformation the styles became more austere, resulting in the regular patterns of diamond-shaped quarries (lozenges) of the later 16th and 17 th centuries, a style which remained popular into the 19th century. The adoption of larger case windows and the desire for larger pane sizes with better optical quality prompted a move from mainly broad to crown production.

The Dumbarton crown works, founded c 1777 was, by the early 19th century, producing the equivalent of more than one third of all English production (Logan 1972, 177). However, another technological advancement in the 1830s turned the wheel full circle with the development of sheet glass; this revolutionised the industry and ultimately killed off crown production. Sheet glass was simply polished broad glass. Always easier and cheaper to make than crown glass, broad glass had one major problem: poor optical quality. When the cylinders were reheated and slit, they had to be flattened against a surface. These surfaces were never particularly good or clean, leading to optical aberration. Crown glass, on the other hand, made by the spun disc method, never came into contact with anything but air and the optical quality was excellent. Once a cheap method was found of polishing out the surface defects in broad glass, it soon became the normal method of manufacture, crown production petering out; Pilkingtons stopped producing crown glass in 1872 (Barker 1977, 126). Dumbarton itself had become defunct by c 1850 (Logan 1972, 177), a combination of business problems and perhaps an inability or unwillingness to embrace the new technology. The final abolition of all duty on glass in 1845 and the window tax in 1851 also contributed to an expansion in the industry and a move towards the thicker product that we know today.

An attempt has been made to assess the Holyrood window shards in terms of comparison with what has been recovered from other sites but, since the possible variables are considerable, dating suggested should not be regarded as definitive, especially if it is in conflict with other more reliable evidence.

Table 1.11 Glass

\begin{tabular}{lc}
\hline Period & $\begin{array}{c}\text { No. of contexts } \\
\text { with glass }\end{array}$ \\
\hline 1 & 0 \\
2.1 & 2 \\
2.2 & 3 \\
2.3 & 9 \\
3 & 19 \\
4.1 & 47 \\
4.2 & 13 \\
5.1 & 20 \\
5.2 & 9 \\
- & 7 \\
Total & 129 \\
\hline
\end{tabular}

\section{Site comments (TABle I. in)}

A total of 129 contexts yielded glass and their distribution by period, as supplied, is shown in table 1.11.

Based on the diagnostic shards recovered from the glassbearing contexts, the dating of the periods should be roughly as follows:

Periods 1-2.2 15th century and earlier Period 2.3 Late 15 th to early 16 th century

Periods 3-4.1 Early 16 th to very early 18 th century

Period 4.2 Later 18th to 19th century

Period 5 19th to 20th century

Under normal circumstances, ie continuous and consistent use of the site, the amount of glass recovered from Period 4.2 should have been significantly greater than that from Period 4.1 , not less. This clearly indicates a change of site occupation/usage around the beginning of the 18th century.

A total of 30 contexts contained shards that were not 
datable or represented a range of dates, which suggested considerable disturbance and contamination. Of the remaining 99 contexts, 83 contained shards of the appropriate period date ranges listed above, or earlier. The latter presumably can be explained by residuality. This leaves 16 contexts apparently containing material later than they should have.

In five contexts, 089, 190, 223, 557 and 837, the apparent discrepancy was due to window glass perhaps appearing more modern than it actually was. As has already been noted, plain glass in particular is very difficult to date and it is quite possible that the shards in question are period-contemporary. Four contexts, 215, 322, 803 and 888, contained other later material in the shape of 18th/19th-century Chinese pottery. Three contexts contained glass which was undoubtedly later than the period date; 002 contained a shard of 20th-century sheet glass; 222 contained a shard of 20th-century beer bottle and 242 contained several fragments of 19th-century beer bottles. Contexts 512 and 627 both yielded wine bottle shards which looked to be later 18th century, but again this conclusion was based on glass colour and condition rather than on diagnostic manufacturing detail, and there is room for doubt.

The shard of wine bottle from Context 193 (Period 4.1) has belling, a localised swelling just above the base ring. This feature would indicate that the bottle really cannot date to before about 1720 and is more likely to be a little later. This single item might just push the terminal Period 4.1 date into the second quarter of the 18th century, while the great majority of finds from that period are somewhat earlier. Context 729 contained a shatter fragment with an apparent 19th/20th-century colour.

\subsection{CERAMIC OBJECTS}

\section{ADRIAN COX}

Small ceramic artefacts recovered from the excavation include a number associated with leisure pursuits (for example, a carpet bowl and a counter fragment). This also applies to the small earthenware or stoneware alleys (nos 116 and 117), which would originally have functioned as parts of closure mechanisms in glass bottles during the 19th century. No. 116 is a glazed example, whereas no. 117 is unglazed. Once the bottles were empty, the alleys were often claimed by children for using in games of marbles. No. 118, one of two almost identical stoneware bottle tops from the site, and of very local origin, was recovered from a service trench in Period 5.2.

Found in the fill of a shallow pit in Period 5.1, no. 119 represents two conjoining fragments of a carpet bowl. Glazed, earthenware carpet bowls were used in wealthier households during the 19th and early 20th centuries for playing indoor

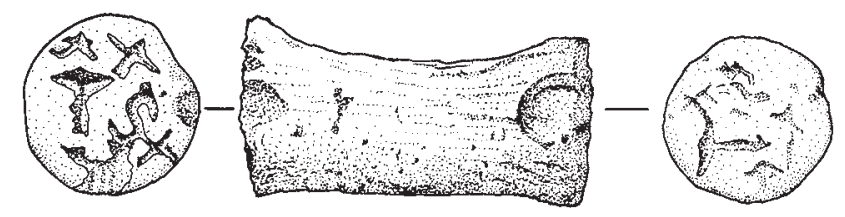

121

Fig. 1.13 Ceramic wig curler (scale 1:2) games of bowls. Such games were part of a Victorian fashion for parlour games. The surface of this example is decorated in green, over a white background, with a repeating pattern of rounded triangles with central dots. A wide range of decorative patterns was used on carpet bowls, executed mainly in red, blue, black and green, above a white background. The bowls also occur in a range of sizes.

A fragment representing approximately half of a disc, derived from a sherd of Reduced Greyware (no. 120, fig. 1.17) was found in the rubble backfill overlying stone-capped culvert 757 in Plot 3.3. It is rather abraded, indicating that it might have moved some distance from the site of its original deposition. Probably used as gaming counters, discs cut from sherds of glazed pottery have also been recovered from other excavations in various parts of Scotland. A disc cut from a sherd of post-medieval earthenware with a yellow glaze was found at Linlithgow Palace (Caldwell 1996b, 841, Fig. 15, No. 44). An example of medieval date, in a variant of the East Coast Redware fabric, was found at Elgin (Cox 1998, 796, Fig. 18, No. 101) and others have come from St Andrews and from Urquhart Castle (Cox 1995, 66, Fig. 11, No. 24; Samson 1982, 475, Fig. 6, No. 93). The fabric from which no. 120 is derived indicates a date in the 15 th or 16 th century. It was associated with window glass of a similar date.

Wigs were fashionable for both men and women from the 16 th century until the early 19th century. Their main period of popularity was during the 18th century (Cunnington et al 1960, 236). Wigs and wig curlers were used throughout that century by men, and became popular for women in the late 18th and early 19th centuries (le Cheminant 1982). No. 121, from a garden soil deposit in Period 4.1, exhibits some aspects of the typical 18th-century form, being cylindrical, with expanded, flat-ended terminals (fig. 1.13). Often, one or both ends of a wig curler were stamped; both ends in the case of no. 121. However, this example is untypically short and squat, as most have a more elongated form.

118) Bottle top. Diameter $30 \mathrm{~mm}$; length $28 \mathrm{~mm}$.

Stoneware bottle top, incorporating a discoid cap and a centrally set screw-threaded shank. The top of the object bears an off-centre stamp bearing the legend 'J.STEWART \& SONS, 62 CANONGATE EDINBURGH'.

Context 1042; IADB 2939; Period 5.2.

119) Carpet bowl. Diameter $72 \mathrm{~mm}$.

Spherical carpet bowl in two conjoining fragments. The stoneware fabric is fine, buff to grey in colour and has an irregular fracture. A pattern of rounded triangles with central dots, executed in green, decorates the entire external surface.

Context 294; IADB 757; Period 5.1.

120) Disc or counter. Projected diameter 48-50mm; thickness $8 \mathrm{~mm}$.

Fragment of a circular disc or counter, derived from a pottery sherd in a dark grey, reduced fabric with an external dark green glaze. Slightly abraded (fig. 1.17). Context 738; IADB 1995; Period 3.

121) Wig curler. Length $35 \mathrm{~mm}$; max. diameter $17 \mathrm{~mm}$. Object made from buff to white clay, in the form of a cylinder with expanded terminals. Each terminal has a flat face, into which the legend ' $\mathrm{T}$ S' has been roughly incised, with diagonal crosses above and below. 


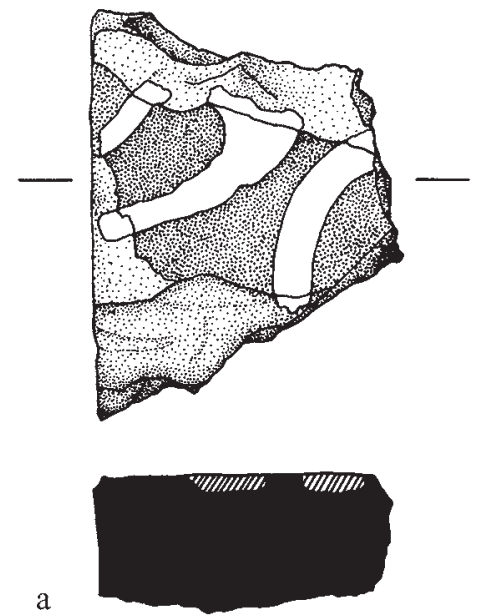

Fig. 1.14 Ceramic tiles (scale 1:1)

The edges of both faces are chipped and abraded (fig. 1.13).

Context 540; IADB 427; Period 4.1.

\subsection{CERAMIC AND STONE BUILDING MATERIAL}

\section{JULIE FRANKLIN}

\subsubsection{Introduction}

A wide variety of building materials was recovered from Holyrood: roof tiles, roof slates, brick, and various floor and wall tiles. The 533 pieces of ceramic and stone only represent a tiny fraction of what would originally have been used on the site. Building materials were, and are, wherever possible, reused, and what was recovered from the site are the items dumped on site or which found their way into the garden soils. It should also be borne in mind that for most of the site's history, building would have been almost entirely in wood, wattle and thatch, none of which materials have survived.

The assemblage spans nine centuries of building work on site, but problems of dating within this are more acute than with portable finds. Building materials may well be several centuries old by the time of their demolition and deposition in archaeological contexts, or they might represent builders' waste dumped at the time of their original use.

The earliest surviving finds were roof tiles. Early roof tiles were probably used only as edging or ridging on a thatched roof. Later medieval tiles from the site are sometimes found associated with slates. They could therefore have been used in conjunction with stone, either to roof different areas or laid in a decorative pattern. Some of these later medieval tiles were glazed green. One was also incised, possibly to add to the decorative effect.

The earliest slates on site appear in the late medieval period
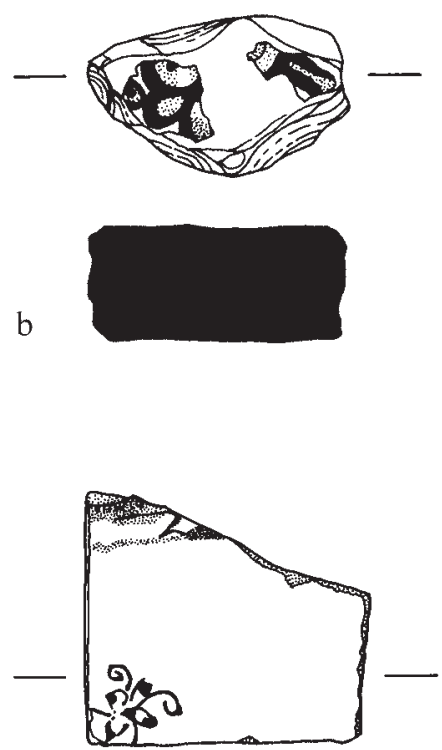

$\mathrm{c}$

but most are made of sandstone rather than true slate.The nearest sources of slate are Aberdeenshire or the West Highlands. Slate of both these types has been identified on site but the majority are of a grey sandstone available around Edinburgh and also from a quarry at Carmyllie in Angus. It seems that even though sandstone was harder to work, it was more economical to use than to import slate from further afield.

Several different kinds of decorated floor tile were found. The earliest is a piece of medieval tile decorated by inlaying white clay into a red body (no. 122, fig. 1.14a). When glazed this gives a yellow design on a brown ground, probably part of a larger panel design. Such tiles were not common and generally only laid in buildings of high status and wealth.

A collection of seven plain glazed tiles provides the only coherent group of floor tiles, though they probably originate from at least two separate floors. Tiles of this type were produced in the Netherlands from the late 14th to the 16th centuries, with similar but lower quality examples being made in Britain. Glazed yellow, green or black, they were laid in chequer-board or other patterns to emulate black and white marble floors. Two examples of probable local origin were found in a 16th-century rubbish deposit. The five Dutch examples were scattered across the site in contexts dating from the medieval period to the 17 th century. Of similar date but less diagnostic was a possible fragment of a reliefdecorated tile (no. 123, fig. 1.15), and even its identification as a tile is not certain. Its fabric and glaze are similar to late medieval pottery but it is extremely thick and flat for a vessel and was found in a post-medieval drain.

The two most eye-catching decorated tiles were both of post-medieval date: a fragment of late 16th-century Maiolica floor tile and a corner of a late 17th-century Delft tile, intended for a fireplace or wall (fig. 1.14b and 1.14c). Only a small area of decoration remains on the Maiolica tile, but the rich blue, green, yellow and orange colours of the design are still visible. Maiolica tiles were produced by Italian potters in the Netherlands until pottery from China 

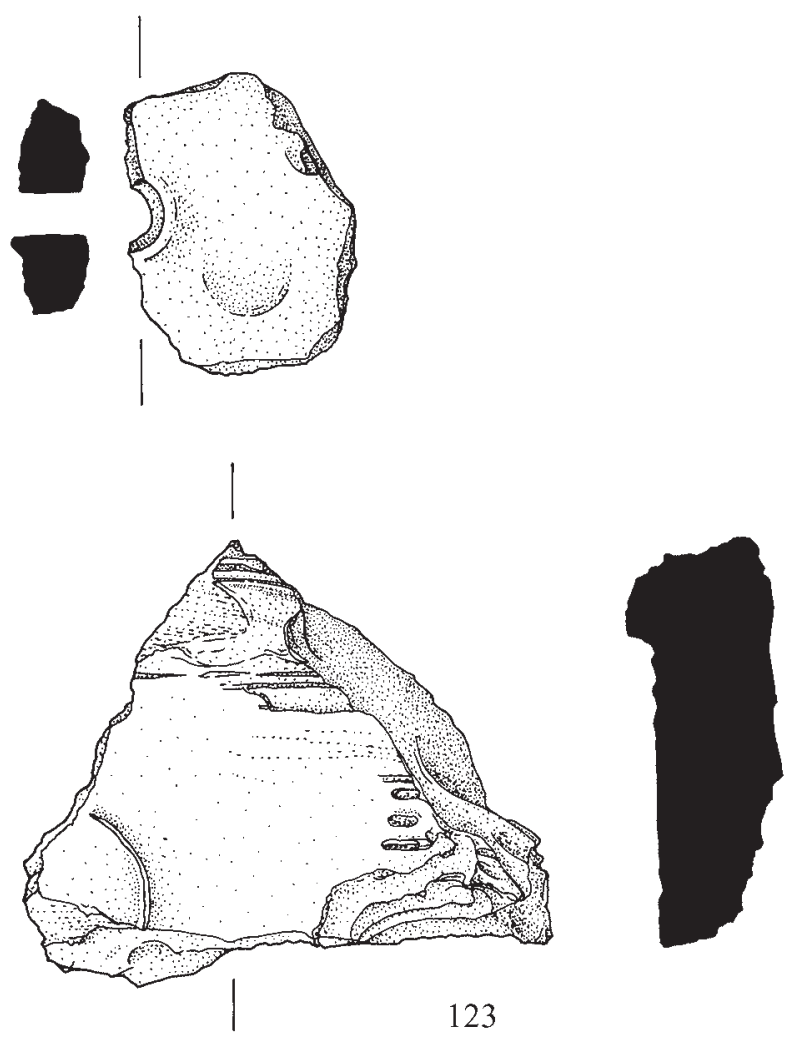

Fig. 1.15 Ceramic tiles (scale 1:1)

inspired the beginning of the blue and white decorated Delft industry.

None of these pieces could be associated with a specific building. Despite being spread over the whole breadth of the site, most of the older pieces, especially those of any status, must have originated from buildings on the Canongate, as there was then no building on the Cowgate. The natural topography of the site would have resulted in the movement of debris towards the rear of the plots. Nothing could definitely be associated with Balmakellie or Queensberry House, though the evidence points towards the roof being slated rather than tiled. Of the interior fittings, only the Delft tile is demonstrably of a corresponding date, but was found at the other end of the site.

Despite the lack of a specific association, several observations can be made: there is a high quality of building implied throughout the site's history, as could be expected for the Canongate. Not only is there evidence for the early use of roof tiles and slates, but also a number of decorative tiles and a tradition of using imported material from the Netherlands.

\subsubsection{Floor and wall tiles}

Only the glazed and decorated floor tiles have been discussed, although a handful of plain unglazed tiles were recovered.The glazed and decorated tiles all dated to the late medieval and early post-medieval periods apart from one earlier medieval fragment with inlaid decoration. Of the five pieces of wall tile recovered, one was modern. The other four were older tin-glazed tiles, one with characteristic Delft blue and white decoration.

\section{INLAID FLOOR TILE}

One fragment from the edge of a floor tile came from the Period 1 boundary ditch in a fill containing only medieval finds. It was decorated using a common medieval method of stamping the design into the red clay tile and inlaying the depression with white clay. The design extended over the edge of the tile and it would have formed part of a larger panel. Unfortunately, not enough remained to identify what this design could have been. Floor tiles were not common in the medieval period and it would have been from a building of some wealth and status, possibly religious.

122) Inlaid floor tile. Thickness $26 \mathrm{~mm}$.

Fabric sandy and micaceous, orange with a grey core. Decoration stamped and filled with white clay. Clear yellow lead glaze, showing yellow on a brown ground (fig. 1.14a.)

Context 785; IADB 2329; Period 2.2.

\section{RELIEF FLOOR TILE}

A large piece of ceramic was found in the fill of a postmedieval drain. It was thick but uneven and sparsely decorated in high relief. It was not a diagnostic fragment and could even have been part of a vessel, though a very unusual one. Its fabric was identical to the local White Gritty pottery, in contrast to the red sandy type of most medieval tiles. The fabric, olive-green glaze and style of decoration imply a date of around the 14 th or 15 th century.

123) Relief decorated tile? Thickness c $21 \mathrm{~mm}$.

Pale orange gritty fabric, with a dark grey reduced core for most of its thickness. Underside flat but uneven, with remains of moulded or applied relief decoration on the top, covered in an olive-green glaze (fig. 1.15.) Context 682; IADB 2256; Period 3.

\section{Plain glazed floor tiles}

There were seven plain glazed floor tiles, some of which were imported from the Netherlands and others of probable local manufacture. Netherlandish tiles were generally of higher quality and had small nail holes in the corners, used for keeping the tile in place on a board while it was being shaped (Norton 1994, 151). Three of the tiles (nos 1246) were identified as from the Netherlands, all had a fine bright orange sandy fabric, were covered in white slip and glazed a bright copper-green. They varied from $25-29 \mathrm{~mm}$ in thickness, and although no complete lengths could be measured, the largest piece was from a tile at least $11.5 \mathrm{~cm}$ wide. This type of tile was imported into Britain from the late 14th century and into the 16th century, according to documentary sources (ibid, 152). The Dutch had a virtual monopoly on the business, and tiles were imported in large numbers. They have been found at many sites in Scotland, especially religious ones. In situ tiles were found in Trinity College Kirk, Edinburgh, Linlithgow Palace, Niddry Castle (ibid, 152) and Friarscroft, Dunbar (Eames 1983); stray finds have been recorded from nearby Edinburgh (High Street) and Leith. Two further tiles were possibly imported (nos 127 $\& 128)$. Both had an orange fabric, were white slipped and 
glazed yellow. Most of the surfaces had flaked away and no corners remained to aid identification. All of the five tiles (nos 124-8) could have come from the same floor but were found scattered across the site. The green tiles came from contexts belonging to slightly later phases than the yellow.

Two tiles (nos 129 \& 130), one glazed yellow and the other glazed black, were of poorer craftsmanship. The streaky fabric of the yellow-glazed example was similar to that of tiles found in Aberdeen (Hall 1989), where it was attributed to badly wedged clay. It is possible that the marble effect on the surface was desired but the spalling that had occurred on both top and bottom surfaces make it unlikely that this was intentional. The two tiles were found together in the back fill of a large stone-lined tank (no. 775) associated with 16thcentury finds.

\section{MAIOLICA FLOOR TILE}

There was one fragment from a Maiolica floor tile (no. 131). Decorative polychrome Maiolica tiles were popular in the late 16 th and early 17 th centuries, when they were made by Italian potters in the Low Countries and, later, in England. They were not ideal as floor tiles because they wore quickly and by the end of the 16th century began to be used as wall tiles. The thickness of this tile implies that it was a floor tile. It was found in a pit associated with late medieval and early post-medieval pottery.

131) Maiolica floor tile. Thickness $23 \mathrm{~mm}$.

Fine cream-coloured fabric. Tin-glazed, though this is mostly missing. The remaining fragments are handpainted with a floral design in blue, dark blue, green, yellow and orange (fig. 1.14b).

Context 668; IADB 1513; Period 2.3.

\section{Delft tile}

Only a corner remained of a decorated Delft tile. It was of a soft sandy fabric with white glaze and corner pin hole typical of Dutch-produced, rather than English, tiles. Production of blue and white ceramics began in Holland around 1620, growing out of the polychrome Maiolica industry and inspired by blue and white pottery being imported from China. It thrived until the introduction of cheaper transfer printing in the late 18th century (Lemmen 1998). The corner motif used is called a 'spider's head' and was common on late 17th-century Dutch tiles (Ray 1973, 97). Its thickness is standard for the late 17 th century (Lemmen 1998, 29). It was at the end of the 17 th and beginning of the 18th centuries that Dutch tiles became very popular and large commissions came in from abroad, and it could have formed part of the original interior of Queensberry House, though its find location at the south-western end of the site does not particularly suggest this. The three plain tin-glazed tile fragments were identical in terms of fabric and glaze to the decorated Delft tile and all were probably of roughly equivalent date.

132) Delft tile. Thickness $8 \mathrm{~mm}$.

Cream fabric with sandy back, glazed white with pin hole in corner. Decoration in blue and dark blue (fig. $1.14 \mathrm{c})$.

Context 222; IADB389; Period 4.2.

\subsubsection{Roof slates}

\section{(WITH THANKS TO SHELLEY BROWN FOR STONE IDENTIFICATION)}

Most of the roof slates were not made of true slate, but of grey sandstone, available around Edinburgh or from a quarry at Carmyllie in Angus. The largest group was also the earliest, from a pit adjacent to a medieval property boundary (Context 808, Period 2.3). None of the 72 pieces in this group had any signs of nail or peg holes, and had the appearance of off-cuts from the slating process, possibly representing the broken surplus from reused slates. A later pit below the terrace (Context 935, Period 4.1) contained nine sandstone slates and two pieces of true slate. Seven of these had nail or peg holes and were the only slates recovered to show this degree of completeness. This, and the variation in stone types in contrast to the earlier pit, implied they came from a demolition deposit. This may have been associated with the clearance of Canongate tenements in advance of the construction of Balmakellie House. Whether these holes were peg or nail holes was unclear. They varied in diameter from $7-15 \mathrm{~mm}$ and none showed any signs of iron staining from nails. Only four pieces of true slate roof slates could be identified from the assemblage, two of Aberdeen type, one from the West Highlands and one unprovenanced.

133) Roof slate. Length 245; width $152 \mathrm{~mm}$; thickness $12 \mathrm{~mm}$.

Near complete with two corners broken with peg or nail hole $7 \mathrm{~mm}$ across cut from both sides. Carmyllie/ Edinburgh-type grey sandstone.

Context 129 (Pit 935); IADB139; Period 4.1.

\subsubsection{Roof tiles}

Of the 239 pieces of roof tile, 18 came from securely medieval contexts. These were mostly either in or associated with the medieval property boundary ditches (Contexts 810 and 780), but three abraded pieces were from a pre-burghal deposit associated with road construction (Context 964). If the early 12 th-century context for these three is secure, they are among the oldest medieval roof tiles in the country. Tiles are generally not found before 13th-century levels.

The medieval tiles were coarsely made of a gritty, micaceous orange fabric. No examples of nib tiles could be identified from the fragmentary remains but one tile showed part of a peg hole. In Perth peg tiles appear in the late 13th or early 14th century (MacAskill 1987, 156). In St Andrews, peg tiles replace nib tiles by the early 14th century (Maxwell 1997b, 91). In Perth, MacAskill suggested that the relatively small quantity of roof tiles found was due to roofs being mainly thatched and only partly tiled, possibly at the edges and corners.

Four of the Holyrood tiles have been glazed olive-green, at least in part. One also has a cross incised into it and was possibly covered in cross-hatching. Glazed tiles would have been more effective in keeping out water, but their main function was probably decorative. Glazed tiles were found in Perth, where they appeared to date to the late 14th and 15th centuries. The glazed tiles from Holyrood were spread 
between Periods 2 and 4, and most probably date from around the 15th and 16th centuries.

The glazed and incised tile (no. 135) was found in a pit (Context 808, Period 2.3) cut into the medieval garden soil adjacent to a property boundary. This was the same pit that contained the largest collection of sandstone slate pieces. A later demolition pit on the Balmakellie House terrace (Context 935, Period 4.1) also contains a glazed roof tile in association with several slates. Glazed tiles may, therefore, have been used in association with stone for roofing, either for edging or set in decorative patterns.

Later tiles are all pantiles, and much more common. They are found in greatest numbers around Haddington House, and in Trench 21 associated with the modern Canongate frontage.

None of the roof tiles or slates can be tied directly into Balmakellie or Queensberry House but since, as seems likely, the previous buildings on site were roofed at least partly in stone, the expertise and raw materials must have been available as early as the 16th century. The fact that so little of this stone was found on site may mean that it was reused to roof the new house, though equally it could have been reused elsewhere.

134) Peg tile. Thickness $14 \mathrm{~mm}$; peg hole approx. $12 \mathrm{~mm}$. Gritty, poorly wedged clay, orange with layers of white visible. (Fig. 1.15.) Context 1684; IADB4636; Period 2.2.

135) Glazed and incised tile. Thickness $12-14 \mathrm{~mm}$. Gritty fabric, brownish orange with a reduced mid grey core. Incised and glazed olive-green. Context 807; IADB2500; Period 2.3.

\subsubsection{Brick and daub}

Brick is found on site from the earliest deposits, but only in fragments too small for any meaningful analysis up until 17 th-century deposits. It is only found in large numbers from the 18 th century onwards. Daub also only survives in small fragments. It is most likely to have been associated with industrial processes, with kilns and furnaces; however, no fragments were found in situ.

\subsection{STONE OBJECTS}

\section{ADRIAN COX}

The small stone artefacts from the excavation include four discs. Two of these (nos $136 \&$ 137, fig. 1.12) are associated with medieval activity on the site, while another (no. 139) is associated with a post-medieval phase, and the remaining example (no. 138) is from an unphased context. No. 136, from a garden soil deposit, is much smaller than the others and may represent a gaming counter. A similar disc, $32 \mathrm{~mm}$ in diameter, was associated with early post-medieval activity at 115 High Street, Elgin (Cox 1998, 794, Fig. 18, No. 81). Part of an incised gaming board found during excavations at Carrick Castle may have been used with small stone discs of approximately this size (Ewart \& Baker 1998, 974-5). Alternative interpretations are also possible, however. Two small
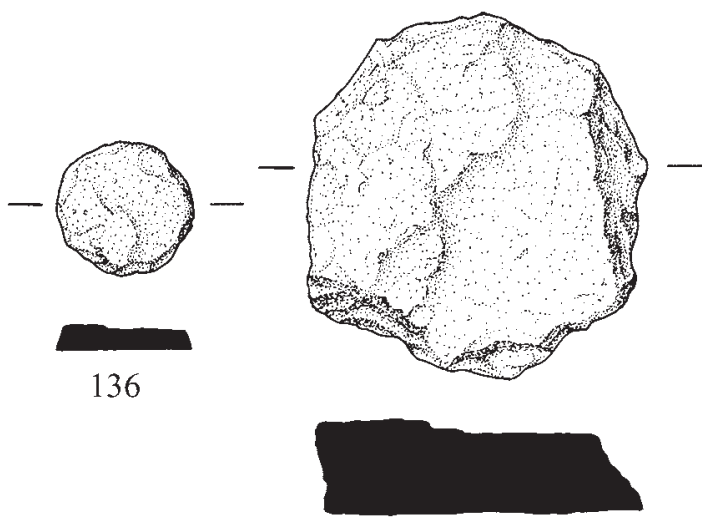

137

Fig. 1.16 Stone discs (scale 1:2)

stone discs from Caerlaverock Castle, one of which is only $23 \mathrm{~mm}$ in diameter, are interpreted as probable pot lids (Laing 1999, 227, Fig. 49, Nos 203 \& 205), for example.

The three larger discs (nos 137-9) are only roughly finished and have uneven thicknesses, although all have at least one fairly flat face. They are of similar sizes, no. 139 being the broadest and thickest. These may have functioned as counters, as is suggested for no. 136 above, but their rather crude finishing and unevenness may indicate a temporary use such as for pot lids. Crudely-shaped stone discs of similar size have been found at Linlithgow Palace (Caldwell 1996b, 864, Fig. 28, No. 146), Curfew Row, Perth (Cox forthcoming) and Rattray (Murray \& Murray 1993, 197, Fig. 45, Nos 297-8).

136) Disc or counter. Diameter $27 \mathrm{~mm}$; thickness $4 \mathrm{~mm}$. Roughly circular disc or counter, derived from micaceous stone. Undecorated. (Fig. 1.16.)

Context 612 (Sample 1605); IADB 2133; Period 2.2.

137) Disc or counter. Diameter $72 \mathrm{~mm}$; max. thickness $18 \mathrm{~mm}$.

Object with a roughly circular outline and one roughly flat face. Undecorated. (Fig. 1.16.)

Context 760; IADB 2677; Period 2.1.

139) Disc or pot lid. Diameter $81 \mathrm{~mm}$; max. thickness $23 \mathrm{~mm}$.

Object with a roughly circular outline and one roughly flat face. The thickness is uneven. Undecorated. Context 1552; (Sample 3815) IADB 3947; Period 3.

Two spindle whorls (nos 140 and 141) were found. No. 140 came from the secondary fill of a stone-lined feature in Period 2.2, and is decorated on both faces by a series of incised, oblique lines. It bears strong similarities to a whorl recently excavated at Curfew Row, Perth (Cox forthcoming), which is slightly larger ( $33 \mathrm{~mm}$ in diameter) but decorated in the same manner.Another close parallel for this type of decoration comes from the excavations at Rattray, where it occurs on a whorl of shallow, conical form, from a 13th- to early 14th-century phase of activity (Murray \& Murray 1993, 197, Fig. 45, No. 290). Another spindle whorl exhibiting a similar form and decorative style was found at Canal Street, Perth, in a context dated to the 15th century (Ford 1987b, 149, 


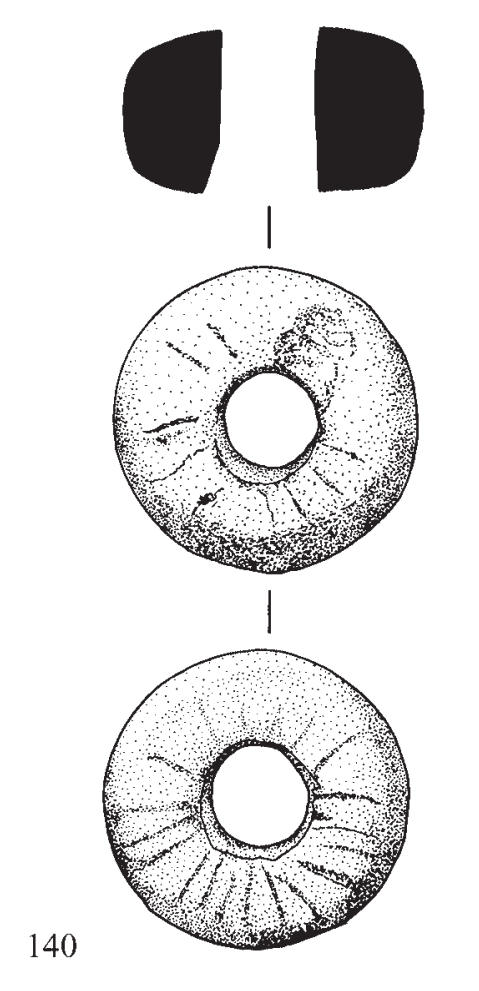

Fig. 1.17 Ceramic disc, stone whorls and bone bead (scale 1:1)

Fig. 80; No. 145). This example was originally of biconical form but had sheared in half across its horizontal axis. No. 141, recovered from a garden soil deposit, has fractured in a similar way. Like no. 140, it is decorated by shallow, incised lines, although in this case they run radially from the centre rather than obliquely.

140) Spindle whorl. Diameter $29 \mathrm{~mm}$; thickness $15 \mathrm{~mm}$. Spindle whorl derived from fine-grained, grey stone, with a central, circular hole and slightly convex faces. Both faces are decorated by a series of incised radial grooves, some of which are slightly oblique. On one face these appear to be shallow and/or more greatly worn than on the other. The outer surface is similarly decorated by roughly equidistant incised diagonal grooves. Slightly abraded. (Fig. 1.17.)

Context 1568; IADB 4093; Period 2.2.

141) Spindle whorl. Projected original diameter c 39mm; thickness $7 \mathrm{~mm}$.

Spindle whorl of discoid or very shallow biconical form, broken across its central, circular hole. A series of shallow, incised radial grooves decorate the upper surface. The object has fractured across its thickness and the lower surface is missing. (Fig. 1.17.)

Context 563; IADB 3161; Period 3.

Recovered from the fill of a rubbish pit in Period 2.3, no. 142 may represent a fragment of a hone or whetstone. No diagnostic tool-sharpening marks are visible on this fragment. Interestingly, one of the broken ends of the object is considerably more abraded than the other, which may indicate continuation of use after the first break occurred. Larger hones, such as that represented by this fragment, would have
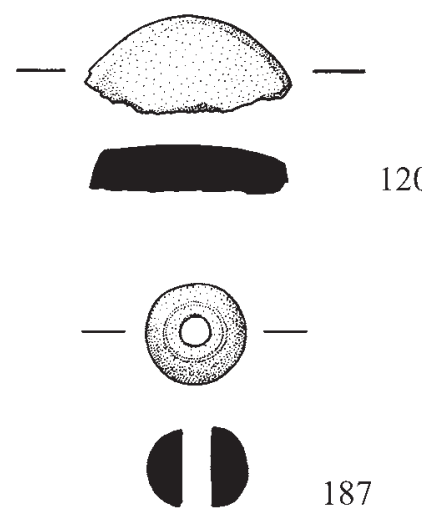

187

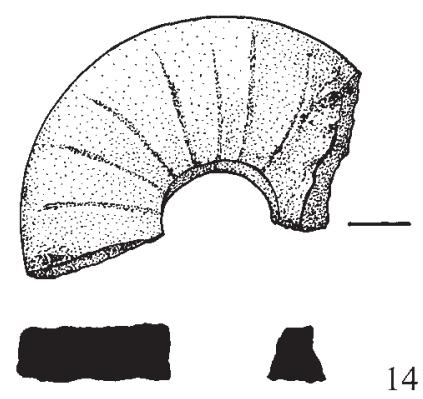

hung in workshops, whereas smaller ones, often perforated at one end for suspension, could be carried about the person.

142) Hone fragment? Length $60 \mathrm{~mm}$; width $31 \mathrm{~mm}$; thickness $25 \mathrm{~mm}$.

Fragment of roughly sub-rectangular cross-section, broken at both ends, chipped and abraded.

Context 694; IADB 1882; Period 2.3.

\subsection{FLAKED STONE}

\section{TORBEN BJARKE BALLIN}

The excavations at the Parliament site produced a total of 44 pieces of worked stone, none of which came from primary contexts. As a result, little can be said about the assemblage, and the report will be restricted to a presentation of the artefacts followed by a subsequent discussion of their possible dates.

\subsubsection{Raw material}

The assemblage is dominated by flint (33 pieces), supplemented by some chert ( 8 pieces) and quartz ( 3 pieces), as shown in table 1.12.

The flint sub-assemblage varies considerably in colour (grey, black, orange and brown) and quality (Maastrichtian/ later Cretaceous), indicating that the raw material came from different sources. This is also suggested by the fact that some pieces have fresh chalky cortex (possibly ballast flint), whereas others have battered and abraded surfaces (from beach or gravel deposits: Saville 1994). 
Table 1.12 The flaked stone assemblage

\begin{tabular}{|c|c|c|c|c|c|}
\hline & & Flint & Chert & Quartz & Total \\
\hline \multicolumn{6}{|l|}{ Debitage and blanks } \\
\hline Chips & & 3 & 1 & & 4 \\
\hline Flakes & & 13 & 2 & 3 & 18 \\
\hline Indeterminate pieces & & 3 & 2 & & 5 \\
\hline Microblades & & 2 & & & 2 \\
\hline & Sub-total, debitage & 21 & 5 & 3 & 29 \\
\hline \multicolumn{6}{|l|}{ Cores } \\
\hline Conical cores & & & 1 & & 1 \\
\hline Irregular cores & & & 1 & & 1 \\
\hline Bipolar cores & & 3 & 1 & & 4 \\
\hline Core fragment & & 1 & & & 1 \\
\hline & Sub-total, cores & 4 & 3 & & 7 \\
\hline \multicolumn{6}{|l|}{ Tools } \\
\hline Scrapers & & 1 & & & 1 \\
\hline Borers & & 1 & & & 1 \\
\hline Pieces with an oblique truncation & 1 & 1 & & & \\
\hline Pieces with edge-retouch & & 2 & & & 2 \\
\hline & Sub-total, tools & 5 & & & 5 \\
\hline Possible ballast flint & & 3 & & & 3 \\
\hline TOTAL NUMBER & & 33 & 8 & 3 & 44 \\
\hline
\end{tabular}

The chert artefacts occur as either grey, blue or green, with or without specks or banding. This raw material is probably local, indicated by a number of nodules and gravel-sized pieces of natural chert collected on the site (Saville 1994). The three quartz flakes are all from small nodules of possibly local milky quartz.

\subsubsection{Assemblage composition}

In the typological presentation of the assemblage the following definitions are applied:

Chips: All flakes and indeterminate pieces the greatest dimension (GD) of which is $\leq 10 \mathrm{~mm}$.

Flakes: All lithics with one identifiable ventral (positive/ convex) surface, GD $>10 \mathrm{~mm}$ and $\mathrm{L}<2 \mathrm{~W}$ ( $\mathrm{L}=$ length; $\mathrm{W}=$ width).

Indeterminate pieces: Worked lithics which cannot be unequivocally identified as either flakes or cores. Generally the problem of identification is due to irregular breaks, frost-shattering or fire-crazing. Chunks are larger indeterminate pieces, and in, for example, the case of quartz, the problem may originate from a piece breaking along natural lines rather than breaking in the usual conchoidal way.

Blades and microblades: Flakes where $\mathrm{L} \geq 2$. In the case of blades W $>8 \mathrm{~mm}$, in the case of microblades W $\leq 8 \mathrm{~mm}$.
Cores: Artefacts with only dorsal (negative/concave) surfaces - if three or more flakes have been detached, the piece is a core, if fewer than three flakes have been detached, the piece is a worked nodule.

Tools: Artefacts with secondary retouch (modification).

\subsubsection{Debitage}

Of the 29 pieces of debitage 4 pieces are chips, 18 pieces flakes, 5 pieces indeterminate pieces or chunks, and 2 pieces are microblades. The flakes have all been detached applying either hard platform technique or bipolar technique, and they give a crude appearance. The two microblades have both been manufactured in bipolar technique. The fact that two thirds of the debitage have some degree of cortex-cover adds to the impression of technological simplicity.

\subsubsection{Cores}

Seven cores were recovered from the site. One is a conical core, one is an irregular core, four are bipolar cores, and one is a core fragment. The conical core (no. 162, fig. 1.18) is a blade core with a faceted platform and minimal preparation of the platform-edge. It seems to have been split diagonally along an internal plane of weakness. The irregular core (no. 159) is very small (greatest dimension $24 \mathrm{~mm}$ ) and completely exhausted. Only one of the four bipolar cores is a certain prehistoric 

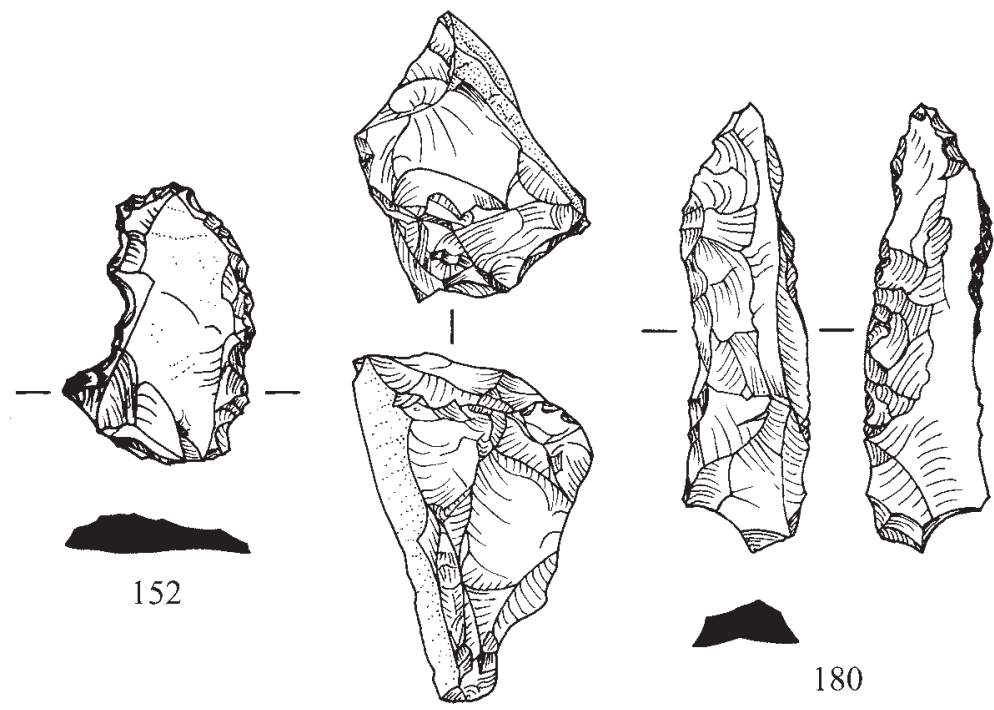

180

162

Fig. 1.18 Flaked stone artefacts (scale 1:1)

artefact; this piece (no. 155) is a thin bipolar core in flint displaying two opposed crushed ridges or terminals and a third crushed ridge at one side, proving that the core was re-orientated during the reduction process (cf Ballin 1999). The bipolar core in chert (no. 154) has pointed terminals and may be a moraine-crushed piece or 'starch fracture' (Ballin 1999; Watson 1956, Fig. 5). The remaining two bipolar cores in flint (nos 165 \& 166) appear more irregular than classic bipolar cores, and as their cortex is fresh they are more likely to be pieces of ballast flint. The core fragment (no. 151) is from a fluted core, most probably a conical core like no. 162; the platform is faceted and the platform-edge is slightly trimmed.

\subsubsection{Tools}

The five tools from the Parliament site include one scraper, one borer, one piece with an oblique truncation, and two pieces with edge-retouch, all in flint. The scraper (no. 152, fig. 1.18) is a double-scraper on a flake with a slightly convex working-edge at either end and steep retouch along both lateral sides. The borer (no. 180, fig. 1.18) is an elongated piece on a flake fragment; it has a retouched point at one end, steep normal retouch along one lateral side, and flat inverse retouch along the other lateral side. The truncated piece (no. 145) has a short, oblique blunting retouch at the distal end; very fine retouch, probably use-wear, on the edge opposite the oblique retouch indicates that this piece is a small cutting implement. The two retouched pieces are both non-formal tools; one piece (no. 147) is a small flake with retouch along the entire circumference, whereas the other piece (no. 163) is a proximal flake fragment with sporadic retouch.

\subsubsection{Possible ballast flint}

Three relatively large pieces of flint (nos 166, 170 \& 181) have been classified as ballast flint. They have some similar- ity to simple irregular cores, but the complete absence of method behind the 'reduction process' combined with fresh chalky cortex and fresh flaking scars suggest that the pieces are not prehistoric (cf Kenworthy 1982, 204, 209).

\subsubsection{Dating}

There are no diagnostic types in the assemblage, ruling out precise typological dating of the lithics. The general impression is, however, that the assemblage contains material from two different technological traditions; most of the lithic material is crude and characterised by either hard-hammer platform technique or bipolar technique, but two artefacts, the conical core and the possible fragment of a conical core, are from a technological tradition involving soft-hammer technique and careful core preparation. Conical blade cores are either Mesolithic or Neolithic, whereas the coarser flake technology characterising the major part of the assemblage will be later, most probably later Neolithic or Bronze Age. The invasive retouch on the flake borer's ventral face confirms this suggestion.

152) Double end-scraper on flake, flint. $28 \times 18 \times 3 \mathrm{~mm}$. Both lateral sides completely retouched. Although the proximal end has been removed, the flake was clearly detached from a platform core. (Fig. 1.18.) Context 332; IADB 1212; Period 2.2.

162) Conical core, chert. $35 \times 29 \times 19 \mathrm{~mm}$.

Split diagonally due to internal planes of weakness. The core has a facetted platform and a minimally prepared platform-edge. (Fig. 1.18.) Context 330; IADB 1822; Period 3.

180) Borer on platform flake, flint. $45 \times 12 \times 8 \mathrm{~mm}$. Retouched point at one end, steep normal retouch along one lateral side, and flat inverse retouch along the other lateral side. (Fig. 1.18.)

Context 689; IADB 1824; Unphased. 


\subsection{BONE AND ANTLER OBJECTS}

\section{ADRIAN COX, WITH SPECIES IDENTIFICATIONS BY CATHERINE SMITH}

A small group of bone and antler artefacts was recovered from a range of contexts, the earliest from Period 2.2 and the latest from Period 5.1. No. 187, found in a levelling deposit in Period 3, is a lathe-turned object in the form of a flattened sphere, with a central perforation (fig. 1.17). This may have functioned as a bead, but since it is undecorated and has quite a broad perforation, it could, alternatively, have functioned as a toggle on a cord attached to clothing or to a bag or purse. A bone bead excavated in Perth, probably of slightly earlier (15th-century) date, is of very similar dimensions but also incorporates a raised rim around its perforation (Cox 1996c, 785, Fig. 27, No. 572). Part of a bead found in Aberdeen is of a smaller, more elongated form (MacGregor 1982, 182, Fig. 105 , No. 28). Glass beads of a similar size to no. 187, groups of which were probably worn together on necklaces, are also known, especially from the later post-medieval period. Bone beads could be made from large ungulate long bone shafts, as this example probably was. Long bone fragments drilled with circular holes, found at Coventry (Gooder et al 1964) and elsewhere, provide possible evidence of bead manufacture.

187) Bead or toggle. Diameter $10 \mathrm{~mm}$; thickness $8 \mathrm{~mm}$. Lathe-turned bead or toggle, probably derived from a large ungulate long bone shaft, in the form of a flattened sphere, with a central, circular perforation, $3 \mathrm{~mm}$ in diameter. Concentric lathe-turning marks are visible particularly bordering the edges of the perforation. (Fig. 1.17.)

Context 660; IADB 3632; Period 3.

Two small bone dice (nos 188 \& 189, fig. 1.19), where all six sides are shown together) are among several artefacts from the excavation associated with games and leisure pursuits. Dice games appear to have enjoyed widespread popularity during the medieval period. Dice could be used to determine the moves of pieces on a board, or used by themselves in games of hazard. Gaming boards rarely survive, perhaps because many must have been made from wood, although rudimentary Nine Men's Morris boards have been excavated from several sites, including Castle Acre in Norfolk, where they were incised on blocks of chalk (Coad \& Streeten 1982, Fig. 51).

Although the earliest known British dice are from Iron Age contexts, small bone dice with numerical values marked by incised ring-and-dot motifs have a long currency, from the Roman period until late medieval times (MacGregor 1982, 182). Throughout this period and into the post-medieval period, most dice appear to have been fashioned from bone or antler, although wooden examples may also have been used. Metallic dice are also known, such as a copper-alloy example from Balmerino, Fife (Cox \& King 1997, 202).

Both nos 188 and 189 are of cuboid form, although asymmetric dice are also known. Cuboid dice give an equal chance of throwing each value represented, while asymmetric examples generally have lower values placed on their narrower faces and higher values on the broader ones, making the throwing of low values more difficult. On no. 189, the surviving motifs represent the numbers $1,2,3$ and 4 . The
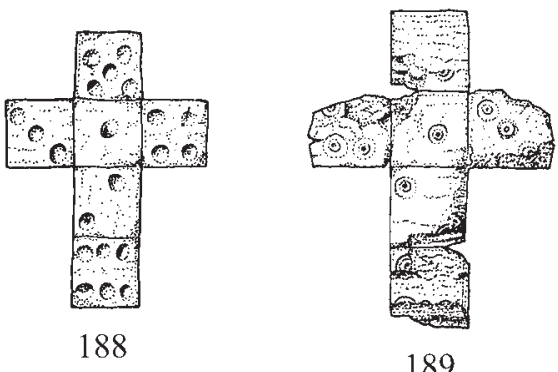

Fig. 1.19 Expanded illustration of bone dice (scale 1:1)

surviving motifs on the remaining two faces indicate that these are likely to represent the numbers 5 and 6 .

The arrangement of numerical values on the two dice represented here follows a convention that appears to have been the norm in pre-Norman times, as it is with post-medieval and modern dice. On both, the numerical values are positioned so that sets of opposing faces add up to seven (ie ' 1 ' faces ' 6 ', '2' faces '5' and ' 3 ' faces ' 4 '). Medieval dice, however, seem to have followed a different convention, where sequential numbers are positioned on opposing faces (ie ' 1 ' faces '2', '3' faces '4' and '5' faces '6'). Dice numbered following the medieval convention have been found, for example, at Southampton (Harvey 1975, 271, Fig. 247, No. 1927) and Streatley, Bedfordshire (Dyer 1974, 19-20), and there are a number of Scandinavian examples, described by Ambrosiani (1981). Other Scottish bone dice include several recovered from the 1975-77 Perth High Street excavations (Bogdan \& MacGregor forthcoming), two from Aberdeen (MacGregor 1982, 182, Fig. 104, Nos 18-19), one from Threave Castle, Galloway (Good \& Tabraham 1981, 129, Fig. 20, No. 213) and one from Tantallon Castle, East Lothian (Caldwell 1991, 346, Fig. 6, No. 130).

188) Die. Length $7 \mathrm{~mm}$; width $7 \mathrm{~mm}$; thickness $7 \mathrm{~mm}$. Die of cuboid form, probably derived from a large ungulate long bone shaft. Each face bears small, drilled circular indentations (with diameters ranging from $1.1 \mathrm{~mm}$ to $1.4 \mathrm{~mm}$ ), arranged to represent the numbers 1 to 6. (Fig. 1.19.)

Context 563; Sample 2957 (retent); Period 3.

189) Die. Length $8 \mathrm{~mm}$; max. width $8 \mathrm{~mm}$; max. thickness $8 \mathrm{~mm}$.

Die, probably derived from a large ungulate long bone shaft. Originally of cuboid form, the object is missing a wedge-shaped piece which has broken away. In addition, other corners and edges are damaged and abraded. Each face bears ring and dot motifs (each $c$ $2 \mathrm{~mm}$ in diameter), although damage to two faces means that a number of the motifs are missing. (Fig. 1.19.)

Context 1505; Sample 3075 (retent); Period 2.2.

A lathe-turned object of biconical form (No. 190) may have served as a handle (for example, on a box or a drawer) or as an end-cap for a metal implement with a circular cross-sectioned handle. It is likely to be of post-medieval date. A handle of tapering, cylindrical form, with a circular end-cap (no. 191, 


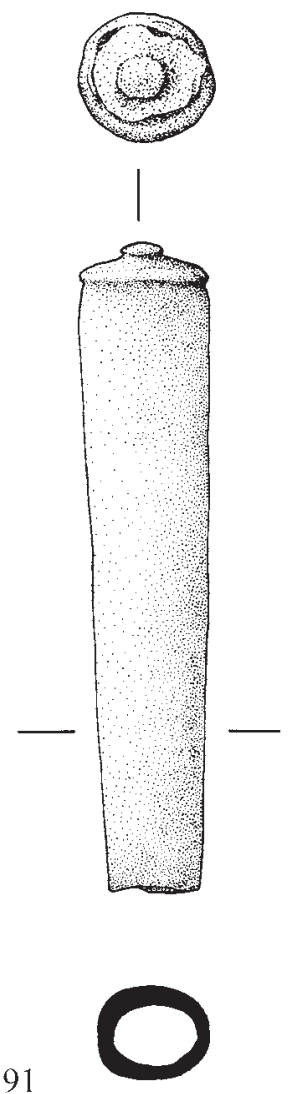

Fig. 1.20 Antler handle (scale 1:2)

fig. 1.16) was found in the fill of a cultivation slot in Period 4.1. It was probably made from an antler tine, and its surface is worn smooth, probably as a result of repeated handling. A fragment of a bone handle of very similar form, with the end covered by a bone disc as in this case, was found at Colchester (Crummy 1988, 75, Fig. 75, No. 3087) in a topsoil deposit. In the Colchester example, the disc of bone is held in place by the burred end of an iron tang, part of which survives within the handle. In the case of no. 191, a small knob forms an integral part of this end-cap. It is difficult to be certain of the type of object this handle formed a component of, but it may have been a toilet implement of some kind, or a button hook.

190) Handle or end cap. Max. diameter 16mm; depth $9 \mathrm{~mm}$.

Handle or end cap of shallow biconical form, with a hollow, circular cross-sectioned interior (diameter $8 \mathrm{~mm}$ ). A small hole at the apex (width $2 \mathrm{~mm}$ ) probably represents damage through wear rather than a deliberate perforation. The object is probably derived from a large ungulate long bone shaft.

Context 1212; IADB 3462; Period 5.1.

191) Handle. length $65 \mathrm{~mm}$; max. diameter $13 \mathrm{~mm}$. Handle of hollow, tapering, roughly cylindrical form, probably derived from an antler tine. It has a subcircular cross-section. The terminal incorporates a circular end-cap with a central knop. The surface is smooth. (Fig. 1.20.)

Context 314; IADB 1449; Period 4.1.
A circular object, decorated with incised, concentric circles (no. 192), was found in a garden soil deposit in Period 4.1. This object has a screw thread around its edge, and probably served a purely decorative function as a mount, attached either to bone (for example, as the central component of a larger gaming piece) or wood (as a decorative mount on a box, for instance). It was probably made from either a large ungulate long bone shaft or from a mandible.

192) Mount. Max. diameter $19 \mathrm{~mm}$; max. thickness $5 \mathrm{~mm}$. Circular mount, probably derived from a large ungulate long bone shaft or a mandible. It is decorated on its upper surface by two sets of incised concentric circles, with a mandrel point at the centre. The object steps inward, below the upper part, reducing in diameter to $15 \mathrm{~mm}$. The lower surface is slightly concave and is undecorated. A screw thread is cut into the outer edge of the object. The edge and face of the object are slightly eroded.

Context 540; IADB 783; Period 4.1.

\subsection{LEATHER OBJECTS}

\subsubsection{Leather-covered ball}

\section{ADRIAN COX}

A leather-covered ball, filled with tightly-packed scraps of leather or textile (no. 193, fig. 1.21), came from a fireplace feature within Queensberry House. The leather cover has a grey to black colouration and is slightly desiccated. One part of it has split, exposing the filling. This represents a ball for playing a game or sport. It has been fabricated by a method very similar to that used in the production of early golf balls. Until the introduction of gutta percha balls in 1848, golf was played using a leather-covered, feather-filled ball. The leather cover was made in three or four pieces, as in this case. After being softened with alum and water, the pieces of leather were sewn together with waxed thread, and then the whole cover was turned inside-out in order that the stitched seams would be on the inside of the ball (Fabian-Baddiel 1994, 28-9). These early golf balls were normally filled with boiled goose or chicken feathers, and, as the wet, newly made ball dried, the feathers expanded and the leather contracted, making the ball tight and hard enough to be hit over considerable distances. St Andrews had an established reputation for golf-ball manufacture, and other well-known makers were based in Leith (eg David Marshall) and Musselburgh (eg John Ramsay and William Robertson) (Henderson \& Stirk 1982, 46). No. 193, with a diameter of $41 \mathrm{~mm}$, fits comfortably within the size range of early leather-covered golf balls, which were normally between $30 \mathrm{~mm}$ and $45 \mathrm{~mm}$ in diameter. Until after 1914, however, there was no limit on the size of a golf ball (ibid, 44).

Although closely resembling a golf ball, there are other possible interpretations of its function. As early as the 17th century, a leather-covered ball filled with wool or flock, known as a sajet, was used for golf in the Netherlands, whereas feather-filled balls were used in a game of Kaatsen (hand tennis), which remains popular in Friesland today (Henderson \& Stirk 1982, 43). Fives balls were also made with leather 


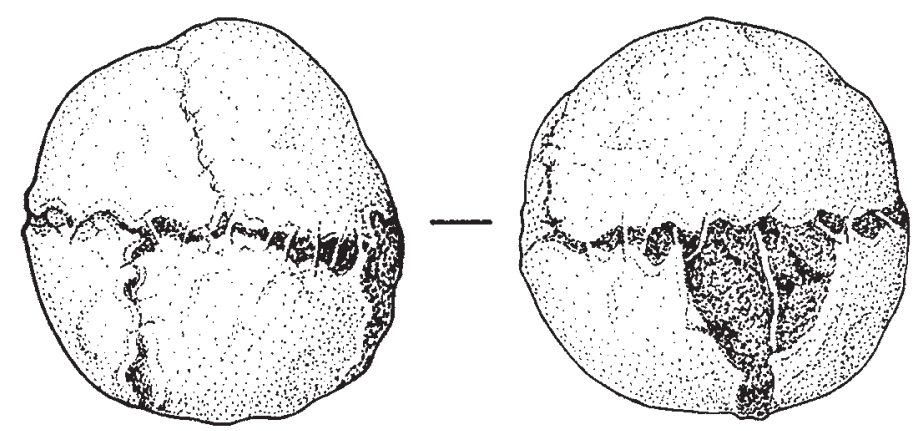

193

Fig. 1.21 Leather ball (scale 1:1)

covers and filled with feathers, but were normally stitched with wire rather than thread. There appears to be a degree of overlap between the characteristics of these types, and it can be concluded that no. 193 may have been used either for golf or in games of fives or hand tennis.

193) Ball. Diameter $41 \mathrm{~mm}$.

Ball with a cover made from four equal-sized pieces of leather, sewn together along edge-to-edge seams with thread (probably cotton or linen). One of the pieces of leather has torn, approximately into halves, revealing part of the internal filling of the ball. This appears to consist of tightly-packed, small scraps of leather or textile. The ball is slightly distorted. (Fig. 1.21.) Queensberry House; Fireplace (FF1); IADB 5359.

\subsubsection{Shoe and miscellaneous fragments}

\section{CLARE THOMAS}

The shoe (no. 194) is clearly of riveted construction, which dates it to the 19 th or 20 th centuries. A sole-riveting machine was patented in 1810 by M I Brunel, in an attempt to use unskilled labour for the manufacture of boots required by the army during the Napoleonic Wars. However, part of his factory burned down after the end of the war in 1815, by which time the demand for such boots had slumped. The use of riveted construction appears to have lapsed until 1853, when Thomas Crick of Leicester patented his method of riveting boots. The outbreak of the Crimean War the following year provided a new demand for cheap, rigid boots; and suitable machines for their manufacture were produced in the 1860s. This form of cheap machine-made working-wear was made in huge quantities until the early 1920s. Accordingly, this shoe most probably dates from the 1850 s onwards.

The two pairs of lace-holes and facing are probably from boots or shoes with front-lacing and appear to be machinesewn. Singer sewing machines, strengthened to cope with leather, were introduced from America in 1856-7. Boots or shoes of riveted construction usually had front-lacing; thus, it is likely that the shoe and the lace-hole fragments represent the same style and construction method, and are of the same date in the second half of the 19th century.
194) Shoe. Length $260 \mathrm{~mm}$; width of forepart $78 \mathrm{~mm}$; width of waist $50 \mathrm{~mm}$; width of seat $63 \mathrm{~mm}$. Length of heelpiece $50 \mathrm{~mm}$; surviving height $26 \mathrm{~mm}$.

Left shoe of riveted construction, comprising composite sole and tiny portion of upper. Sole comprises fulllength outer sole, forepart mid-sole, rand or welt with rivet holes, full-length insole and heel-piece. Heelpiece consists of at least seven lifts or layers of leather. Sole is slender and on a very straight alignment, with only a very slight inward inclination of the forepart; it ends in a broad square toe. Sole is worn, especially the outer portion of the top-piece. Outer sole has two holes, towards rear of forepart. Insole is fragmentary, and full-length mid-sole is very thin and incomplete. Tiny portion of front of vamp of upper survives. Margin of upper is sandwiched between forepart midsole and rand or welt with rivet holes. Very faint trace of two parallel grain-flesh stitching channels, $2 \mathrm{~mm}$ apart, and with a stitch length of $1 \mathrm{~mm}, 15 \mathrm{~mm}$ from front of vamp, suggests that this may be a toe-cap. Shoe is of riveted construction; rivets survive and are clearly visible at waist of outer sole. Holes for rivets are also visible on mid-sole and on insole. Diameter of rivet heads $2 \mathrm{~mm}$; rivets are $6-8 \mathrm{~mm}$ apart.

Context 294; IADB 459; Period 5.1.

\subsection{COINS AND JETONS}

\section{NICHOLAS HOLMES}

Twenty-four apparently numismatic items were recovered, of which 16 coins and two jetons were identifiable. These range in probable date of loss from the late 15th century to some time in the 20th century.

All the coins fall into the category of 'small change'. The earliest could have been minted as early as around 1450, and the latest is a halfpenny dated 1920. The largest concentration is of 17th-century copper coins, comprising five Scottish, one English, two French and one Dutch coin, and representing a fair cross-section of the low-value coins circulating in Scotland at that time. There is only one coin from the 18th century, and this has been identified only on the basis of its size and weight, there being no trace of its designs. There are three bronze issues 
ofVictoria and George V.All the coins are of types which were frequently lost and swept out with domestic rubbish, and there is no direct evidence from the assemblage of any economic activity in the area from which they came.

The two Nuremberg jetons are of common types. Although these items would undoubtedly have been used over long periods, neither of these specimens shows much evidence of wear. Like the coins, they could well have been dropped inside a nearby building and swept out with refuse.

\section{Select catalogue}

\section{SCOTLAND}

199) James II-III copper 'Crux Pellit'. 20.0mm; 1.62g; die axis 11.0. Type IIa (c 1450-82).

Uneven striking; some accretion; moderate wear. Obverse: double annulet stops; orb upwards and to right. Reverse: double annulet stops; pellets on cusps; nothing in spandrels.

Context 859; IADB 2558; Period 4.1.

200) James III copper farthing. $11.5 \times 12.0 \mathrm{~mm} ; 0.33 \mathrm{~g}$; die axis 7.0. 'Ecclesiastical' type II or III (probably c 1475-82).

Heavy and damaged green patina; probably moderate wear.

Context 612; IADB 2531; Period 2.2.

201) Mary billon bawbee. $20.5 \mathrm{~mm} ; 0.90 \mathrm{~g}$; die axis 5.0 . Edinburgh (1543-58).

Much edge damage; some weak striking and flattening; slight wear.

Context 1200; IADB 3296; Unphased.

\section{ENGLAND}

207) Charles I copper farthing token. $13.5 \times 13.0 \mathrm{~mm}$; $0.93 \mathrm{~g}$; die axis 12.0. Rose type 1 (d) (c 1636-39).

Heavy green patina; accretion on reverse; slight wear. Context 888; IADB 3159; Period 4.1.

FRANCE

212) Louis XIII copper double tournois. $20.5 \times 20.0 \mathrm{~mm}$; 2.24g; die axis 5.5 (1639).

Slightly buckled; uneven striking; obverse very worn, reverse worn.

Context 1000; IADB 61; Unphased.

213) Bouillon and Sedan: Frédéric-Maurice de la Tour copper double tournois. $18.5 \times 20.0 \mathrm{~mm}$; $1.01 \mathrm{~g}$; die axis 6.0.

Probably 1640, possibly 1630 or 1650; cf Poey d'Avant type 6358 (Poey d'Avant 1858-62); slightly buckled; heavy and damaged green patina; mostly very worn. Context 211; IADB 761; Period 4.2.

\section{NeTHERLANDS}

214) West Friesland: copper duit. $22.5 \times 23.0 \mathrm{~mm} ; 2.34 \mathrm{~g}$; die axis 12.0. (1604); type as Purmer and van der Wiel 3001.1 (Purmer and van der Wiel 1996).

Heavy green patina; slight accretion; moderate wear. Context 1000; IADB 118; Unphased.
JETONS

215) Brass jeton. $26.0 \times 25.5 \mathrm{~mm}$; $2.40 \mathrm{~g}$; die axis 9.5 .

Nuremberg anonymous 'ship penny' type (c 14901550); cf Mitchiner types 1168-76; cracked and chipped at 1.5 obverse); slightly damaged green patina; slight to moderate wear.

Context 89; IADB 274; Unphased.

216) Brass jeton. $22.0 \times 21.0 \mathrm{~mm} ; 1.33 \mathrm{~g}$; die axis 12.0 .

Hans Krauwinckel II, Nurembergl rose/orb type (1586-1635); as Mitchiner type 1539; slight wear. Context 120; IADB 275; Unphased.

\subsection{CLAYTOBACCO PIPES}

DENNIS GALLAGHER

Nine hundred and eight fragments of clay tobacco pipes were recovered during the excavation of the Parliament site, the majority of which were manufactured in the half century from $c$ 1630-80 (figs 1.22-1.41). This was a period in Edinburgh which witnessed the rapid growth of the fashion for pipe-smoking. Smoking was introduced into Scotland in the early years of the 17th century and, despite royal disapproval manifested by James VI's wellknown Counterblaste to Tobacco, the practice soon increased in popularity. The king, however, was not averse to using tobacco as a source of revenue. A monopoly to manufacture pipes in Scotland, issued in 1619 to Lord Kinclevin, appears in practice to have been the privilege of the pipemaker William Banks, in Edinburgh. The first known documentary reference to Banks was in 1622, when he was named as a 'tobacco pype maker' in the Canongate. He successfully defended his right to this monopoly in 1642 and continued to be the dominant figure in Scottish pipe production until his death in 1659.

The shape of pipes changed rapidly during the 17 th century in response to the dictates of fashion, those of the earlier part of the century resembling heeled London forms. There are no pipes of the very early 17 th century in the present assemblage.

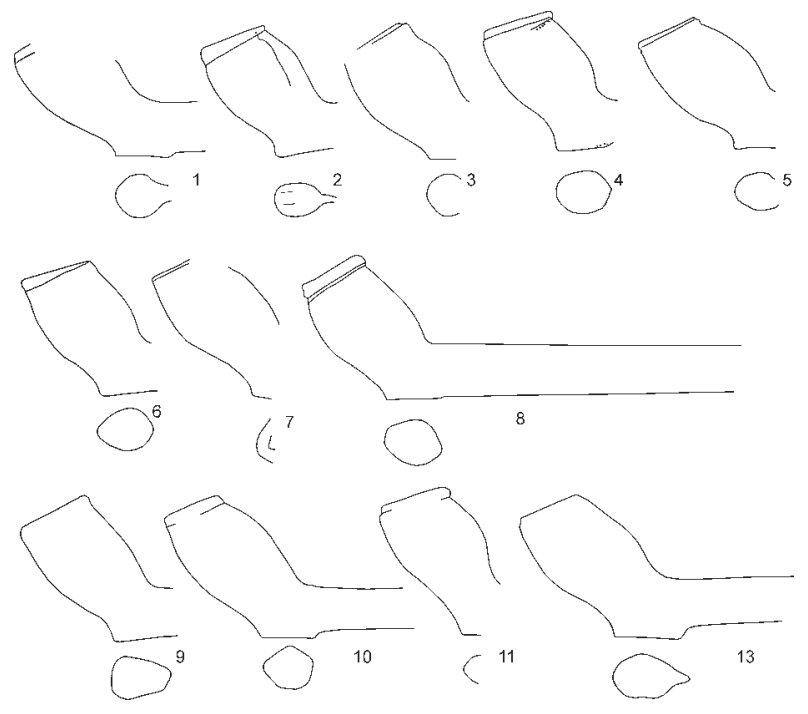

Fig. 1.22 Clay tobacco pipes (scale 1:1) 


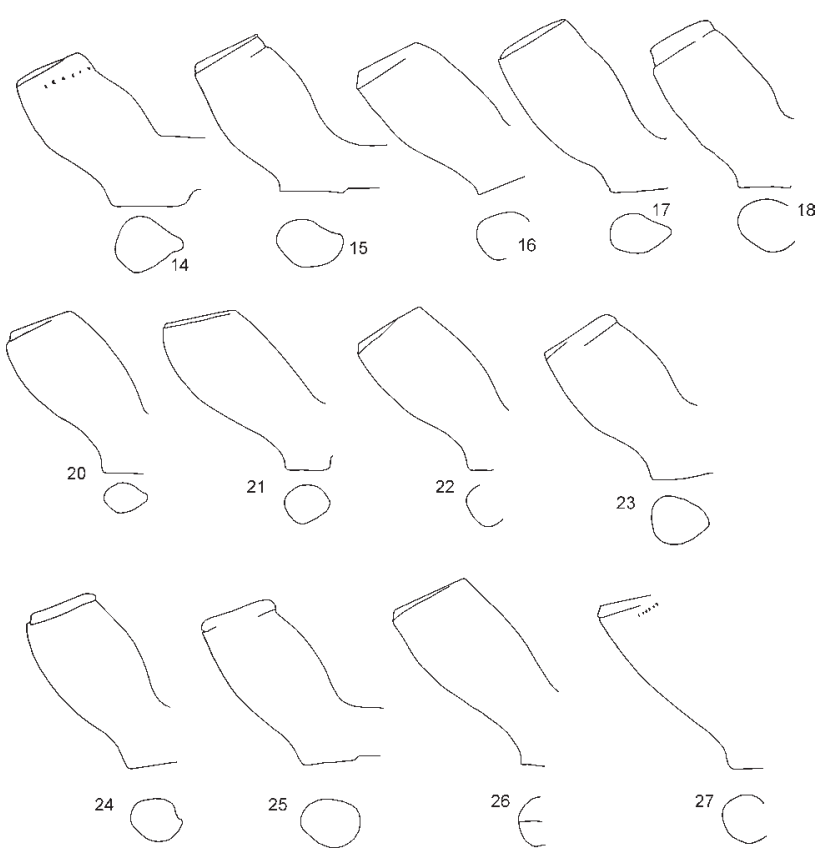

Fig. 1.23
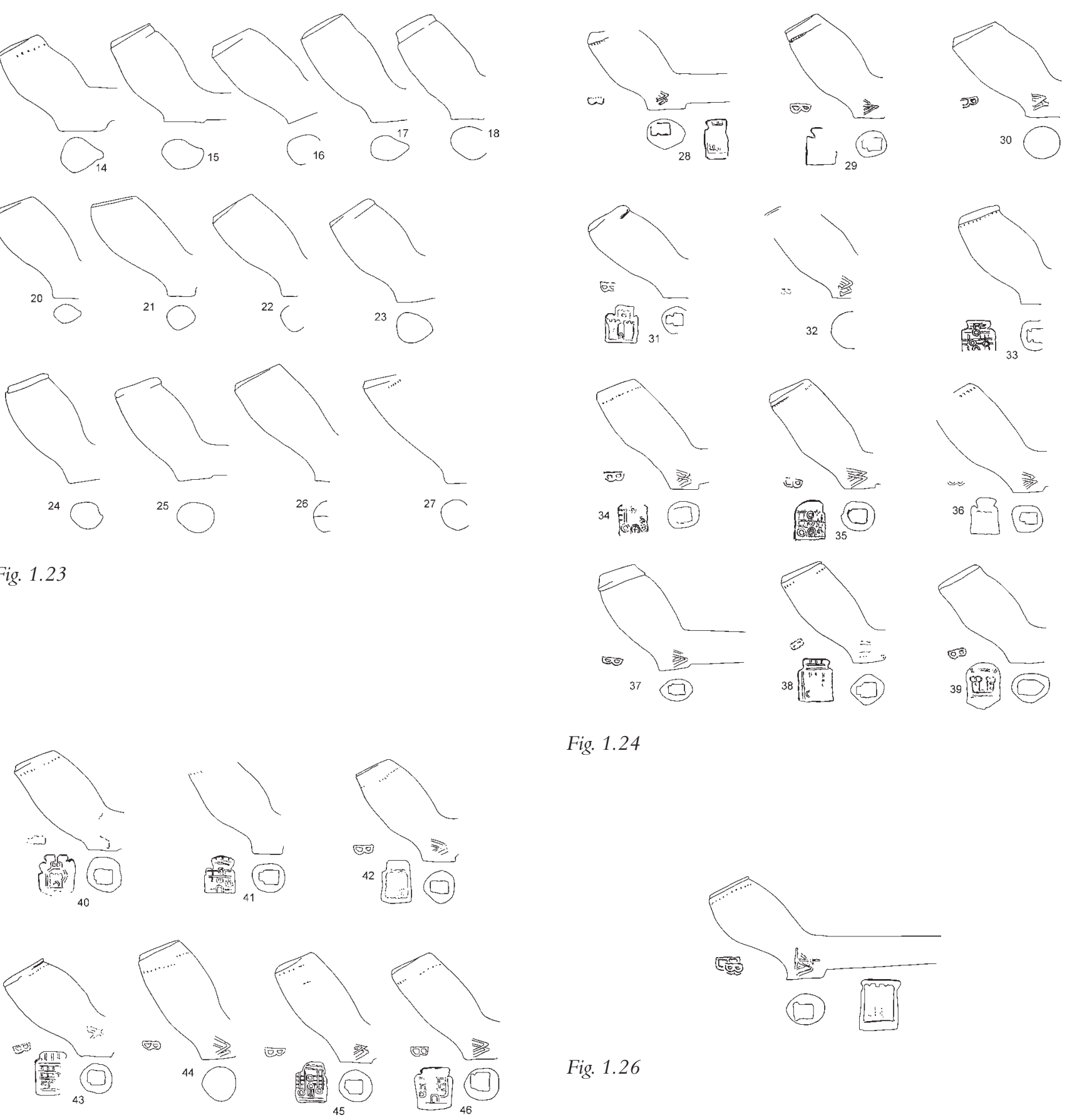

Fig. 1.24

Fig. 1.25

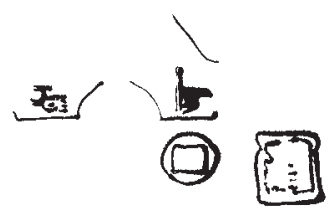

48

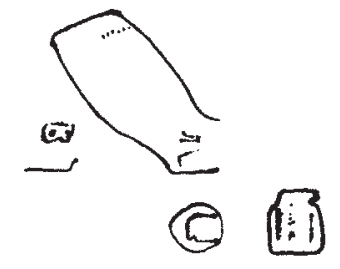

49

Fig. 1.27

Figs 1.23-1.28 Clay tobacco pipes (scale 1:1) 
Although examples are occasionally found in Scotland, their rarity suggests that smoking was not popular until after $c 1630$ 40.The earliest pipes from the Parliament site (nos 223-8) date from the period c 1620-40, and are comparable in form with some found under the Tron Kirk, Edinburgh in a pre-1637 context (Gallagher 1987a). The bowls have a compact barrel shape and vary from a squat form to a more elegant shape whose fronts have a shallow S-shape. By 1650 bowls become taller, with a straighter back (nos 238-40). Contemporary with a more parallel form (eg nos 238-40) are bowls with a more emphasised S-shaped front, common c 1660-80 (nos 242-4), similar to the English West Country form. A taller bowl with a wider mouth became popular towards the end of the century, with nos 248 and 249 having a more forward-leaning style. Contemporary with these bowls is a more upright form, with a heavy splayed base (nos 317 \& 318) similar to a Broseley form 3 (Atkinson 1975, 25). Snuff-taking seems to have replaced pipe smoking as the accepted method of tobacco consumption after $c$ 1730; pipes became uncommon in most of Scotland during the remainder of the 18 th century.

\subsubsection{Edinburgh makers}

\section{WiLLIAM BANKS}

Among the marked pipes, the present group includes 25 bowls that can be identified as products of the workshop of William Banks, who is first recorded as a maker in 1622. None of his products from this early period have been recognised, although some of the unmarked pipes of this date may be Banks's products. Banks is likely to have initiated the Edinburgh style of marking pipes, placing the maker's initials on the side of the bowl and stamping the base with a castle, based on the town crest and identifying it as an Edinburgh product.

A number of Banks's bowls have forward-leaning, wellcurved forms, varying in size from the small bowl no. 250 to his last pipes, no. 269. The series is likely to range from $c 1640$ to $c 1660$. A prominent example is a bowl with the initials TB superimposed over WB (see below), indicating that it was in use shortly after William Banks's death in 1659 (no. 269). The majority of the WB pipes in the present group have straighter sides (eg nos 264-8), being slimmer versions of London type 18 (Atkinson \& Oswald 1969, 178), and must date from the last decade of Banks's life.

\section{JoHn AND ThOmas Banks}

Two of William Banks's children, John and Thomas, became pipe-makers: and both are described as pipe-makers in the documentary evidence shortly after their father's death in 1659. It is not known how they divided the family business, whether they worked as partners or as independent makers. The present group shows that Thomas inherited some of his father's pipe moulds. Bowls no. 269-70 show that the WB of William Banks has been changed on the mould to a TB. Bowl no. 279 has a sub-circular depression in its side, apparently made during manufacture. Despite this defect, the pipe was given a high-quality finish, being stamped, its rim milled and its surface burnished.

The products of John Banks (no. 275) at times can be difficult to distinguish from those of his brother, Thomas, as the initial I on the side of the base can be obscured by wear of the mould and/or by finishing.

\section{WiLliam YounG}

William Young was described, in 1653, as a 'tobacco pipemaker in Pleasance'. Three years later he acquired land in the Canongate, formerly belonging to William Banks. He appears to have prospered as a pipe-maker, taking on an apprentice in 1667 . He died in 1670 and was buried in Greyfriars churchyard. Five bowls in the present group (nos 283-7) have been identified as products of Young, plus one from within Queensberry House (no. 351). The bowls are rather heavy, bulbous forms, often with the base trimmed to slope towards the smoker. No. 284 is unusual in having a bowl with more parallel sides. The later forms are heavy, thick-walled bowls, no. 287 being a taller form.

\section{Robert Smith}

The RS pipes (nos 304-9) may be identified as products of Robert Smith. Little is known of this maker; he appeared as a witness at two Edinburgh baptisms, in 1682 and 1683 (Gallagher 1987b, 11). The pipes belong typologically to the later 17 th century, with the exception of no. 305, a smaller, straight-sided form which is typologically slightly earlier. All the maker's initials are crudely cut and have a distinctive retrograde letter S. The RS bowls in the present assemblage have only one basal stamp, most examples being from a very worn die.

\section{UNIDENTIFIED EDINBURGH MAKERS}

A number of pipes carry initials that, on the basis of current documentary research, cannot be ascribed with any certainty to a particular maker (nos 310-19). Three bowl fragments with constricted bases and flared sides bear the initials AA (no. 310). These may be products of Alexander Aiken, who appears in the Edinburgh and Leith hearth tax records for 1690 (NAS E69/16/3, p3). However, shortly after this date an Alexander Aiken, pipe-maker, was working in Glasgow (Gallagher 1987c, 41-2). It is possible that this maker moved to Glasgow shortly after 1690 . The pipes with the initials IA (nos 316-8) are possibly products of another member of the Aiken family.

There are a number of pipes of probable Edinburgh manufacture which bear initials that cannot be assigned to any makers known from the documentary sources. Among these is a single bowl with the initials AM (no. 311), which has a basal stamp in the form of an incuse castle, rather than the motif being in relief. One lower bowl fragment has the initials SB and a castle style of basal stamp.

\section{Patrick Crawford}

The workshop of Patrick Crawford was dominant in Edinburgh during the latter decades of the 17th century, and his pipes are among the finest produced in Edinburgh. He is recorded in Edinburgh in 1671 and died c 1696. His widow, Jean Wemyss, continued the business and was able to supply 900 gross of pipes to the Company of Scotland for their illfated new colony at Darien (Gallagher 1987d, 234). 

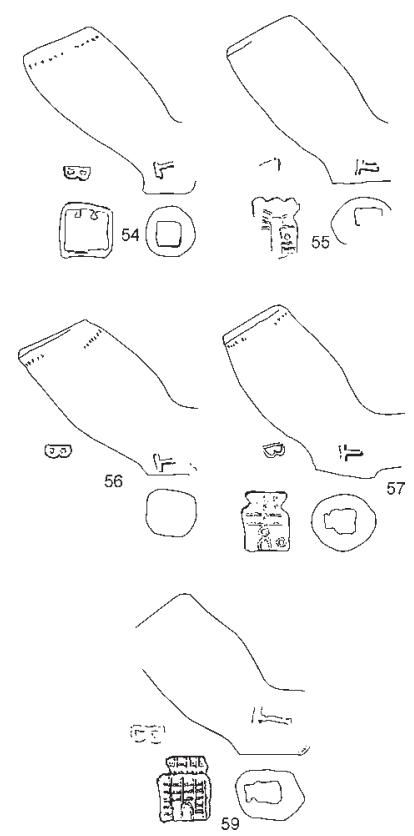

Fig. 1.29
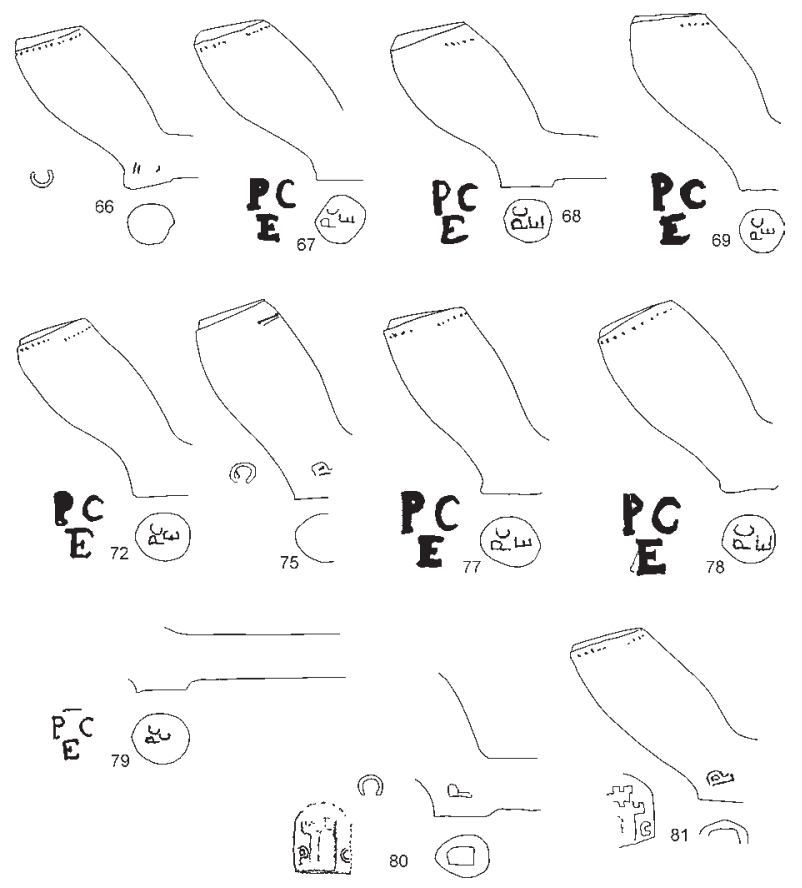

Fig. 1.31

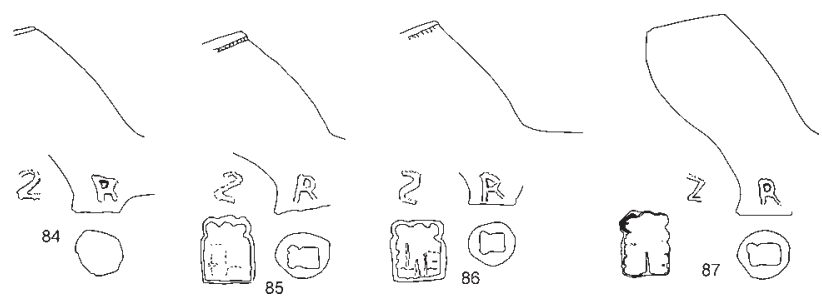

Fig. 1.32

Figs 1.29-1.34 Clay tobacco pipes (scale 1:1)
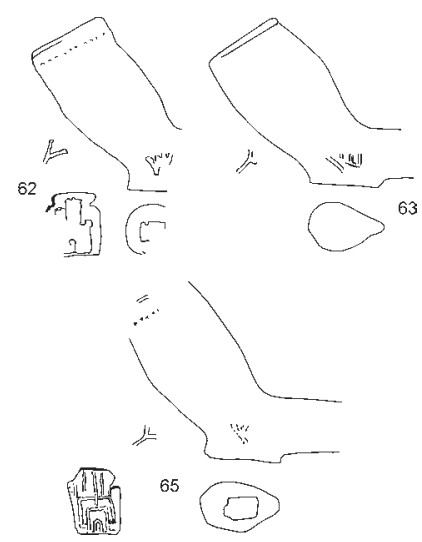

Fig. 1.30

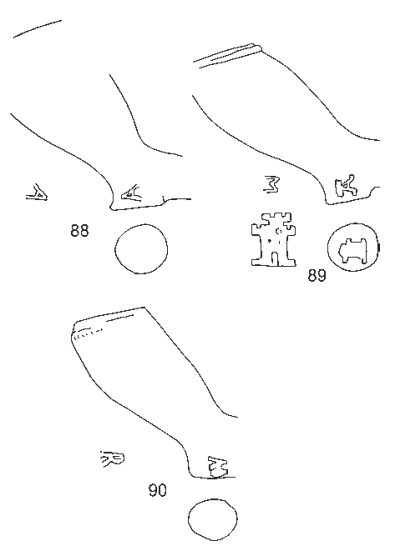

Fig. 1.33

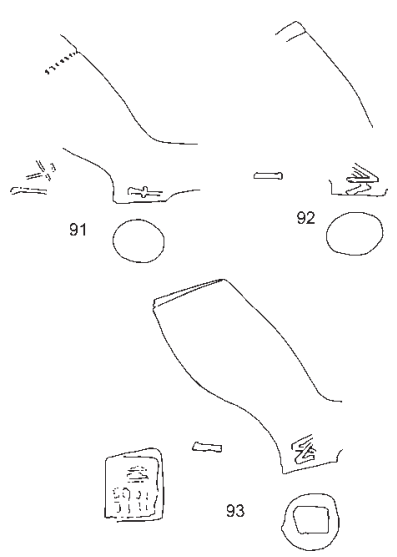

Fig. 1.34 
Most of the Crawford pipes from the Parliament site are marked with a distinctive three-letter basal stamp, incorporating Crawford's initials and the letter E, for Edinburgh. The present group includes marks from at least two different dies of this form of stamp, a smaller and a larger form. A small number of other Scottish makers also made use of this style of stamp, including Thomas Banks and James Colquhoun of Glasgow (Gallagher 1984). At least three different dies of this three-letter stamp can be identified in the present assemblage, although differences are at times obscured by careless application of the die and the use of worn dies. One stamp with small lettering is present only on a basal fragment (no. 301). The three-letter stamp most common in the present group is found on elegant bowls that have fronts with a pronounced S profile (eg nos 291, 294). An example of the third, larger, die is found on bowl no. 299, a form with straighter sides. Crawford also used variants on the castle-style of basal stamp and there are two examples from the Parliament site (nos 302-3). These are normally of a very high quality in their detail, and often incorporate the maker's initials beside the castle, a feature unique among Edinburgh pipe-makers.

Some of the pipes produced by Crawford's workshop in 1696-97 for the Darien venture have been recovered during excavations on the site of the colony in Panama (Horton et al 1987, 243-4). These were much larger bowls than any of the Crawford pipes from the Parliament site and no threeletter stamps were reported in the sample published. This would suggest that the Crawford pipes from the Parliament site were all produced earlier in his career, although this must be accepted with caution as makers could continue to use old moulds, especially for the production of poor-quality pipes.

\section{DAVID BANKS}

The group contains one pipe (no. 320) produced by David, a son of Thomas Banks, who appears to have continued his father's business. Pipes are known with the initial TB altered to that of DB (Martin 1987,197, No. 70), although none were found in the present group. David Banks inherited property in Leith in 1698; and the burials of two of his children are recorded in 1705 and 1706. The form of the bowl fits this late 17 th-century/early 18th-century date. A similar DB pipe was found in a 1698-1700 context at the Scottish Darien colony (Horton et al 1987, 244-5).

\subsubsection{Imported and 19th-century pipes}

Whilst the pipes are predominantly Edinburgh products, the group contains a number of Dutch imports. These include a bowl with a moulded rose (no. 329), a cheap export form that is the commonest type of Dutch pipe found in Scotland (Davey 1992, 280). There are also three basal fragments of higher-quality Dutch pipes (nos 332-4). One of these, a heel fragment with an EB basal stamp, is similar to that of Edward Bird, an English pipe-maker active in Amsterdam, c 1630-83 (Duco 1981, 399).

There are also some English-style pipes in the present group, all from the period c 1640-85 (nos 338-42 and 350). None have maker's marks. They differ from contemporary Scottish pipes in having bowls with spurs rather than heels.
There were extremely few fragments of 19th-century date. Two bowls are from TW pipes, spurred pipes with a TW facing the smoker (no. 345). This mark may have originated with the early 19th-century Edinburgh maker Thomas White, but was soon to be a design produced by almost every Scottish maker. The stem of a fluted pipe by Thomas White \& Co of Edinburgh (no. 352) was found within Queensberry House, dating from after the death of Thomas White in 1847 , when the business continued as a company. Another two pipes bear a hatched heart design, a reference to the "heart of Ulster' (nos 343-4). The Irish connection is enforced on one of the pipes with an unusual motif of a cross on a shamrock, in relief on the base of the bowl (no. 343). This may be identified with the 'St Patrick' pipe produced by McDougall of Glasgow; an identical design appears in their illustrated catalogue of c 1850-88 (unpublished; copy in possession of $\mathrm{P}$ Hammond). This was evidently a favourite pipe, for its rim is heavily worn with use.

One remarkable survival, from a well, is a 19th-century porcelain pipe. Only slightly damaged, it depicts a young lady reading a book whilst resting on a plinth. This plinth, which supports a garlanded urn, is inscribed with the legend 'DenKmal der Jugend' (Monument of Youth). The pipe is German. A precise dating within the 19th century is problematic, as the genre of the picture is of the first half of the century (c 1820-40), while the deep blue background colour of the pipe suggests a later date (D Duco pers comm).

\subsubsection{The pipes in relation to the site}

The majority of the pipes were found in deposits associated either with garden cultivation or with the levelling prior to the construction of Haddington House. In general the date ranges of the pipes from many of the contexts fall within the last three decades of the 17th century. Very few pipes of a post-1700 date were found on the site.

Comparatively large numbers of pipes were recovered from the post-medieval garden soil, Contexts 211, 217 and 540. A number of contexts produced smaller numbers of pipes with a mid 17 th-century date range. Context 1789 , the fill of the sub-circular stone lining, had pipes dating 1630-50. The midden-like deposit, Context 1600, had fragments dating 1630-50. Those fragments associated with the construction of drain 601 (Context 617) can be dated to 1640-60.

Twenty bowls dating c 1640-80 were recovered from Context 211, a make-up layer inside Haddington House. Another four bowls were also recovered from a similar deposit, Context 222. Smaller quantities of pipes were recovered from contexts associated with the make-up of floors: of the canteen phase (Context 532) and the Quartermaster's store (Context 536), with date ranges of 1660-1710 and 1680-1710 respectively. Four bowls from the infill/make-up in Haddington's Entry (Context 222) date from 1640-80. The levelling layer for Hatton House contained 13 bowls with a date range of 1650-85. A pipe from the fill of wall 503 (Context 5940) dates from 1660-80. The packing (636) for terrace wall 629 contained a bowl of 1660-1700.

While most of the fragments of post-1800 date were unstratified or from overburden, a few were from stratified contexts. A single stem of probable 19th-century date was found in the foundation cut, Context 182, of the standing wall 


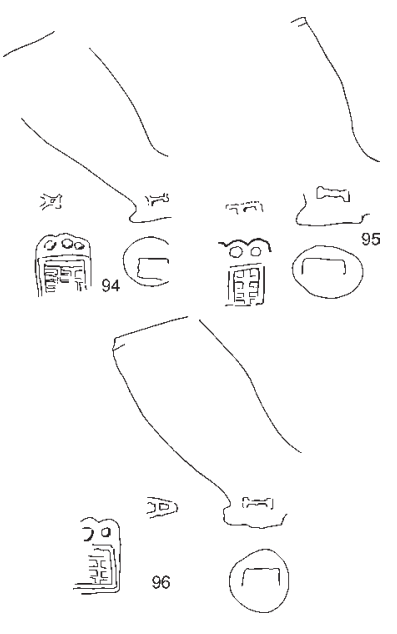

Fig. 1.35

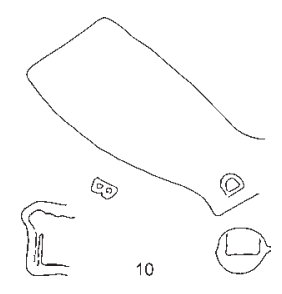

Fig. 1.37
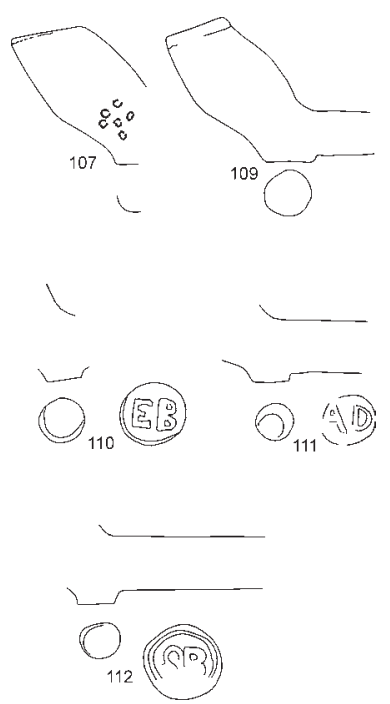

Fig. 1.39

Figs 1.35-1.41 Clay tobacco pipes (scale 1:1)

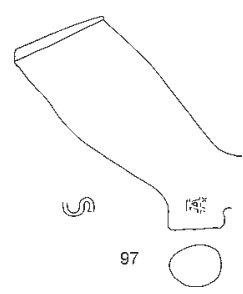

Fig. 1.36

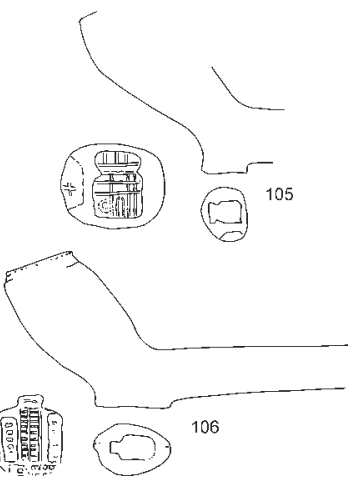

Fig. 1.38

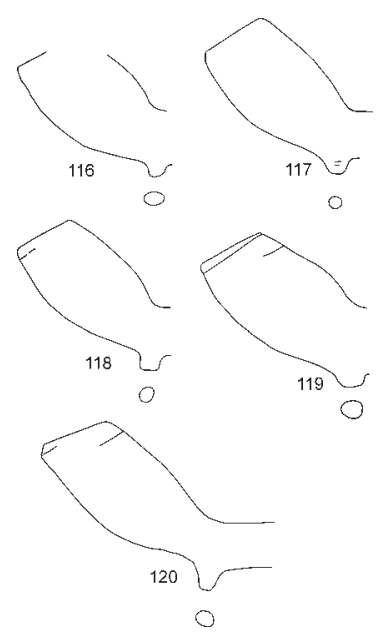

Fig. 1.40

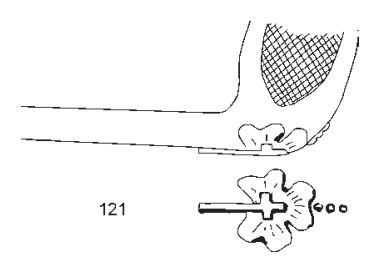

Fig. 1.41 
1111. A single fragment of 19th-century date was retrieved from the fill of a cess tank (1093). A stem by William White of Glasgow was found in the fill of pit 294. The early 19thcentury porcelain pipe came from the fill of well 214.

\subsection{ARTEFACTS FROM QUEENSBERRY HOUSE}

A diverse artefact assemblage recovered during the excavation of three rooms in the basement of Queensberry House is discussed below. A selective catalogue of the most diagnostic artefacts is included, with separate catalogues for the finds and the pottery, as for the main site. All finds numbers are preceded by the abbreviation $\mathrm{QH}$, to distinguish them from the finds excavated from the main site. Much of the material is of 19th-century date, although some earlier material is also present. Measurements are generally expressed to the nearest $1 \mathrm{~mm}$; where appropriate, they have been expressed to the nearest $0.1 \mathrm{~mm}$.

\subsubsection{Pottery (fig. 1.42)}

\section{DEREK W HALL}

The excavations within the basement of Queensberry House produced 235 sherds of pottery. All these sherds have been examined by eye and where possible assigned a recognised fabric name.

\section{Scottish Post-Medieval Oxidised Redwares}

This fabric represents a late medieval version of the earlier medieval redwares discussed below, often referred to as 'Throsk-type' Ware in the literature, this fabric was almost certainly being manufactured at other, as yet unidentified, production centres between the 15th and 18th centuries (Caldwell \& Dean 1992). The 72 sherds from Queensberry House are from skillets, jugs, bowls, pirlie pigs and a crucible. The skillets were used as cooking vessels and are distinguished by their very distinctive folded handles, there are a minimum of 21 of these vessels in this assemblage.

\section{Scottish Post-Medieval Reduced Greywares}

This fabric can be regarded as a contemporary reduced version of the Redwares described above. It was first described and identified as such in the report on the excavations at Stirling Castle in 1980 (Haggarty 1980). The 17 vessels present in this assemblage are all green-glazed jugs.

\section{SCOTTISH ReDWARES}

This fabric has been long identified as a Scottish medieval east coast tradition that utilises the Carse River clays (Hall 1998). There are only four sherds present in this assemblage, all from glazed jugs.

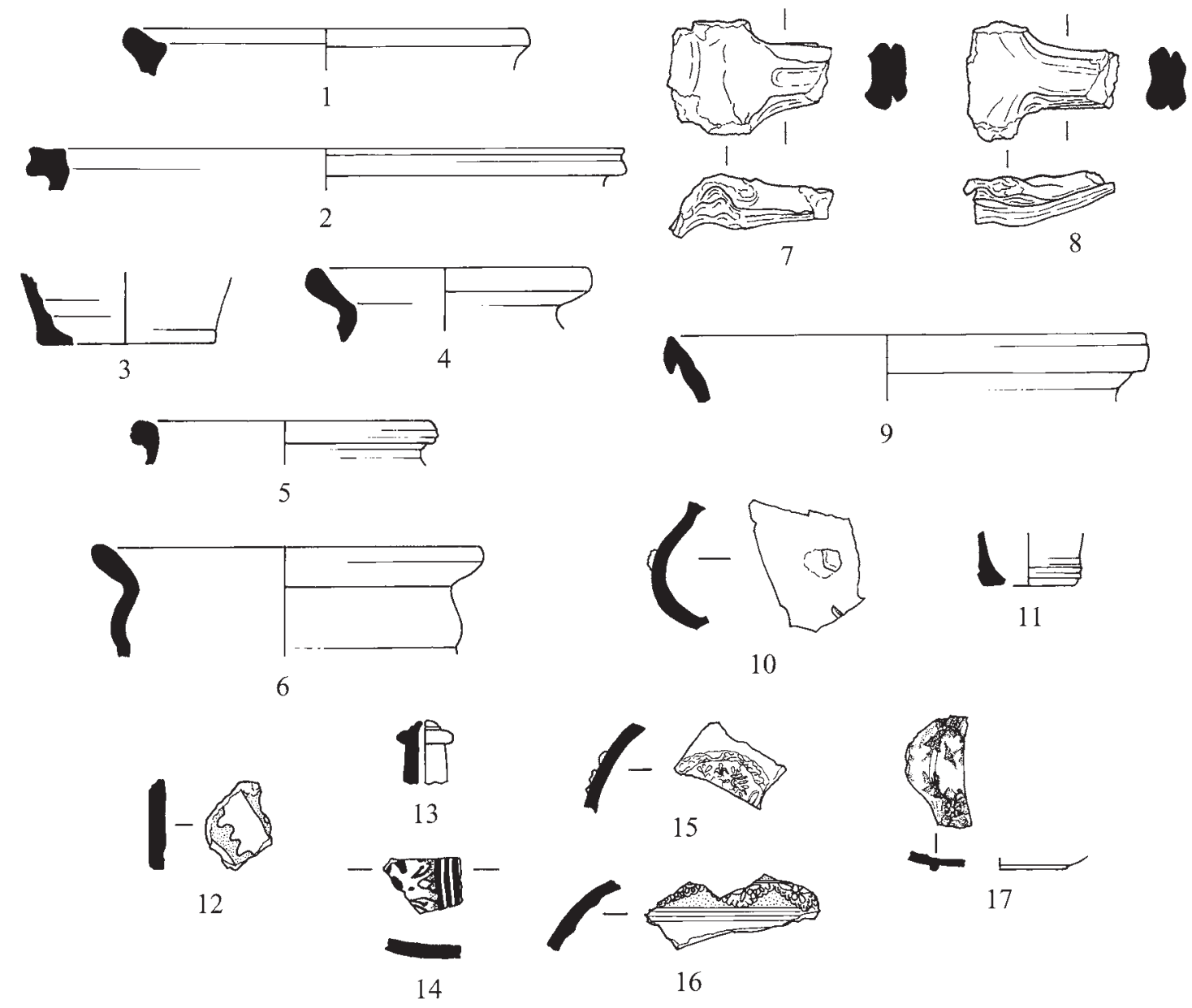

Fig. 1.42 Pottery (QH Pot nos 1-17) from Queensberry House (scale 1:1) 
Recent chemical sourcing and analysis of this fabric suggests that there may have been many kilns producing this pottery type across Scotland (Jones et al 2003). It has been found in Perth in association with 12th-century fabrics and appears to predate the Scottish East Coast Redware industry and may have ceased production by the 15th century (Hall 1996b, 127). It is most commonly highly fired to a white or grey colour and is quartz tempered. There are 51 sherds in the assemblage from Queensberry House, from 38 glazed jugs, ten jars probably used for cooking and two other vessel forms.

\section{RHENISH STONEWARES}

There are nine sherds from vessels in this highly fired fabric. They are from vessels manufactured in Siegburg, Frechen and Westerwald and date to the 16th or 17th centuries (Hurst et al 1986, 214-21, Gaimster 1997, 251-3).

\section{North European Earthenwares}

This fabric type, first named by W J Lindsay in 1983, is thought to originate from as yet unidentified production centres in northern Europe during the 16th and 17th centuries (Lindsay 1983, 567-72). It is most commonly represented by handled tripod pipkins and the single sherd from Queensberry House is part of a tubular spout from such a vessel (QH Pot no. 13).

\section{Tin-GLAZEd EARTHENWARES}

The largest group of this pottery comes from unphased Context 7111/5 and appears to represent vessels of 18thor 19th-century date. There are three sherds from Period 4.1 that appear to be from vessels in Netherlands Maiolica dating to the 16th and 17th centuries (Hurst et al 1986, 117-26). There is a single sherd that appears to be from an open bowl or dish in this fabric from Context 7064, with an external lead glaze and an internal tin glaze with traces of blue and white floral decoration (QH Pot no. 14). The other two sherds are from Context 7011. These include a slightly everted rim with internal blue line decoration on a white background and a bodysherd with internal blue and brown geometric decoration.

\section{Chinese Porcelain}

The four sherds of this fabric are from a saucer and a teacup dating to the 19th century and come from layers associated with the military occupation of Queensberry House.

\section{Brown-GLAZED EARTHENWARES}

There are six sherds in this fabric, which is of 18th- or 19thcentury date.

\section{SLIPWARES}

The three sherds of slipware are very similar to pieces from the main Holyrood excavation that are of uncertain provenance. This fabric is certainly of 17 th- or 18th-century date and is either a Low Countries product or a local copy.

\section{Scottish White Gritty Ware}

QH 1) Rimsherd from unglazed jar. Context 7010; Period 4.1.

QH 2) Rimsherd from unglazed jar. Context 7018; Period 4.1.

QH 3) Basal angle from unglazed vessel. Context 7010; Period 4.1.

$\mathrm{QH} 4)$ Rimsherd from vessel with internal green glaze and external smoke-blackening. Context 403; Period 4.1.

QH 5) Rimsherd from jug with small patch of green glaze. Context 463; Period 4.1.

Scottish Post-Medieval Oxidised Redware

QH 6) Rimsherd from skillet, internally glazed green and externally smoke-blackened. Context 1319; Period 5.2 .

QH 7) Folded skillet handle junction glazed green externally and internally. Context 435; Period 3.

QH 8) Folded skillet handle junction glazed green externally and internally. Context 7028; Period 4.1.

QH 9) Rimsherd from bowl glazed green-brown internally and externally. Context 7070; Period 4.1.

$\mathrm{QH}$ 10) Bodysherd from pirlie pig glazed green with traces of coin slot. Context 402; Period 4.1.

$\mathrm{QH}$ 11) Basal angle from drug jar glazed green-brown externally and green internally. Context 7009; Period 4.1 .

\section{SLIPWARE}

QH 12) Bodysherd from dish glazed brown and decorated with yellow-glazed white-slipped decoration. Context 463; Period 4.1.

\section{North European Earthenware}

QH 13) End of tubular spout from pipkin. Context 435; Period 3.

\section{Tin-glazed Earthenware}

$\mathrm{QH}$ 14) Bodysherd internally glazed with white, blue and brown pattern. Context 7064; Period 4.1.

\section{Rhenish Stoneware}

Frechen

$\mathrm{QH}$ 15) Bodysherd from jug glazed speckled brown with fragment of medallion. Context 7032; Period 4.1.

Westerwald

$\mathrm{QH}$ 16) Two joining bodysherds from vessel decorated with incised lines and triangles containing floral decoration. Vessel glazed with patches of cobalt blue on light grey background. Context 7044; Period 4.1. 
Chinese Porcelain

$\mathrm{QH}$ 17) Basesherds from plate or saucer with traces of blue glaze landscape on internal surface. Context 1305; Period 5.2.

\subsubsection{Iron objects}

\section{ADRIAN COX}

Demolition and make-up deposits underlying the wooden floor in Room E (the kitchen area) contained several iron objects. In addition to those described below is a group of nail fragments and other miscellaneous fragments of iron. Of particular interest among this assemblage are a group of five brackets (including QH nos 1 and 2), a long-handled shovel (QH no. 3) and fragments of a blade (QH no. 4). The brackets have tapering shafts for driving into walls. There is some variation among the five examples, particularly in the form of the flange at the broader ends of the objects, which in some cases is perpendicular to the shaft (eg QH no. 1) and in other cases of curving, elliptical form (eg QH no. 2). These fittings may have been used to secure internal fixtures such as water pipes. The flat-bottomed shovel (QH no. 3) may have functioned as a dust-pan or hearth-pan, into which ashes or other debris could be swept. QH no. 4 represents fragments of a large, single-edged blade.

$\mathrm{QH}$ no. 5, from the fill of a culvert, could be part of a fish hook or a buckle or brooch pin, as it incorporates an acute angle near one end. Unfortunately, both ends are missing, precluding closer identification. Among the nails recovered, $\mathrm{QH}$ no. 6 is the most complete example, and has an unusually broad head, possibly indicating that it had a decorative function in addition to its utilitarian one, for example in a door.

Catalogue of iron objects from Queenberry House

QH 1) Bracket. Length 98mm; width 23mm; depth $47 \mathrm{~mm}$.

Bracket in the form of a rectangular cross-sectioned bar, tapering steadily towards a point, with a curving, elliptical flange at the broader end. Context 7069; IADB 5501; Period 5.2.

QH 2) Bracket. Length $129 \mathrm{~mm}$; width $17 \mathrm{~mm}$; depth $71 \mathrm{~mm}$.

Bracket in the form of a rectangular cross-sectioned bar, tapering steady towards a point, with a tapering, perpendicular flange at the broader end.

Context 7069; IADB 5501; Period 5.2.

QH 3) Shovel. Length 298mm; max. width 193mm; max. depth $44 \mathrm{~mm}$.

Part of a shovel or scoop consisting of a broad pan with a flat base and approximately perpendicular sides, with a rectangular cross-sectioned handle, secured by two circular cross-sectioned rivets. Context 7069; IADB 5499; Period 5.2.

$\mathrm{QH} 4$ ) Blade. Length (total of surviving fragments) $265 \mathrm{~mm}$; max. width $49 \mathrm{~mm}$; thickness (disregarding corrosion products) $6 \mathrm{~mm}$.

Fragments, including two conjoining pieces, of a broad, single-edged blade. The blade back and edge are roughly parallel, both curving gently towards a rounded tip.

Context 7069; IADB 5594; Period 5.2.

\subsubsection{The industrial waste from the basement of Queensbery House}

\section{EFFIE PHOTOS-JONES}

\section{InTRODUCTION AND MethodOLOGY}

Materials described as slag/industrial waste originating from contexts 7007, 7105, 7016 and 7099 within Rooms H, I and E, at Queensberry House were examined. Those relevant to the discussion here were from two features within Room $\mathrm{E}$ (where a brick floor surface and a culvert represent the postmedieval Queensberry House kitchens): the culvert 7096 and the brick feature 7097 and their associated waste fills 7105 and 7099 respectively. Of the two, 7099 was the richer in terms of quantity and diversity of materials, and therefore, attention was focused on this particular deposit as a means of elucidating the role of feature 7097. The results of the scientific analysis of the above accumulations suggest that debris from both domestic as well as metal-working activity was collected within the drains and culverts.

Archaeological/historic industrial waste, whether of domestic or industrial origin, is difficult to characterise purely on visual grounds. Instead, characterisation relies heavily on a combination of optical microscope examination and chemical analysis with the scanning electron microscope with energy dispersive analyser (SEM-EDAX) and mineralogical analysis with X-Ray Diffraction (XRD). X-Ray Diffraction provides mineralogical identification of major and minor crystalline phases. The samples are ground to a fine powder and are radiated with a $\mathrm{CuK}$ source. However, for industrial waste, with its multitude of glassy, semi-crystalline and micro-crystalline phases, X-Ray Diffraction can at times provide only limited information.

Chemical analysis with the SEM-EDAX is based on both area (entire surface of the specimen) and spot (single phase) analysis to determine the composition of matrix and individual phases or inclusions respectively. Of particular relevance to the present discussion is the spot analysis of metallic inclusions within diverse materials like coal and vitrified fuel ash slag (VFA). For SEM-EDAX analysis, samples were mounted on metallographic resin, ground with a series of silicon carbide papers and polished with a $6 \mu \mathrm{m}$ and a $3 \mu \mathrm{m}$ diamond paste. They were subsequently carbon-coated for examination and analysis.

\section{AnAlytical Results}

The purpose of the present discussion is not only to identify and characterise the materials within the said waste accumulations, but also to provide information on the contexts from which they derive. Table 1.13 gives a list of the materials examined, their contexts and the results of the analyses either by SEM-EDAX or XRD. In general, the samples divide between those which were natural (fragments of iron pan, basaltic rock, coal, shell) and those which were man-made, either building materials or waste from metal-working oper- 
Table 1.13 Queensberry House: list of samples and results of SEM-EDAX and XRD analyses

\begin{tabular}{|c|c|c|}
\hline SASAA no. & SEM-EDAX results & $\mathrm{XRD}$ results \\
\hline $\begin{array}{l}\text { PS/QH67 } \\
7007 / \text { Room I }\end{array}$ & & $\begin{array}{l}\text { Fragments of heated natural ferruginous material consist- } \\
\text { ing of magnetite, hematite and quartz. }\end{array}$ \\
\hline $\begin{array}{l}\text { PS/QH65 } \\
7105 / 5551 \\
\text { Room E }\end{array}$ & $\begin{array}{l}\text { Fragments of basaltic rock including feldspars, olivines and } \\
\text { pyroxenes as well as iron-titantium oxides (ulvospinel and } \\
\text { ilmenite). }\end{array}$ & \\
\hline $\begin{array}{l}\text { PS/QH60 } \\
7016 / 5387 \\
\text { Room H }\end{array}$ & $\begin{array}{l}\text { Fragment of VFA heavily coated with coal powder with } \\
\text { nickel-iron-copper sulphide inclusions. }\end{array}$ & \\
\hline $\begin{array}{l}\text { PS/QH62 } \\
7099 / 5550 \\
\text { Room E }\end{array}$ & $\begin{array}{l}\text { PS62A: Fragments of natural ferruginous material, a platy } \\
\text { iron-pan type material, recovered in association with fine } \\
\text { fragments of basaltic rock. }\end{array}$ & $\begin{array}{l}\text { PS62B: forge hammer scale consisting of hematite, } \\
\text { magnetite as major constituents and fayalite, an iron silicate, } \\
\text { as a minor constituent. }\end{array}$ \\
\hline $\begin{array}{l}\text { PS/QH66.S1 } \\
7099 / 5550 \\
\text { Room E }\end{array}$ & & $\begin{array}{l}\text { Fragments of shell, consisting of calcite (major peak) and } \\
\text { quartz (minor). }\end{array}$ \\
\hline $\begin{array}{l}\text { PS/QH66.S2 } \\
7099 / 5550 \\
\text { Room E }\end{array}$ & Fragments of VFA & \\
\hline $\begin{array}{l}\text { PS/QH66.S3 } \\
7099 / 5550 \\
\text { Room E }\end{array}$ & Fragments of mortar, the binder in the brick feature 7097. & \\
\hline $\begin{array}{l}\text { PS/QH68 } \\
7099 / 5550 \\
\text { Room E }\end{array}$ & $\begin{array}{l}\text { Fragments of coal with small inclusions of a copper-tin } \\
\text { alloy reflecting bronze-melting practices }\end{array}$ & \\
\hline
\end{tabular}

ations. The results from other rooms within Queensberry House are included.

Naturally occurring magnetic materials, whether basaltic rock (PS/QH65: Room E, 7105/5551) or ferruginous materials (PS/QH67: Room I, 7007) were found in both Rooms $\mathrm{E}$ and I. Hammer scale was found in the accumulation of the brick feature 7097 (PS/QH62B, Room E 7099/5550). In the same feature were also found shell, natural ferruginous materials, fragments ofVFA, mortar and coal. One of the coal samples analysed contained metallic inclusions of a coppertin alloy, suggesting that some bronze melting was taking place on site. Within 7099 the predominant concentration of material was coal, with mortar from the construction of the forge (see below) and VFA coming second in approximately similar amounts. The paragraphs below concentrate on the discussion of two specific materials:VFA and fragments of a cupellation crucible.

PS/QH60, Room H, 7016/5387

This was a fragment of vitrified fuel ash slag, a glassy, porous and light density greenish-white material, heavily coated with charcoal powder. Analysis showed its composition to be a calcium-iron alumino-silicate with traces of phosphorus. The presence of small metallic inclusions suggests that this fragment derived from non-ferrous metal-working.

PS/QH64, Room H, 7015/5551

SEM-EDAX examination and analysis revealed a material the matrix of which was found to consist of bone ash with metallic inclusions which were found to be silver/silver sulphide. The matrix, which appears cracked, presumably the result of shrinkage during heating, is bone ash mixed with non-crystalline iron oxides. Small fragments of quartz, feldspar, bone, calcite, basaltic rock and coal were found scattered as inclusions within the matrix, some added intentionally.

It is suggested that PS/QH64 is a fragment from a bone ash crucible/cupel used in refining/assaying or simply melting of silver. Cupelation, or the separation of silver from base metals with the use of lead in highly absorbent bone ash cupels, is a technique which has been used since the medieval period. Since no lead or other base metals were detected within this fragment, it is suggested that pure silver may have simply been melted in this bone ash crucible.

The above analytical results offer limited yet tantalising evidence for non-ferrous/precious metals melting activities in Room E of Queensberry House in the post-medieval period, and even some forging. Indeed, in reference to brick feature 7097, we would suggest that it might have been the foundations of a rectangular all-purpose furnace. A metal grate on which a crucible would have rested would be placed on the base of a brick structure. This structure could have doubled as a forge and would have been operated with bellows. The material accumulating below the grate would consist of the type of waste encountered within accumulation 7099. The same materials may belatedly bear testimony to 'dodgy practices' which led to Lord Hatton's expulsion from the Mint whilst he was the Treasurer Depute of Scotland and owner of the house (HAPT, Chapter 10.4). Alternatively, the 'kitchen' may have been his bona fide workshop. 


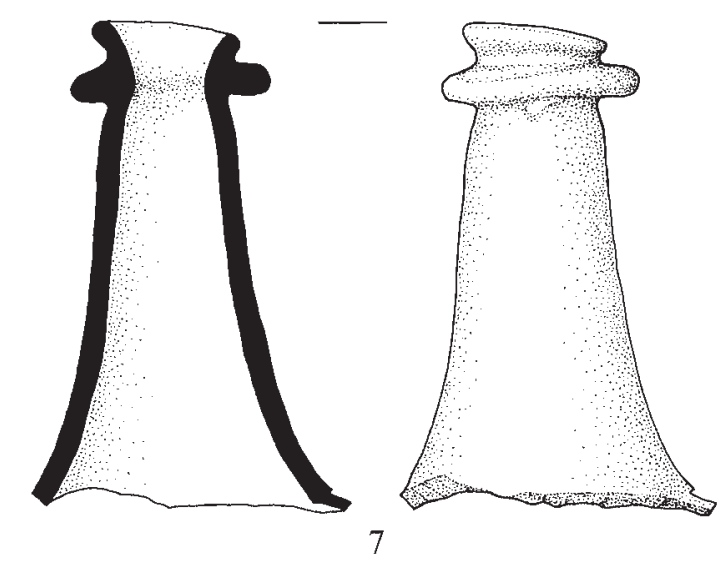

Fig. 1.43 Glass from Queensberry House (QH nos 7 \& 10) (scale 1:2)

\subsubsection{Glass}

\section{ADRIAN COX}

Thirty-two fragments of vessel glass and 19 of window glass were recovered, along with a single indeterminate fragment. Among the vessel glass assemblage is a variety of bottles, and a single fragment from a drinking glass. The window glass from Room H includes small fragments of possibly 16 th- to 17 thcentury date. The most diagnostic pieces are described below.

\section{VesSel gLAss}

Probably the earliest of the vessel glass fragments is $\mathrm{QH}$ no. 7 , a neck fragment from a wine bottle with a broad, disclike string rim, characteristic of the period c 1680-1700 (fig. 1.43). The top of the neck has a distinctive flare, resulting in a waisted appearance just above the string rim. This feature helped to secure the string-rim to the bottle neck and made pouring of the contents easier. This piece was recovered from the demolition deposits in Room E, which contain material of predominantly 19th-century date (including QH nos 912 , below), although 17 th-century clay pipe fragments were also present.

A bottle neck with a rounded lip and a deep string rim (QH no. 8) probably dates from the early years of the 19th century (c 1800-15), and includes a form of string rim characteristic of the period just before the widespread adoption of more mechanical, cone-shaped rims. By the 1820s, many glass houses had introduced a three-piece mould system of manufacturing bottles, achieving standardisation of capacity and quality.

QH no. 9 represents a cylindrical neck fragment from a slender bottle with an applied lip. Part of a cork stopper survives in the top of the neck. This bottle was probably used to contain sauce or another food ingredient. Also among the finds from Room $\mathrm{E}$ is the body of a mineral water bottle embossed with a legend indicating a connection with $\mathrm{Dr}$ Struve's mineral waters business (fig. 1.43). Dr Struve, who

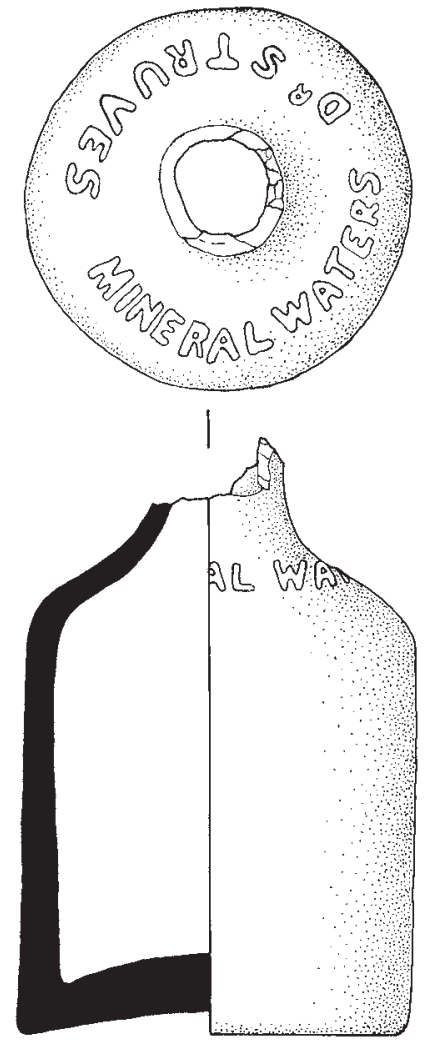

10

applied for a patent for his mineral water products in 1823 , developed manufacturing units in Europe for the production of carbonated water and artificial mineral water. Messrs Struve and Co. also manufactured mineral waters in Britain. The 'German spa' and pump room, established in 1825 by R F A Struve, still survives in Brighton, and provided competition for British-owned mineral water manufacturers. Bottles like QH no. 10 are typical of bottles used by companies like Messrs Struve and Co. and Schweppes during the 19th century and into the early 20 th for mineral waters, and are sometimes referred to as 'dumpy seltzers'.

QH no. 11 is from a moulded bottle of octagonal crosssection, also of 19th-century date. A great variety of products, including cure-alls, medicines, chemicals, perfumes and products used in cooking, were sold in small, straight-sided bottles such as this. Dating from around the mid 19th century, QH no. 12 represents the lower part of the stem and the foot of a wine glass of a heavy, relatively plain style.

\section{Catalogue of glass from Queensberry House}

QH 7) Bottle neck. Surviving depth 97mm; external diameter at rim $30 \mathrm{~mm}$; internal diameter at rim $22 \mathrm{~mm}$.

Neck of a blown bottle, in green glass, with a broad, discoid string rim set $6-8 \mathrm{~mm}$ below the neck top. The neck top itself has a distinct flare. The neck is moderately short and tapers smoothly, and is broken where it begins to widen towards the shoulder. Some surface deterioration is evident and deposits of mortar adhere to the object both internally and externally. (Fig. 1.43.)

Context 7069; IADB 5508; Period 5.2. 
QH 8) Bottle neck. Surviving depth 108mm; external diameter at rim $33 \mathrm{~mm}$; internal diameter at rim $22 \mathrm{~mm}$.

Neck and part of the shoulder of a blown bottle, in green glass, with a rounded lip and a deep string rim of equal diameter below it. Some surface deterioration is evident.

Context 10065; IADB 5448; Unstratified.

QH 9) Bottle neck. Surviving depth 66mm; external diameter at rim $23 \mathrm{~mm}$; internal diameter at rim $16 \mathrm{~mm}$.

Cylindrical neck with an applied lip, in almost clear glass with a green tint. The lowest surviving part of the neck has a ribbed surface. Part of a cork stopper survives in the top of the neck.

Context 7069; IADB 5508; Period 5.2.

QH 10) Bottle base. Surviving depth $106 \mathrm{~mm}$; diameter at base $76 \mathrm{~mm}$.

Base and a small part of the neck of a moulded bottle with a circular cross-sectioned body and a flat base. The body narrows sharply at the shoulder, which is embossed with the legend 'DR STRUVES MINERAL WATERS'. The bottle is broken at the junction of neck and shoulder. (Fig. 1.43.)

Context 7069; IADB 5507; Period 5.2.

QH 11) Bottle base. Surviving depth 83mm; max. width $59 \mathrm{~mm}$.

Base from an eight-sided, moulded bottle, in almost clear glass with a greenish tint. The surviving part of the body is straight-sided.

Context 7069; IADB 5508; Period 5.2.

$\mathrm{QH}$ 12) Wine glass stem. Surviving depth $41 \mathrm{~mm}$; diameter of base $c 57 \mathrm{~mm}$.

Fragment representing the lower part of the stem, and part of the foot, of a wine glass in clear, transparent glass. The incomplete foot is of shallow conical form, and the surviving part of the stem incorporates a flange.

Context 7069; IADB 5508; Period 5.2.

\section{WINDOW GLASS}

The recovered window glass fragments are mainly very small. A few fragments appear to be from small, diamondshaped or 'quarry'-shaped pieces, which characterise domestic glazing in the 16 th and 17 th centuries. Triangular pieces of glass, fragments of which are also represented here, were used at the edges of window frames. A lattice of lead alloy cames was used to join pieces of glass together within a window, and four pieces of glass exhibit the characteristic staining and differential weathering, along their edges, that results from insertion into cames. One of these pieces came from Context 7030, in Room $\mathrm{H}$; the remaining three were unstratified.

A fragment from Context 7010, also in Room H, exhibits grozed edges. Panes were cut to size by scoring the surface and then breaking the glass, the broken edges sometimes being finished by paring with grozing tongs, producing a series of tiny conchoidal fractures. In addition to these possibly 16th- or 17th-century pieces, a number of fragments of more recent window glass were recovered, mainly from unstratified contexts.

\subsubsection{Leather}

\section{ADRIAN COX}

An assemblage of leather from shoes was recovered from the demolition deposits below the wooden floor in Room $\mathrm{E}$ (the kitchen). The assemblage includes two near-complete soles, penetrated by small iron tacks, and several fragments of similar soles. There are also several pieces of uppers, some including rows of circular, copper-alloy eyelets for lacing. These are clearly parts of boots, and are very probably associated with activities during the period when Queensberry House functioned as a House of Refuge (1834-1949). Along with numerous small scraps, there are offcuts, and at least some of the assemblage appears to represent the repairing of boots. As suggested by Dawson (Part 1.14.8), this may have been among the tasks performed by inmates of the House.

\subsubsection{Stone and ceramic building material}

\section{ADRIAN COX}

A fragment of sandstone moulding was recovered from an unstratified context. This may have come from decorative edging, for example around a doorway or a window. Part of a large, rectangular slate, presumably a roof slate, was recovered from a rubble spread in Room I (Context 7070).

Ten fragments of pantiles were recovered from a range of contexts in Rooms E and I. No concentrations of this material are evident. These tiles are $15-16 \mathrm{~mm}$ thick, generally sanded on their convex surfaces, and have a streaky, red to orange fabric with occasional voids. Most contain few inclusions, but a single fragment from Context 7009 in Room I contains numerous inclusions. Pantiles were also excavated from the area around Haddington House and near the modern Canongate frontage.

Two fragments from hand-made floor tiles $(\mathrm{QH}$ nos 13 and 14 , fig. 1.44) were also recovered. These may be of 17 thor 18th-century date. Both came from Room I, and are of a similar fabric and form, although QH no. 14 is from a thicker and slightly narrower tile than that represented by QH no. 13. The latter fragment bears traces of burning or sooting along one edge.

A single, complete brick (QH no. 15) was retained for examination. This example came from a remnant of a brick floor in Period 4.2, and it appears that the bricks were reused from an earlier surface. This brick was handmade, and probably pallet-moulded. This technique involves the use of a stock board, nailed to the moulder's bench, and onto this is set the mould in which the clay is shaped. The mould itself was generally dusted with sand, and sand was also used when forming a quantity of clay into a clot or warp, which was thrown hard into the mould in order to completely fill it. The use of sand in pallet-moulding produces sand-faced bricks, as in $\mathrm{QH}$ no. 15. The unsanded upper surface of this example exhibits smoothing marks. The size of this brick closely matches the dimensions stipulated in a charter of $1571(9 \times$ $4 \frac{1}{2} \times 2^{1 / 4}$ in). Given the manufacturing technique, size and context of this brick, it is likely to date from the later part of the 17 th century. 


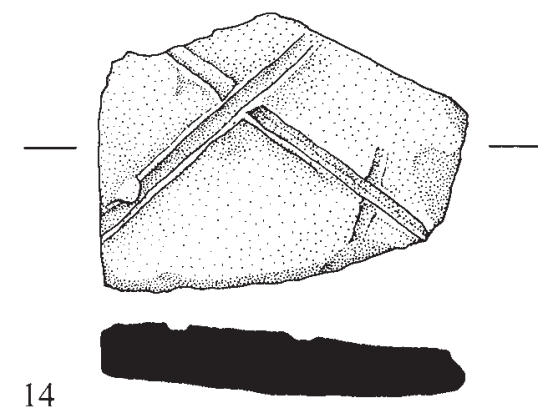

Fig. 1.44 Tile from Queensberry House (scale 1:2)

QH 13) Tile. Max. surviving length $83 \mathrm{~mm}$; width $64 \mathrm{~mm}$; thickness $28 \mathrm{~mm}$.

Part of a square or rectangular tile in a coarse, slightly micaceous, red to orange fabric with frequent rounded and angular inclusions. The lower face of the tile is sanded and uneven. The upper face bears finger impressions. Parts of two edges also survive, and one of these bears traces of burning or sooting. One broken edge has a fragment of corroded iron adhering to it.

Context 7051; IADB 5482; Period 4.1.

QH 14) Tile. Max. surviving length $78 \mathrm{~mm}$; width $80 \mathrm{~mm}$; thickness $31 \mathrm{~mm}$.

Part of a square or rectangular tile in a coarse, slightly micaceous, red to orange fabric (grey internally, where reduced) with frequent rounded and angular inclusions. The lower face of the tile is sanded. The upper face bears finger impressions. Parts of two edges also survive. (Fig. 1.44.)

Context 7028; IADB 5433; Period 4.1.

$\mathrm{QH}$ 15) Brick. Length 230mm; width $112 \mathrm{~mm}$; thickness $64 \mathrm{~mm}$.

Complete brick in a hard, red to orange fabric with a variety of fine inclusions and occasional voids. All but one of the faces are sanded.

Context 7079; IADB 5620; Period 4.2.

\subsubsection{Clay tobacco pipes}

\section{DENNIS GALLAGHER}

This report considers 180 pipe fragments excavated from 24 different contexts.

This assemblage consists predominantly of Edinburgh pipes dating from 1630 to 1660 . Within this date bracket there are two distinct groups of Scottish pipes. One consists of those with biconical forms which may be dated to $c$ 1630-50. Most are unmarked, but it includes one of the earliest recorded basal stamps from this pipemaking centre, a castle-type stamp. Variations on this design of basal stamp continued to be used by almost all Edinburgh pipe-makers throughout the 17th and early 18th centuries. Another, larger, bowl bears a poor impression of what appears to be the same stamp. Unlike later Edinburgh pipes, the pipes in this group have no initials on the side of the base identifying the maker. It is very possible that the majority are products of William Banks, who held a monopoly on Scottish pipemaking (Gallagher 1987b, 6).

The other group of Scottish pipes has a taller, more barrelshaped form. It includes late pipes of William Banks, who died in 1659, and one pipe of William Young, who is first recorded as a maker in 1653 and died in 1670.

Two Dutch-style bowls have been identified, both cheap export forms that are variations on Duco type 1 (Duco 1987, 26). One bowl is decorated with a debased form of the moulded rose, a form that has been excavated on a widespread number of Scottish sites (Davey 1992, 280). The other is a slightly later form, datable to c 1640-60.

A burnished stem fragment from Context 7051 has a secondary mouthpiece formed after a break by whittling the broken end.

The assemblage produced very few pipes of 19thcentury date or later. One stem is a product of Thomas White \& Co, who was the major manufacturer in Edinburgh, with a factory in the Canongate from 1827 to 1867 (Gallagher 1987d, 26). The spurred TW pipe is an example of a style produced by all the major Scottish pipe-makers. Although the TW on the pipe originally may have identified a maker, it soon became identified with a particular form of spurred pipe that was very popular among Scottish smokers.

\subsubsection{House of Refuge finds}

\section{JO DAWSON}

\section{INTRODUCTION}

Queensberry House was a House of Refuge from 1834 until 1949 (Hume \& Boyd 1984). During excavations carried out in the basement of Queensberry House in April 2001, a quantity of finds relating to the House of Refuge period was recovered. The vast majority of these finds came from the kitchen (Room E) in rubble (7069) between the most recent floor and the flagged floor below it. The kitchen had a sunken floor and the raising of the floor brought it level with the other rooms in the basement of Queensberry House. The assemblage of finds from Context 7069 (Period 5) will be discussed here.

The House of Refuge, which was a charity, operated alongside the Poorhouses of Edinburgh, which were run by the parish councils or parochial boards. It often provided accommodation for the able-bodied poor, who were not entitled to relief under the Poor Law (ibid, 28-9). Police sent people who had been caught begging to the House as a more effective alternative to putting them in the cells.

The House had a small number of staff, and the women inmates did all the housework (ibid, 11). All men who had a trade were provided with materials to enable them to work in the House (ibid). Girls were provided with positions in households and boys were apprenticed where possible (ibid, 19). On entering the House, cheap, clean clothes were given to the new inmates, in exchange for their own, which were mended where possible and returned to them when they left (ibid, 11). There was no uniform, but the routine was strict, with bells dividing the day into different tasks, and religious education featuring prominently (ibid, 18, 26). Food was simple and monoto- 
nous - porridge with weak beer morning and evening, with broth or soup for dinner.

\section{Methods AND BIASES}

Excavation conditions biased the finds recovery in favour of larger objects, and ones of a contrasting colour to the rubble, which was grey-black. Since larger objects break into larger pieces, utility ware is highly represented in terms of numbers of sherds, in comparison to teacups. There are also biases in the objects which end up being broken and therefore in the assemblage. For example, teacups are more likely to break than saucers, given the greater amount of handling they receive and hot and cold liquids causing thermal shock to the fabric (Miller 1991).

\section{THE POTTERY}

Many of the types and numbers of finds are typical of an average domestic assemblage of the time. The patterns present are very common - Willow, Broseley and Fibre were manufactured by most of the major Scottish potteries (Kelly 1999). Verona was the stock pattern for the Links Pottery, Kirkcaldy, similarly Bosphorus was Bo'ness Pottery's stock pattern (ibid, 23, 142). As expected, numbers of teacups are higher than numbers of saucers. Breakfast ware is highest represented, followed by dinnerware, utility ware and finally bedroom ware, in terms of minimum number of individuals. The high number of spongeware porringers indicates the low economic level of the site. The number of teapots represented is unusually high, being more than one for every teacup, and no explanation of this can be offered at present. Plain white earthenware vessels are not as highly represented as might have been expected.

The pottery was glued together where conjoining sherds were identified once it had been washed and dried. It was very noticeable that many half and complete vessels were present, although smaller sherds had often not been recovered due to the factors mentioned above. The dating of the transfer patterns (Willow where marked, Bosphorus and Verona), the clay pipe stems (Thomas White \& Co., Edinburgh), the presence of the spongeware and the Struves Mineral Waters bottle provide a date range of between 1847 and 1859. None of the finds fall obviously outwith this date range. This dates the finds to well within the early period of the House of Refuge. Crockery, however, is not mentioned in any of the abstracts of accounts which appear in the surviving annual reports of the House of Refuge (House of Refuge 1835, 10; 1841, I 30-31, II 19-21). It may well be that most or all of the crockery was acquired by donations from members of the public and was second-hand. This would push the dating of the use of crockery in the House of Refuge to a slightly later period, possibly the 1860 s.

The context in which the finds were discovered must not be ignored. It is clear that this only accounts for a small amount of refuse produced by the House of Refuge, and there must have been a midden in the grounds where the majority of the rubbish was deposited. An alternative is that it was included in the fulzie (dung and street sweepings) sold by the House (ibid). It is not clear whether residents were collecting the fulzie from the streets of Edinburgh and then selling it, or whether it consisted of refuse from the House itself. In any case, the finds present are not likely to be representative of the full range of refuse produced by the House, and this makes their interpretation less straightforward than if they had come from the place where refuse was normally dumped.

\section{SOCIAL CONTEXT}

In comparison to poorhouses and other institutions of the time, this crockery stands out as being very different. Craiglockhart Poorhouse used crockery marked Edinburgh City Poorhouse for a number of years from its establishment in 1870 (Dawson 2000, 71-5). At the Royal Edinburgh Asylum (REA) during the same period as the House of Refuge finds (1840s-60s), rich patients used blue transfer ware such as Willow and Broseley, whereas paupers were given white crockery. Initially this crockery had 'REA 3rd MG' on it and later only 'REA' and a slightly larger selection of vessels which included shallow soup plates (Dawson 1999, 18; Dawson forthcoming). At the House of Refuge there is no sign of purpose-made, institutional crockery. This may be partly due to economy. There was no uniform for the inmates and old clothes were sometimes donated by members of the public (Hume \& Boyd 1984, 16), whereas in Craiglockhart Poorhouse there was a strict uniform. However, the lack of institutional crockery surely relates to the attitude of not stigmatising the inmates:

Whatever may have been the crimes or punishment of the inmates before their admission, no one was allowed to revive these 'either by opprobrious names or remarks'. (Hume \& Boyd 1984, 14)

The House of Refuge achieved its aims best if it rehabilitated the inmates and enabled them to find work outside. The use of crockery typical to average domestic dwellings of the time, including a larger range of vessel types than in the poorest dwellings, surely aided this.

\section{DiET}

The evidence for the diet at the House of Refuge is scarce. In the abstracts of accounts from the three surviving annual reports, foodstuffs purchased throughout the year are listed: bread, oatmeal, barley, pease (sic), butcher meat, milk, small beer (weak beer), potatoes, vegetables and salt (House of Refuge 1835, 10; 1841, I: 30-31, II 19-21). There was no significant change in the foodstuffs being purchased in the three years recorded. As stated above, elsewhere it is claimed that the food was simple and monotonous - porridge with weak beer morning and evening, with broth or soup for dinner. This must have been in strange contrast to the range of crockery in use, which would be expected to reflect a far more varied diet. As noted above, a disproportionately large number of teapots was recovered. Tea is not mentioned in the basic diet or indeed in the foodstuffs purchased, but it is quoted as one of the payments in kind or 'little indulgences' given to the residents in exchange for work done, along with sugar (Hume \& Boyd 1984, 11).

\section{LEATHER-WORKING}

The utility wear recovered comes in two body shapes. Shape A is similar to a milk-skimming dish but is deeper and not as 
wide - a general, flat-bottomed basin. Shape B is cauldronshaped with unusually low handles below its mid point. It is possible, given the presence of a significant quantity of shoerepair debris, that these vessels were used for soaking leather.

The pieces of leather recovered, as noted previously, would seem to be shoe-repair debris. Both sole and upper fragments are represented, but almost exclusively they are single pieces of leather, as though worn parts of shoes have been removed and discarded before being replaced. This would have been carried out by a male inmate of the House of Refuge. Men who had a trade were supplied with materials at the cost of the House of Refuge so that they could work while they stayed there (ibid). A small profit was normally made from the sale of the goods manufactured in the House (House of Refuge 1835, 10; 1841, I 30-31, II 19-21).

\section{GLASS BOtTLES}

Some glass bottle sherds were recovered, including sherds from at least two wine bottles. The base of a wine glass was also found. There is one bottle neck which probably was part of a sauce bottle, and one almost complete bottle of Dr Struves Mineral Waters. Due to the large number of alcoholics residing in the House of Refuge, 'spirituous liquors, porter, ale or strong drinks' were not allowed (Hume \& Boyd $1984,19)$. Whether wine was permitted is not clear, but the presence of the bottles and glass merely adds to the somewhat conflicting evidence of the documentary sources and the archaeological evidence. 

PART 2

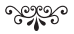

\section{The environmental remains}

The environmental evidence comprised carbonised plant remains, animal and fish bone, and soils and sediments. The data were collected during the initial evaluation, various set-piece excavations and watching briefs. During the main excavation, data collected by hand were supplemented by an intensive programme of soil sieving. In particular, the extensive spreads of 'garden soil' were targeted and the results of this work can be found in Part 2.5. The reports on the carbonised plant remains (Part 2.2) and the faunal remains (Part 2.3) deal with the assemblages from the main excavation and Queensberry House separately, but each considers the results in a final discussion. 



\subsection{SUMMARY OF RESULTS}

\section{STEPHEN CARTER}

Analysis of the soils and sediments focused on the relationship between the natural topography of the site and how this has influenced settlement patterns, the soil processes which have shaped this part of the Canongate to the present day and how these processes have enabled us to interpret the history of past settlement here.

The strange angle at which Queensberry House sits in relationship to the Canongate street frontage, for example, is due to the odd angle of the underlying slope, which runs from north-west to south-east across the site. This frontage area has also been significantly terraced over the centuries, to such an extent that no archaeological levels survive here. In fact, the topography of the whole area has been subject to much alteration, particularly of the natural drainage channels, which have been diverted to create areas suitable for settlement (HAPT 2008, Fig. 2.1). These channels are thought to have taken water down past the tail-end of the plots that extended both north and south from the Canongate street frontage to what are now Calton Road and Holyrood Road respectively. The process of draining this area was almost certainly undertaken by the abbey in order to improve what must have been marginal land. Elsewhere on the site, the level terrace that forms the central area of the site was clearly an attractive place to establish the formal gardens that occupied this area in the post-medieval period.

The analyses of the soils and sediments and the carbonised plant remains both confirm that coal was the dominant source of fuel from very early on. This also supports the evidence from the study of the metal-working debris. Only in the very earliest period (Period 1) was coal absent. This coincides with the use of wood as both fuel and constructional material, and perhaps also with the use of turf. The disappearance of coal from the archaeological record in the 17 th century neatly marked the end of the use of these properties for light industrial use and the establishment of formal gardens, as individual plots were bought up and larger properties created, a process which started with Dame Balmakellie. This radical change in use is also reflected in the carbonised plant assemblage. Here, grain was concentrated in the early levels only. Much of this grain is thought to have come in from East Lothian and the barley in particular is thought to have been used in brewing, an industry which became synonymous with this area from the late 18 th century onwards.

Coal ash, thought to have derived from domestic and light industrial middens subsequently dumped across the site, was the single largest component in accumulation of soils on the site. Analysis of these soils and their deposition confirms the archaeological findings that the western half of the site has a very different history from the eastern. This may relate to the eastern half being part of, or at least associated with, the abbey until quite late in the medieval period. Even if this area was laid out as properties from which rent was derived as income for the abbey, it would seem that they were not used for light industrial or craft-working as the western plots were.

The influence of the abbey may also be seen in the faunal remains recovered from the site. The dominance of sheep/ goat over cattle in the assemblage is a pattern that has been identified in the Borders and is unlike most other east coast burghs where cattle are the dominant component. In the Borders, the dominance of sheep/goat is thought to have been due to the large flocks of sheep maintained on the vast estates of the four great abbeys, Melrose, Dryburgh, Kelso and Jedburgh. Wool and woolfells (whole skins) were the staple goods of the Scottish economy in the medieval period and were exported through the many ports on the east coast of Scotland (most notably Berwick-upon-Tweed) to the great Flemish cities of Bruges and Ghent. The meat itself would have been a lesser by-product.

The diet did not only consist of beef, mutton and lamb however, for pork, rabbit, hare, poultry, partridge, red grouse, cormorant, fish and shellfish were also on the menu. There appears to have been consistent consumption of mainly white fish (cod, haddock, whiting), herring and mackerel, with some freshwater fish (salmon or trout) and shellfish. The last were significant from the earliest times, particularly oysters, for which the Firth of Forth was famous until they were over-exploited in the 18th century.

In terms of craft-working, there appears to have been a tradition of leather workers in this part of the Canongate. A number of the animal bones recovered from the site showed knife cuts consistent with skinning but, interestingly, these were foxes, dogs, cats and horses, which perhaps suggests that they were not processed in a commercial tannery.

\subsection{CARBONISED PLANT REMAINS}

\section{TIM HOLDEN AND MHAIRI HASTIE}

\subsubsection{Methodology}

During the course of the excavations 363 standard samples, ranging in size from 10 to 30 litres, were taken for flotation and wet sieving. Most well-stratified deposits were sampled with the purpose of recovering material that might help to identify the nature of activities being undertaken in the backlands of the Canongate and how any such activities were distributed across the site. The samples were processed through a system of flotation and wet sieving in a Siraf-style flotation tank. The floating debris was collected in a $250 \mu \mathrm{m}$ sieve and, once dry, scanned using a binocular microscope. Any material remaining in the flotation tank was wet sieved through a $1 \mathrm{~mm}$ mesh and air-dried. This was then sorted by eye and any material of archaeological significance removed for identification.

Identifications were made with reference to the collection of Headland Archaeology Ltd and standard seed atlases. This account draws out some of the main observations of the analysis. The complete dataset forms part of the site archive report. A summary of the results is provided in tables 2.1 and 2.2.

\subsubsection{Main excavation site}

Preservation of most organic remains on site was by charring, although two samples $(1657,1730)$ contained waterlogged remains and occasional fragments of uncharred wood. Compared with most urban archaeological sites, an unusually small percentage of samples contained charcoal, which 
Table 2.1 Summary of carbonised plant remains by period

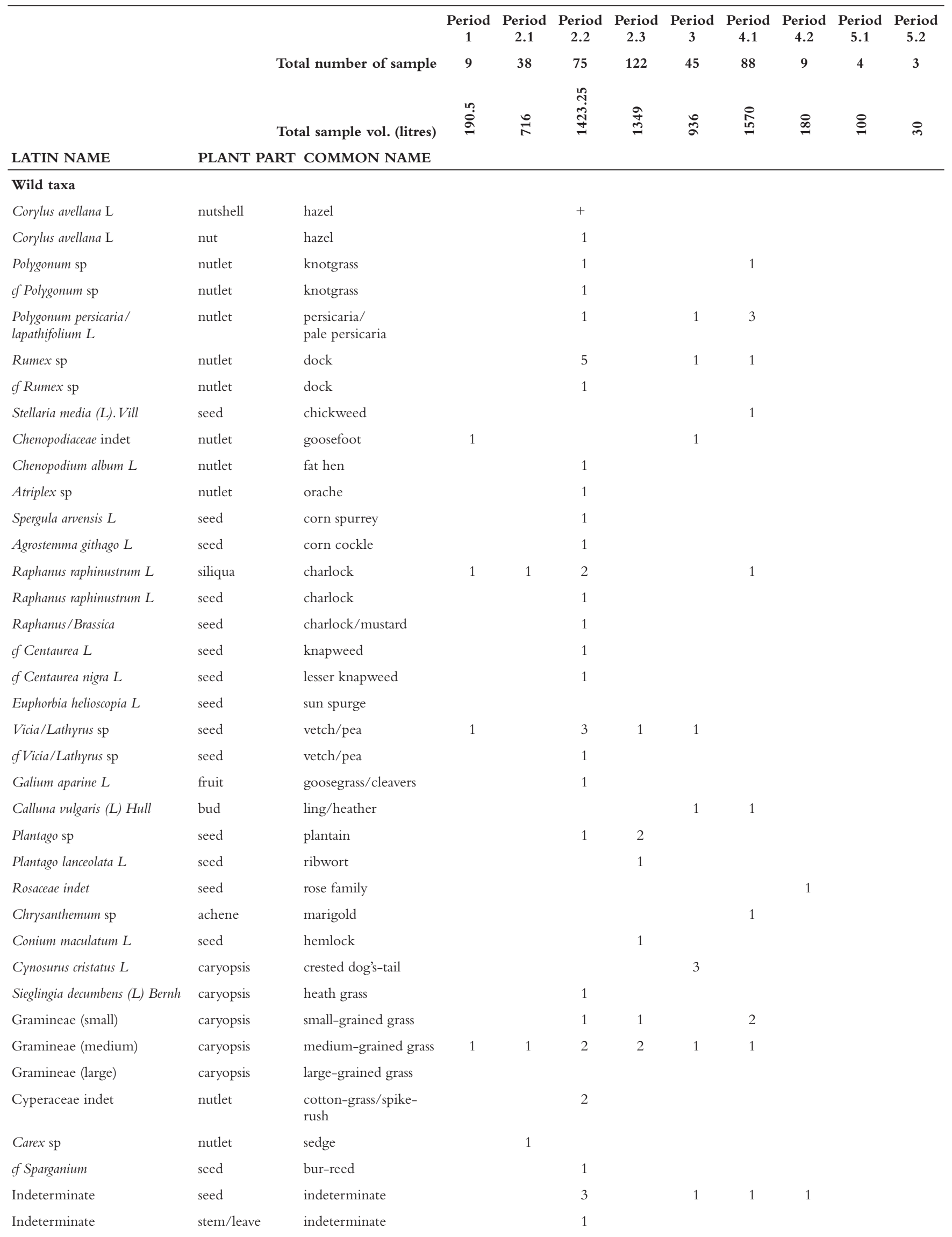


Table 2.1 (cont.) Summary of carbonised plant remains by period

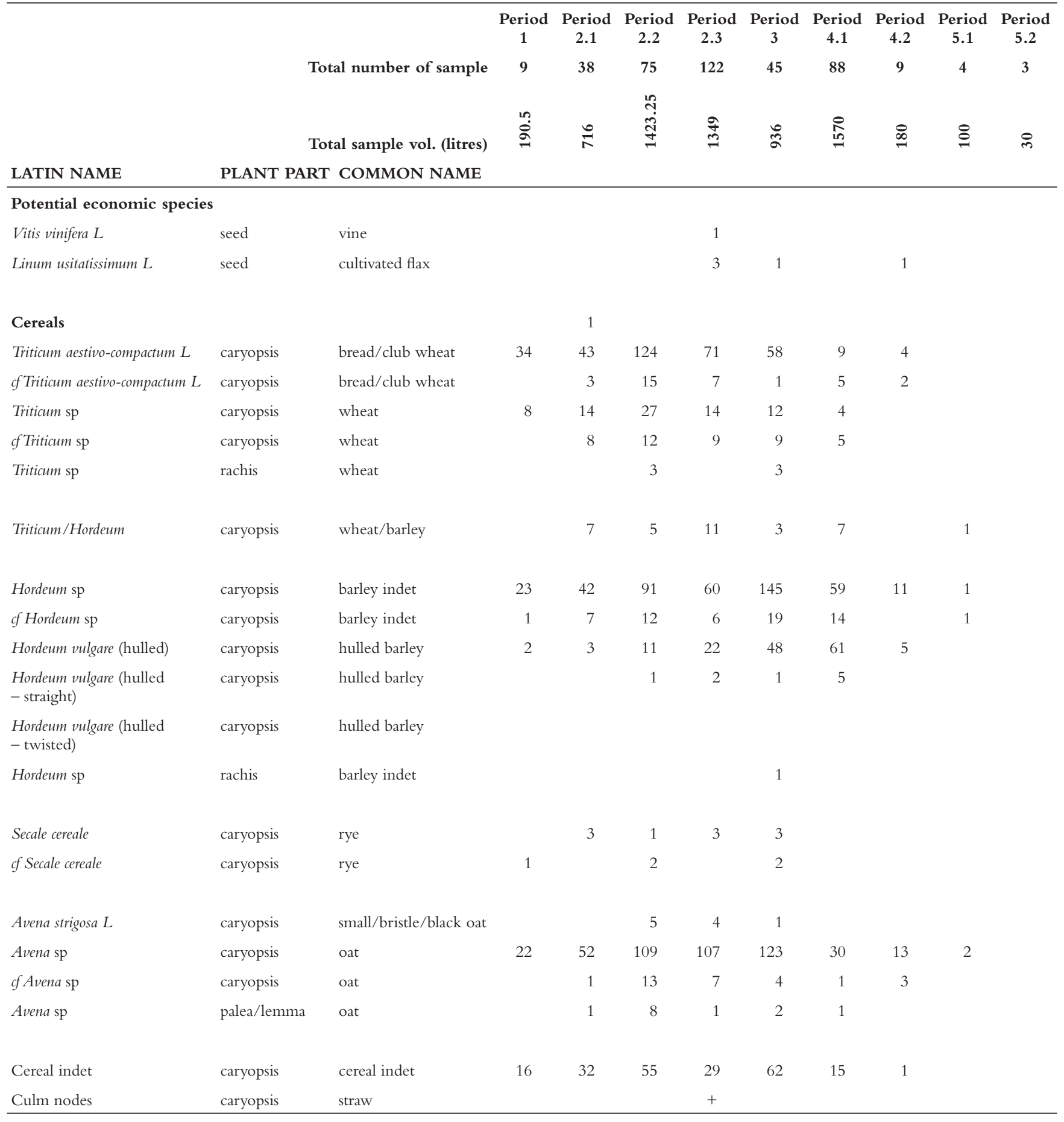

Rare + , Occasional ++ , Common +++ , Abundant ++++

seemed to indicate that coal was the main fuel throughout occupation. The most common charcoal component in each period was oak (Quercus sp) but smaller amounts of alder (Alnus sp), birch (Betula sp), hazel (Corylus avellana), heather (Ericaceae indet), pine (Pinus sp), blackthorn (Pinus spinosa) and willow (Salix sp) were also present.

In contrast to the charcoal, many samples contained occasional cereal grains and weed seeds but few large concentrations were encountered. Most grain-bearing samples contained barley (Hordeum vulgare) and wheat (Triticum aestivo-compactum) in approximately equal proportions, fre- quently with similar concentrations of oat (Avena sp). Rye (Secale cereale) grains were occasionally present. Virtually all of the cereal identifications were made on the grain, as chaff was extremely rare. A concentration of barley and oat chaff dominated by culm fragments was recovered from one Period 3 context (Context 1511, Phase 5) and a small number of flax (Linum usitatissimum) and grape seeds (Vitis vinifera) seeds were recovered from Period 2 (Phase 4). The 'weed seeds' comprised common weeds of cultivation and waste places and, in view of the low concentrations, offered little scope for detailed analysis. 
Table 2.2 Waterlogged plant remains

\begin{tabular}{|c|c|c|c|c|c|c|}
\hline \multirow[b]{4}{*}{ Latin name } & \multirow[b]{4}{*}{ Plant part } & \multirow{3}{*}{$\begin{array}{l}\text { Context number } \\
\text { Sample number }\end{array}$} & \multicolumn{2}{|l|}{ ME } & \multicolumn{2}{|l|}{$\mathrm{QH}$} \\
\hline & & & 1657 & 1730 & 7007 & 7105 \\
\hline & & & 3361 & 4425 & 5383 & 5551 \\
\hline & & Common name & & & & \\
\hline \multicolumn{7}{|l|}{ Wild taxa } \\
\hline Urtica dioica $L$ & seed & stinging nettle & + & ++ & & \\
\hline Polygonum persicaria/lapathifolium & nutlet & persicaria/pale persicaria & + & + & & \\
\hline Polygonum sp & nutlet & knotgrass & + & & & \\
\hline Rumex sp & nutlet & dock & ++ & ++ & & \\
\hline Chenopodium sp & nutlet & fat hen family & ++ & + & & \\
\hline Atriplex sp & nutlet & orache & + & + & & \\
\hline Stellaria media $(L)$ Vill & seed & chickweed & + & + & & \\
\hline Ranunculus sp & achene & buttercup & + & + & & \\
\hline Euphorbia helioscopia $L$ & seed & sun spurge & + & + & & \\
\hline Conium maculatum $L$ & seed & hemlock & ++++ & & & \\
\hline Lamium purpureum $L$ & seed & red-dead nettle & ++++ & + & & \\
\hline Stachys sp & seed & woundwort & & & & \\
\hline Sambucus nigra $L$ & seed & elder & + & + & & \\
\hline Cirsium sp & achene & thistle & + & & & \\
\hline Carex sp & nutlet & sedge & & & & \\
\hline Degraded wood fragments & & & & & + & + \\
\hline \multicolumn{7}{|l|}{ Potential economic species } \\
\hline Corylus avellana $L$ & nutshell & hazel & + & + & & \\
\hline Ficus carica $L$ & seed & fig & ++ & & & \\
\hline Papaver somniferum $L$ & seed & opium poppy & + & & & \\
\hline Rubus of idaeus/fruticosus & seed & raspberry/blackberry & + & & & \\
\hline Rubus sp & seed & raspberry/blackberry & & & + & + \\
\hline Fragaria sp & seed & strawberry & + & & + & \\
\hline Pyrus/Malus sp & seed & pear/apple & & & & + \\
\hline Vitis vinifera $L$ & seed & grape & & & & + \\
\hline Carbonised cereal grains & & & + & & & \\
\hline
\end{tabular}

ME: main excavation; QH: Queensberry House

Rare + , Occasional ++ , Common +++ , Abundant ++++

The base of a tree stump of rowan (Sorbus aucuparia) was identified from Context 803 (Period 3). The only waterlogged deposits from the main excavation were from a well (Context 1727, Period 2) and a wood-lined late medieval pit (Context 1664, Period 3). The preservation was better than elsewhere but still restricted to degraded wood fragments and other more robust plant parts (table 2.2). The pit contained a small number of wild taxa and was of only limited interpretative value. From the well, however, it was possible to identify hazel shell (Corylus avellana) and the remains of a number of edible fruits such as pear/apple (Pyrus/Mallus), blackberry/raspberry (Rubus sp) and strawberry (Fragaria sp). These would all have been locally available and probably formed seasonal additions to the diet. Other species such as fig (Ficus carica) and grape must have been imported as dried fruits. A seed of the poppy (Papaver somniferum) was also encountered and is likely to represent the remains of a spice used in food preparation. The above taxa are all common on medieval sites and are frequently associated with faecal material. Also present were considerable numbers of seeds of plants that rapidly colonise damp, waste ground (eg hemlock - Conium maculatum). This would be consistent with the well having been open and somewhat overgrown at some point and, together with the food species, seems to indicate that this was a deposit associated with abandonment of the feature.

\subsubsection{Queensberry House}

Five samples were taken during excavations within Queensberry House basement, from two brick features within the kitchen and a number of culvert fills. The charred assem- 
blage was extremely small, with only two cereals of oat and wheat (Avena sp and cf Tritcum sp) recovered from Context 485. Charcoal was sparse and only present in one culvert fill (Context 7016). Two other culvert fills (Contexts 7007, 7105) were notable for the presence of a small quantity of waterlogged plant remains (table 2.2). The assemblages consisted mainly of fruit seeds/pips, with no evidence for soft tissue or cereal bran. The taxa recovered are likely to represent food remains, including locally grown species such as apple/pear, and more exotic fruits such as grape.The origin of the remains is unclear, but their presence within the culvert suggests that they represent either kitchen waste or the remains of human faecal material.

\subsubsection{Discussion}

The plant remains were characterised by an extremely low diversity, rarely comprising more than five taxa per sample. Barley, oats and wheat occurred in most samples. Other economic species, flax, grape, apple/pear, were only rarely present.

The concentration of identifiable components in most samples was so low that there would be little value in discussing any detailed aspects of context-related variation. However, a number of broad trends could be identified:

1. The concentration of wood charcoal across all phases of the site was extremely low as opposed to the high concentrations of coal. The most obvious explanation for this has to be that coal was the main source of fuel on the site from the earliest medieval period.

2. Charcoal was concentrated in the earliest phase (Period 1) and perhaps indicated a greater prevalence of wood as a fuel and potentially also as a construction material at that time. Across both the site and throughout each period carbonised oak remained the dominant wood type. Other species present represented smaller shrub material such as alder and willow. Pine appeared within the post-medieval period and could have reflected increased imports of Baltic timber through the port at Leith (Mowat 1994).

3. The concentrations of grain in the earlier periods (1-3) were significantly higher than in the later ones (4 and 5). This reflected the changing use of the area from the backlands of burgage plots to formal gardens, military grounds and brewery.

4. One notable observation was the uniformity in the concentration of charred remains across the site. Almost none of these appeared to have been charred in situ and this gives the impression that the sediments, particularly the extensive soil horizons, had been thoroughly mixed by animal and human agencies.

Based on evidence from the Byre Theatre excavations, St Andrews, and elsewhere, Carter (2001) has suggested that soil horizons such as those seen at the Parliament site may represent a sediment accumulation brought about at least partially by repeated building and demolition of timber and turf structures. The topography of the Parliament site suggested that much of the material forming the accumulation may have migrated downslope from the frontage areas. In this inter- pretation the charred remains are likely to represent material reworked from domestic and other structures. Here, as at many other urban sites in towns such as Perth, St Andrews (Holden \& Hastie 2001) and Dundee (Holden 1998; Hastie \& Holden 2000), direct evidence for the source of the charred plant remains is often lacking. However, large quantities of burnt grain could have been created as a result of accidents in corn-drying kilns or ovens, and also the cumulative effect of many smaller accidents in a domestic context. The construction materials used in medieval structures such as wattle and daub and turf would only have had a short lifespan and would need to be demolished and rebuilt repeatedly. In an active soil interspersed with periods of small-scale cultivation and the cutting of pits and other features, the charred cereal and other remains would quickly be distributed through the accumulating soils.

The burgesses may have cultivated a proportion of the grain themselves, although their plots or tofts were probably used more for the cultivation of vegetable crops and fruit. Dennison suggested that it was likely that the burgesses had land in Broughton and this was a potential place for them to have grown cereal crops (HAPT 2008, Chapter 4.6). Although detailed records regarding the grain trade only survive from later periods, it can be assumed that the patterns observed in the 17th century reflected similar, although possibly less welldeveloped, patterns in the medieval period. East Lothian was clearly an obvious source of grain, which, with its favoured environment and fertile soils, was capable of growing a wide variety of crops, including wheat for bread-making. East Lothian was the setting for many agricultural improvements affecting productivity and the production of surpluses that could be sold in the markets of Edinburgh and Canongate. As a result, by the end of the 17th century, the old infieldoutfield system of agriculture was changing and systems involving more complicated crop rotations, liming and fallow were being introduced (Fenton 1963; Whyte 1976).

Until the Turnpike Act of 1750 the difficulty of overland transport was, however, a major constraint on the provisioning of Edinburgh and the Canongate from East Lothian (Snodgrass 1953). In 1744, for example, potatoes designated for the city were brought from no further than six miles because of transport costs (Marshall 1986). Much of the grain for the burghs was brought by sea via the Port of Leith (Mowat 1994). By the 17th century surviving records show grain coming not only from ports in East Lothian but also others on the east coast, as far away as Eyemouth to the south and Moray in the north (McNeill \& MacQueen 1996). This trade probably had much older roots and emphasised both Edinburgh's and the Canongate's roles as consumer centres, and Leith's as an entrepôt.

A proportion of the cereals entering the Canongate would have been in the form of flour and meal rather than as grain, and would have left little trace in the archaeological record. During the earlier periods it is possible that hand-milling using quern stones and corn-drying over the hearth were undertaken, but this would have been restricted to smallscale domestic activity. Most cereal producers would have been thirled to an estate mill and obliged to grind their corn there rather than in the burgh.

There were, however, evidently some mills in the vicinity but their history is somewhat obscure. One is known to have been granted to the canons of Holyrood by David I in the 
12th century (Stevenson et al 1981). Later, they had mills in the area that became known as Canonmills and by the early 18 th century there were numerous other mills on the Water of Leith. Still less grain would have entered the Canongate itself as the occupants of the site ceased processing their own grain and began to purchase processed grain products. Unfortunately, reworking of earlier sediments into what are commonly called 'garden soils' confuses the archaeological data and it is difficult to identify any clear trends.

Throughout the medieval and early post-medieval periods, grain, particularly barley, would undoubtedly have been brought to the site for the purposes of brewing. This could be undertaken both commercially and domestically and it is known that, at least in the 14th century, each burgess would have had his own brewing vat (Ewan 1990). Brewing requires the production of malt and this is undertaken by soaking the grain in order to promote germination, kilning in order to kill the sprouting grain and grinding the grain. This was probably one of the main reasons why kilns such as that found at the Byre Theatre Site, St Andrews (Moloney \& Baker 2001) were still being used in a 13th- to 14th-century urban context. Unfortunately for this hypothesis, only rarely do traces of the sprouted grain that are characteristic of malting come to light in any quantity.

The above possibilities offer some explanations of how and why cereal grain might have been brought to a medieval burgh. Somehow, a fraction of the total amount brought into the town became charred, later to be incorporated into thick organic-rich sediments that form horizons over large areas of the backlands. Throughout the excavation these horizons were routinely sampled in order to identify any temporal or spatial trends in the presence of charred plant and other remains. No specific trends were identified, as the grain was consistently present but only in low quantities. This situation has already been noted from the so-called 'garden soils' on other urban excavations in Edinburgh, St Andrews, Perth and Dundee, but rarely is it clear whether the small quantities of grain are the result of a low number of major conflagrations or numerous smaller incidents in, for example, the kitchen. Whatever the source, human activity and the biologically active soils into which they were deposited have served to mix and distribute the charred grain over much of the site. It can only be hoped that future excavations will provide the direct evidence for the source of the charred material that is presently lacking. This, combined with a focused analysis of the historic sources for potential evidence, will one day undoubtedly help us to explain an apparently common phenomenon.

\subsection{MAMMALIAN, BIRD AND MOLLUSCAN REMAINS}

\section{CATHERINE SMITH}

\subsubsection{Selection criteria for mammal bone samples}

Animal bones were retrieved from the Holyrood site both by hand excavation and by an extensive programme of soil sieving (Part 2.4), recovering more than 23 standard boxes of bone. However, the condition of the animal bone was found to vary from context to context. Although some of the material was well-preserved and the individual fragments of a large size, the condition of much of the bone was unfortunately less good than might have been hoped. Many of the bones were abraded and fragmentary, and thus could not provide the anatomical measurements or epiphyseal fusion data which are essential for the estimation of age and stature of animals. The soil-sampling process retrieved much bone, but unfortunately the prevailing conditions of preservation were such that the majority of the smaller mammalian fragments recovered by sieving were not identifiable. Thus approximately $75 \%$ of the material from bulk-sieved samples consisted of small, abraded fragments which could not be identified either to species or body part. A selection process was employed to separate out those contexts which contained the best-preserved material, using the following criteria:

- degree of surface abrasion

- recognisability of the fragments (as to bone and species)

- fragment size

- numbers of fragments per context

Stratigraphic importance was also taken into account. Contexts representing the fills of pits, or fills of other features, were selected in order to help establish their function.

During the assessment process, the entire animal bone assemblage was briefly examined as to its suitability for inclusion. The opportunity was taken at this point to extract all bird, fish and amphibian bone. Thus the entire bird assemblage, from both the sieved and hand-excavated samples, was recorded.

The mammal and bird bones were identified by direct comparison with modern comparative material and were allocated to particular bone and species where possible. Where it was not possible to identify bones as far as species, the terms large ungulate, small ungulate and indeterminate mammal were used: thus all large vertebrae other than the atlas and axis were described as large ungulate, while small vertebrae were described as small ungulate. Ribs were similarly allocated depending on their size. On the basis of probability, large ungulate bones were most likely to have come from cattle, but could also have come from horse or red deer. Similarly, small ungulate bones were most likely to have come from sheep, but could possibly have originated from goat, pig or roe deer. All other mammalian fragments for which neither species nor bone could be ascertained were described as indeterminate mammal. Boessneck's (1971) criteria for differentiating between the bones of sheep and goat, which are morphologically very similar, were applied where feasible.

Measurements were made in accordance with the scheme of von den Driesch (1976) and are expressed in millimetres. Mandibular tooth wear and eruption patterns were assessed using Grant's (1982) scheme for cattle, sheep/goats and pigs, as well as Payne's (1973) scheme for sheep/goats. Horn cores were aged using Armitage's (1982) criteria.

\section{MAMMAL, BIRD AND MOLLUSC SPECIES PRESENT}

The range of mammalian species present in the hand-excavated samples was essentially similar to that recovered from the sieved samples, although rather more extensive. Thus, the handexcavated species were mainly domesticated mammals: cattle, sheep/goat, pig, horse, dog and cat, although wild roe deer (Capreolus capreolus), fox (Vulpes vulpes) and rabbit (Oryctolagus 
Table 2.3 Total number of mammal bones in sampled and hand-excavated contexts at the Parliament site, by phase

$\begin{array}{llllll}\text { Phase } 1 & \text { Phase } 2 & \text { Phase } 3 & \text { Phase } 4 & \text { Phase } 5 & \text { Phase } 6\end{array}$

\begin{tabular}{|c|c|c|c|c|c|c|c|c|c|c|c|c|c|c|c|}
\hline Species & $\begin{array}{l}\overrightarrow{0} \\
\stackrel{0}{0} \\
\tilde{E} \\
\tilde{D}\end{array}$ & 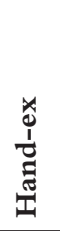 & 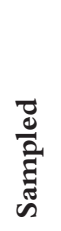 & 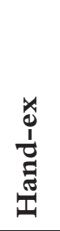 & 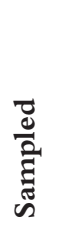 & 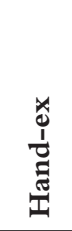 & $\begin{array}{l}\overrightarrow{0} \\
\frac{0}{2} \\
\text { हूँ }\end{array}$ & 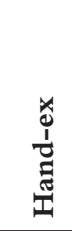 & 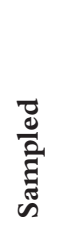 & 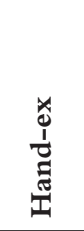 & 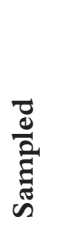 & 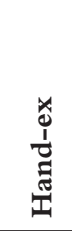 & 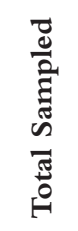 & 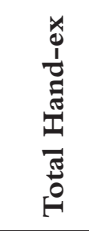 & 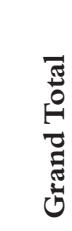 \\
\hline Cattle & & & & 4 & 1 & 49 & 15 & 87 & 4 & 11 & 2 & 52 & 22 & 203 & 225 \\
\hline Sheep/goat & & & & 4 & 4 & 66 & 47 & 144 & 4 & 31 & 11 & 106 & 66 & 351 & 417 \\
\hline Pig & & & & & & 1 & & 5 & & 4 & & 5 & & 15 & 15 \\
\hline Horse & & & & & & 4 & & 27 & & $1^{\star}$ & & 13 & & 45 & 45 \\
\hline Roe deer & & & & & & & & 1 & & & & & & 1 & 1 \\
\hline Dog & & 2 & & & & 2 & & 3 & & & & 9 & & 16 & 16 \\
\hline Dog/Fox & & & & 1 & & & & 3 & & & & 1 & & 5 & 5 \\
\hline Fox & & & & 1 & & & & & & & & 1 & & 2 & 2 \\
\hline Cat & & & & & & & & 1 & 4 & 5 & 1 & 1 & 5 & 7 & 12 \\
\hline Rabbit & & & & & & 1 & & 2 & & & & & & 3 & 3 \\
\hline Large ungulate & & 1 & & 2 & 1 & 40 & 3 & 71 & & 11 & 1 & 64 & 5 & 189 & 194 \\
\hline Small ungulate & & & & 1 & & 12 & 3 & 24 & & 2 & 5 & 48 & 8 & 87 & 95 \\
\hline Indeterminate Mammal & & & & 12 & 13 & 84 & 272 & 210 & 58 & 55 & 69 & 194 & 412 & 555 & 967 \\
\hline Total & & 3 & & 25 & 19 & 259 & 340 & 578 & 70 & 119 & 89 & 494 & 518 & 1479 & 1997 \\
\hline
\end{tabular}

^excludes skeleton

cuniculus) were also present. The sieved samples contained only cattle, sheep/goat and cat bones (see table 2.3). It is noteworthy that sheep/goat bones were more plentiful than those of cattle in both the medieval and post-medieval periods. Certainly it is the bones of these two economically important species which dominate the faunal assemblage.

Tables 2.4 and 2.8 present a comparison of the numbers and percentages of the larger food-forming mammals found at the main Parliament site, Queensberry House and at other medieval and post-medieval sites in Scotland. From these figures it can be seen that the dominance of sheep in the Parliament animal-bone assemblage is similar to the Borders sites of Briggait (Smith 2003), in the burgh of Peebles (medieval Phase 2), as well as to the religious site at Jedburgh Friary (Grove 2000, 65) but contrasts sharply with medieval sites in Perth such as 75-7 High Street (PHSE) and Meal Vennel, where cattle predominate (Smith 1996; 2003). Data covering the post-medieval period in Scotland are scanty; but the cattle/sheep ratio in the later phases of occupation at Castle Park, Dunbar (Phases 22 and 23) is more similar to that at the Parliament site than it is to the medieval phases at Dunbar itself (Smith 2000a, 202).

Bones of pigs, although occurring in most of the later site periods, are relatively scarce. Horse bones are more common than those of pigs in all of the periods. A pit in Period 3 containing a single horse skeleton is thought to represent the burial of a fallen casualty.

Amongst the birds, the domestic fowl was the most common species, followed by goose (table 2.5). The goose bones may have come from either the domestic bird, or its wild progenitor, the greylag (Anser anser). Similarly, bones of duck came either from the mallard (Anas platyrhynchos) or its domesticated descendant, although all duck bones from the site were small and referable to the wild species. Other bird species occurred only in small numbers and included grey partridge (Perdix perdix), red grouse (Lagopus lagopus), black-headed gull (Larus ridibundus), possible cormorant (Phalacrocorax cf carbo), feral pigeon/rock dove (Columba livia) and crow (Corvus corone).

Mollusca were mainly marine, although a few shells of garden snail (Helix aspersa) were present. The molluscan assemblage was dominated by oyster shells, and it was apparent that mortar was adhering to many of the oyster valves. These had probably been incorporated as pinning in walls or other stone structures. Other marine species were edible and included limpet (Patella sp), cockle (Cerastoderma $\mathrm{sp}$ ), whelk (or periwinkle, Littorina littorea), and flat periwinkle (L obtusata), buckie (Buccinum ondatum), mussel (Mytilus sp) and queen scallop (Aequipecten opercularis). Several Nucella shells, a species which parasitises other marine mollusca, were also present. These may have been brought into the site in building sand as they are not considered to be edible. A full catalogue of mollusc identifications is available in the site archive.

\subsubsection{Summary of animal bone by period}

Period I (I2TH-I4TH CENTURIES)

Few bones were recovered and identified from Period 1 contexts. Context 756, which contained mammal and bird 
Table 2.4 Comparisons of numbers and percentages of food-forming mammals

\begin{tabular}{|c|c|c|c|c|c|c|}
\hline & \multicolumn{2}{|c|}{ Medieval Phases2, $3 \& 4$} & \multicolumn{2}{|c|}{ Post-medieval Phases $5 \& 6$} & \multicolumn{2}{|c|}{ Total } \\
\hline & $\mathbf{n}$ & $\%$ & $\mathbf{n}$ & $\%$ & $\mathbf{n}$ & $\%$ \\
\hline Cattle & 156 & 34.0 & 69 & 28.3 & 225 & 32.0 \\
\hline Sheep/goat & 265 & 57.7 & 152 & 62.3 & 417 & 59.3 \\
\hline Pig & 6 & 1.3 & 9 & 3.7 & 15 & 2.1 \\
\hline Horse & 31 & 6.8 & 14 & 5.7 & 45 & 6.4 \\
\hline Deer (all species) & 1 & 0.2 & & & 1 & 0.1 \\
\hline Total & 459 & 100.0 & 244 & 100.0 & 703 & 99.9 \\
\hline
\end{tabular}

bone as well as fragments of mollusc shell, was a natural silt inwash in a boundary ditch and may represent material which originated elsewhere or accumulated in the ditch over a protracted period of time. The presence of two bones from a very large dog may be explained as resulting from a medieval midden deposit. Amphibian bone from 1761 is evidence of a damp environment.

Period 2 (I4Th-I5Th Centuries)

\section{Period 2.1}

The mammalian and bird species present were cattle, sheep/ goat, fox, foetal dog/fox and domestic fowl. As in Period 1, the bone and mollusc shell originated mainly from ditch fills and may represent a deposit which built up over time. Amphibian bones were associated with a large sub-circular feature and, as for Period 1, must represent damp conditions.

\section{Period 2.2}

Medieval garden soil and associated features. Present in Period 2.2 were cattle, sheep/goat, pig, horse, dog, rabbit and domestic fowl bones, originating mainly from pit fills. A deposit covering the top of a well (Context 1731) also contained animal bone, including, not surprisingly, amphibian. The suite of mammalian species is typical of the medieval period, with the possible exception of the single rabbit bone in Context 1500, the primary fill of an industrial feature. Since rabbits are burrowing animals, the bone may represent an intrusion from a later period. Sheep/goat bones were more numerous than those of cattle. Of interest in Period 2.2 is the presence of a butchered horse bone in Context 1730 , the fill of a sub-circular cut, and a dog bone with cut marks in 740, a pit fill. These two bones may represent the waste products of skinning.

\section{Period 2.3}

Medieval features. A substantial faunal assemblage, including bones of cattle, sheep/goat, pig, horse, roe deer, dog, dog/ fox, cat, rabbit, domestic fowl, goose and amphibian was recovered from Period 2.3. As in the previous phase, sheep/ goat bones were more numerous than those of cattle, while pig bones were very scarce. Types of feature in which bones were present included fills of pits, stone structures and a twin tank feature. Notable amongst the mammal bones contained in the fills of the twin tank were horse bones bearing knife cuts (Contexts 811 and 835). Stone structure 775 contained dog bones with knife cuts (Context 806) amongst the mammalian assemblage. The presence of these butchered horse and dog bones is again indicative of a small-scale skinning industry. The tanks may thus have been involved in a process connected with skinning or tanning, which later became filled with debris.

Period 3 (i6Th-I7Th Centuries; Post-Medieval garden SOIL AND ASSOCIATED FEATURES)

Mammals and birds present in post-medieval Period 3 were cattle, sheep/goat, pig, horse, cat (and kitten), domestic fowl, duck and feral pigeon. Following the medieval trend in Period 2, sheep/goat bones outnumbered those of cattle while pigs were not plentiful. It is notable that Period 3 is the first in which duck bones appear. They are absent from the medieval phases. A single horse skeleton was recovered from a pit (Context 1513). The bones were unbutchered and the skeleton, although in a fragmentary condition, was substantially complete. Standing at approximately 15:2 hands height, this horse was larger and sturdier than the typical pony of the medieval period. The animal may have been a natural casualty, buried close to the spot at which it died. The partial cat and kitten skeletons showed no evidence of knife cuts, and thus may also represent natural casualties rather than skinned carcasses, although this is by no means certain.

\section{Period 4.I (I7TH-I8Th CeNTURIES)}

Mammalian species present in Period 4.1 were cattle, sheep/ goat, pig, horse, dog, fox, $\operatorname{dog} /$ fox and cat. As in the previous contexts, sheep/goat bones were more plentiful than cattle. Horse bones were, as in Period 2, more plentiful than those of pig. The presence of fox is interesting, since it implies that animals may have been skinned at the site for their pelts. In addition, horse bones with skinning cuts were recovered from Contexts 710 and 859 (the latter being the upper fill of a pit). This seems to be evidence for a continued small-scale skinning industry at the site.

Period 4.1 contexts also contained a wider range of bird species than found in earlier phases. Edible species present, besides domestic fowl, goose and duck, were red grouse, partridge, cormorant and black-headed gull. Bones of crow and passerine species probably came from natural casualties rather than birds which were eaten. 


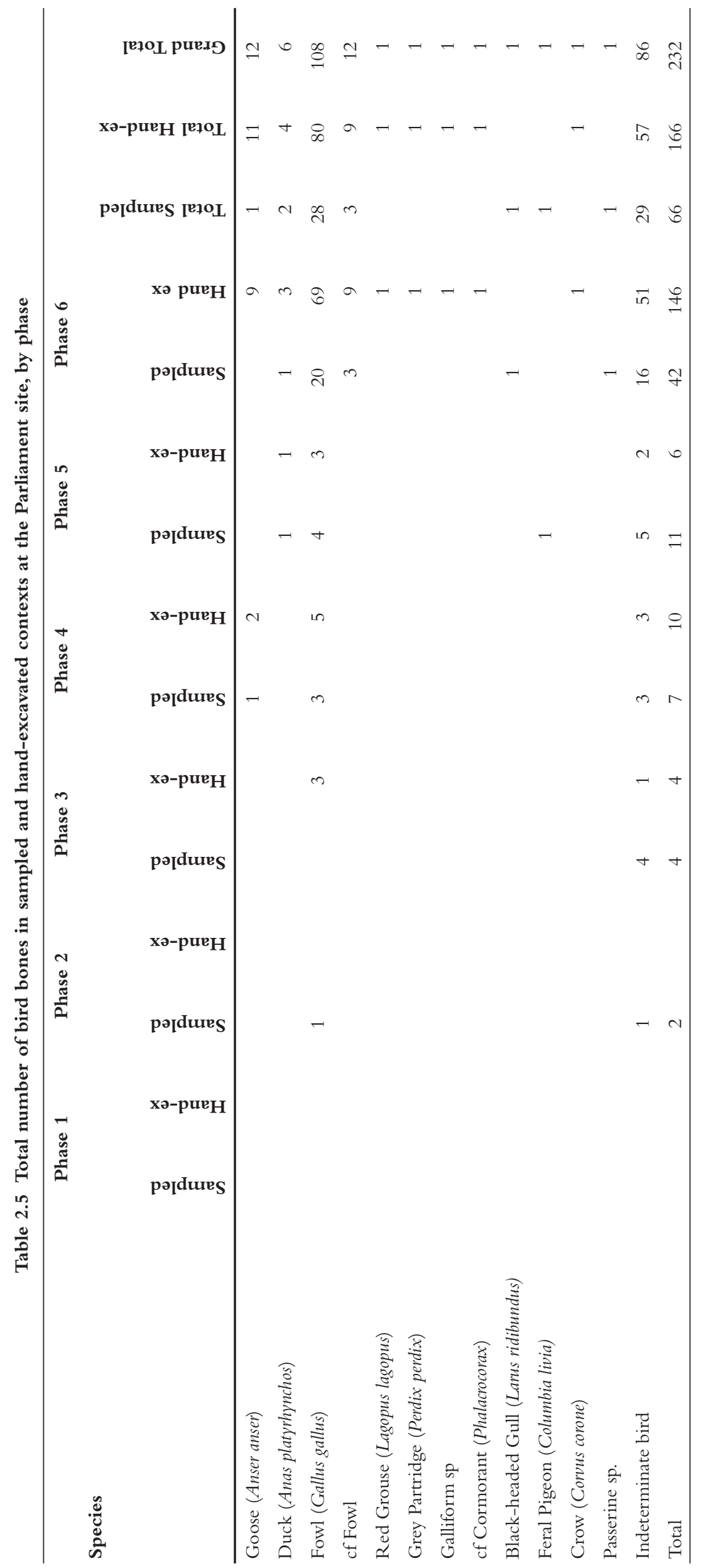


Table 2.6 Comparisons of numbers and percentages of food-forming mammals from Scottish medieval and post-medieval sites

\begin{tabular}{|c|c|c|c|c|c|c|c|c|c|c|c|}
\hline \multirow[b]{2}{*}{ Site } & \multirow[b]{2}{*}{ Date } & \multicolumn{2}{|c|}{ Cattle } & \multicolumn{2}{|c|}{ Sheep/goat } & \multicolumn{2}{|c|}{ Pig } & \multicolumn{2}{|c|}{ Horse } & \multicolumn{2}{|c|}{ Deer } \\
\hline & & $\mathbf{n}$ & $\%$ & $\mathbf{n}$ & $\%$ & $\mathbf{n}$ & $\%$ & $\mathbf{n}$ & $\%$ & $\mathbf{n}$ & $\%$ \\
\hline $\begin{array}{l}\text { Parliament Phases 2, } \\
3 \& 4\end{array}$ & medieval & 156 & 34.0 & 265 & 57.7 & 6 & 1.3 & 31 & 6.8 & 1 & 0.2 \\
\hline $\begin{array}{l}\text { Parliament Phases } 5 \\
\& 6\end{array}$ & post-medieval & 69 & 28.3 & 152 & 62.3 & 9 & 3.7 & 14 & 5.7 & & \\
\hline $\begin{array}{l}\text { Peebles, Briggait, } \\
\text { Phase II }\end{array}$ & medieval & 93 & 35.6 & 142 & 54.4 & 7 & 2.7 & 10 & 3.8 & 9 & 3.4 \\
\hline $\begin{array}{l}\text { Peebles, Briggait, } \\
\text { Phase III }\end{array}$ & 15 th -17 th $/ 18$ th century & 152 & 28.0 & 350 & 64.5 & 17 & 3.1 & 22 & 4.1 & 2 & 0.4 \\
\hline $\begin{array}{l}\text { Dunbar, Castle Park, } \\
\text { Phases } 22 \& 23\end{array}$ & post-medieval & 538 & 38.3 & 606 & 43.2 & 202 & 14.4 & 39 & 2.8 & 19 & 1.4 \\
\hline $\begin{array}{l}\text { Perth, } \\
\text { PHSE }\end{array}$ & medieval & 12572 & 63.5 & 5366 & 27.1 & 1636 & 8.3 & 200 & 1.0 & 26 & 0.1 \\
\hline $\begin{array}{l}\text { Perth, Meal Vennel, } \\
\text { Phases 6-7 }\end{array}$ & post-medieval & 1645 & 62.0 & 828 & 31.2 & 122 & 4.6 & 54 & 2.0 & 3 & 0.1 \\
\hline
\end{tabular}

Table 2.7 Total number of mammalian bones recovered from Queensberry House

\begin{tabular}{|c|c|c|c|c|c|c|}
\hline Species & Period 2.1 & Period 3 & Period 4.1 & Period 4.2 & Period 5.2 & Total \\
\hline Cattle & 14 & 24 & 62 & 7 & 2 & 109 \\
\hline Sheep/goat & 16 & 19 & 82 & 18 & 1 & 136 \\
\hline Pig & & 2 & & & & 2 \\
\hline Horse & & & 3 & & & 3 \\
\hline Hare & & & 2 & 1 & & 3 \\
\hline Rabbit & & 1 & 5 & 1 & & 7 \\
\hline Rat & & & 2 & & & 2 \\
\hline Large ungulate & 2 & 5 & 35 & 5 & 2 & 49 \\
\hline Small ungulate & & 6 & 51 & 7 & 2 & 66 \\
\hline Indeterminate mammal & 37 & 27 & 107 & 9 & & 180 \\
\hline Total & 69 & 84 & 349 & 48 & 7 & 557 \\
\hline
\end{tabular}

The rabbit bone present in this phase could not have been intrusive, since it bore a knife cut. Its presence in a postmedieval context (512) is not, however, problematic.

Queensberry House (Periods 2-5)

Faunal remains were recovered from watching briefs and excavation carried out at Queensberry House. Bones and mollusc shells were recovered from Periods 2, 3, 4 and 5, and were generally well preserved, and in most cases appeared in better, less eroded condition than those from the main Parliament excavation.

Mammalian bones recovered from Queensberry House were mainly those of large domestic animals (cattle, sheep/ goat, pig and horse), although hare (Lepus capensis), rabbit (Oryctolagus cuniculus) and brown rat (Rattus norvegicus) were also represented. Bird species were domestic fowl (Gallus gallus), domestic or greylag goose (Anser anser), duck cf mallard (Anas cf platyrhynchos), grey partridge (Perdix perdix) and small Passerine species. Amphibian bones were also recovered from Period 3. The range of species is thus similar to those recovered from the main excavation, although less extensive.

Shown in tables 2.6 and 2.7 are the numbers of mammalian, bird and amphibian bones present in each phase at Queensberry House. The total bone sample $(n=621)$ recovered from Queensberry House is much smaller than that recorded from outside the building $(n=1997)$ and this should be borne in mind when comparing results. As at the main excavation, the total number of sheep/goat bones was greater than that of cattle; in this case 135 sheep/goat bones as compared with 107 cattle, excluding modern Period 19.2. However, the bias towards sheep/goat is not as marked as at the site outside the building. This may be due to sample bias, since bulk sieving was not carried out, in contrast to the main excavation, or, much more likely, due to better conditions of preservation 
Table 2.8 Total number of bird and amphibian bones recovered from Queensberry House

\begin{tabular}{|c|c|c|c|c|}
\hline Species & Period 3 & Period 4.1 & Period 5.2 & Total \\
\hline Domestic fowl & 2 & 31 & 3 & 36 \\
\hline cf Domestic fowl & & 1 & & 1 \\
\hline Grey partridge & & & 1 & 1 \\
\hline Goose & & 4 & & 4 \\
\hline Duck cf mallard & & 1 & & 1 \\
\hline Small passerine $\mathrm{sp}$ & & 1 & & 1 \\
\hline Indeterminate bird $\mathrm{sp}$ & 1 & 13 & 1 & 15 \\
\hline Amphibian & 5 & & & 5 \\
\hline Total & 8 & 51 & 5 & 64 \\
\hline
\end{tabular}

Table 2.9 Cattle mandibles arranged by Grant's (1982) wear stages

\begin{tabular}{ccccccc}
\hline Phase & $\begin{array}{c}\text { Hand-excavated } \\
\text { or Sampled }\end{array}$ & Context & IADB & Grant TWS & Grant MWS & 5th cusp of M3 \\
\hline 3 & H-ex & 740 & 2397 & $1 \mathrm{kj}$ & 45 & in wear \\
4 & H-ex & 668 & 1515 & $1 \mathrm{k}-$ & $42-46$ & in wear \\
4 & H-ex & 1780 & 5039 & -11 & $50-51$ & in wear \\
5 & H-ex & 1523 & 4055 & $\mathrm{kkk}$ & 45 & in wear \\
\hline
\end{tabular}

TWS: tooth wear stage; MWS: mandible wear stage; H-ex: hand-excavated; S: sampled

at Queensberry House as compared to the main Parliament excavation. The excavators noted the presence of large quantities of lime-based mortar containing oyster shell fragments, associated with the rubble of demolished buildings. This would have the effect of lowering the acidity of the soil, hence the better local preservation of bone. Finally, there was some indication that the material recovered from Queensberry House originated from levelling dumps prior to the erection of the building itself. The assemblage almost certainly contained re-deposited bone from earlier phases of the site.

Pig bones were scarce at Queensberry House: only two were recovered, from Phase 5 (Period 3). Horse bones were much less numerous than outside the building, where it is likely that natural casualties had been buried. Of the wild animal species, rabbit bones occurred in three periods, all of post-medieval date. Hare occurred in two post-medieval periods. Although some of the rabbit bones could have been intrusive, it is likely that, as at the main Parliament site, their meat had been eaten, as with the hares.

With the exception of the small Passerine bird species (a bird the size of a sparrow or its like), all of the other bird species were probably eaten.

As noted above, oyster shells were plentiful in the assemblage. In some cases, the shells were coated with mortar, and had probably been used as pinning material in building construction, once the oyster flesh had been consumed (Context 7046, Period 3; Context 7053, Period 4.1; Context 7089, Period 4.1). A very few fragments of other marine species, periwinkle or whelk (Littorina littorea), buckie (Buccinum ondatum), mussel (Mytilus edulis) and cockle (Cerastoderma $\mathrm{sp}$ ), were also present. The smaller specimens may have come from imported beach sand, while the larger shells such as buckie may represent food detritus. Two shells of large land snail (Helix and Cepea), both species favouring cool, shady habitats such as walls, were also found.

\subsubsection{The domestic livestock}

Ages OF MAMMALS AT DEATH

In order to understand better the role of the domestic livestock in the economy of the Holyrood site, the question of the culling pattern has been addressed by assessing the age at which animals were killed. It should be pointed out that some methods of assessing age at death are more reliable than others. In particular, age estimated on the basis of mandibular tooth eruption and wear pattern gives a more accurate result than that estimated from the state of epiphyseal fusion of the long bones. However, because of varying conditions of preservation across and between different archaeological sites, as well as varying butchery and rubbish disposal practices, the bones required to give the most accurate result are not always the ones which are retrieved. In the case of the Holyrood assemblage, it has already been noted that conditions of preservation were not particularly good and it seems very likely that more delicate bone elements have not survived as well as denser ones. Thus, bones and mandibles of young animals, being less densely mineralised than those from older animals, have not survived well, and have been subject to 'differential preservation'. In addition, particular bone elements, such as the dense, hard, distal epiphysis of the humerus of an adult animal, survive more readily than the proximal epiphysis, which has a more spongy, friable honeycomb structure.

With these shortcomings in mind, tables 2.9 and 2.10 show the numbers of mandibles from cattle and sheep assessed as 
Table 2.10 Sheep/goat mandibles arranged by Grant's (1982) and Payne's (1973) wear stages

\begin{tabular}{|c|c|c|c|c|c|c|c|}
\hline \multirow[b]{2}{*}{ Phase } & \multirow[b]{2}{*}{$\begin{array}{l}\text { Hand-excavated } \\
\text { or Sampled }\end{array}$} & \multicolumn{6}{|c|}{ Grant } \\
\hline & & Context & IADB & TWS & MWS & Payne stage & Age inference \\
\hline 2 & H-ex & 1734 & 4965 & ggf & 35 & F & $3-4$ years \\
\hline 3 & H-ex & 1568 & 4196 & $-f$ & - & $\mathrm{F}$ & $3-4$ years \\
\hline 4 & S & 1538 & 4295 & gfc & 31 & E & $2-3$ years \\
\hline 4 & H-ex & 794 & 37 & $\mathrm{kgf}$ & 38 & $\mathrm{~F}$ & $3-4$ years \\
\hline 4 & H-ex & 806 & 2564 & mhg & 42 & $\mathrm{H}$ & $6-8$ years \\
\hline 4 & H-ex & 811 & 2505 & gge & 34 & $\mathrm{~F}$ & $3-4$ years \\
\hline 4 & H-ex & 811 & 2505 & $-g d$ & $33-35$ & $\mathrm{E}$ & $2-3$ years \\
\hline 4 & H-ex & 825 & 2580 & ggb & 31 & E & $2-3$ years \\
\hline 5 & H-ex & 1620 & 4506 & hgg & 37 & G & $4-6$ years \\
\hline 6 & H-ex & 512 & 983 & $\operatorname{ggd}$ & 33 & $\mathrm{E}$ & $2-3$ years \\
\hline 6 & H-ex & 859 & 3385 & $-b$ & & $\mathrm{E}$ & $2-3$ years \\
\hline
\end{tabular}

Table 2.11 Age categories based on epiphyseal fusion of long bones (after Silver 1969)

\begin{tabular}{llcc}
\hline & & & Age Category \\
Date of fusion & Bone & Unfused & Fused \\
\hline Early & Scapula & $\mathrm{J}$ & $\mathrm{I} / \mathrm{A}$ \\
Late & Humerus (proximal) & $\mathrm{J} / \mathrm{I}$ & $\mathrm{A}$ \\
Early & Humerus (distal) & $\mathrm{J} / \mathrm{I}$ & $\mathrm{I} / \mathrm{A}$ \\
Early & Radius (proximal) & $\mathrm{J} / \mathrm{I}$ & $\mathrm{I} / \mathrm{A}$ \\
Late & Radius (distal) & $\mathrm{A}$ \\
Late & Ulna (proximal) & $\mathrm{J} / \mathrm{I}$ & $\mathrm{A}$ \\
Late & Ulna (distal) & $\mathrm{J} / \mathrm{I}$ & $\mathrm{A}$ \\
Intermediate & Metacarpal (distal) & $\mathrm{J} / \mathrm{I}$ & $\mathrm{A}$ \\
Late & Femur (proximal) & $\mathrm{J} / \mathrm{I}$ & $\mathrm{A}$ \\
Late & Femur (distal) & $\mathrm{J} / \mathrm{I}$ & $\mathrm{A}$ \\
Late & Jibia (proximal) & $\mathrm{J} / \mathrm{I}$ & $\mathrm{A}$ \\
Intermediate & Tibia (distal) & $\mathrm{J} / \mathrm{I}$ & $\mathrm{A}$ \\
Late & Calcaneum & $\mathrm{J} / \mathrm{I}$ & $\mathrm{J} / \mathrm{I}$ \\
Intermediate & Metatarsal (distal) & $\mathrm{J} / \mathrm{I}$ & $\mathrm{A}$ \\
Early & 1st phalange (proximal) & $\mathrm{J} / \mathrm{I}$ & $\mathrm{J} / \mathrm{I}$ \\
Early & 2nd phalange (proximal) & & $\mathrm{I} / \mathrm{A}$
\end{tabular}

Key: J - Juvenile; J/I - Juvenile/Immature; I - Immature; I/A - Immature/Adult; A - Adult

to their relative age after the methods of Grant (1982) and Payne (1973).

Tables 2.12-2.14 show epiphyseal fusion data for cattle sheep/goat and pig. A key to the dates of fusion, based on data compiled by Silver (1969), is shown in table 2.11. Here, long bones fusing at either an early, intermediate or late date are grouped together in age categories. Unfortunately, because of overlapping ages of fusion of certain bones, it is in some cases impossible to distinguish between immature and adult bones, or similarly, between juvenile and immature bones. For example, the distal humerus fuses at an early date, while the proximal epiphysis of the same bone fuses at a late stage. If both epiphyses are present and both are fused, then the animal must be mature. If the distal is fused and the proximal unfused, then the animal is immature, but if only a fused distal end is present, the animal may be either immature or adult. This demonstrates the need for an age category immature/ adult (I/A), and is the reason for the large number of cattle and sheep/goat bones falling into this category in tables 2.12 and 2.13 .

It can be seen that only four cattle mandibles survived in both the hand-excavated and sieved samples. All of these came from adult animals in which the third molar, the last of the cheek teeth to erupt, was present and in wear. The high value of the mandible wear stage (MWS) is an indicator that the animals were fully advanced in maturity, and the wear 
Table 2.12 Cattle long bones in each age category, by phase

\begin{tabular}{|c|c|c|c|c|c|}
\hline \multirow[b]{2}{*}{ Phase } & \multirow[b]{2}{*}{$\begin{array}{l}\text { Hand-excavated } \\
\text { or Sampled }\end{array}$} & \multicolumn{4}{|c|}{ Age Category } \\
\hline & & $\mathrm{J} / \mathrm{I}$ & I/A & $\mathbf{A}$ & Total \\
\hline 3 & S & & & & \\
\hline 3 & H-ex & 1 & 8 & 11 & 20 \\
\hline 4 & S & & 4 & & 4 \\
\hline 4 & H-ex & 3 & 9 & 11 & 23 \\
\hline 5 & S & & & & \\
\hline 5 & H-ex & & 1 & & 1 \\
\hline 6 & S & & & & \\
\hline 6 & H-ex & 2 & 11 & 4 & 17 \\
\hline Total Sampled & S & & 4 & & 4 \\
\hline Total Hand-excavated & H-ex & 6 & 29 & 26 & 61 \\
\hline Grand total & & 6 & 33 & 26 & 65 \\
\hline$\%$ & & 9.2 & 50.8 & 40.0 & 100.0 \\
\hline
\end{tabular}

Table 2.13 Sheep/goat long bones arranged by age category

\begin{tabular}{|c|c|c|c|c|c|c|c|}
\hline \multirow[b]{2}{*}{ Phase } & \multirow[b]{2}{*}{$\begin{array}{l}\text { Hand-excavated } \\
\text { or Sampled }\end{array}$} & \multicolumn{6}{|c|}{ Age Category } \\
\hline & & $\mathbf{J}$ & $\mathrm{J} / \mathrm{I}$ & I & I/A & A & Total \\
\hline 2 & H-ex & & & & 1 & 1 & 2 \\
\hline 3 & S & & 1 & & & & 1 \\
\hline 3 & H-ex & & 7 & 2 & 18 & 12 & 39 \\
\hline 4 & S & & 3 & & 5 & 2 & 10 \\
\hline 4 & H-ex & 2 & 10 & 13 & 26 & 18 & 69 \\
\hline 5 & S & & & & & & \\
\hline 5 & H-ex & & 6 & 1 & 3 & 6 & 16 \\
\hline 6 & S & & & & 1 & & 1 \\
\hline 6 & H-ex & 3 & 7 & 3 & 9 & 15 & 37 \\
\hline Total Sampled & & & 4 & & 6 & 2 & 12 \\
\hline Total H-ex & & 5 & 30 & 19 & 57 & 52 & 163 \\
\hline Grand total & & 5 & 34 & 19 & 53 & & 175 \\
\hline$\%$ & & 2.9 & 19.4 & 10.9 & 36.0 & 30.9 & 100.1 \\
\hline
\end{tabular}

on the fifth cusp of the third molar indicates that they were probably all at least five years old in modern terms. The epiphyseal fusion data for cattle confirms the presence of adult animals in Periods 2.2, 2.3 and 4.1, but also indicates that younger, juvenile or immature beasts were killed (or died) in the same periods. No very young (foetal or neonatal) cattle bones were found, but for reasons of poor preservation, this is not surprising.

In the case of sheep/goat, more mandibles survived than was the case for cattle (table 2.10). Because the time period spanned the medieval and post-medieval phases it was not possible to compile a meaningful culling diagram. It can only be stated that individual animals died at particular estimated ages: over the whole time period, five sheep/goats died between the ages of 2 and 3 years, four between the ages of
3 and 4 years, one between the ages of 4 and 6 years and one between the ages of 6 and 8 years. The greatest number of mandibles (six examples) occurred in Period 2.3 (14th/15th centuries), which also contained the oldest individual at 6-8 years of age.

A larger sample of sheep/goat bones than that of cattle was available for epiphyseal assessment. Results are presented in table 2.13. Although adult sheep/goats were well represented $(30.9 \%$ of bones were in age category A), a substantial number were from juveniles $(2.9 \%)$, juvenile or immature (19.4\%) and immature (10.9\%). Of sheep/ goats, $30.9 \%$ were in the age category which included immature or adult (I/A) individuals. These figures may be compared with those for cattle, where $9.2 \%$ were juvenile or immature $(\mathrm{J} / \mathrm{I}), 50.8 \%$ were immature or adult (I/A) 
Table 2.14 Pig long bones by age category and phase

\begin{tabular}{lccccc}
\hline Phase & Hand-excavated/ & & Age Category & J/A & Total \\
Sampled & J & J/I & I & 1 & 1 \\
\hline 3 & H-ex & & 1 & 1 & 2 \\
5 & H-ex & 1 & 1 & & 1 \\
Total & H-ex & 1 & 2 & 1 & 5 \\
\hline
\end{tabular}

Table 2.15 Catalogue of butchered horse bone

\begin{tabular}{|c|c|c|c|c|c|}
\hline Phase & $\begin{array}{l}\text { Hand- } \\
\text { excavated/ } \\
\text { Sampled }\end{array}$ & Context & IADB & Bone & Details \\
\hline 3 & H-ex & 1730 & 5047 & L humerus (distal) & Shaft very probably chopped mediolaterally. \\
\hline 4 & H-ex & 694 & 1879 & L mandible & Knife cut on ascending ramus, near condyle. Possibly chopped. \\
\hline 4 & H-ex & 811 & 2505 & $\begin{array}{l}\text { L calcaneum, astra- } \\
\text { galus and lateral } \\
\text { splint }\end{array}$ & $\begin{array}{l}\text { Represent left hind leg (metatarsal II/III also present). Knife cuts on } \\
\text { posterior aspects of calcaneum, astragalus and lateral splint (metatarsal } \\
\text { I). Knife cuts probably caused by skinning of lower hind leg. }\end{array}$ \\
\hline 4 & H-ex & 835 & 2614 & $\mathrm{R}$ tibia, distal & Shaft chopped mediolaterally. \\
\hline 6 & H-ex & 710 & 2235 & L scapula & Possible knife cuts on neck and anterior blade (abraded). \\
\hline 6 & H-ex & 859 & 3385 & 1st phalange & Parallel mediolateral knife cuts near lateral edge of shaft, distal. \\
\hline
\end{tabular}

Table 2.16 Catalogue of butchered dog bone

\begin{tabular}{lcccll}
\hline Phase & $\begin{array}{c}\text { Hand- } \\
\text { excavated/ } \\
\text { Sampled }\end{array}$ & Context & IADB & Bone & Details \\
\hline 3 & H-ex & 740 & 2397 & R ulna & 7 knife cuts on posterior shaft, distal to medial articulation. \\
4 & H-ex & 806 & 2564 & L metacarpal III & Knife cuts on and around distal articulation. \\
4 & H-ex & 806 & 2564 & L metacarpal IV & Knife cuts on and around distal articulation. \\
\hline
\end{tabular}

and $40.0 \%$ were fully adult. It would seem that more sheep were killed at a younger age than was the case for cattle. The culled lambs were probably surplus males, fattened and killed before their first winter.

As regards the pigs, very little information on age at death was available. No mandibles and few suitable long bones survived in the sample. Table 2.14 indicates only the presence of one juvenile $(\mathrm{J})$, two juvenile or immature animals $(\mathrm{J} / \mathrm{I})$, one immature (I) and one immature or adult animal (I/A). Given the very small number of pig bones in the sample, it is not surprising that mature adult animals were absent.

In the case of dogs, cats and horses, there was evidence of the presence of both juvenile and adult animals. Although most of the very small sample of cat bones came from adults, one partial skeleton of a kitten was present in Period 3, in association with bones from an adult cat. Most of the dog bones were from mature animals, with the exception of an unfused tibia (Context 679) and unfused femur (Context 694) in Period 2.3, which came from juveniles. In Period 2.1 , a single tibia from an adult fox was found in association with an unfused humerus, possibly from a foetus of the same species (Context 760). All of the horse bones in the selected contexts were thought to have come from adult animals. One fragmentary horse skull in Period 4.1 (Context 974) was in poor condition but the teeth were in a reasonable state of preservation and provided an estimated age of between 7 and 10 years at death (Silver 1969).

\section{BUTCHERY}

Cut and hack marks were present on many of the bones of large mammals, and on some bird bones. The main meatbearing animals were naturally the most heavily butchered, but in some cases bones of dog and horse were also affected (tables 2.15 and 2.16). In the case of the carnivores, these marks were merely knife cuts and perhaps implied only that the animals had been skinned for their pelts. For example, two associated dog (or possibly fox) metacarpals from Period 2.3 bore knife cuts both on and around their distal articulations. These knife cuts would have been caused during removal of the paws, at the point in the skinning process where the pelt is freed from the body. Similarly, a dog ulna from Period 2.2 (Context 740) bore approximately seven knife cuts on the posterior aspect of the shaft, distal to the medial articulation. This bone corresponds with the stifle joint, or elbow, which in the live animal lies very close to the surface of the skin. Hence it would be relatively easy to cut through to the bone when removing the pelt. 
When the butchered horse bones are considered, however, it seems feasible, given the evidence, that not only were carcasses skinned, but meat was removed, presumably to be eaten. Long bones were chopped across the shaft in a manner identical to that used in butchering cattle. Whether the meat was then eaten by humans or used as dog food is not known, but there is ample evidence from Scottish urban sites of medieval and post-medieval date for the practice of horse butchery (Smith 1998). Interestingly, eight horse bones out of a total number of 45 (17.8\%) from Periods 2 and 4, show some evidence of butchery. Another process which may have been carried out involves boiling hooves in order to produce glue. Thus a horse phalange or toe bone was marked by several parallel knife cuts which indicated either skinning of the lower limb, or perhaps removal of the soft tissue, to be used in glue manufacture.

The types of cuts produced on the bones are characteristic of the fleshing implements used. Thus skinning and meat removal was usually carried out with metal blades, which produce a typical V-shaped profile. Long bone shafts were chopped or hacked mediolaterally (from side to side), sagittally (lengthwise, in the median plane) or dorso-ventrally (lengthwise, at right-angles to the median plane), generally by means of axes or cleavers. Vertebrae were also chopped with axes rather than saws. There was little evidence of sawing at the site in Periods 1 to 4.1 .

The butcher's axe is referred to in early burgh records of Scotland, the Statuta Gilda (Innes \& Thomson 1854, I, 436), under the term securis (simply, an axe). The axe, as a symbol of the trade, often appears on post-medieval gravestones and in heraldic devices such as the coat of arms of the Nine Incorporated Trades of Dundee, displayed in St Andrews Trades Kirk (built 1722) (Smith 1995, Fig. 1). Here, the axe is shown as possessing a curving handle and flat, almost quadrilateral blade, curving at the leading edge. It is crossed in the coat of arms with a pole-axe, the implement used both to dispatch the animal and then dismember it. The pole-axe is hafted centrally with a long handle, and the posterior part of the blade terminates with a cylindrical knob. This is probably the implement known from medieval documents as securis danica. The beast was tethered to a low ring in the floor so that its head was lowered almost to the ground; the knob of the pole-axe was then driven into the beast's skull. Roping the animal in this way is no longer legal, but was previously the most common method used (Gerrard 1977, 66).

\section{Size AND STATURE OF ANimALS}

Anatomical measurements were made on the bones where the conditions of preservation allowed (after von den Driesch 1976; table 2.17). Abraded or eroded bones were not measured, with very few exceptions (where withers heights could not otherwise be estimated). A summary of measurements is available in the site archive. With the single exception of a dog bone from Period 1, all other measurements were made on bones from medieval Period 2 or the post-medieval period (Periods 3 and 4) and have been grouped together accordingly in order to aid comparison.

Unfortunately, the number of cattle measurements available was small in both the medieval group (Period 2) and the post-medieval group (Periods 3 and 4). Comparison with the largest Scottish urban medieval assemblage currently known, that recovered from the excavation at 75-7 High Street, Perth (Perth High Street Excavations (PHSE); Hodgson et al forthcoming) indicates that all of the bones from the Scottish Parliament site fell within the PHSE size ranges. However, comparing mean measurements from both sites indicates that the Parliament means were in many cases slightly greater than those for PHSE. As already stated, however, the Parliament measurement sample is extremely small and it is not feasible to compare them statistically. As an example, a single cattle metatarsal with greatest length (GL) of $208 \mathrm{~mm}$ was recovered from the Parliament site. The PHSE range was $178-215 \mathrm{~mm}$, but in this case 73 examples were found, with a mean metatarsal length of $198 \mathrm{~mm}$. The Parliament example was thus $10 \mathrm{~mm}$ greater than the PHSE mean, but still well within the medieval size range. Estimated withers heights based on the metatarsal are $1.14 \mathrm{~m}$ for the Parliament beast and $0.97-1.17 \mathrm{~m}$ at PHSE. These animals would have been small by modern standards.

A greater number of measurements was available for sheep/ goat from the Parliament site. Comparison with sheep/goat bones from PHSE indicates that, as with the cattle, all of the bones fell within the medieval ranges at PHSE. Fourteen mean measurements from the Parliament sheep/goats lay above the corresponding PHSE means, three were below and five means were identical. The comparison between the two sets of measurements probably indicates populations of a similar stature.

Several intact sheep/goat long bones were recovered from the Parliament site, from which it was possible to calculate withers heights, or height at the shoulder (after Teichert 1975). Based on a complete radius, metacarpal and tibia, three medieval individuals were estimated to stand at $0.53 \mathrm{~m}, 0.56 \mathrm{~m}$ and $0.58 \mathrm{~m}$ respectively; all fell well within the medieval range estimated for PHSE of $0.46-0.66 \mathrm{~m}$. As for cattle, sheep at the Parliament site in both the medieval and post-medieval phases were small by modern standards, but were the norm for animals found at medieval Scottish sites.

Unfortunately, no measurements were available for pigs at the Parliament site, due partly to their very insignificant presence, and partly to poor preservation. The surviving bones, however, suggest that they were of a similar size to animals found at Scottish medieval sites. Indeed, pigs changed little in size in some remote parts of Scotland until the early years of the 20th century (Smith 2000b).

Survival of a few intact horse bones allowed estimation of the withers heights to be made, after the method of Kieswalter (quoted in Ambros \& Muller 1980, 30). A humerus and metatarsal from medieval Period 2.3 were estimated to come from small horses of $1.34 \mathrm{~m}$ and $1.19 \mathrm{~m}$ at the withers. Heights of live horses are usually expressed in hands, a unit of four inches. The heights of the Period 2.3 horses are equivalent to 13 hands and 11:3 hands respectively. Any horse of 14:2 hands $(1.48 \mathrm{~m})$ or under is defined as a pony and these two animals may be considered as such. An investigation into the heights of medieval Scottish horses (Smith 1998) showed that animals from Perth, Stirling, Aberdeen and Dunfermline did not exceed 14:2 hands height, and that in common with horses in medieval Lincoln, York and Southampton, heights clustered around 13 to 14 hands. The smallest Scottish animal came from Stirling, and at 12 hands was slightly taller than the 11:3 hands-high horse found in Period 2.3 of the Parliament site. 
Table 2.17 Size range summary

\section{Cattle}

\begin{tabular}{|c|c|c|c|c|c|c|c|}
\hline \multirow[b]{2}{*}{ Bone } & \multirow[b]{2}{*}{ Measurement } & \multicolumn{3}{|c|}{ Phases $2,3 \& 4$} & \multicolumn{3}{|c|}{ Phases $5 \& 6$} \\
\hline & & Range & $\mathbf{n}$ & Mean & Range & $\mathbf{n}$ & Mean \\
\hline \multirow[t]{4}{*}{ Horn core } & $\max$ & $36.0-47.0$ & 3 & 40.0 & & & \\
\hline & $\min$ & $31.5-39.0$ & 3 & 57.6 & & & \\
\hline & $\mathrm{BC}$ & 106-135 & 3 & 116.7 & & & \\
\hline & OC & $\star 100-157$ & 3 & 119 & & & \\
\hline \multirow[t]{2}{*}{ Axis } & $\mathrm{BF} \mathrm{cr}$ & & & & 87.4 & 1 & \\
\hline & SBV & & & & 47.8 & 1 & \\
\hline Scapula & SLC & 46.0 & 1 & & & & \\
\hline \multirow[t]{4}{*}{ Radius } & $\mathrm{Bp}$ & $69.4-70.4$ & 2 & 69.9 & & & \\
\hline & $\mathrm{BFp}$ & $64.2-65.8$ & 2 & 65.0 & & & \\
\hline & $\mathrm{Bd}$ & 57.8 & 1 & & & & \\
\hline & $\mathrm{BFd}$ & 56.0 & 1 & & & & \\
\hline \multirow[t]{2}{*}{ Metacarpal } & $\mathrm{Bp}$ & 54.6 & 1 & & & & \\
\hline & $\mathrm{Dp}$ & 31.8 & & & & & \\
\hline Innominate & LAR & 58.0 & 1 & & & & \\
\hline \multirow[t]{2}{*}{ Tibia } & $\mathrm{Bd}$ & $51.0-54.8$ & 4 & 52.9 & & & \\
\hline & $\mathrm{Dd}$ & $37.0-41.0$ & 3 & 39.5 & & & \\
\hline \multirow[t]{2}{*}{ Astragalus } & GLl & & & & $56.0-64.0$ & 2 & 60.0 \\
\hline & $\mathrm{Bd}$ & & & & $36.6-41.0$ & 2 & 38.8 \\
\hline Naviculo-cuboid & GB & 47.0 & 1 & & 51.6 & 1 & \\
\hline \multirow[t]{6}{*}{ Metatarsal } & GL & 208 & 1 & & & & \\
\hline & $\mathrm{Bp}$ & 45.0 & 1 & & & & \\
\hline & $\mathrm{Dp}$ & 42.9 & 1 & & & & \\
\hline & $\mathrm{Bd}$ & $46.4-49.0$ & 3 & 47.3 & & & \\
\hline & SD & 24.8 & 1 & & & & \\
\hline & $\mathrm{Dd}$ & 27.8 & 1 & & & & \\
\hline \multirow[t]{4}{*}{ 1st phalange } & GLpe & $48.2-51.8$ & 5 & 50.1 & $48.6-51.4$ & 2 & 50.0 \\
\hline & $\mathrm{Bp}$ & $24.6-28.0$ & 5 & 46.5 & $26.0-27.0$ & 2 & 26.5 \\
\hline & $\mathrm{Bd}$ & 25.2 & 1 & & $23.6-24.8$ & 2 & 24.2 \\
\hline & SD & $20.6-24.8$ & 3 & 22.3 & $20.6-23.2$ & 2 & 21.9 \\
\hline \multirow[t]{4}{*}{ 2nd phalange } & GL & & & & $31.0-32.0$ & 2 & 31.5 \\
\hline & $\mathrm{Bp}$ & & & & $23.0-24.0$ & 2 & 23.5 \\
\hline & $\mathrm{Bd}$ & & & & 18.6-19.8 & 2 & 19.2 \\
\hline & SD & 22.2 & 1 & & 18.6 & 1 & \\
\hline \multirow[t]{2}{*}{ 3rd phalange } & DLS & & & & 64.2 & 1 & \\
\hline & $\mathrm{Ld}$ & & & & 44.4 & 1 & \\
\hline
\end{tabular}


Table 2.17 (cont.) Size range summary

Sheep/goat

\begin{tabular}{|c|c|c|c|c|c|c|c|}
\hline \multirow[b]{2}{*}{ Bone } & \multirow[b]{2}{*}{ Measurement } & \multicolumn{3}{|c|}{ Phases $2,3 \& 4$} & \multicolumn{3}{|c|}{ Phases $5 \& 6$} \\
\hline & & Range & $\mathbf{n}$ & Mean & Range & $\mathbf{n}$ & Mean \\
\hline \multirow[t]{3}{*}{ Axis } & LCDe & & & & 57.0 & 1 & \\
\hline & $\mathrm{BF} c \mathrm{r}$ & & & & 41.5 & 1 & \\
\hline & SBV & 23.0 & 1 & & 25.0 & 1 & \\
\hline \multirow[t]{2}{*}{ Scapula } & SLC & $16.4-20.4$ & 8 & 19.2 & $18.0-20.2$ & 2 & 19.0 \\
\hline & GLP & $29.8-35.6$ & 8 & 32.5 & & & \\
\hline \multirow[t]{5}{*}{ Humerus } & $\mathrm{Bp}$ & & & & 38.6 & 1 & \\
\hline & $\mathrm{Bd}$ & $28.2-32.0$ & 7 & 29.2 & $28.3-32.0$ & 2 & 30.1 \\
\hline & $\mathrm{BT}$ & $26.2-28.6$ & 5 & 27.1 & 27.6 & 1 & \\
\hline & $\mathrm{HT}$ & $16.0-19.6$ & 9 & 17.5 & 14.8 & 1 & \\
\hline & HTC & $13.0-15.4$ & 9 & 14.0 & 18.2 & 1 & \\
\hline \multirow[t]{4}{*}{ Radius } & GL & 131.0 & 1 & & & & \\
\hline & $\mathrm{Bp}$ & $27.8-32.4$ & 8 & 30.0 & 30.8 & 1 & \\
\hline & $\mathrm{Bd}$ & $26.0-26.8$ & 2 & 26.4 & & & \\
\hline & $\mathrm{SD}$ & $15.0-15.2$ & 2 & 15.1 & & & \\
\hline \multirow[t]{2}{*}{ Ulna } & DPA & $23.9-25.0$ & 3 & 24.5 & 28.6 & 1 & \\
\hline & SDO & $19.8-21.4$ & 2 & 20.6 & 25.1 & 1 & \\
\hline \multirow[t]{3}{*}{ Metacarpal } & GL & $\star 115$ & 1 & & & & \\
\hline & $\mathrm{Bp}$ & 23.0 & 1 & & $17.6-21.6$ & 2 & 19.6 \\
\hline & $\mathrm{Bd}$ & $25.2-28.0$ & 2 & 26.6 & & & \\
\hline Innominate & LAR & 23.4 & 1 & & & & \\
\hline \multirow[t]{3}{*}{ Femur } & $\mathrm{Bp}$ & 46.0 & 1 & & & & \\
\hline & $\mathrm{Dp}$ & 20.3 & 1 & & 20.0 & 1 & \\
\hline & $\mathrm{Bd}$ & 37.6 & 1 & & & & \\
\hline \multirow[t]{5}{*}{ Tibia } & GL & 194 & 1 & & & & \\
\hline & $\mathrm{Bp}$ & $39.2-42.2$ & 2 & 40.7 & & & \\
\hline & $\mathrm{Bd}$ & $24.2-26.0$ & 5 & 25.2 & $23.8-27.6$ & 5 & 25.2 \\
\hline & $\mathrm{Dd}$ & $19.2-20.4$ & 3 & 19.7 & $18.2-22.8$ & 5 & 19.8 \\
\hline & $\mathrm{SD}$ & $13.8-14.8$ & 3 & 14.3 & & & \\
\hline Calcaneum & GL & 59.8 & 1 & & 47.2 & 1 & \\
\hline Naviculo-cuboid & GB & & & & 22.8 & 1 & \\
\hline \multirow[t]{5}{*}{ Metatarsal } & $\mathrm{Bp}$ & 19.2 & 1 & & 20.8 & 1 & \\
\hline & $\mathrm{Dp}$ & 20.0 & 1 & & & & \\
\hline & $\mathrm{Bd}$ & $21.8-24.0$ & 3 & 22.7 & 24.8 & 2 & 24.8 \\
\hline & $\mathrm{Dd}$ & $14.6-17.0$ & 2 & 15.8 & 16.2 & 1 & \\
\hline & SD & $10.0-14.8$ & 2 & 12.4 & 16.2 & 1 & \\
\hline \multirow[t]{3}{*}{ 1st phalange } & GLpe & 33.0 & 1 & & 32.0 & 1 & \\
\hline & $\mathrm{Bp}$ & 13.0 & 1 & & 17.4 & 1 & \\
\hline & SD & $8.2-10.1$ & 2 & 9.2 & 10.2 & 1 & \\
\hline 2nd phalange & $\mathrm{Bd}$ & 7.8 & 1 & & & & \\
\hline
\end{tabular}


Table 2.17 (cont.) Size range summary

Horse

\begin{tabular}{|c|c|c|c|c|c|c|c|}
\hline \multirow[b]{2}{*}{ Bone } & \multirow[b]{2}{*}{ Measurement } & \multicolumn{3}{|c|}{ Phases $2,3 \& 4$} & \multicolumn{3}{|c|}{ Phases $5 \& 6$} \\
\hline & & Range & $\mathbf{n}$ & Mean & Range & $\mathbf{n}$ & Mean \\
\hline \multirow[t]{4}{*}{ Atlas } & GL & 90.2 & 1 & & & & \\
\hline & GB & 134.4 & 1 & & & & \\
\hline & $\mathrm{BF} \mathrm{cr}$ & 87.2 & 1 & & & & \\
\hline & $\mathrm{BFcd}$ & 80.2 & 1 & & & & \\
\hline \multirow[t]{2}{*}{ Scapula } & SLC & & & & 69.2 & 1 & \\
\hline & GLP & & & & 95.4 & 1 & \\
\hline \multirow[t]{10}{*}{ Humerus } & GL & 278 & 1 & & & & \\
\hline & GLl & 275 & 1 & & & & \\
\hline & $\mathrm{Bp}$ & 90.4 & 1 & & & & \\
\hline & $\mathrm{Bd}$ & $73.0-77.4$ & 2 & 75.2 & & & \\
\hline & $\mathrm{BT}$ & $69.8-72.0$ & 2 & 70.9 & & & \\
\hline & $\mathrm{HT}$ & 44.4 & 1 & & & & \\
\hline & & 34.6 & 1 & & & & \\
\hline & & 35.6 & 1 & & & & \\
\hline & HTC & 34.6 & 1 & & & & \\
\hline & SD & 35.6 & 1 & & & & \\
\hline \multirow[t]{5}{*}{ Radius } & $\mathrm{Bp}$ & 78.2 & 1 & & & & \\
\hline & BFp & 70.4 & 1 & & & & \\
\hline & $\mathrm{Bd}$ & 73.3 & 1 & & & & \\
\hline & $\mathrm{BFd}$ & 62.4 & 1 & & & & \\
\hline & SD & 36.0 & 1 & & & & \\
\hline \multirow[t]{2}{*}{ Ulna } & DPA & $56.0-62.4$ & 2 & 59.2 & & & \\
\hline & SDO & 42.5 & 1 & & & & \\
\hline \multirow[t]{7}{*}{ Metacarpal } & GL & & & & $241-247$ & 2 & 244 \\
\hline & $\mathrm{Ll}$ & & & & $231-240$ & 2 & 235.5 \\
\hline & $\mathrm{Bp}$ & & & & $55.0-55.8$ & 2 & 55.4 \\
\hline & $\mathrm{Dp}$ & & & & 35.2 & 1 & \\
\hline & $\mathrm{SD}$ & & & & $37.4-37.7$ & 2 & 37.6 \\
\hline & $\mathrm{Bd}$ & & & & $52.4-53.6$ & 2 & 53.0 \\
\hline & $\mathrm{Dd}$ & & & & $39.2-39.6$ & 2 & 39.4 \\
\hline \multirow[t]{2}{*}{ Patella } & GL & 67.2 & 1 & & & & \\
\hline & GB & 67.0 & 1 & & & & \\
\hline \multirow[t]{2}{*}{ Tibia } & $\mathrm{Bd}$ & 72.0 & 1 & & & & \\
\hline & $\mathrm{Dd}$ & 43.6 & 1 & & & & \\
\hline \multirow[t]{4}{*}{ Astragalus } & $\mathrm{LmT}$ & 50.5 & 1 & & & & \\
\hline & $\mathrm{BFd}$ & 44.6 & 1 & & & & \\
\hline & GB & 54.0 & 1 & & & & \\
\hline & GH & 51.0 & 1 & & & & \\
\hline Calcaneum & GL & $83.0-110.5$ & 3 & 99.8 & & & \\
\hline \multirow[t]{4}{*}{ Metatarsal } & GL & 230 & 1 & & 296 & 1 & \\
\hline & $\mathrm{Ll}$ & 223 & 1 & & 293 & 1 & \\
\hline & $\mathrm{Bp}$ & 42.8 & 1 & & 58.0 & 1 & \\
\hline & $\mathrm{Dp}$ & 34.4 & 1 & & 49.0 & 1 & \\
\hline
\end{tabular}


Table 2.17 (cont.) Size range summary

Horse (cont.)

\begin{tabular}{|c|c|c|c|c|c|c|c|}
\hline \multirow[b]{2}{*}{ Bone } & \multirow[b]{2}{*}{ Measurement } & \multicolumn{3}{|c|}{ Phases $2,3 \& 4$} & \multicolumn{3}{|c|}{ Phases $5 \& 6$} \\
\hline & & Range & $\mathbf{n}$ & Mean & Range & $\mathbf{n}$ & Mean \\
\hline \multirow{8}{*}{ 1st phalange } & $\mathrm{Bd}$ & 42.4 & 1 & & & & \\
\hline & $\mathrm{Dd}$ & 32.6 & 1 & & & & \\
\hline & SD & 26.2 & 1 & & 35.4 & 1 & \\
\hline & GL & & & & $73.0-85.0$ & 3 & 790.2 \\
\hline & $\mathrm{Bp}$ & & & & $50.0-58.0$ & 3 & 52.7 \\
\hline & $\mathrm{BFp}$ & & & & $45.8-52.6$ & 2 & 49.2 \\
\hline & $\mathrm{Dp}$ & & & & $35.0-37.8$ & 2 & 36.4 \\
\hline & $\mathrm{SD}$ & & & & $30.2-37.7$ & 3 & 33.8 \\
\hline \multirow{7}{*}{ 2nd phalange } & $\mathrm{Bd}$ & & & & $39.9-50.8$ & 2 & 45.4 \\
\hline & $\mathrm{BFd}$ & & & & $37.2-46.8$ & 3 & 42.7 \\
\hline & $\mathrm{Dd}$ & & & & 25.5 & 1 & \\
\hline & GL & 47.9 & 1 & & $47.4-50.0$ & 2 & 48.7 \\
\hline & $\mathrm{Bp}$ & 50.6 & 1 & & $53.8-56.2$ & 2 & 55.0 \\
\hline & $\mathrm{BFp}$ & 43.8 & 1 & & $31.2-49.6$ & 2 & 40.4 \\
\hline & $\mathrm{Bd}$ & 44.6 & 1 & & & & \\
\hline \multirow{3}{*}{ 3rd phalange } & SD & 39.8 & 1 & & $43.6-48.4$ & 2 & 46.0 \\
\hline & $\mathrm{BF}$ & $46.0-61.6$ & 2 & 53.8 & 50.0 & 1 & \\
\hline & $\mathrm{LF}$ & $25.6-26.4$ & 2 & 26.0 & & & \\
\hline
\end{tabular}

Dog - Phase 1

\begin{tabular}{lccc}
\hline Bone & Measurement & Range & n \\
\hline Radius & GL & 221 & 1 \\
& Bp & 22.4 & 1 \\
& Bd & 29.8 & 1 \\
Innominate & SD & 16.2 & 1 \\
& LAR & 26.4 & 1 \\
\hline
\end{tabular}

Dog - other phases

\begin{tabular}{|c|c|c|c|c|c|c|c|}
\hline \multirow[b]{2}{*}{ Bone } & \multirow[b]{2}{*}{ Measurement } & \multicolumn{3}{|c|}{ Phases $2,3 \& 4$} & \multicolumn{3}{|c|}{ Phases $5 \& 6$} \\
\hline & & Range & $\mathbf{n}$ & Mean & Range & $\mathbf{n}$ & Mean \\
\hline \multirow[t]{4}{*}{ Humerus } & $\mathrm{Bp}$ & & & & 18.4 & 1 & \\
\hline & $\mathrm{Dp}$ & & & & 23.0 & 1 & \\
\hline & $\mathrm{Bd}$ & & & & 21.0 & 1 & \\
\hline & SD & & & & 8.0 & 1 & \\
\hline \multirow[t]{2}{*}{ Ulna } & DPA & 30.4 & 1 & & & & \\
\hline & SDO & 26.4 & 1 & & & & \\
\hline \multirow[t]{2}{*}{ Metatarsal III } & GL & & & & 86.8 & 1 & \\
\hline & $\mathrm{Bd}$ & & & & 12.0 & 1 & \\
\hline
\end{tabular}


Table 2.17 (cont.) Size range summary

Cat

\begin{tabular}{|c|c|c|c|c|c|c|c|}
\hline \multirow[b]{2}{*}{ Bone } & \multirow[b]{2}{*}{ Measurement } & \multicolumn{3}{|c|}{ Phases $2,3 \& 4$} & \multicolumn{3}{|c|}{ Phases $5 \& 6$} \\
\hline & & Range & $\mathbf{n}$ & Mean & Range & $\mathbf{n}$ & Mean \\
\hline Humerus & $\mathrm{Bd}$ & & & & 17.4 & 1 & \\
\hline Ulna & DPA & & & & 11.0 & 1 & \\
\hline \multirow[t]{4}{*}{ Femur } & GL & & & & 130.0 & 1 & \\
\hline & $\mathrm{Bp}$ & & & & 19.4 & 1 & \\
\hline & $\mathrm{Bd}$ & & & & 17.2 & 1 & \\
\hline & $\mathrm{SD}$ & & & & 9.0 & 1 & \\
\hline \multirow[t]{2}{*}{ Tibia } & $\mathrm{Bd}$ & 12.4 & 1 & & & & \\
\hline & SD & 6.4 & 1 & & & & \\
\hline
\end{tabular}

Roe deer

\begin{tabular}{lccccccc}
\hline & & Phases 2, 3 \& 4 & & Phases 5 \& 6 \\
Bone & Measurement & Range & n & Mean & Range & n & Mean \\
\hline Tibia & Bp & 40.6 & 1 & & & \\
\hline
\end{tabular}

Domestic fowl (Gallus gallus)

\begin{tabular}{|c|c|c|c|c|c|c|c|}
\hline \multirow[b]{2}{*}{ Bone } & \multirow[b]{2}{*}{ Measurement } & \multicolumn{3}{|c|}{ Phases $2,3 \& 4$} & \multicolumn{3}{|c|}{ Phases $5 \& 6$} \\
\hline & & Range & $\mathbf{n}$ & Mean & Range & $\mathbf{n}$ & Mean \\
\hline \multirow[t]{3}{*}{ Coracoid } & GL & & & & $48.8-55.3$ & 3 & 52.5 \\
\hline & LM & & & & $50.4-52.0$ & 2 & 52.2 \\
\hline & $\mathrm{BF}$ & & & & 13.0 & 2 & 13.0 \\
\hline Scapula & $\mathrm{DiC}$ & & & & $11.2-11.4$ & 2 & 11.3 \\
\hline \multirow[t]{4}{*}{ Humerus } & GL & $71.9-72.8$ & 2 & 72.4 & & & \\
\hline & $\mathrm{Bp}$ & $17.4-21.0$ & 3 & 19.2 & & & \\
\hline & $\mathrm{Bd}$ & $15.4-15.8$ & 2 & 15.6 & 14.4 & 1 & \\
\hline & $\mathrm{SC}$ & 7.6 & 2 & 7.6 & & & \\
\hline \multirow[t]{4}{*}{ Ulna } & GL & & & & $60.6-70.6$ & 3 & 69.3 \\
\hline & $\mathrm{Bp}$ & & & & $8.4-10.9$ & 8 & 9.0 \\
\hline & Did & & & & $8.2-10.0$ & 8 & 9.0 \\
\hline & $\mathrm{SC}$ & & & & $3.9-5.6$ & 4 & 4.7 \\
\hline \multirow{3}{*}{$\begin{array}{l}\text { Carpo-meta- } \\
\text { carpus }\end{array}$} & GL & & & & $35.4-35.6$ & 2 & 35.5 \\
\hline & $\mathrm{Bp}$ & & & & $10.3-11.6$ & 2 & 10.8 \\
\hline & $\mathrm{Bd}$ & & & & 7.1 & 1 & \\
\hline \multirow[t]{4}{*}{ Femur } & GL & & & & $70.0-86.2$ & 5 & 76.1 \\
\hline & $\mathrm{Bp}$ & & & & $14.0-19.0$ & 10 & 15.6 \\
\hline & $\mathrm{Bd}$ & 16.8 & 1 & & $14.2-17.4$ & 9 & 15.1 \\
\hline & SC & 7.9 & 1 & & $6.0-7.7$ & 7 & 6.9 \\
\hline \multirow[t]{4}{*}{ Tibio-tarsus } & GL & 113.6 & 1 & & 96.8 & 1 & \\
\hline & Dip & 22.6 & 1 & & $12.7-22.2$ & 4 & 17.4 \\
\hline & $\mathrm{Bd}$ & $12.0-12.6$ & 2 & 12.3 & $10.0-14.6$ & 7 & 11.7 \\
\hline & SC & $6.6-7.4$ & 2 & 7.0 & 5.4 & 2 & 5.4 \\
\hline \multirow[t]{2}{*}{ Tarso-metatarsus } & $\mathrm{Bp}$ & 11.8 & 1 & & & & \\
\hline & $\mathrm{Bd}$ & 12.2 & 1 & & 15.2 & 1 & \\
\hline
\end{tabular}


Table 2.17 (cont.) Size range summary

Goose (Anser anser)

\begin{tabular}{|c|c|c|c|c|c|c|c|}
\hline \multirow[b]{2}{*}{ Bone } & \multirow[b]{2}{*}{ Measurement } & \multicolumn{3}{|c|}{ Phases $2,3 \& 4$} & \multicolumn{3}{|c|}{ Phases $5 \& 6$} \\
\hline & & Range & $\mathbf{n}$ & Mean & Range & $\mathbf{n}$ & Mean \\
\hline Radius & $\mathrm{Bd}$ & & & & 10.8 & 1 & \\
\hline Ulna & $\mathrm{Bd}$ & & & & 13.4 & 1 & \\
\hline Tibio-tarsus & $\mathrm{Bd}$ & & & & 18.6 & 1 & \\
\hline
\end{tabular}

Duck cf Mallard (Anas platyrhynchos)

\begin{tabular}{|c|c|c|c|c|c|c|c|}
\hline \multirow[b]{2}{*}{ Bone } & \multirow[b]{2}{*}{ Measurement } & \multicolumn{3}{|c|}{ Phases $2,3 \& 4$} & \multicolumn{3}{|c|}{ Phases $5 \& 6$} \\
\hline & & Range & $\mathbf{n}$ & Mean & Range & $\mathbf{n}$ & Mean \\
\hline Humerus & $\mathrm{Bp}$ & & & & 20.1 & 1 & \\
\hline $\begin{array}{l}\text { Carpo-meta- } \\
\text { carpus }\end{array}$ & Did & & & & 7.4 & 1 & \\
\hline \multirow[t]{4}{*}{ Femur } & GL & & & & 50.8 & 1 & \\
\hline & $\mathrm{Bp}$ & & & & 13.4 & 1 & \\
\hline & $\mathrm{Bd}$ & & & & 12.6 & 1 & \\
\hline & $\mathrm{SC}$ & & & & 5.1 & 1 & \\
\hline
\end{tabular}

Note: Measurements are made according to the scheme of von den Driesch (1976) and are expressed in millimetres. Additional measurements on the humerus are after Legge and Rowley-Conwy (1988). Horn core measurements are as follows: $\max .=$ maximum diameter; min $=$ minimum diameter; OC $=$ outer curvature; $\mathrm{BC}=$ basal circumference; ${ }^{\star}$ indicates an estimated measurement.

In the post-medieval period at Parliament, there was some evidence of animals which stood taller than pony height.Thus, two metacarpals from Period 4.1 were estimated to come from animals of 14:2 hands/1.48m (a pony) and 15 hands/ $1.54 \mathrm{~m}$ (a horse). One fragmentary skeleton from Period 3 had an estimated withers height of $15: 1$ hands $/ 1.56 \mathrm{~m}$. The smaller medieval ponies may have been pack animals, but the larger post-medieval individuals may well have been riding horses.

Two bones of dog, probably from the same individual, were amongst the very small animal bone sample from early medieval Period 1. This animal proved to be a large one, standing at approximately $0.72 \mathrm{~m}$ high at the shoulder, calculated using the method of Harcourt (1974). In a study of medieval Scottish dogs, the archaeological evidence showed that the largest animal came from a site at Meal Vennel in Perth, and was approximately $0.64 \mathrm{~m}$ tall at the shoulder (Smith 1998, 862). Another tall individual is known from the Byre Theatre site in St Andrews, of about $0.7 \mathrm{~m}$ (Smith 2001). However, the shoulder height of the Byre dog was calculated by a different method, that of Clark $(1995,22)$, based on the metapodials, and thus there is a danger of not comparing like with like. The dog from Period 1 at the Parliament site is, however, probably still slightly larger than other known medieval individuals. It may represent a hunting animal.

A dog ulna from Period 3 also came from a large animal, of approximately $0.71 \mathrm{~m}$ shoulder height. In Period 4.1, a postmedieval dog metatarsal was estimated to have come from an animal of approximately $0.65 \mathrm{~m}$, using Clark's (1995) factors. The dog bones from the Parliament site are interesting in that the medieval examples are larger than those already known from Scotland.

The assemblage of cat bones from the site was unfortu- nately small. Of the measurable material, the single medieval bone, a tibia from Period 2.3, fell within the known range at PHSE, as did a post-medieval humerus and ulna. A single large femur from post-medieval Period 3 was much larger than typical medieval examples. However, since medieval cats appear to have been much smaller than their modern-day equivalents, this is possibly not surprising. It may have come from a large male domestic cat, or even the wild species, although there is no proven method for distinguishing between the long bones of the two.

Measurable bones of domestic fowl were present in both the medieval and post-medieval periods, although perhaps more plentiful in the latter. However, with one exception (a proximal femur), both the medieval and post-medieval birds were within the PHSE ranges (Smith \& Clark forthcoming). Similarly, the goose bones were within the PHSE ranges.

\section{AbNORMALITIES OF BONE}

A catalogue of abnormal bones is presented in table 2.18. In general, these abnormalities were infrequent and often fairly insignificant and only the most severe are discussed here. Cattle, sheep/goats and horses were the only species affected. The poor condition of the bones may, however, be responsible for the apparently low incidence of diseases affecting the skeleton.

\section{Dental abnormalities}

Dental abnormality was apparent on a cattle incisor (Period 2.3) which displayed a degree of enamel hypoplasia on its buccal surface. This condition manifests as ridges in the tooth enamel and is caused by disruption during the period when 
Table 2.18 Catalogue of abnormal bone

\begin{tabular}{|c|c|c|c|c|c|}
\hline Phase & Context & IADB & Species & Bone & Details \\
\hline $3 \mathrm{H}-\mathrm{ex}$ & 1568 & 4196 & Cattle & 1st phalange & Extension of proximal articulation. \\
\hline $4 \mathrm{~S}$ & 794 & 2421 & Cattle & L mandible & $\begin{array}{l}\text { PM2 absent. Alveolus pitted and rough. Probable ante-mortem } \\
\text { tooth loss. }\end{array}$ \\
\hline 4 H-ex & 694 & 1879 & Cattle & 1st phalange & $\begin{array}{l}1 \text { Type } 1 \text { lesion in proximal articulation; } 1 \text { large lesion, distal; } \\
\text { extension of distal articulation. }\end{array}$ \\
\hline $4 \mathrm{H}-\mathrm{ex}$ & 726 & 2245 & Cattle & Skull & $\begin{array}{l}\text { Smooth-edged perforations in parietal. Eight holes present, varying } \\
\text { in diameter from } 4.8 \mathrm{~mm} \text { to } 11.2 \mathrm{~mm} \text {. Distributed mainly in centre } \\
\text { and on right parietal with exception of one hole near junction of } \\
\text { left frontal. }\end{array}$ \\
\hline $4 \mathrm{H}-\mathrm{ex}$ & 776 & 2391 & Cattle & Tooth & Incisor; enamel hypoplasia on buccal surface. \\
\hline 4 H-ex & 811 & 2505 & Horse & L calacaneum & $\begin{array}{l}\text { Small interarticular lesion on sustentaculum (articulation for astra- } \\
\text { galus). Slight bone deposition around edge of facet. Slight degree of } \\
\text { eburnation corresponding to articular facet of astragalus (q v). }\end{array}$ \\
\hline 4 H-ex & 811 & 2505 & Horse & $\mathrm{L}$ astragalus & $\begin{array}{l}\text { Bone deposition and slight eburnation on articulation for } \\
\text { calcaneum (q v). Slight eburnation and interarticular lesion on } \\
\text { medial edge of navicular facet. }\end{array}$ \\
\hline $4 \mathrm{H}-\mathrm{ex}$ & 811 & 2505 & Horse & $\begin{array}{l}\text { Lateral splint } \\
\text { (metatarsal I) }\end{array}$ & $\begin{array}{l}\text { Interarticular lesion around edge of proximal articulation. Associ- } \\
\text { ated with astragalus, calcaneum above, as well as metatarsal II/III } \\
\text { and medial splint; represents lower left hind leg. }\end{array}$ \\
\hline 4 H-ex & 825 & 2580 & $\begin{array}{l}\text { Large Ungulate } \\
\text { (cf horse) }\end{array}$ & Thoracic vertebra & $\begin{array}{l}\text { Caudal articulation of vertebral centrum and rib facets deeply } \\
\text { pitted and eroded; extension of articular facets; bone deposition } \\
\text { extending to body of vertebra, ventral. Slight eburnation on caudal } \\
\text { rib facet. Rib facets on cranial aspect are extended. }\end{array}$ \\
\hline 4 H-ex & 825 & 2580 & $\begin{array}{l}\text { Large Ungulate } \\
\text { (cf horse) }\end{array}$ & Ribs & $\begin{array}{l}\text { Three examples with new bone formation on shafts. May be associ- } \\
\text { ated with above vertebra. }\end{array}$ \\
\hline 5 H-ex & 1620 & 4526 & Sheep/goat & Tooth & Lower M3 Fifth cusp reduced. Root twisted and deformed. \\
\hline $6 \mathrm{H}-\mathrm{ex}$ & 236 & 383 & Sheep/goat & Metatarsal (distal) & $\begin{array}{l}\text { New porous bone formation on anterior ridge of shaft (? caused by } \\
\text { lifting of periosteum; traumatic damage). }\end{array}$ \\
\hline $6 \mathrm{H}-\mathrm{ex}$ & 859 & 3385 & Sheep/goat & $\begin{array}{l}\text { R metatarsal } \\
\text { (distal) }\end{array}$ & $\begin{array}{l}\text { Medial distal trochlea extended. Interarticular lesions present on } \\
\text { bony extension. }\end{array}$ \\
\hline $6 \mathrm{H}-\mathrm{ex}$ & 859 & 3385 & Horse & Navicular tarsals & $\begin{array}{l}\text { Fused tarsals: navicular, lateral cuneiform and mid cuneiform. } \\
\text { Specimen in poor, abraded condition, but some evidence of interar- } \\
\text { ticular lesions on lateral cuneiform and slight new bone growth. }\end{array}$ \\
\hline
\end{tabular}

the tooth is forming in the jaw. An infectious or other serious illness during this formative period is sufficient to cause such a disruption. Possible ante-mortem tooth loss was observed in a cattle mandible from Period 2.3. Here, the lower second premolar was absent and the corresponding alveolar region of the jaw was pitted and roughened, which would not be the case if the absence had been congenital. The tooth is most likely to have been lost because of the effects of periodontal disease, or possibly traumatic damage. A further dental abnormality was noted in a sheep/goat third molar, in which the fifth cusp was of a reduced size. This abnormality occurs fairly regularly in archaeological material, and has been observed in Scottish cattle, sheep/goats and red deer from the Iron Age onwards. It is thought to be congenital in origin (Andrews \& Noddle 1975) and would have had no effect on the health of the affected animals.

\section{Abnormalities of joints}

A small collection of articulating horse tarsals, the remains of a left lower hind leg, was affected by interarticular lesions between the tarsals, bone deposition around the edges of articulating facets and slight eburnation (polishing) of the joint surfaces (Period 2.3). Affected were the calcaneum, astragalus and proximal articulation of the lateral splint (metatarsal I). The major metatarsal was also present but was not visibly affected. The condition may be described as spavin, which is an arthropathy of the hock joint. Baker and Brothwell $(1980,118)$ consider several causal factors to play a part in this disease, including bad conformation of the leg, faulty shoeing, heavy work and concussion against hard surfaces. Spavin interferes with the flexion of the joint and results in lameness, most obvious when the horse first comes out of the stable, but decreasing with exercise (Smythe \& Goody 1975, 66). Incidentally, the Parliament horse bones bore evidence of knife cuts, and it is interesting to speculate that the animal was deliberately culled and skinned because of its lameness.

A further group of horse tarsals (Period 4.1) was fused together by a disease process. The group consisted of the navicular tarsal, lateral cuneiform and mid cuneiform, and there was some evidence of interarticular lesions on the lateral cuneiform accompanied by slight new bone growth. This is probably also a case of spavin which would have resulted in lameness. 
An arthritic condition was noted on a large ungulate (most probably horse) thoracic vertebrae and three associated ribs. The vertebra was affected by extensive new bone formation, extension of the articular surfaces, eburnation on the caudal rib facet and pitting of the articular surfaces, while the ribs were affected by a well-developed new bone growth on the shafts. The pathology meets the criteria for osteoarthritis (Baker \& Brothwell 1980, 115). As with the horses affected by spavin, this animal may have been culled because of its poor state of health.

\subsubsection{Discussion of the mammalian and bird remains}

Perhaps the most notable aspect of the Parliament faunal assemblage is the dominance of sheep/goats over cattle. This is at first sight unusual in a medieval urban context, since at most of the sites which have been investigated to date, cattle have been the predominant species (see Smith 1996, table 4 for a summary of relative frequencies for sites in Perth). It is thought that bulk sieving did not bias the retrieval of bones in favour of sheep/goats, and the reason for their prevalence may have more to do with factors of site economy than with taphonomy.

Although sheep bones were also in the majority at Queensberry House, the bias towards sheep with respect to cattle was not so marked as outside the building. Several factors may be responsible for this difference: firstly, the conditions of preservation outside the building may not have been identical to those at Queensberry House. Here, bones showed evidence of better preservation, probably because of the presence of lime mortar and crushed oyster shell in the surrounding deposits ensuring less acidic (and thus more favourable) conditions. Secondly, some of the material from Queensberry House was recovered from a long-term watching brief, rather than controlled excavation. These factors may have favourably affected the retrieval of cattle bones with respect to sheep bones at Queensberry House.

To date, the majority of excavations at medieval sites have taken place on Scotland's north-eastern seaboard, but despite this geographical similarity, there is a clear contrast with the Parliament site, at least as regards the relative frequencies of the most economically important species. As noted above, however, investigations in medieval Peebles have also recovered evidence of a primarily sheep-based economy, which continued into the post-medieval period. In the Borders, the influence of the great medieval religious houses of Melrose, Jedburgh, Dryburgh and Kelso provided the impetus for sheep-rearing, and it may be that the Abbey of Holyrood, intimately associated with the burgh of Canongate, was similarly influential as regards the occupiers of the Parliament site.

Sheep were of vital importance in the economy of Scotland because of the wool and woolfells (skins with the wool still attached) which they produced. Customs raised on these products sustained the economic life of the burghs. In the later medieval period, an important trade took place between Edinburgh and Bruges in the Low Countries, involving hides, wool, woollen cloth and skins (Davidson \& Gray 1909, 130). The bones from the medieval phases of the Parliament site may reflect the importance of this trade. On the evidence of the Exchequer Rolls, Edinburgh raised more revenue on wool, woolfells and woollen cloth between 1460 and 1599 than any other Scottish burgh (Guy 1982, Fig. 3.1). Although the Parliament site was situated within the adjacent burgh of Canongate, rather than in Edinburgh itself, it is not unreasonable to suppose that the high relative frequency of sheep bones found at the site relates to this lucrative trade in sheep by-products. While sheep predominated, cattle hides were nevertheless an invaluable source of taxable revenue, and during the period between 1460 and 1599 the Exchequer Rolls indicate that Edinburgh was the top hide-exporting burgh in Scotland (ibid, Fig. 4.5).

In addition to the products of the larger domesticated mammals, documentary evidence shows that smaller animals were also exploited for their pelts. The record of the toll to be paid, the Assisa Tolloneis, records an early reference to the custom to be raised on different types of skins, or 'peloure': 'of a tymmyr of skynnis of toddis quytredis mertrikis cattis beveris sable firrettis ... iiijd'. In other words, a custom of fourpence was to be paid on a quantity of skins called a 'timmer', about 40 skins held between two boards, or timbers. These skins were of fox, stoats or weasels, martens, cats (wild or domestic), beavers, sables or ferrets. A timmer of squirrel ('skurel') skins, on the other hand, raised only twopence (APS, c2, I, 667). The presence of fox bones at the Parliament site is probably evidence of this trade in pelts.

However, as well as furs and hides from the more obvious domesticates, there is evidence from the site of skinned dogs and horses. This is not unusual in medieval and postmedieval Scotland: similar evidence has been found at sites in Perth, Inverness, Stirling, Aberdeen and Elgin (Smith 1998). However, at the Parliament site the skinning may be related to a tradition of leather workers living in the Canongate.

There was no evidence for any animal-related industry such as skinning having taken place at Queensberry House. Here, the bones were probably domestic in origin and indicated a diet containing the meat of cattle, sheep, pig, rabbit, hare, domestic poultry, partridge and marine shellfish.

Although it is not known whether any fleshers (butchers) inhabited the site, there is ample evidence on the animal bones for their activities. Interestingly, an entry in the Acts of Parliament of Scotland for the year 1540 'For policy in Edinburgh' warns all fleshers dwelling in the wynd on the east side of 'halzyrudhouse' against 'temyng of intellis of beistis generand corruptioun' under the pain of confiscation 'of all sic flesche slane' by the provost and baillies of Edinburgh and the Canongate (APS, c20, II, 374). The act seems to have been necessary because of the squalor caused by dumping of entrails in the streets 'quairby all strangearis and utheris ... passis and repassis' (ibid).

In addition to the large animals which were the fleshers' stock-in-trade, smaller creatures were killed and eaten. These included domestic poultry, wild birds such as grey partridge and red grouse and, in the later medieval period, rabbits. The relative prices of these in Edinburgh in the year 1553 indicate that the best quality 'cunnyng' (rabbit) should cost 18 pence, a capon 16 pence, a 'tame guis' 20 pence and a 'wild guis' the same (Davidson \& Gray 1909, 40). Smaller wild fowl are also listed; the range of birds sold and consumed in Edinburgh in the 16th century included partridge ('pordrik'), red grouse ('mure hen'), capercailzie, black grouse ('black cok' and 'gray hen'), woodcock, snipe, pigeon ('pudzeon'), wild duck ('wyld duik') and teal, which are all still consumed at the present day, 
as well as several species which are no longer commonly eaten: lapwing, plover, dotterell and larks or 'lawerocks', which sold at fourpence the dozen. To this list of edible birds might be added the cormorant and the black-headed gull, whose bones were found at the Parliament site in Period 4.1. The habitat of some of these wild birds and mammals may have been the environs of Arthur's Seat, described by Fynes Moryson in 1598 as being situated in a 'Parke of Hares, Conies and Deare' (Hume Brown 1891, 83).

The diet of the inhabitants of the Canongate also included large quantities of fish (Part 2.4) and shellfish, most notably oysters (tables 2.19 and 2.20). While many of the oyster shells found on site were coated with mortar, having apparently been used as pinning between masonry, it seems likely that the contents were eaten first. The oyster beds of the Forth were at one time extremely bountiful, and in the 18 th century supported a fishery based in Prestonpans, Cockenzie and Newhaven (Yonge 1960,157). In the late 16th century they yielded, according to Fynes Morison, 'plentifully ... (among other fish) store of oysters and shel fishes' (Hume Brown 1891, 85). A sense of the rate at which the Forth beds were depleted is indicated by the record of exports from the Port of Leith: in the year 1666, 721,000 casks went out through the port, yet in 1690, the number had fallen to 10,000 (Mowat 1994, 219). Now, alas the oyster beds in the Forth are extinct, mainly due to continued overfishing.

Table 2.19 Mollusc catalogue (hand-excavated contexts; for abbreviations, see table 2.20)

\begin{tabular}{|c|c|c|c|c|c|c|c|}
\hline \multirow[b]{2}{*}{ Phase } & \multirow[b]{2}{*}{ Context } & \multirow[b]{2}{*}{ IADB no. } & \multirow[b]{2}{*}{ Species } & \multicolumn{3}{|c|}{ Oyster (Ostrea edulis) } & \multirow[b]{2}{*}{ Other species } \\
\hline & & & & Upper & Lower & Fragment & \\
\hline 0 & 019 & 071 & Helix aspersa & & & & 11 \\
\hline 0 & 049 & 068 & Ostrea edulis & & & 1 & \\
\hline 0 & 143 & 073 & Ostrea & & 1 & & \\
\hline 0 & 145 & 075 & Ostrea & 2 & 4 & 3 & \\
\hline 0 & 176 & 033 & Littorina littorea & & & & 1 \\
\hline 0 & 182 & 078 & $\begin{array}{l}\text { Ostrea ( } 2 \text { valves have mortar } \\
\text { adhering) }\end{array}$ & 3 & & & \\
\hline 0 & 182 & 078 & Patella sp & & & & 1 \\
\hline 0 & 182 & 078 & Mytilus edulis & & & & 1 \\
\hline 0 & 190 & 533 & Ostrea & & 1 & & \\
\hline 0 & 685 & 1877 & Ostrea & & 1 & & \\
\hline 0 & 1000 & 059 & Ostrea & & 1 & & \\
\hline 0 & 1000 & 060 & Ostrea & 1 & 1 & & \\
\hline 0 & 1000 & 063 & Ostrea & & & & \\
\hline 0 & 1000 & 065 & Ostrea & 1 & 1 & & \\
\hline 0 & 1000 & 065 & Buccinum & & & & 1 \\
\hline 0 & 1000 & 369 & Aequipecten opercularis & & & & 1 \\
\hline 0 & 1000 & 369 & Ostrea & 21 & 18 & & \\
\hline 0 & 1000 & 369 & Buccinum & & & & 1 \\
\hline 0 & 1000 & 369 & Helix aspersa (land species) & & & & 3 \\
\hline 0 & 1000 & 4502 & Ostrea & 1 & 1 & & \\
\hline 0 & 1415 & 5009 & Ostrea & 1 & & & \\
\hline 0 & 1733 & 5000 & Ostrea & 11 & & & \\
\hline 1 & 756 & 2242 & Ostrea & 2 & 1 & + & \\
\hline 2 & 734 & 2248 & Ostrea & & & 3 & \\
\hline 2 & 745 & 2227 & Ostrea & 16 & 17 & + & \\
\hline 2 & 745 & 2227 & Nucella & & & & 1 \\
\hline 2 & 1726 & 4996 & Ostrea & 1 & 1 & + & \\
\hline 3 & 752 & 2208 & Ostrea & 1 & 1 & 1 & \\
\hline 3 & 763 & 2253 & Ostrea & 5 & 8 & & \\
\hline 3 & 763 & 2253 & L littorea & & & & 1 \\
\hline 3 & 763 & 2253 & Unidentified & & & + & \\
\hline 3 & 785 & 2486 & Ostrea & & 1 & & \\
\hline 3 & 1634 & 3516 & Ostrea & 1 & & & \\
\hline
\end{tabular}


Table 2.19 (cont.) Mollusc catalogue (hand-excavated contexts; for abbreviations, see table 2.20)

\begin{tabular}{|c|c|c|c|c|c|c|c|}
\hline \multirow[b]{2}{*}{ Phase } & \multirow[b]{2}{*}{ Context } & \multirow[b]{2}{*}{ IADB no. } & \multirow[b]{2}{*}{ Species } & \multicolumn{3}{|c|}{ Oyster (Ostrea edulis) } & \multirow[b]{2}{*}{ Other species } \\
\hline & & & & Upper & Lower & Fragment & \\
\hline 3 & 1640 & 4625 & Ostrea & 12 & 10 & 7 & \\
\hline 3 & 1640 & 4625 & Buccinum & & & & 1 \\
\hline 3 & 1727 & 4837 & Ostrea & 3 & 3 & & \\
\hline 3 & 1730 & 5018 & Ostrea & 1 & 1 & & \\
\hline 3 & 1730 & 5049 & Ostrea & 2 & & + & \\
\hline 3 & 1731 & 4429 & Ostrea & 3 & 1 & + & \\
\hline 3 & 1754 & 5006 & Ostrea & 3 & 4 & + & \\
\hline 4 & 668 & 1516 & Ostrea & 4 & 5 & & \\
\hline 4 & 668 & 1516 & Buccinum & & & 1 & \\
\hline 4 & 679 & 1952 & Ostrea & 2 & 4 & 3 & \\
\hline 4 & 687 & 1885 & Ostrea & & 1 & & \\
\hline 4 & 694 & 1880 & Ostrea & 8 & 7 & 1 & \\
\hline 4 & 697 & 1817 & Ostrea & & 1 & & \\
\hline 4 & 700 & 2004 & Ostrea & 1 & 1 & & \\
\hline 4 & 725 & 2212 & Ostrea & 3 & 2 & & \\
\hline 4 & 725 & 2212 & L littorea & & & & 1 \\
\hline 4 & 726 & 2264 & Ostrea & & 1 & & \\
\hline 4 & 735 & 2008 & Ostrea & & 1 & & \\
\hline 4 & 776 & 2392 & Unidentified (abraded) & & & & 1 \\
\hline 4 & 776 & 2392 & Ostrea & & 1 & & \\
\hline 4 & 806 & 2495 & Ostrea & & 2 & & \\
\hline 4 & 807 & 2501 & Ostrea & & 1 & ++ & \\
\hline 4 & 811 & 2509 & Ostrea & 10 & 12 & + & \\
\hline 4 & 811 & 2509 & Buccinum & & & & 1 \\
\hline 5 & 215 & 855 & Ostrea & 3 & & & \\
\hline 5 & 302 & 1240 & Ostrea & & & + & \\
\hline 5 & 563 & 2563 & Buccinum & & & & 1 \\
\hline 5 & 660 & 1353 & Ostrea & & 1 & & \\
\hline 5 & 682 & 1595 & Ostrea & & 1 & & \\
\hline 5 & 738 & 1998 & Ostrea & & 1 & & \\
\hline 5 & 803 & 2493 & Ostrea & 2 & 1 & + & \\
\hline \multirow[t]{2}{*}{5} & 803 & 2493 & & & & & \\
\hline & Nucella & & & & 1 & & \\
\hline 5 & 1620 & 4507 & Ostrea & 7 & 9 & + & \\
\hline 5 & 1620 & 4507 & L littorea & & & & 1 \\
\hline 5 & 1620 & 4707 & Buccinum & & & & 1 \\
\hline 5 & 1676 & 4813 & Ostrea & 1 & 1 & + & \\
\hline 5 & 1766 & 4436 & Ostrea & & 1 & + & \\
\hline 6 & 227 & 511 & Ostrea & 4 & 2 & 2 & \\
\hline 6 & 236 & 384 & L littorea & & & & 1 \\
\hline 6 & 242 & 556 & $L$ littorea & & & & 1 \\
\hline 6 & 316 & 1362 & Ostrea & 1 & 2 & & \\
\hline 6 & 512 & 987 & Ostrea & 22 & 27 & +++++ & \\
\hline 6 & 514 & 593 & Ostrea & 2 & 1 & + & \\
\hline 6 & 514 & 593 & $L$ littorea & & & & 2 \\
\hline
\end{tabular}


Table 2.19 (cont.) Mollusc catalogue (hand-excavated contexts; for abbreviations, see table 2.20)

\begin{tabular}{|c|c|c|c|c|c|c|c|}
\hline \multirow[b]{2}{*}{ Phase } & \multirow[b]{2}{*}{ Context } & \multirow[b]{2}{*}{ IADB no. } & \multirow[b]{2}{*}{ Species } & \multicolumn{3}{|c|}{ Oyster (Ostrea edulis) } & \multirow[b]{2}{*}{ Other specie } \\
\hline & & & & Upper & Lower & Fragment & \\
\hline 6 & 514 & 1188 & Ostrea & 7 & 10 & ++ & \\
\hline 6 & 518 & 865 & $\begin{array}{l}\text { Ostrea (1 fragment with mortar } \\
\text { adhering) }\end{array}$ & 2 & & 3 & \\
\hline 6 & 518 & 865 & Cerastoderma sp & & & & 1 \\
\hline 6 & 540 & 439 & Ostrea & & & 2 & \\
\hline 6 & 540 & 474 & Ostrea & & 1 & & \\
\hline 6 & 540 & 632 & Ostrea & & & + & \\
\hline 6 & 540 & 632 & $L$ littorea & & & & 2 \\
\hline 6 & 540 & 641 & Ostrea & & & 1 & \\
\hline 6 & 540 & 648 & Ostrea & & & + & \\
\hline 6 & 540 & 648 & $L$ littorea & & & & 1 \\
\hline 6 & 540 & 648 & Unidentified (abraded fragment) & & & & 1 \\
\hline 6 & 540 & 660 & Ostrea & 1 & 1 & ++ & \\
\hline 6 & 540 & 660 & Nucella & & & & 1 \\
\hline 6 & 540 & 660 & Buccinum (juvenile; very small) & & & & 1 \\
\hline 6 & 540 & 675 & Ostrea & & & + & \\
\hline 6 & 540 & 685 & Ostrea & & & 2 & \\
\hline 6 & 540 & 733 & Ostrea & & & 2 & \\
\hline 6 & 556 & 553 & Ostrea & & 1 & & \\
\hline 6 & 558 & 803 & Ostrea & 10 & 12 & ++ & \\
\hline 6 & 558 & 803 & Patella & & & & 3 \\
\hline 6 & 559 & 1090 & Ostrea & 8 & 5 & 8 & \\
\hline 6 & 559 & 1090 & Nucella & & & & 1 \\
\hline 6 & 559 & 1090 & Unidentified (abraded fragment) & & & & 1 \\
\hline 6 & 560 & 1149 & Ostrea & 1 & 1 & & \\
\hline 6 & 560 & 1149 & Mytilus & & 1 & 6 & \\
\hline 6 & 561 & 630 & Ostrea & 4 & 1 & & \\
\hline 6 & 590 & 1203 & Ostrea & 6 & 6 & 9 & \\
\hline 6 & 590 & 1203 & Gastropod cf Buccinum & & & & 1 \\
\hline 6 & 631 & 1222 & Ostrea & & 1 & & \\
\hline 6 & 634 & 1228 & Ostrea & 1 & 1 & & \\
\hline 6 & 636 & 1371 & $\begin{array}{l}\text { Ostrea (1 valve with mortar } \\
\text { adhering) }\end{array}$ & 2 & 1 & & \\
\hline 6 & 690 & 2085 & Ostrea & 2 & 4 & & \\
\hline 6 & 707 & 1800 & Ostrea & 2 & 1 & & \\
\hline 6 & 709 & 1970 & Ostrea & 5 & 5 & 4 & \\
\hline 6 & 713 & 1781 & Ostrea & & 2 & 4 & \\
\hline 6 & 739 & 1898 & Ostrea & 1 & & & \\
\hline 6 & 1600 & 4445 & Ostrea & 3 & 2 & 5 & \\
\hline 6 & 1600 & 4445 & Lobtusata & & & & 1 \\
\hline 6 & 1600 & 4445 & Cerastoderma & & & & 1 \\
\hline 6 & 1604 & 4449 & Ostrea (mortar adhering) & 3 & & & \\
\hline 6 & 1608 & 4453 & Ostrea & 1 & 1 & & \\
\hline 6 & 1610 & 4455 & Ostrea & & 1 & & \\
\hline 6 & 1612 & 4460 & Ostrea & 3 & 1 & & \\
\hline 6 & 1614 & 4485 & Ostrea & 3 & 2 & 3 & \\
\hline
\end{tabular}


Table 2.19 (cont.) Mollusc catalogue (hand-excavated contexts; for abbreviations, see table 2.20)

\begin{tabular}{|c|c|c|c|c|c|c|c|}
\hline \multirow[b]{2}{*}{ Phase } & \multirow[b]{2}{*}{ Context } & \multirow[b]{2}{*}{ IADB no. } & \multirow[b]{2}{*}{ Species } & \multicolumn{3}{|c|}{ Oyster (Ostrea edulis) } & \multirow[b]{2}{*}{ Other species } \\
\hline & & & & Upper & Lower & Fragment & \\
\hline 6 & 1616 & 4493 & Ostrea & & 1 & 1 & \\
\hline 6 & 1618 & 4471 & Ostrea & 1 & 2 & 5 & \\
\hline 6 & 1622 & 4480 & Ostrea & 3 & 2 & + & \\
\hline 6 & 1622 & 4480 & L littorea & & & & 1 \\
\hline 6 & 1625 & 4509 & $\begin{array}{l}\text { Ostrea (1 valve with circular hole } \\
\text { bored through) }\end{array}$ & & 2 & 1 & \\
\hline 6 & 1625 & 4509 & Gastropod & & & & 2 \\
\hline 6 & 1625 & 4509 & Patella sp & & & & 1 \\
\hline 6 & 1625 & 45009 & $L$ littorea & & & & 1 \\
\hline 6 & 1638 & 4628 & Ostrea & 2 & 5 & + & \\
\hline 6 & 1638 & 4628 & Buccinum & & & & 1 \\
\hline 6 & 1652 & 4660 & Ostrea & & 1 & & \\
\hline 6 & 1654 & 4819 & Unidentified & & & & 1 \\
\hline 6 & 1656 & 4666 & Ostrea & & 1 & 1 & \\
\hline 6 & 1657 & 4669 & Ostrea & 1 & 1 & & \\
\hline 6 & 1657 & 4669 & $L$ littorea & & & & 1 \\
\hline 6 & 1657 & 4669 & Ostrea & 1 & 1 & & \\
\hline 6 & 1659 & 4648 & Ostrea & 1 & & 2 & \\
\hline 6 & 1678 & 4676 & Ostrea & & 1 & & \\
\hline 6 & 1678 & 4676 & Lobtusata & & & & 1 \\
\hline 7 & 235 & 346 & Nucella lapillis & & & & 1 \\
\hline 7 & 277 & 829 & $L$ littorea & & & & 1 \\
\hline 7 & 277 & 829 & Nucella & & & & 1 \\
\hline 7 & 280 & 839 & Ostrea & 2 & 3 & 2 & \\
\hline 7 & 617 & 1214 & Ostrea & 1 & 3 & 1 & \\
\hline 7 & 632 & 894 & Unidentified cf Lutraria (abraded) & & & & 1 \\
\hline 7 & 1738 & 5003 & $\begin{array}{l}\text { Ostrea (mortar adhering to } 1 \\
\text { valve) }\end{array}$ & 2 & 1 & + & \\
\hline 7 & 1739 & 4968 & $\begin{array}{l}\text { Ostrea (mortar adhering to } 1 \\
\text { valve) }\end{array}$ & 1 & 2 & 5 & \\
\hline 7 & 1776 & 5015 & Ostrea & 1 & & & \\
\hline 7 & 1783 & 5025 & Ostrea & 6 & 5 & ++ & \\
\hline 7 & 1787 & 5021 & Ostrea & & 1 & & \\
\hline 8 & 176 & 033 & Ostrea & 2 & & & \\
\hline 8 & 269 & 611 & Mytilus & & & & 1 \\
\hline 8 & 269 & 611 & Unidentified & & & & 1 \\
\hline 8 & 273 & 493 & of Ostrea & & & 1 & \\
\hline 8 & 277 & 829 & Ostrea & & & 1 & \\
\hline 8 & 287 & 568 & Mytilus & & & & 3 \\
\hline 8 & 536 & 795 & Buccinum ondatum & & & & 1 \\
\hline 8 & 615 & 880 & $L$ littorea & & & & 1 \\
\hline 9 & 532 & 520 & Ostrea & & 1 & & \\
\hline 9 & 532 & 520 & Cerastoderma sp & & & & 1 \\
\hline 9 & 541 & 1194 & $\begin{array}{l}\text { Modiolus sp ( } 2 \text { valves filled with } \\
\text { mortar) }\end{array}$ & & & & 1 \\
\hline 9 & 594 & 812 & Ostrea & 1 & 2 & & \\
\hline
\end{tabular}




\begin{tabular}{|c|c|c|c|c|c|c|c|c|}
\hline \multirow[b]{3}{*}{ Phase } & \multirow[b]{3}{*}{ Context } & \multirow[b]{3}{*}{ Sample } & \multirow[b]{3}{*}{ IADB } & \multirow[b]{3}{*}{ Species } & \multicolumn{3}{|c|}{ Oyster (Ostrea edulis) } & \multirow[b]{3}{*}{ Other species } \\
\hline & & & & & & Valve & & \\
\hline & & & & & Upper & Lower & Fragment & \\
\hline 0 & 39 & 002 & 227 & Ostrea edulis & 1 & & 2 & \\
\hline 0 & 145 & 23 & 4699 & Littorina littorea & & & & 1 \\
\hline 0 & 190 & 44 & 4701 & Ostrea & & & 3 & \\
\hline 0 & 557 & 513 & 1267 & Ostrea & & 1 & 3 & \\
\hline 0 & 557 & 513 & 1267 & L littorea & & & & 1 \\
\hline 0 & 860 & 2610 & & Ostrea & & & 2 & \\
\hline 0 & 936 & 2903 & & Ostrea & 1 & & & \\
\hline 0 & 942 & 2909 & 3367 & Ostrea & & 1 & 5 & \\
\hline 0 & 942 & 2909 & 3367 & L obtusata & & & & 1 \\
\hline 0 & 992 & 3428 & 4708 & Unidentified $\mathrm{sp}$ & & & & + \\
\hline 0 & 992 & 3429 & 4709 & Ostrea & & 1 & 4 & \\
\hline 0 & 992 & 3430 & & Ostrea & & & 2 & \\
\hline 0 & 992 & 3432 & 3570 & Ostrea & & 1 & 14 & \\
\hline 0 & 1000 & 0369 & & $\begin{array}{l}\text { Ostrea (mortar adhering to } 1 \\
\text { valve) }\end{array}$ & 4 & 4 & & \\
\hline 0 & 1000 & 0369 & & Cerastoderma & & & & 1 \\
\hline 0 & 1000 & 3278 & & Ostrea & & 1 & & \\
\hline 0 & 1001 & 3488 & & Ostrea & 2 & & & \\
\hline 0 & 1088 & 3259 & 3547 & Ostrea & & & ++ & \\
\hline 0 & 1088 & 3500 & & Ostrea & & 1 & & \\
\hline 0 & 1103 & 3380 & & Littorina $s p$ & & & & 4 fragments \\
\hline 0 & 1564 & 3852 & 4209 & Unidentified & & & & + \\
\hline 0 & 1572 & 4084 & & Ostrea & 1 & 3 & & \\
\hline 0 & 1572 & 4084 & & L littorea (mortar adhering) & & & & 1 \\
\hline 0 & 1646 & 4351 & & Ostrea & & 1 & & \\
\hline 0 & 1646 & 4352 & & Cepea hortensis (land species) & & & & 1 \\
\hline 0 & 1680 & 4366 & & Ostrea & & & 1 & \\
\hline 0 & 1733 & 4393 & & Ostrea & 1 & & & \\
\hline 1 & 790 & 2339 & 043 & Pectinidae & & & & 1 \\
\hline 2 & 745 & 1788 & 4875 & Ostrea & 1 & 3 & 15 & \\
\hline 2 & 758 & 1979 & 2259 & Ostrea & & & +++ & \\
\hline 2 & 768 & 2014 & 2307 & Ostrea & & 1 & ++ & \\
\hline 2 & 768 & 2014 & 2307 & L littorea & & & & 1 \\
\hline 2 & 768 & 2015 & & Ostrea & & 1 & & \\
\hline 2 & 778 & 2033 & 2175 & Ostrea & 2 & 3 & +++ & \\
\hline 2 & 778 & 2033 & 2175 & Buccinum & & & & 1 \\
\hline 2 & 778 & 2033 & 2175 & Gastropod & & & & 1 \\
\hline 2 & 778 & 2033 & 2175 & Pectinidae & & & & 1 \\
\hline 2 & 778 & 2163 & & Ostrea & & & & 2 \\
\hline 2 & 861 & 2689 & & Ostrea & 1 & 2 & & \\
\hline 2 & 1767 & 4413 & & Ostrea & 1 & & & \\
\hline 2 & 1767 & 4413 & & $L$ littorea & & & & 1 \\
\hline 3 & 612 & 1606 & 2149 & Unidentified & & & & 1 \\
\hline
\end{tabular}


Table 2.20 (cont.) Mollusc catalogue (retents)

\begin{tabular}{|c|c|c|c|c|c|c|c|c|}
\hline \multirow[b]{2}{*}{ Phase } & \multirow[b]{2}{*}{ Context } & \multirow[b]{2}{*}{ Sample } & \multirow[b]{2}{*}{ IADB } & \multirow[b]{2}{*}{ Species } & \multicolumn{3}{|c|}{ Oyster (Ostrea edulis) } & \multirow[b]{2}{*}{ Other specie } \\
\hline & & & & & Upper & Lower & Fragment & \\
\hline 3 & 612 & 2671 & & Ostrea & 1 & 1 & & \\
\hline 3 & 612 & 3033 & 3333 & Ostrea & & & 1 & \\
\hline 3 & 612 & 3093 & 3214 & Ostrea & 1 & & & \\
\hline 3 & 667 & 1103 & 2094 & Unidentified & & & & 1 \\
\hline 3 & 733 & 1782 & 4873 & Ostrea & 1 & & 2 & \\
\hline 3 & 742 & 1785 & 4874 & Ostrea & & & 1 & \\
\hline 3 & 743 & 1786 & & Ostrea & 1 & & & \\
\hline 3 & 743 & 1786 & & L littorea & & & & 1 \\
\hline 3 & 763 & 2009 & 2287 & Ostrea & 2 & 1 & + & \\
\hline 3 & 763 & 2009 & 2287 & Nucella & & & & 1 \\
\hline 3 & 763 & 2076 & 2299 & Ostrea & 1 & & + & \\
\hline 3 & 763 & 2076 & 2299 & L littorea & & & & 1 \\
\hline 3 & 781 & 2165 & 4876 & Ostrea & & & 4 & \\
\hline 3 & 785 & 2330 & 2467 & Buccinum & & & & 1 \\
\hline 3 & 1568 & 3858 & 4249 & Ostrea & & & 2 & \\
\hline 3 & 1634 & 4344 & & Ostrea & 1 & & 2 & \\
\hline 4 & 611 & 1598 & 4938 & Ostrea & & & 2 & \\
\hline 4 & 652 & 2101 & 994 & Ostrea & & & 2 & \\
\hline 4 & 679 & 2173 & 2406 & Ostrea & & 1 & + & \\
\hline 4 & 679 & 2173 & 2406 & cf Mytilus & & & & 1 \\
\hline 4 & 681 & 2162 & 2263 & Ostrea & & 1 & 6 & \\
\hline 4 & 687 & 1357 & 1906 & Ostrea & & & +++ & \\
\hline 4 & 687 & 1358 & 1586 & Ostrea & & & 5 & \\
\hline 4 & 687 & 1358 & 1586 & $L$ littorea & & & & 1 \\
\hline 4 & 687 & 1423 & 3994 & Ostrea & & & 1 & \\
\hline 4 & 687 & 1423 & 4943 & Ostrea & & & 2 & \\
\hline 4 & 694 & 1596 & 4944 & Ostrea & 1 & & & \\
\hline 4 & 726 & 1740 & 4871 & Ostrea & & & 1 & \\
\hline 4 & 727 & 1771 & 4872 & Ostrea & & & 1 & \\
\hline 4 & 727 & 1771 & 4872 & Gastropod cf Buccinum & & & & 1 \\
\hline 4 & 807 & 2222 & 2453 & Unidentified & & & & 1 \\
\hline 4 & 811 & 2340 & 2515 & Ostrea & 1 & & 5 & \\
\hline 4 & 822 & 1822 & 2535 & Ostrea & 1 & 1 & 7 & \\
\hline 4 & 825 & 2581 & & Ostrea & & 1 & & \\
\hline 4 & 835 & 2615 & & Ostrea & 9 & 15 & + & \\
\hline 4 & 835 & 2615 & & Buсcinum & & & & 1 \\
\hline 4 & 835 & 2615 & & Pectinidae & & & & 1 \\
\hline 4 & 836 & 2374 & 4706 & L littorea & & & & 1 \\
\hline 4 & 837 & 2376 & 2759 & Ostrea & & & 7 & \\
\hline 4 & 837 & 2376 & 2759 & $L$ littorea & & & & 2 \\
\hline 4 & 837 & 2376 & 2759 & Gastropod & & & & 1 \\
\hline 4 & 912 & 2919 & & Ostrea & 2 & 4 & & \\
\hline
\end{tabular}


Table 2.20 (cont.) Mollusc catalogue (retents)

\begin{tabular}{|c|c|c|c|c|c|c|c|c|}
\hline \multirow[b]{3}{*}{ Phase } & \multirow[b]{3}{*}{ Context } & \multirow[b]{3}{*}{ Sample } & \multirow[b]{3}{*}{ IADB } & \multirow[b]{3}{*}{ Species } & \multicolumn{3}{|c|}{ Oyster (Ostrea edulis) } & \multirow[b]{3}{*}{ Other species } \\
\hline & & & & & & Valve & & \\
\hline & & & & & Upper & Lower & Fragment & \\
\hline 4 & 993 & 3463 & & $L$ littorea & & & & $\begin{array}{l}2 \text { (mortar } \\
\text { embedded in } \\
\text { mouth of one } \\
\text { shell) }\end{array}$ \\
\hline 4 & 993 & 3463 & & L obtusata & & & & 2 \\
\hline 4 & 993 & 3463 & & Ostrea & 6 & 1 & 3 & \\
\hline 4 & 1536 & 3810 & 4282 & Ostrea & & 1 & & \\
\hline 4 & 1538 & 3811 & 4297 & Ostrea & & 1 & 4 & \\
\hline 4 & 1538 & 3811 & 4297 & Gastropod & & & & ++ \\
\hline 5 & 215 & 420 & 1055 & Ostrea & & & 5 & \\
\hline 5 & 215 & 1093 & 1390 & Ostrea & 1 & & 1 & \\
\hline 5 & 215 & 1094 & 1459 & Ostrea & & & 1 & \\
\hline 5 & 215 & 1094 & 1459 & L littorea & & & & 1 \\
\hline 5 & 215 & 1095 & 1549 & Ostrea & & & 1 & \\
\hline 5 & 215 & 1096 & 2030 & Ostrea & & & 1 & \\
\hline 5 & 215 & 1099 & 1866 & Ostrea & & & 3 & \\
\hline 5 & 215 & 1100 & 1396 & $L$ littorea & & & & 1 \\
\hline 5 & 215 & 1100 & 1396 & Ostrea & & & 1 & \\
\hline 5 & 563 & 949 & 1856 & Ostrea & & & 2 & \\
\hline 5 & 563 & 955 & 1702 & Ostrea & & 1 & & \\
\hline 5 & 563 & 955 & 1702 & Unidentified fragment & & & & 1 \\
\hline 5 & 563 & 966 & 1334 & Ostrea & 1 & 6 & & \\
\hline 5 & 563 & 967 & 1502 & Ostrea & 1 & & & \\
\hline 5 & 563 & 968 & 1339 & Ostrea & & 1 & & \\
\hline 5 & 563 & 971 & 1473 & Ostrea & 1 & & 3 & \\
\hline 5 & 563 & 972 & 1755 & Ostrea & & & 1 & \\
\hline 5 & 563 & 973 & 1762 & Ostrea & & 1 & 3 & \\
\hline 5 & 563 & 976 & 1773 & Ostrea & & & 2 & \\
\hline 5 & 563 & 2897 & 3177 & Ostrea & & & 2 & \\
\hline 5 & 563 & 2897 & 3177 & Cerastoderma sp & & & & 3 \\
\hline 5 & 563 & 2897 & 3010 & Ostrea & & & + & \\
\hline 5 & 563 & 2959 & 3351 & Ostrea & 1 & & 5 & \\
\hline 5 & 563 & 2962 & 3189 & Ostrea & & & 1 & \\
\hline 5 & 659 & 1213 & 1510 & Ostrea & 1 & 2 & 4 & \\
\hline 5 & 659 & 1213 & 1510 & $L \mathrm{cf}$ littorea & & & & 1 \\
\hline 5 & 659 & 1213 & 1510 & Lobtusata & & & & 1 \\
\hline 5 & 659 & 1213 & 1510 & Littorina $s p$ & & & & 1 \\
\hline 5 & 659 & 1213 & 1510 & cf Nucella & & & & 1 \\
\hline 5 & 659 & 1213 & 1510 & Pectinidae & & & & 1 \\
\hline 5 & 659 & 1213 & 1510 & Unidentified & & & & 1 \\
\hline 5 & 659 & 1230 & 4940 & Ostrea & & 1 & & \\
\hline 5 & 659 & 1230 & 4940 & L littorea & & & & 2 \\
\hline 5 & 659 & 1230 & 4940 & L obtusata & & & & 1 \\
\hline 5 & 659 & 1248 & 1579 & Ostrea & 1 & & 1 & \\
\hline
\end{tabular}




\begin{tabular}{|c|c|c|c|c|c|c|c|c|}
\hline \multirow[b]{2}{*}{ Phase } & \multirow[b]{2}{*}{ Context } & \multirow[b]{2}{*}{ Sample } & \multirow[b]{2}{*}{ IADB } & \multirow[b]{2}{*}{ Species } & \multicolumn{3}{|c|}{ Oyster (Ostrea edulis) } & \multirow[b]{2}{*}{ Other species } \\
\hline & & & & & Upper & Lower & Fragment & \\
\hline 5 & 659 & 1249 & 4939 & L littorea & & & & 2 \\
\hline 5 & 659 & 1249 & 4939 & L obtusata & & & & 1 \\
\hline 5 & 803 & 2294 & 4705 & Ostrea & & 1 & & \\
\hline 5 & 1502 & 3884 & & Ostrea & & & 4 & \\
\hline 5 & 1507 & 3483 & 3690 & Ostrea & 21 & 14 & +++++ & \\
\hline 5 & 1507 & 3483 & 3690 & Lobtusata & & & & 2 \\
\hline 5 & 1507 & 3483 & 3693 & L littorea & & & & 1 \\
\hline 5 & 1507 & 3483 & 3693 & Gastropod & & & & 1 \\
\hline 5 & 1507 & 3483 & 3693 & Unidentified & & & & 2 \\
\hline 5 & 1507 & 3484 & & Ostrea & 13 & 6 & 1 & \\
\hline 5 & 1507 & 3484 & & Littorina sp & & & & $\begin{array}{l}1 \text { (embedded } \\
\text { in mortar) }\end{array}$ \\
\hline 5 & 1507 & 3484 & & Lobtusata & & & & 2 (very small) \\
\hline 5 & 1507 & 3484 & & $L$ littorea & & & & 4 (very small) \\
\hline 5 & 1507 & 3484 & & Littorea sp & & & & 3 \\
\hline 5 & 1507 & 3484 & & Turritella $\mathrm{sp}$ & & & & 1 \\
\hline 5 & 1507 & 3484 & & Nucella lapillus & & & & 1 \\
\hline 5 & 1511 & 3695 & & Unidentified fragments & & & & + \\
\hline 5 & 1513 & 3691 & & Unidentified fragments & & & & + \\
\hline 5 & 1513 & 3692 & 4312 & Ostrea & & & 3 & \\
\hline 5 & 1513 & 3694 & 4304 & Ostrea & & 1 & 1 & \\
\hline 5 & 1523 & 4057 & & Ostrea & 3 & & 1 & \\
\hline 5 & 1525 & 3711 & & Unidentified fragments & & & & + \\
\hline 5 & 1525 & 3711 & & Gastropod & & & & + \\
\hline 5 & 1620 & 4331 & & L littorea & & & & 1 (very small) \\
\hline 5 & 1670 & 4409 & & Nucella lapillus & & & & 1 \\
\hline 5 & 1670 & 4409 & & Lobtusata & & & & $\begin{array}{l}2 \text { (very small; } \\
\text { mortar } \\
\text { adhering) }\end{array}$ \\
\hline 5 & 1766 & 4412 & & Ostrea & & & 2 & \\
\hline 5 & 1766 & 4412 & & $L$ littorea & & & & 1 \\
\hline 5 & 1766 & 4412 & & L obtusata & & & & 1 \\
\hline 6 & 307 & 775 & 1140 & Ostrea & & 1 & 2 & \\
\hline 6 & 307 & 775 & 1140 & Gastropod & & & & 1 \\
\hline 6 & 307 & 775 & 1140 & Unidentified fragments & & & & 2 \\
\hline 6 & 307 & 776 & 1532 & Unidentified bivalve & & & & 1 \\
\hline 6 & 307 & 777 & 1540 & Ostrea & & & 2 & \\
\hline 6 & 307 & 778 & 1555 & Ostrea & & & 3 & \\
\hline 6 & 307 & 779 & 1262 & Ostrea & & & 1 & \\
\hline 6 & 316 & 997 & 4704 & Ostrea & 1 & & 6 & \\
\hline 6 & 514 & 463 & 4864 & Ostrea & & 1 & & \\
\hline 6 & 514 & 463 & 4864 & L littorea & & & & 1 \\
\hline 6 & 514 & 463 & 4864 & Lobtusata & & & & $\begin{array}{l}1 \text { (mortar } \\
\text { embedded in } \\
\text { mouth) }\end{array}$ \\
\hline
\end{tabular}




\begin{tabular}{|c|c|c|c|c|c|c|c|c|}
\hline \multirow[b]{3}{*}{ Phase } & \multirow[b]{3}{*}{ Context } & \multirow[b]{3}{*}{ Sample } & \multirow[b]{3}{*}{ IADB } & \multirow[b]{3}{*}{ Species } & \multicolumn{3}{|c|}{ Oyster (Ostrea edulis) } & \multirow[b]{3}{*}{ Other species } \\
\hline & & & & & & Valve & & \\
\hline & & & & & Upper & Lower & Fragment & \\
\hline 6 & 540 & 416 & 1422 & Unidentified fragment & & & & 1 \\
\hline 6 & 540 & 1143 & 040 & Cerastoderma sp & & & & 1 \\
\hline 6 & 540 & 2543 & 3130 & Gastropod & & & & 1 \\
\hline 6 & 540 & 2543 & 3130 & Unidentified & & & & 8 \\
\hline 6 & 540 & 2544 & 3082 & Ostrea & 1 & & + & \\
\hline 6 & 540 & 2544 & 3082 & cf Mytilus & & & & 1 \\
\hline 6 & 540 & 2545 & 3147 & Ostrea & & & 2 & \\
\hline 6 & 540 & 2545 & 3147 & $L$ littorea & & & & 2 \\
\hline 6 & 540 & 2545 & 3147 & Unidentified & & & & 1 \\
\hline 6 & 540 & 2546 & 2831 & $L$ littorea & & & & 1 \\
\hline 6 & 540 & 2546 & 2831 & Unidentified & & & & 1 \\
\hline 6 & 540 & 2547 & 2693 & Ostrea & & & 2 & \\
\hline 6 & 540 & 2548 & 2702 & Gastropod & & & & 1 \\
\hline 6 & 540 & 2548 & 2702 & Unidentified & & & & 1 \\
\hline 6 & 540 & 2548 & 2702 & Unidentified & & & & 1 \\
\hline 6 & 540 & 2550 & 2716 & Ostrea & 1 & & + & \\
\hline 6 & 540 & 2550 & 2716 & Mytilus & & & & 1 \\
\hline 6 & 540 & 2550 & 2716 & Cerastoderma sp & & & & 1 \\
\hline 6 & 540 & 2550 & 2716 & $L$ littorea & & & & 1 \\
\hline 6 & 540 & 2551 & 3099 & Ostrea & & & 3 & \\
\hline 6 & 540 & 2553 & 2731 & Ostrea & 1 & & + & \\
\hline 6 & 540 & 2554 & 2740 & Ostrea & & & + & \\
\hline 6 & 540 & 2555 & 3118 & Nucella & & & & 1 \\
\hline 6 & 540 & 2556 & 2846 & Ostrea & 1 & & + & \\
\hline 6 & 558 & 494 & 4865 & Ostrea & 5 & 4 & 2 & \\
\hline 6 & 558 & 507 & 1288 & Ostrea & 5 & 6 & 10 & \\
\hline 6 & 558 & 507 & 1288 & $L$ littorea & & & & 2 \\
\hline 6 & 559 & 470 & 4866 & Ostrea & 1 & 1 & 5 & \\
\hline 6 & 559 & 470 & 4866 & Pectinidae & & & & 1 \\
\hline 6 & 559 & 470 & 4866 & Cerastoderma sp & & & & 1 \\
\hline 6 & 559 & 470 & 4866 & $L$ littorea & & & & 2 \\
\hline 6 & 559 & 470 & 4866 & L obtusata & & & & 1 \\
\hline 6 & 559 & 470 & 4866 & Gastropod & & & & 1 \\
\hline 6 & 561 & 531 & 1296 & Ostrea & 8 & 5 & 9 & \\
\hline 6 & 561 & 531 & 1296 & L littorea & & & & 1 \\
\hline 6 & 561 & 531 & 1296 & L obtusata & & & & 1 \\
\hline 6 & 561 & 531 & 1296 & Cerastoderma sp & & & & 3 \\
\hline 6 & 561 & 691 & 4867 & Ostrea & 4 & 1 & 8 & \\
\hline 6 & 561 & 691 & 4867 & Turritella sp & & & & 1 \\
\hline 6 & 562 & 518 & 1301 & Ostrea & & & 1 & \\
\hline 6 & 562 & 518 & 1301 & Gastropod cf Nucella & & & & 1 \\
\hline 6 & 589 & 516 & & Ostrea & 1 & & & \\
\hline 6 & 591 & 522 & & Ostrea & & & 2 & \\
\hline
\end{tabular}


Table 2.20 (cont.) Mollusc catalogue (retents)

\begin{tabular}{|c|c|c|c|c|c|c|c|c|}
\hline \multirow[b]{2}{*}{ Phase } & \multirow[b]{2}{*}{ Context } & \multirow[b]{2}{*}{ Sample } & \multirow[b]{2}{*}{ IADB } & \multirow[b]{2}{*}{ Species } & \multicolumn{3}{|c|}{ Oyster (Ostrea edulis) } & \multirow[b]{2}{*}{ Other species } \\
\hline & & & & & Upper & Lower & Fragment & \\
\hline 6 & 591 & 522 & & $L$ littorea & & & & 1 \\
\hline 6 & 592 & 692 & & L littorea & & & & 2 \\
\hline 6 & 634 & 1641 & 1645 & Ostrea & & & 5 & \\
\hline 6 & 643 & 3381 & & Ostrea & 1 & 2 & 2 & \\
\hline 6 & 663 & 1024 & 4942 & L littorea & & & & 1 \\
\hline 6 & 709 & 1718 & 4868 & Gastropod & & & & + \\
\hline 6 & 712 & 1614 & 4869 & Ostrea & & 1 & & \\
\hline 6 & 712 & 1614 & 4869 & $L$ littorea & & & & 2 \\
\hline 6 & 715 & 1819 & 4870 & Ostrea & & & 1 & \\
\hline 6 & 859 & 2910 & 3262 & Ostrea & & 1 & & \\
\hline 6 & 859 & 2911 & 3255 & Ostrea & 1 & & & \\
\hline 6 & 859 & 3386 & & Ostrea & 3 & 4 & + & \\
\hline 6 & 859 & 3386 & & Gastropod & & & & 1 \\
\hline 6 & 888 & 3041 & 3453 & Ostrea & & 1 & & \\
\hline 6 & 888 & 3042 & 3399 & Ostrea & & 1 & 3 & \\
\hline 6 & 888 & 3043 & 3407 & Ostrea & & 1 & 3 & \\
\hline 6 & 888 & 3045 & 3478 & Lobtusata & & & & 1 \\
\hline 6 & 888 & 3045 & 3478 & Unidentified cf Ostrea & & & & 2 \\
\hline 6 & 888 & 3046 & 3468 & Ostrea & & 1 & & \\
\hline 6 & 921 & 2825 & 4719 & Ostrea & & & 1 & \\
\hline 6 & 921 & 2825 & 4719 & $L$ littorea & & & & 1 \\
\hline 6 & 921 & 2825 & 4719 & Gastropod & & & & 1 \\
\hline 6 & 921 & 2868 & 4707 & $L$ littorea & & & & 1 \\
\hline 6 & 949 & 2946 & 3376 & Ostrea & & 1 & 9 & \\
\hline 6 & 951 & 3026 & & $L$ littorea & & & & $\begin{array}{l}1 \text { (embedded } \\
\text { in mortar) }\end{array}$ \\
\hline 6 & 961 & 3027 & & Ostrea & 1 & & & \\
\hline 6 & 961 & 3027 & & Lobtusata & & & & 1 \\
\hline 6 & 961 & 3027 & & Littorina sp & & & & 2 \\
\hline 6 & 961 & 3027 & & Unidentified sp & & & & + \\
\hline 6 & 974 & 3231 & & Ostrea & 1 & & & \\
\hline 6 & 1087 & 3507 & & Ostrea & 1 & & 1 & \\
\hline 6 & 1610 & 4334 & & Ostrea & & 1 & & \\
\hline 6 & 1612 & 4333 & & Ostrea & 1 & 1 & 1 & \\
\hline 6 & 1614 & 4336 & & Ostrea & 1 & & & \\
\hline 6 & 1616 & 4337 & & Ostrea & 1 & & & \\
\hline 6 & 1622 & 4324 & & Ostrea & & & 2 & \\
\hline 6 & 1626 & 4332 & & Littorina sp & & & & 1 (very small) \\
\hline 6 & 1626 & 4332 & & Ostrea & 1 & & & \\
\hline 6 & 1638 & 4349 & & Ostrea & 2 & 2 & 2 & \\
\hline 6 & 1648 & 4356 & & Ostrea & & 1 & 6 & \\
\hline 6 & 1656 & 4360 & & Ostrea & & 1 & & \\
\hline 6 & 1700 & 4383 & & L littorea & & & & 4 \\
\hline
\end{tabular}


Table 2.20 (cont.) Mollusc catalogue (retents)

\begin{tabular}{|c|c|c|c|c|c|c|c|c|}
\hline \multirow[b]{3}{*}{ Phase } & \multirow[b]{3}{*}{ Context } & \multirow[b]{3}{*}{ Sample } & \multirow[b]{3}{*}{ IADB } & \multirow[b]{3}{*}{ Species } & \multicolumn{3}{|c|}{ Oyster (Ostrea edulis) } & \multirow[b]{3}{*}{ Other species } \\
\hline & & & & & & Valve & & \\
\hline & & & & & Upper & Lower & Fragment & \\
\hline 6 & 1700 & 4383 & & Littorina sp & & & & 3 fragments \\
\hline 6 & 1704 & 4385 & & Ostrea & & 1 & 1 & \\
\hline 6 & 1706 & 4386 & & Ostrea & & 1 & & \\
\hline 6 & 1710 & 4387 & & $L$ littorea & & & & 1 \\
\hline 6 & 1729 & 4392 & & Ostrea & 3 & & & \\
\hline 6 & 1742 & 4398 & & Ostrea & 1 & & & \\
\hline 6 & 1742 & 4398 & & L obtusata & & & & 1 \\
\hline 6 & 1746 & 4400 & & $L$ littorea & & & & 3 (very small) \\
\hline 6 & 1746 & 4400 & & Littorina sp & & & & 1 (very small) \\
\hline 6 & 1771 & 4414 & & L obtusata & & & & 1 (very small) \\
\hline 6 & 1773 & 4415 & & $L$ littorea & & & & 1 (very small) \\
\hline 6 & 1773 & 4415 & & Lobtusata & & & & 1 (very small) \\
\hline 6 & 1773 & 4415 & & Unidentified sp & & & & 1 fragment \\
\hline 7 & 177 & 29 & 4700 & Ostrea & & 1 & & +++ \\
\hline 7 & 177 & 29 & 4700 & $L$ littorea & & & & 1 \\
\hline 7 & 177 & 29 & 4700 & Gastropod & & & & + \\
\hline 7 & 633 & 1026 & 4941 & Ostrea & 3 & 2 & 3 & \\
\hline 7 & 633 & 1026 & 4941 & Gastropod & & & & 1 \\
\hline 7 & 1056 & 2929 & & Ostrea & 1 & & & \\
\hline 7 & 1056 & 2929 & & Mytilus & & & & 1 \\
\hline 7 & 1062 & 3497 & & Ostrea & 1 & & & \\
\hline 7 & 1739 & 4396 & & L obtusata & & & & 1 \\
\hline 7 & 1777 & 4418 & & Ostrea & & 1 & ++ & $\begin{array}{l}\text { NB Oyster } \\
\text { valve encrusted } \\
\text { with mortar }\end{array}$ \\
\hline 7 & 1777 & 4418 & & Unidentified & & & & + \\
\hline 7 & 1777 & 4418 & & cf Macoma sp & & & & $\begin{array}{l}1 \text { (mortar } \\
\text { adhering) }\end{array}$ \\
\hline 7 & 1783 & 3321 & & Ostrea & & 1 & & \\
\hline 7 & 1787 & 4424 & & Ostrea & 1 & 1 & 1 & \\
\hline 7 & 1787 & 4424 & & L obtusata & & & & 1 \\
\hline 8 & 269 & 356 & 4703 & Mytilus edulis & & & & + \\
\hline 8 & 269 & 356 & 4703 & $L$ littorea & & & & $\begin{array}{l}1 \text { (embedded } \\
\text { in mortar) }\end{array}$ \\
\hline 8 & 269 & 356 & 4703 & L littorea & & & & 1 (very small) \\
\hline 8 & 269 & 356 & 4703 & cf Macoma sp & & & & 1 \\
\hline 8 & 269 & 356 & 4703 & Gibbula sp & & & & 1 \\
\hline 8 & 269 & 356 & 4703 & Gastropod & & & & + \\
\hline 8 & 269 & 356 & 4703 & Unidentified sp & & & & $\begin{array}{l}1 \text { fragment in } \\
\text { mortar }\end{array}$ \\
\hline 8 & 1045 & 3283 & & Nucella & & & & 1 \\
\hline 8 & 1051 & 2935 & & Ostrea & & 2 & 2 & \\
\hline 8 & 1051 & 2935 & & $\begin{array}{l}\text { Unidentified (abraded fragment } \\
\text { with mortar adhering) }\end{array}$ & & & & 1 \\
\hline 8 & 1098 & 3803 & & Ostrea & & 2 & & \\
\hline
\end{tabular}


Table 2.20 (cont.) Mollusc catalogue (retents)

\begin{tabular}{|c|c|c|c|c|c|c|c|c|}
\hline \multirow[b]{2}{*}{ Phase } & \multirow[b]{2}{*}{ Context } & \multirow[b]{2}{*}{ Sample } & \multirow[b]{2}{*}{ IADB } & \multirow[b]{2}{*}{ Species } & \multicolumn{3}{|c|}{ Oyster (Ostrea edulis) } & \multirow[b]{2}{*}{ Other species } \\
\hline & & & & & Upper & Lower & Fragment & \\
\hline 9 & 1069 & 3240 & & Ostrea & & & 1 & \\
\hline 9 & 1093 & 3541 & 3532 & Ostrea & & & 2 & \\
\hline 9 & 1619 & 4339 & & Unidentified sp & & & & + \\
\hline 9 & 1666 & 4362 & & Ostrea & & & + & \\
\hline 9 & 1666 & 4362 & & $L$ littorea & & & & 2 (very small) \\
\hline 9 & 1666 & 4362 & & Littorina sp & & & & 3 (very small) \\
\hline
\end{tabular}

Note: + indicates up to 10 small fragments; ++ indicates more than 10 small fragments

$\begin{array}{ll}\text { Latin name } & \text { Common name } \\ \text { Ostrea edulis } & \text { Oyster } \\ \text { Littorina littorea } & \text { Edible periwinkle/Whelk } \\ \text { Littorina obtusata } & \text { Flat periwinkle } \\ \text { Littorina sp } & \text { Flat or edible periwinkle } \\ \text { Macoma sp } & \text { Tellin } \\ \text { Turritella } & \text { Tower shell }\end{array}$

\subsection{Fish remains}

\section{RUBY CERÓN-CARRASCO}

\subsubsection{Methodology}

The fish remains from Holyrood derived from a variety of contexts. One hundred and one contexts were chosen for this analysis according to their functional description, in order to be able to assess the fish remains in terms of social and economic basis. The selected contexts, from middens, rubbish dumps, drain fills and other domestic deposits, were considered to be the most representative of the site for this purpose. The identification of the fish bone elements was done by comparison with modern fish bone reference material. All the fish bones were examined and identified to the highest taxonomic level, usually to species or to the family group. Broken fragments were classed as unidentifiable. Nomenclature follows Wheeler and Jones (1989, 122-3). Where appropriate, all major paired elements were assigned to the left or right side of the skeleton. All elements were examined for signs of butchery and burning. The preservation of the remains was recorded in terms of texture on a scale of 1-5 (indicating fresh to extremely crumbly bone) and erosion, also on a scale of 1-5 (none to extreme). The sum of both was then used as an indication of the condition of the bone; fresh bone would score 1 while extremely poorly preserved bone would score 10 (after Nicholson 1991). The fragmentation of the bone was also noted in terms of percentage to show how much of the element had survived.

The size of the cod family fish, the Gadidae, was calculated by giving an approximate size range. This was done by matching the archaeological material to modern skeletons of known size based on 'total body length'. Therefore, the elements were categorised as 'very small' $(<150 \mathrm{~mm})$, 'small'

$\begin{array}{ll}\text { Latin name } & \text { Common name } \\ \text { Nucella lapillus } & \text { Dog whelk } \\ \text { Gibbula sp } & \text { Topshell } \\ \text { Cerastoderma sp } & \text { Cockle } \\ \text { Buccinum ondatum } & \text { Buckie } \\ \text { Pectinidae } & \text { Scallop family }\end{array}$

(150-300mm), 'medium' (300-600mm), 'large' (600mm$1.2 \mathrm{~m})$ and 'very large' $(1.2-1.5 \mathrm{~m})$. The size of the identified non-gadoid species was calculated by comparison with modern specimens of known size and these were categorised as 'juvenile' and 'mature' specimens. In the case of the salmon family, only vertebrae were recovered at Holyrood. These could not be identified to species level and thus were assigned to family Salmonidae, and could therefore have come from either trout (Salmo trutta) or salmon (Salmo salar).

Minimum number of individuals (MNI) was not calculated, since the assemblage was analysed as one unit, that is, regardless of the retrieval methods used, in this case handcollected and sieved material. The sieved samples contained most of the smaller elements while the hand-retrieved samples contained the larger most robust material as well as elements from small specimens. This was considered to be a well-balanced representation as most contexts also produced both sieved and hand-collected material. Quantification was instead calculated as NISP (Number of Identified Species) by fragment count.

\subsubsection{Results}

A full catalogue of results is available in the site archive, and displays the results of identification by context, sample number and by retrieval method (sieved or hand-collected). Table 2.21 summarises the species representation by period and NISP.

The assemblage is dominated by fish of the cod family (Gadidae). Haddock (Melanogrammus aeglefinus), cod (Gadus morhua), whiting (Merlangius merlangus), saithe (Pollachius virens) and pollack (Pollachius pollachius) are the most significant species of the Gadidae group present in the assemblage. Other significant marine species include herring (Clupea 
Table 2.21 Fish species represented in each period, by NISP

\begin{tabular}{|c|c|c|c|c|c|c|c|c|}
\hline \multirow[t]{2}{*}{ Species } & \multicolumn{8}{|c|}{ Period } \\
\hline & 2.1 & 2.2 & 2.3 & 3 & 4.1 & 4.2 & 5.1 & 5.2 \\
\hline Cod & 2 & 15 & 11 & 14 & 53 & 2 & & 2 \\
\hline Pollack & & & & 14 & 12 & 1 & & \\
\hline Saithe & & 4 & 1 & 5 & 45 & 1 & & \\
\hline Haddock & 3 & 7 & 7 & 16 & 27 & & & 8 \\
\hline Whiting & & 7 & 9 & 12 & 17 & & 1 & 1 \\
\hline Gadidae & 5 & 12 & 10 & 14 & 33 & 2 & 9 & 3 \\
\hline Herring & 1 & 1 & 27 & 40 & 28 & 1 & & 6 \\
\hline Mackerel & & & & 3 & & & & \\
\hline Dab & 1 & 1 & & & & & & \\
\hline Plaice & & & & 1 & & & & \\
\hline Rocker & 2 & 6 & 9 & 7 & 1 & & & \\
\hline Gurnard & & & & & 3 & & & 3 \\
\hline Dogfish & & & 1 & 2 & & & & \\
\hline Elasmobranch & & & & 1 & & & & \\
\hline Salmon/Trout & & & 1 & 1 & 1 & & & \\
\hline Eel & & & & & 1 & & & \\
\hline 3-spined stickleback & & & 1 & & & & & \\
\hline Total & 14 & 53 & 77 & 130 & 221 & 7 & 10 & 23 \\
\hline
\end{tabular}

harengus), which was present in most contexts. Mackerel (Scomber scombrus), another shoaling fish, was also present in the assemblage. Rocker or thornback ray (Raja clavata) was also important. Flatfishes included dab (Limanda limanda) and plaice (Pleuronectes platessa). Gurnard (Eutrigla gurnardus) was also recovered. Non-marine species include Salmonidae (salmon/trout) and eel (Anguilla anguilla). A few remains of the tiny three-spined stickleback (Gasterosteus aculeatus) were also recovered.

\subsubsection{Discussion by period}

\section{Period 2 (I4Th/I5Th Centuries)}

In Period 2.1 very few fish remains were recovered (table 2.21). These consisted mainly of cod family fishes (Gadidae) of which haddock and cod were the main species represented. Rocker was also present, as well as herring and dab. In Period 2.2 the main species represented was cod, while haddock, whiting and saithe were important too. Rocker was another important species represented in this period, and herring and dab were also present. In Period 2.3 herring was the main species represented. Cod, whiting and haddock were also significantly represented, as well as rocker. Dogfish and salmon/trout were also present. One bone from a threespined stickleback was also recovered.

\section{Period 3 (i6Th/I7Th Centuries)}

The main species represented was herring. Haddock, cod, whiting, pollack and saithe were all important Gadidae species present in this phase, haddock being the most plentiful.
Rocker, mackerel, plaice and dogfish as well as salmon/trout were also present.

Period 4 (I7Th/i 8Th Centuries)

In Period 4.1 the main species represented was cod, while saithe, haddock, whiting and pollack were also present. Herring was also an important species in this phase. Rocker, gurnard and salmon/trout were present too. One eel bone was recovered.

Few fish remains were recovered from Period 4.2, though cod, pollack, saithe and herring were present.

\section{Period 5 (I8Th/I9Th/2OTh Centuries)}

Period 5.1 also contained very few fish remains. Gadids were present in this phase, the only identified species being whiting. In Period 5.2 haddock was the main species present, while cod and whiting were also recovered. Herring and gurnard were also present in this phase.

\section{GENERAL DISCUSSION OF THE FISH REMAINS}

Fish resources have played an important part in the social, political, economic and religious history of Scotland. The relative safety of the East Lothian shores has offered a variety of fish species since antiquity. Fishing has been important in contributing to the food supply in Scotland, and from medieval times onwards fish have also featured prominently in Scottish commerce (Coull 1996). The importance of fishing in Scotland is related to the main concentrations of the population relatively close to the coast, which rendered sea fish relatively easily available to large numbers of the population. 
The main fish stocks in Scotland are generally divided into three groups of species. These include demersal or 'white' fish such as cod, haddock, flatfishes, skates etc, which are bottomdwellers, and the pelagic species which include herring and mackerel, species which spend part of their lives in the upper levels of the sea and move in shoals. In addition there are also freshwater fish, among which the most important is the anadromous salmon (Salmo salar).

Documentary records such as the Exchequer Rolls attest to the importance of fish and fishing, and, for example, they indicate an extensive trade in 'mullones' or 'stockfish', which generally means dried and salted cod. Cod is the best species suitable for this type of preservation because of its relatively large size. This process does not require barrels. Various other species have also been used for this purpose, for example saithe (coalfish), hake (Merluccius merluccius), ling (Molva molva) and haddock can also be so preserved (Coull 1996). Haddock and saithe, as well as cod, were recovered at Holyrood.

The burghs played a leading role in commercial fisheries, and matters relating to herring fishery and white fishery (fishing for cod, haddock, flatfishes, etc) were frequently mentioned in the records of the Convention of Royal Burghs (ibid). Fishing was controlled by the Laws of the Four Burghs, and thus the fishing industry was strictly a burghal monopoly. Each burgh had the powers to pass regulations affecting the price, quality and sale of fish. The building of boats and harbours, also wood for barrels, and the provision of salt, all connected with the fishing industry, were controlled by these regulations (Anson 1950).

In the Firth of Forth, the ports were well-placed in relation to the rich fishing grounds of the North Sea. Saithe or coalfish (Pollachius virens), which breed in large shoals near the beach or among kelp and seaweed, has provided a tasty source of nutrition (Gibson 1994). Herring spawning grounds were not far from the east coast and stretched from Berwickshire to Sutherland. Herring was also caught in the Firth of Forth. Most were dried and exported. The earliest records from the 12th century show that rights to herring fishing were vested in the Crown, and that herring was one of the most important fish species (Coull 1996). In the fisheries of the Forth, there is also a record of the granting of a right to fish herring in the 12th century by David I to the Abbey of Holyrood (Cochran-Patrick 1892) (the Augustinian Order was in charge of Holyrood Abbey (McGowran 1985)). Red herring are documented in the records relating to Berwick in 1299-1300 (ibid; Anson 1950). The term 'red herring' refers to herring processed by smoking (Samuel 1918), although herring appears to have been regarded as of little commercial importance, in terms of trading, until the middle of the 18th century.

Fishing villages around the east coast of Scotland are well known. Eyemouth, for example, flourished as one of the main white fishery ports from the 13th century and by 1850 it had become one of the main herring ports in Scotland. Throughout the 18th century Dunbar was the main herring fishing port in the country. Other important ports were North Berwick, Port Seton, Cockenzie, Fisherrow and, situated closer to the Holyrood location, were the fishing ports of Newhaven and Leith. The fishing port of Newhaven has been in operation since the 15th century (Anson 1950).

Fishing must have been one of the earliest activities of the settlers at Leith although shore fishing became more periph- eral once the harbour was developed to accommodate larger vessels. Newhaven on the other hand maintained an unbroken tradition of fishing and by the mid 16th century the Free Fishermen's Society of Newhaven was an active organisation. Fishing was mainly for herring, from open, undecked boats, suitable only for inshore coastal waters. At times, herring was plentiful and a short trip from Newhaven brought the boats to the fishing ground (Marshall 1986).

The fishermen of Newhaven, however, were not entirely dependent on herring fishing, since haddock, saithe and pollack were also available not far from the coast (ibid). From the 1700s at Newhaven the general pattern of the fishing year was a summer of net fishing for herring, while oyster dredging and line fishing for haddock and cod took place during the winter months. Herring was also caught to a lesser extent during November and December (McGowran 1985).

Other fish besides herring and the gadids were also commercially important. The range of flatfish in Scottish coastal waters is considerable. In the Holyrood assemblage, plaice (Pleuronectes platessa) and dab (Limanda limanda) were identified. Plaice are found all around the Scottish coast (Lockhart 1997) and are easily caught in sandy beaches by line.

Mackerel is found in large shoals in Scotland during summer and early autumn and can easily be caught on lines. Mackerel decomposes quite rapidly once caught, particularly during warm weather, and thus during the 17 th and 18th centuries this fact allowed for their being sold immediately, even on Sundays after divine service (ibid).

Remains of ray (Raja clavata) were also recovered in significant numbers at Holyrood; these were probably caught by line while fishing for cod and haddock.

As well as marine species, a small number of freshwater fish were represented in the assemblage from Holyrood: these could derive from a number of sources. The River Almond, which enters the Forth at Cramond, is still a popular spot for fishing sea trout and salmon during September and October when the fish enter the tidal waters. Other sources of salmonid and other freshwater species would have been the River Esk, where the sea trout and salmon are plentiful, especially when these enter the tidal waters in April and again during September. The salmon fishery was carried out using stake-nets during the 1800s at the mouth of the River Esk, the season beginning early in February until mid September (NSAS 1845). The Water of Leith is at present a small river but must have been larger before five reservoirs sucked up its headwaters. During medieval times, however, the construction of weirs ended the runs of salmon, and the use of the river as a sewer by the growing populations along its banks must have made the trout an unpalatable dish (Graham 1980). Eels were probably caught while fishing for salmon and trout. The tiny three-spined stickleback may have been used as bait or could have come from the stomach contents of a larger fish.

The consumption of fish must be considered in its contemporary context. Until the 15th century, throughout Britain, the rules of the Church were quite strict. Until the early 13th century, adults were forbidden 'four-footed freshmeat' on three days a week and in other fasting periods of one or more nights and days. By the 15th century these rules had been relaxed in lay society and monasteries, and only Fridays were obligatory weekly fasting or 'fysshe' days, although Wednes- 
days and Saturdays may have been respected by the pious, and by Church dignitaries in public. Annual fasts such as Advent and Lent, which then as now lasted six weeks, were more seriously observed and were the only time when eggs and dairy products were banned as well as meat (Black 1992).

The fish remains recovered during the excavation of the Holyrood site have allowed for an interesting insight into the development of the fishing industry of Scotland, particularly in terms of the social, economic and religious aspects of life in the medieval and post-medieval periods in Edinburgh and the surrounding areas. With increasing population strong markets quickly developed and Edinburgh, with its developing importance, must have provided a strong demand. Fish have played a considerable part in the development of the Scottish nation and their remains recovered from sites such as Holyrood are an important source of evidence to support the early historical records. The fish remains from Holyrood further demonstrate the important role of fish in Scotland's history, contributing invaluable nutrition to the diet of its population, while providing the country with a valuable export industry.

\subsection{SOILS AND SEDIMENTS}

\section{STEPHEN CARTER}

\subsubsection{Sediment sources and processes of accumulation}

Archaeological excavation of the Scottish Parliament site was characterised by the recording of isolated stone structures and cut features set in deep and extensive layers of soil. Up to $2.5 \mathrm{~m}$ of accumulated deposits were excavated, all of which had accumulated or been modified from existing natural soils since the 12 th century AD. Deep soil deposits are a characteristic feature of medieval burghs, but there has been little effort made in the past to determine how and why they accumulated (Carter 2001). The purpose of this section of the report is to present the evidence for the sources of this large volume of sediment and the processes that led to its accumulation.

The extensive soil layers have been divided into three main stratigraphic units, based on their field characteristics and stratigraphic relationships. These have been assigned to Periods 2, 3 and 4 .

\section{Period 2 (I4TH/I5TH Centuries)}

The basal soil layer identified in all of the main excavation areas. Defined by its distinctive brown colour (contrasting with all overlying layers, which were very dark brown). Diffuse upper boundary with Period 3 soil.

\section{Period 3 (i6Th/I7Th Centuries)}

Very dark brown soil layer/s overlying the Period 2 soil and cut by the widespread Period 4 cultivation trenches. Present in all of the main excavation areas.

\section{Period 4 (I7Th/I8Th CENTURIES)}

Very dark brown soil layer/s overlying the cultivation trenches. Extensively truncated by Period 5 buildings and only recorded in some areas of the western half of the site.

Information has been collected about these soils at various scales of observation. The principal source of data for the analysis of the soils is a series of soil thin sections taken from three stratigraphic sequences in the western half of the site. These provide quantitative information on the composition of the soils at a microscopic level. The thin-section data are supported by the results of a programme of wet sieving of bulk soil samples from Period 2 and 3 soils in the western half of the site. Wet sieving has been used to quantify larger, rarer components in the soils, for example pottery and bone. Finally, field observations and records have been used to provide relevant information on the largest scale.

\subsubsection{Soils}

It is necessary to establish the nature of the soils prior to significant human modification to allow those modifications to be detected. The natural soil profile has been highly altered over the whole site and the upper soil horizons have been incorporated into what were excavated as Period 2 soils. Therefore the position of the natural ground surface (as opposed to the natural level of the subsoil) is difficult to determine. There are no stone-built surfaces or other structures from the earliest medieval phases of activity from which the level of the ground surface can be deduced, so total natural soil depth can only be estimated.

Composition of the basal Period 2 soils comes closest to the natural soil. These are generally brown, freely draining, slightly stony sandy silt loams. The parent material for this soil is the underlying till which is derived from local sedimentary and igneous rocks. It is suggested that the natural soil profile was roughly $0.5 \mathrm{~m}$ deep over the surviving subsoil surface, based on comparisons with similar present-day soils in the Lothians.

Excavation close to the foot of the steep slope at the Canongate frontage exposed relatively deep Period 2 soil deposits (up to $0.8 \mathrm{~m}$ deep compared with a maximum of only $0.4 \mathrm{~m}$ out on the terrace). These deposits are interpreted as a deeper wedge of colluvial soils at the foot of the slope, possibly up to $1 \mathrm{~m}$ deep. Colluvium is the product of natural soil erosion, possibly augmented in this case by disturbanceinduced erosion once the Canongate was established. It is coarser in texture than the terrace soils: the colluvium is a moderately stony sandy loam.

\subsubsection{Materials and methodology}

Undisturbed block samples were collected in $8 \times 5 \times 5 \mathrm{~cm}$ Kubiena tins from three stratigraphic sequences in the western half of the site.

Trench 22 (western baulk on Reid's Close)

Sample 11 (Period 4)

Sample 12 (Period 3)

Sample 13 (Period 3/2 intergrade)

Sample 14 (Period 2) 
Table 2.22 Composition of the thin sections

\begin{tabular}{|c|c|c|c|c|c|c|}
\hline \multirow[t]{2}{*}{ Sample } & \multirow[t]{2}{*}{ Period } & \multicolumn{5}{|c|}{ Component ( $\%$ of area of thin section excluding voids) } \\
\hline & & Rocks & Sand & Silt/clay & Coal & Other exotics \\
\hline \multicolumn{7}{|c|}{ Trench 22 (Reid's Close) } \\
\hline 11 & 4 & 12 & 10 & 48 & 24 & 6 \\
\hline 12 & 3 & 7 & 13 & 50 & 30 & 0 \\
\hline 13 & $3 / 2$ & 8 & 26 & 54 & 12 & 0 \\
\hline 14 & 2 & 10 & 29 & 48 & 13 & 0 \\
\hline \multicolumn{7}{|l|}{ Trench 1} \\
\hline 15 & 3 & 9 & 21 & 54 & 16 & 0 \\
\hline 16 & $3 / 2$ & 15 & 27 & 47 & 9 & 2 \\
\hline 17 & 2 & 21 & 33 & 46 & 0 & 0 \\
\hline \multicolumn{7}{|c|}{ Trench 22 (Queensberry House Gardens) } \\
\hline 18 & 4 & 5 & 19 & 45 & 27 & 4 \\
\hline 19 & 3 & 4 & 19 & 57 & 20 & 0 \\
\hline 20 & 2 & 3 & 26 & 69 & 2 & 0 \\
\hline \multicolumn{7}{|c|}{ Trench 21} \\
\hline 3725 & 2 & 18 & 44 & 38 & 0 & 0 \\
\hline
\end{tabular}

\section{Trench I (NW CORNER OF SITE)}

Sample 15 (Period 3)

Sample 16 (Period 3/2 intergrade)

Sample 17 (Period 2)

Trench 22 (Centre of Queensberry House Garden)

Sample 18 (Period 4)

Sample 19 (Period 3)

Sample 20 (Period 2)

One additional sample (3725) was collected from a Period 2 soil in Trench 21 adjacent to the east end of Queensberry House. Resin impregnation of the soil blocks and thin section preparation was undertaken by the Department of Environmental Science, University of Stirling, and followed standard procedures (Murphy 1986). The thin sections were interpreted using the descriptive scheme and terminology recommended by Bullock et al (1985). Quantification of the principal components was achieved using point counting (100 points per section).

The principal soil layers assigned to Periods 2 and 3 from the western half of the site (Trench 22) were bulk sampled for on-site wet sieving. The following layers were sampled:

Period 2: 298, 612, 667, 671, 839 (Total: 76 samples)

Period 3: 215, 563 (Total: 52 samples)

Soil samples were collected with a standard volume of 60 litres and wet sieved through a $10 \mathrm{~mm}$ mesh. The retent in the mesh was sorted and all artefacts and other exotic inclusions (coal for example) collected. These were bagged by material type and quantified by fragment number and weight. In the analysis only weights have been quoted, as this was considered to be a more meaningful measure of abundance for highly fragmented material.

\subsubsection{Results}

\section{COMPOSITION IN THIN SECTION}

The composition of the thin sections is summarised in table 2.22 and the various classes of material are discussed further here.

\section{Rocks}

This includes all rock fragments greater than $2 \mathrm{~mm}$ in size with the exception of coal, which is treated as a separate category because it is definitely an introduced component. Abundance of rock fragments varies between 3\% and 21\%, with both the highest and lowest values occurring in Period 2 soils; Period 4 soils are much less variable. The Period 2 soils in Trenches 1 and 21 are considerably stonier than the other soils.

The local subsoil contains a mixture of sedimentary and igneous rocks and this is reflected in the rock types observed in thin section: siltstone, sandstone, tuff and basalt. All types occur throughout the stratigraphic sequence but sandstone and basalt are most abundant. A few fragments of sedimentary rock have been burnt so it is reasonable to suggest that they were introduced with the coal as fuel ash. However, there is no evidence that sedimentary rocks vary in abundance with coal so the majority of the rock fragments must have a different source.

SAND

Sand has been defined as all mineral grains between $50 \mu \mathrm{m}$ and $2 \mathrm{~mm}$ in size. It is most abundant in the Period 2 soils (44\% in Sample 3725) and declines up through the stratigraphic sequence to as little as $10 \%$ in Sample 11. Highest values are seen in Trenches 1 and 21 (matching the results for rocks). 


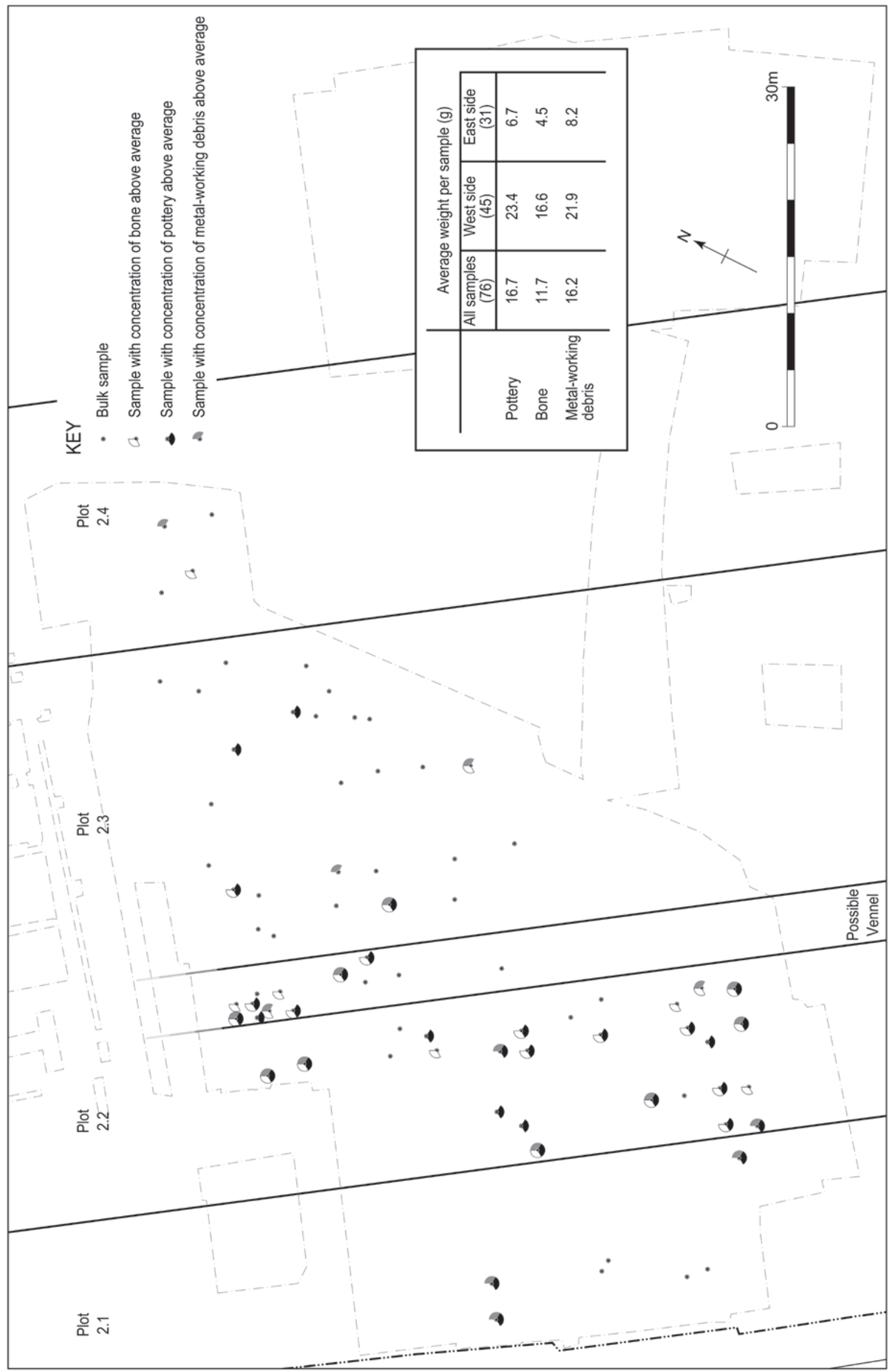

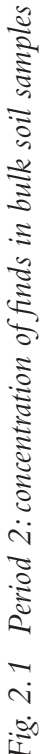


This is the fine fraction of the soil comprising all mineral grains less than $50 \mu \mathrm{m}$ in size. There is little variation in the abundance of this component, with most soils containing between $45 \%$ and 55\% silt and clay. Sample 3725 (Period 2) has an exceptionally low value, emphasising the coarse texture of this soil sample. Individual grains cannot be readily identified but there is evidence of systematic variation in the composition of the fine fraction. In Period 4 samples and, to a lesser degree, Period 3 samples, the fine fraction is highly reflective, with numerous red and black reflective particles. These indicate the presence of very fine burnt mineral particles in the Period 3 and 4 soils, but their absence from Period 2. These fine particles probably account for the dark colour of the Period 3 and 4 soils compared with Period 2.

\section{COAL}

Coal is by far the most abundant exotic component in these soils, rising as high as 30\% in Sample 12 (Period 5). Coal can occur naturally in the soils of the Edinburgh area but if it is present naturally on the Holyrood Parliament site it is apparently in very low concentration. It is absent or very rare in three out of four Period 2 soils and in the fourth the fragments of coal are burnt, proving that they have been used as fuel. It is therefore assumed that all of the coal present in these soils has originated as partially burnt fuel discarded with coal ashes.

\section{OTHER EXOTIC COMPONENTS}

This category includes a wide variety of introduced materials but all are rare, totalling no more than $6 \%$ in one Period 4 sample. Only bone, mortar, charcoal and slag were abundant enough to register in the point counting, but marine shell and pottery fragments were also noted. These material types too rare to be quantified in small soil thin sections are best assessed from the results of the wet sieving (see below).

\section{DISTRIBUTION OF EXOTIC COMPONENTS IN BULK SOIL SAMPLES}

The programme of on-site wet sieving recovered a wide range of artefacts and other exotic materials, but only three material types were common enough in the Period 2 and 3 samples to allow further analysis of their abundance and distribution. They were pottery, bone and metal-working debris (mainly iron slag). Figures 2.1 and 2.2 show the location of the samples from Periods 2 and 3 respectively. Average weights per sample were calculated for each of the three material types and these are tabulated in figures 2.1 and 2.2. Variation in abundance has been demonstrated by highlighting the location of samples producing concentrations higher than the average for any material type in that period.

The results for Period 2 (fig. 2.1) reveal a clear difference between samples on the west side of Trench 22 and those on the east side. If the samples are split into two groups along the line of the possible vennel between burgage Plots 2.2 and 2.3, $85 \%$ of the above-average results lie to the west. Recalculation of average concentrations for the two data sub-sets (fig. 2.1) shows that all three material types are present in significantly higher concentrations in the west of Trench 22 .
Inspection of the Period 3 results (fig. 2.2) reveals no such pattern. Individual high concentrations are uniformly distributed and if the samples are split along the same boundary as the Period 2 samples, the resulting sub-sets produce similar average concentrations.

\subsubsection{Sediment depth and distribution}

Compilation of level data from drawn site sections and plans reveals that the accumulation of deposits on the site has not been uniform. The total depth of deposits on the site can be calculated by plotting the difference between the level of the natural subsoil and the 1998 ground surface. As noted above, this depth will include the upper part of the natural soil profile and allowance must be made for this in any calculation of total sediment accumulation. The total depth of deposits across the site is shown in fig. 2.3. The calculation of total depth was complicated by the presence of standing buildings, and in these areas the depth is based on the ground level immediately outside the building.

The site can be divided into two distinct blocks of sediment, divided along a property boundary that marks a sudden drop in sediment depth. To the west there is $2.0-2.5 \mathrm{~m}$ of sediment on the level terrace, but total depth rapidly declines as the ground surface rises towards the Canongate. To the east there is only $1.0-1.5 \mathrm{~m}$ of sediment over the terrace, but sediment depth increases to over $2.5 \mathrm{~m}$ as the natural ground level falls away in the south-east corner of the site. This area has therefore been levelled up, hiding the presence of the natural slope.

The major difference in sediment depth on either side of this property boundary was reflected in an actual difference in ground level of roughly $1 \mathrm{~m}$ before demolition for the new Parliament building commenced in 1998. The property boundary (a substantial stone wall) marked the division between the Scottish \& Newcastle Brewery and the grounds of Queensberry House Hospital. The site was therefore divided up to 1998 into two roughly level terraces: the brewery site partially levelled up but also deeply cut into solid rock on the north side of the site (thereby destroying all archaeological deposits in this area), and the hospital site with Queensberry House perched on the slope beside the Canongate overlooking a levelled area of gardens with subsidiary buildings.

The total depth of deposits as mapped in fig. 2.3 is not the same as the total depth of soils accumulated on the site. Total deposit depth includes significant thicknesses of deposits of 19th- and 20th-century date. These include levelling deposits for the military parade ground to the south of Queensberry House, created when it was converted into barracks and deep foundation rafts for the brewery buildings.

Recorded total soil depth (excluding modern deposits: table 2.23) ranges from a maximum of $2.2 \mathrm{~m}$ on the west side of Trench 22 adjacent to Reid's Close to only $0.8 \mathrm{~m}$ on the brewery site (Trench 26). This difference was initially assumed to reflect a higher level of truncation on the brewery site, given the total loss of archaeological deposits over much of this area. However, despite severe truncation on the brewery site and elsewhere, it is possible to demonstrate that much more soil has accumulated in the western half of the site. This can be demonstrated by the difference in depth of soil 


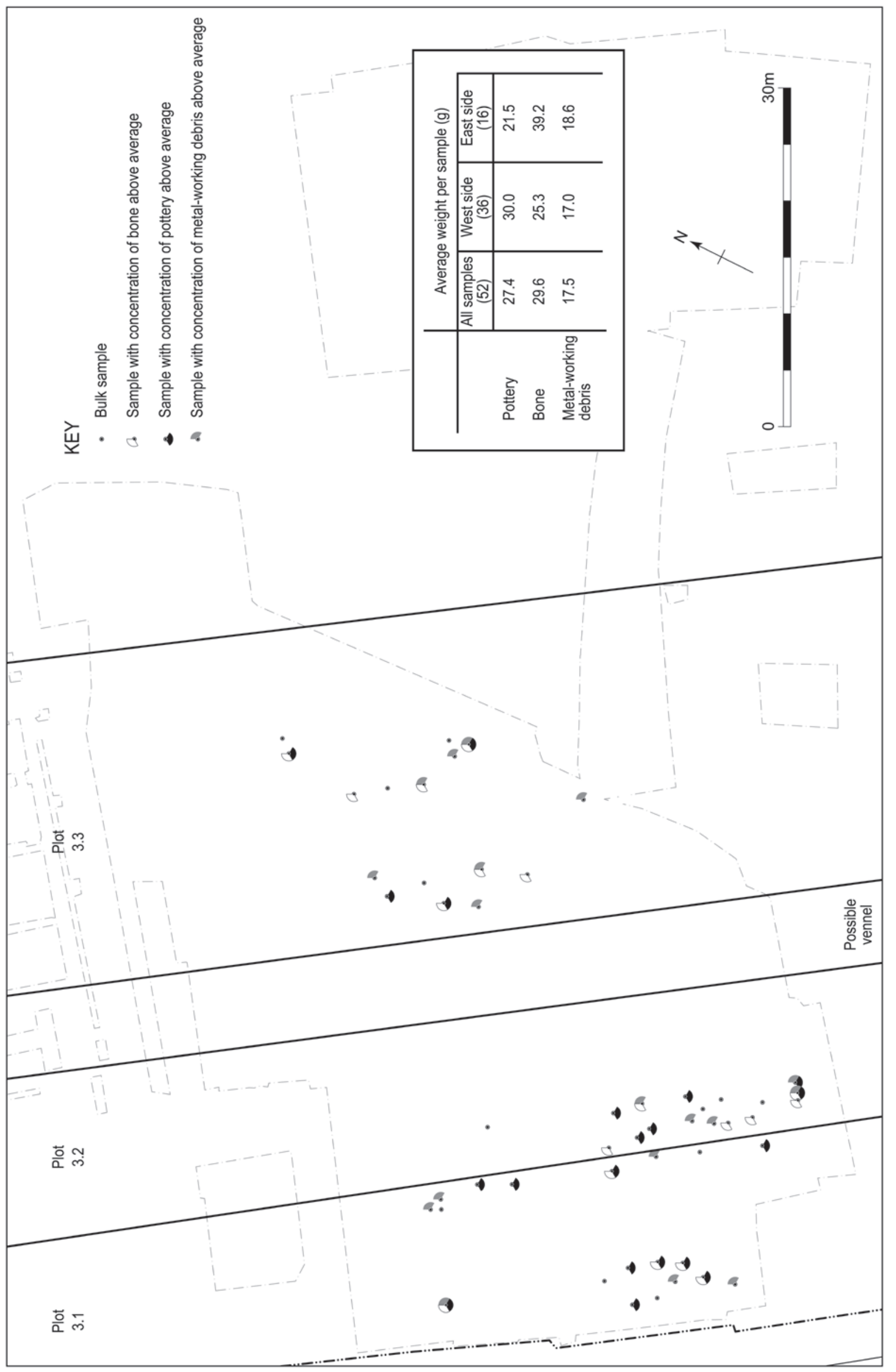

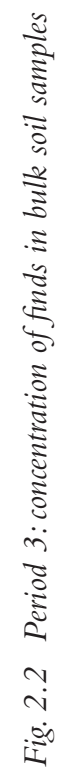




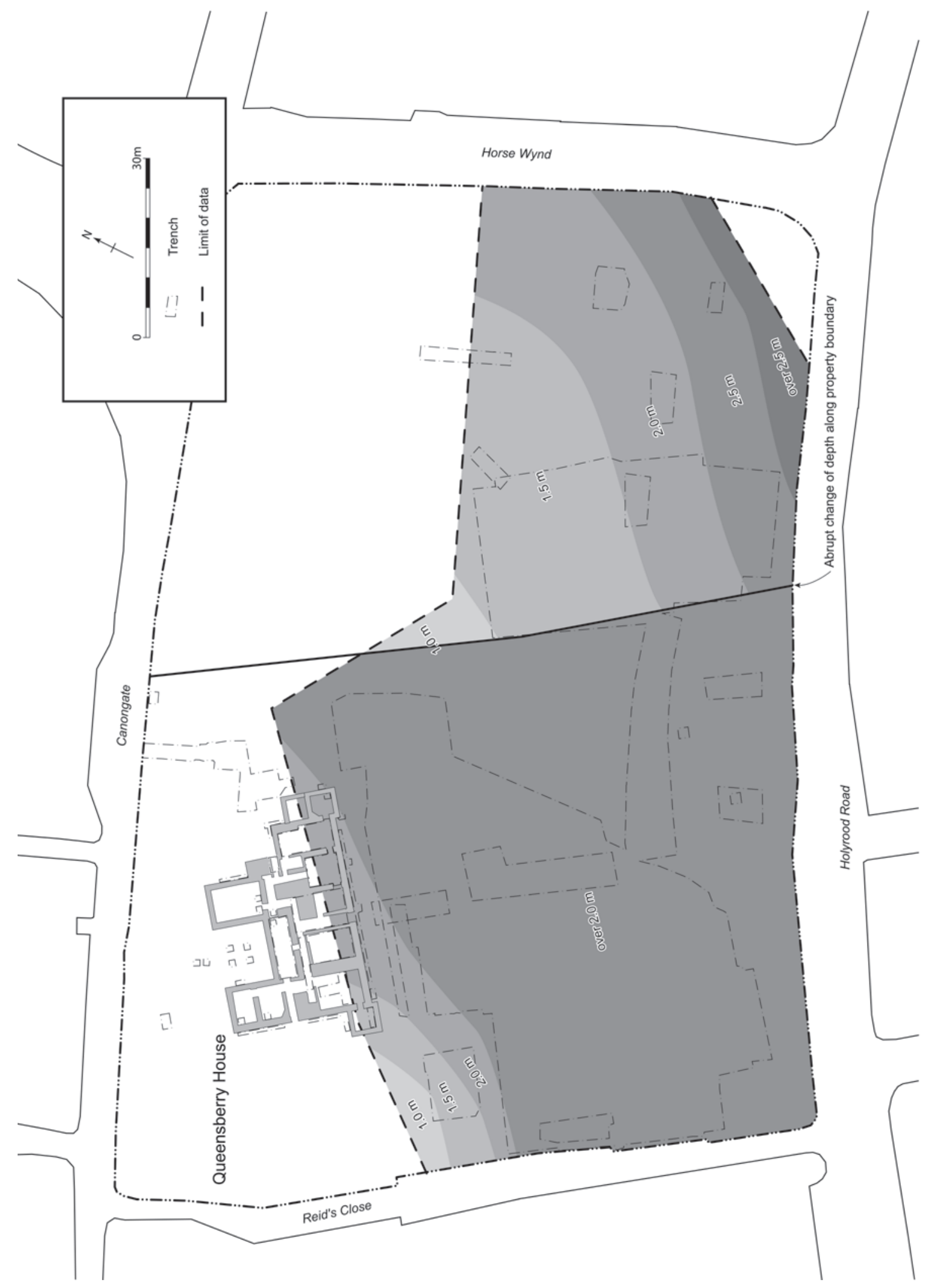

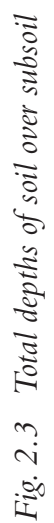


Table 2.23 Estimates of total accumulated soil depth

\begin{tabular}{lccc}
\hline Area & $\begin{array}{c}\text { Recorded soil depth } \\
\text { below trench }\end{array}$ & $\begin{array}{c}\text { Total depth of } \\
\text { soil (estimate) }\end{array}$ & $\begin{array}{c}\text { Accumulated soil depth by } \\
\text { 17th/18th century (estimate) }\end{array}$ \\
\hline Trench 22, west side & $1.5 \mathrm{~m}$ & $2.2 \mathrm{~m}$ & $1.7 \mathrm{~m}$ \\
Trench 22, east side & $0.9 \mathrm{~m}$ & $1.6 \mathrm{~m}$ & $1.1 \mathrm{~m}$ \\
Trench 26, Brewery & $0.2 \mathrm{~m}$ & $0.9 \mathrm{~m}$ & $0.4 \mathrm{~m}$ \\
\hline
\end{tabular}

below the cultivation trenches that were dug over most of the undeveloped land in Period 4. If it is assumed that all were dug to a similar depth below ground level, the trench bases provide an index of contemporary ground surface in the 17th or 18th centuries. Actual ground surfaces do not generally survive, but the more complete sequences have a maximum trench depth of $0.4 \mathrm{~m}$ below roughly $0.3 \mathrm{~m}$ of topsoil. Therefore the ground surface may have been roughly $0.7 \mathrm{~m}$ above the bases of the trenches. Total accumulated soil above original (pre-burgh) ground surface may be obtained by subtracting an allowance for the natural soil horizons (already estimated at $0.5 \mathrm{~m}$ ).

Estimates of total accumulated soil depth have been calculated for three locations across the level terrace that occupies the centre of the site. This avoids the natural slopes where soil accumulation will have been affected by local topographic factors. The results are tabulated in table 2.23. The results indicate that there is a significant decrease in the total depth of accumulated soils from west to east across the site.

\subsubsection{Discussion}

\section{Sediment SOURCES}

Calculations of total accumulated soil depth demonstrate that significant volumes of mineral material have been imported onto this site and become incorporated in the deepening soil layers. The results of the thin-section analysis and wet-sieving programme suggest that there is only one exotic material present in significant volumes in the accumulating soil layers: coal ash. This is represented by fragments of partially burnt coal, rarer burnt sedimentary rock fragments (reflecting the burning of low-grade or poorly sorted coal) and fine burnt residues (ash). It is not possible to calculate the volume occupied by the ash but it seems unlikely that coal ash would have been dominated by fragments of unburnt fuel, so it may be assumed that the fine ash was more abundant than the coal fragments. Further evidence for significant additions of fines is provided by the declining quantity of sand relative to fines between Period 2 and 4 soils. It is clear that the later soils are relatively enriched in silt/clay and the highly reflective nature of this material indicates the source is ash. Given that coal fragments constitute between $15 \%$ and $30 \%$ of the Period 3 and 4 soils examined in thin section, it seems likely that coal ash (coal, rocks and fines together) is the dominant constituent of these accumulated soils (as high as $50-75 \%$ ).

The Period 3 and 4 soils can be assumed to contain a proportion of the original soil, mixed upwards as sediment gradually accumulated, and this is demonstrated by the presence of large numbers of medieval pottery fragments in Period 4 soils. The local soil component would become progressively diluted through time as further sediment accumulated, but it could be argued that it accounts for the remainder of the Period 3 and 4 soils. However, it does not account for the relatively coal-free nature of the Period 2 soils. The comparative absence of coal in the Period 2 soils could indicate either that coal or coal ash was not being spread in significant quantities at this time or that soil-mixing processes failed to incorporate the coal ash, i.e. the Period 2 soils are simply the relatively 'clean' lower portions of a soil profile unaffected by surface-mixing processes. This latter option is refuted by the presence of pottery, bone and slag in the Period 2 soils and in concentrations similar to those recorded in Period 3 soils (figs $2.1 \& 2.2$ ). This demonstrates that soil-mixing processes were operating in the Period 2 soil and therefore we must conclude that coal ash was not being applied in any quantity.

In the absence of coal ash, what explains the accumulation of soil during Period 2? There is certainly no direct evidence for another major external source of sediment after coal ash but this, in itself, does point to one other possible source of sediment: local soil or turfs. Turf was widely used in medieval burghs for construction, animal bedding and in some cases as fuel. If it had been collected from a nearby area with similar soils, once degraded it would be impossible to distinguish from the in situ soil. Given the ubiquity of turf in the medieval burgh, at least before building in stone became common, it would be hard to argue that there is not a turf component in the accumulating soils, although it is simply impossible to prove. Similarly, there could be a component of local soil washed off the ridge that the Canongate occupies, and accumulating at the foot of the slope. Clearly this process has not been dominant because the only evidence for deepened colluvial soils probably reflects much earlier (early Holocene) slope instability. In any event, these colluvial deposits are restricted to the foot of the slope off the Canongate and cannot account for the uniformly deep accumulations of soil covering the level terrace to the south.

\section{Processes of ACCUMUlation}

From the preceding analysis of sediment sources, it seems that there are two significant processes to discuss: the deposition of coal ashes and the deposition of turf/soil. The wide distribution of the coal ash demonstrates that it was being spread and not simply allowed to accumulate in large piles. This indicates use of the ash rather than the accumulation of a waste product; the most likely use is as a soil fertiliser. It is unlikely that the ash would have been spread fresh, directly onto the soil. It is more likely to have been one component of a midden that was periodically spread onto cultivated ground. Other material in the midden could include the low concentration of pottery, bone and other artefacts recorded in the soils - domestic refuse. However, a midden is likely to have been dominated by organic waste, particularly excrement 
(human and animal) and the ashes would have served a useful role in soaking up and helping to retain liquid waste. Organic components have not survived on this site and it is important to remember the heavy bias this places on our understanding of the soils and sediments. The dominance of coal ash in the Period 3 and 4 soils in part results from the loss through oxidation of any organic components in these soils.

The possible role of turf as a component of the accumulating soils, particularly in Period 2, has been mentioned above. Whatever the original reason for bringing turf onto the site, disposal along with other midden material is the most likely route for it to reach the backlands. Turf would have performed the same function in the midden as the ashes, soaking up the nutrient-rich organic waste before being spread as part of the fertiliser.

\section{RATE AND DURATION OF SOIL ACCUMULATION}

Having identified the main processes leading to sediment accumulation, it is possible to consider the rate at which accumulation occurred and the duration of the process. There are two particular observations that relate to these issues and require explanation: the comparative absence of coal in the Period 2 soils, and the variable depth of soil accumulated in different parts of the site.

Analysis of the carbonised plant remains has shown that wood charcoal is rare throughout the deposits of all periods compared to coal and therefore it seems probable that coal was the common fuel from the origins of the burgh onwards. The rarity of coal in Period 2 soils and its abundance from Period 3 onwards can therefore be interpreted as evidence for increasing availability of hearth ashes. The quantity of ash may be taken as proxy evidence for the number of hearths and therefore dwellings in the vicinity: few during Period 2 , many from Period 3 onwards.

The low-density scatter of artefacts in Period 2 soils suggests manuring at this time. Deposition of turf, or turf-derived sediment, was also occurring at the same time and, again, manuring is the mostly likely process in what appear to have been relatively undeveloped backlands during Period 2. The change in inputs between Periods 2 and 3 therefore records a transition from relatively undeveloped plots used primarily for cultivation to developed plots with large volumes of domestic waste (primarily ash) deposited in the backlands.

The variable depth of accumulated soils across the site presents a different problem. It can be explained either as the product of variation in the rate of accumulation or the duration of accumulation. The lack of precise chronological markers makes it difficult to offer evidence in support of either of these alternative explanations; pottery date ranges are simply too broad. However, some relevant observations can be made. The stratigraphic position of the $17 \mathrm{th} / 18 \mathrm{th}-$ century cultivation trenches suggests that accumulation had stopped by this date: no more than $0.3 \mathrm{~m}$ of soil is recorded over the trenches and they were designed to function beneath a cultivated topsoil. This sets an upper time limit on the duration of soil accumulation that appears to be roughly the same across the whole site. Therefore any variation in the duration of accumulation must relate to the start date, not the end date.

Did plots of land further to the west start to receive organo-mineral manures before those to the east? One piece of evidence tends to support this proposition. The depth of the Period 2 soils in the western half of the site (Trench 22 ) is roughly $0.4 \mathrm{~m}$, away from the deeper colluvial profiles adjacent to Queensberry House. The Period 2 soil as identified in the eastern half of the site (Trench 26) is described as a shallow interface layer between the Period 3 soil and the natural subsoil; it contained very few finds. This would be consistent with a late start to soil accumulation; if coal ash was present from the start, no coal-free Period 2 soil would be preserved. This evidence does not rule out the possibility of variable rates of soil accumulation, and indeed some variation is to be expected as adjacent plots developed along different lines, reflecting the owner's use of the land. The contrasting concentrations of artefacts in the Period 2 soils of Trench 22 (fig. 2.1) may be evidence of this type of variation in land-use.

\subsubsection{Conclusions}

Analysis of the composition of the Period 3 and 4 soils indicates that coal ash was the dominant material responsible for the accumulation of these soils. It is assumed that the coal ash was initially cleared out into a midden and was subsequently spread on cultivated plots as a component of the manure. The process of soil accumulation through deposition of ash appears to have ended before the 17th/18th centuries. This may reflect a decline in the importance of cropping in the backlands as the status of the area rose and formal gardens became the norm. The relative absence of coal ash from Period 2 soils indicates a period of sediment accumulation when little ash was being deposited. Turf, used initially for construction and then for manure, may have been the source of sediment at this time.

The depth of soil that accumulated varies considerably across the site. Estimates of total accumulated soil depths range from $1.7 \mathrm{~m}$ on the western edge of the site to only $0.4 \mathrm{~m}$ in the east. There is some evidence to suggest that this reflects a later start to soil accumulation on the east side of the site.Variation in depth may also have resulted from differing rates of accumulation. Both of these processes are indicative of different land-use histories for the medieval burgage plots that lie within the excavated areas. 



\section{PART 3}

శே\%?

The archaeological evidence from the Parliament site

Simon Stronach, Adrian Cox, Derek Hall and Stephen Carter

Part 3 is Chapter 3, reprinted from

Scotland's Parliament and the Canongate: archaeology and history (HAPT 2008) 



\subsection{Introduction}

SIMON STRONACH

This chapter describes the main archaeological features encountered during the excavation, and the artefactual and environmental evidence where appropriate. The results are prefaced by a summary of the main archaeological findings. At the end of the chapter is a brief discussion of how the archaeological results shed light on the main research questions posed at the beginning of the project.

A recurring issue for archaeologists working in historic towns is how to deal with 'dark earth' or 'garden soils'. These are deep accumulations of wellmixed homogeneous loams often containing isolated stone features such as walls, stone-lined wells, drains and kilns which appear to be 'floating' within the soils. This phenomenon is common to many of Scotland's historic towns and Canongate was no exception. There were two distinct spreads of these soils at the Parliament site: one of medieval date and the other post-medieval. During initial post-excavation work, features were grouped together into nine stratigraphic phases based on whether archaeological features were sealed beneath, contained within, or cut into these deposits from above. With subsequent analysis of the structure and content of the soils it became clear that the dating provided by pottery and other artefacts did not support chronological separation of the phases beyond a broad association with the medieval or post-medieval horizons. The phases, however, conveniently fitted within the wider chronological periods (Periods 1-5) used to structure the narrative of the report (Chapter 1), which weaves together the history, archaeology and architecture of the site and its environs. It was decided, therefore, to work with these same periods in order to provide continuity. The original phases have been expressed as sub-periods where more than one were subsumed within a period. Each period description is preceded by a summary of its stratigraphic background related to sub-periods.

In each period, the text and the drawings have been structured around the identification of burgage plots (properties established in the medieval period) and vennels (paths between plots). Where there was some physical evidence for the boundaries that marked these plots (fence lines, ditches and gullies), the properties they defined have been labelled according to period and plot. Through historic processes such as amalgamation, and the archaeological bias of preservation, the plot boundaries were not static. To avoid confusion the plot numbers are prefaced by their period, for example Period 2, Plot 1 is referred to as Plot 2.1. All the evidence for plot boundaries was found in the southern half of the site, but these properties would originally have extended the whole distance from the Canongate street frontage to the end of these plots on what is now Holyrood Road. Property boundaries, where visible, have therefore been projected northwards and southwards.

Fig 1.3 shows all of the areas which were investigated during both the main excavation and earlier phases of evaluation, except areas inside, or immediately outside, Queensberry House (for example, Trenches 9-15, 20, 30) for reasons of scale. In each of the period plans that follow (Periods 1-5; figs 3.1, 3.4, 3.9, 3.14, 3.19) there is an inset showing the area of archaeological interest (shaded) in relation to Queensberry House (a useful reference point on an extensive site such as this), a large-scale plan showing features attributed to that period, and additional insets showing individual features enlarged to provide more detail. Photographs and section drawings of key features support the information contained in the period plans.

\subsection{Summary of the archaeological evidence}

\section{SIMON STRONACH}

It appears that the site was the location for prehistoric human activity, perhaps from the earliest period of habitation in Scotland. Several features, such as a hearth, that may have derived from this activity were preserved, although the only certain evidence came from a residual assemblage of struck stone scattered 
around the site. Whether this ephemeral evidence reflects the transient nature of prehistoric use or the removal of more substantial remains by later activity is difficult to say.

A substantial ditch was cut at the south end of the site at an unknown date. Sometime after the 13 th century it was left to silt up for a while and then deliberately filled. No other features could be attributed to this period and it is presumed that the ditch was defining an area that lay to the north, since marshes lay to the south. For reasons that are explored fully in Chapter 3.11 this feature seemed more likely to have acted as a boundary within the precinct of Holyrood Abbey than within the burgh. Given a paucity of finds and features associated with the ditch, it may have defined an area used for cultivation or horticulture.

After the ditch was filled in, the land was reorganised by cutting a series of gullies running at right angles to Canongate. These divided the site into characteristic medieval properties or burgage plots. The pattern was not wholly regular and it seems that amalgamation of some plots may have occurred immediately. The backlands of some plots contained simple stone tanks and drains, probably associated with flimsy structures constructed of wood, turf or thatch, which have not left visible traces. The features are likely to have been the focus for craft activities. In other plots there were no features of this kind and perhaps these areas were used as gardens or stockyards. Buildings lined the Canongate and these comprised clay-bonded stone wall footings, presumably supporting timber superstructures.

During the later medieval and post-medieval periods most of the site was given over to decorative gardens. Tightly-packed tall tenements lined the Canongate until such time as many were cleared to make way for grand townhouses. A complicated system of underground culverts was used to provide drainage. By the Early Modern period, the numerous narrow medieval properties had been replaced by two large properties: Queensberry House and grounds occupied the western half of the site, and Lothian Hut, another grand townhouse, occupied the eastern half before this area was progressively developed as a brewery.

\subsection{Early features}

\section{SIMON STRONACH}

With the possible exception of one feature (890) all contexts in this period were truncated and survived below the level of subsoil (fig 3.1). The topsoil, which must have originally covered the area, had since been incorporated into a thick loam that was sealed in the late medieval period.

The homogeneity of the loam indicated that it had been thoroughly mixed by both human and natural processes. In these circumstances it is not surprising that the earliest archaeological deposits survived at and below the level of subsoil. The fact that later medieval activity may have destroyed traces of earlier settlement was highlighted by the recovery of a small lithic assemblage, although all of this should probably be regarded as residual (fig 3.2). These waste flakes from the making of stone tools and some finished tools came from two technological traditions and indicate that the site saw sporadic activity from the Mesolithic to the Bronze Age. In the earlier period the site would have been covered by a mixed forest of oak, hazel and elm, occupied by communities who survived by hunting and gathering. Later, it would have been suitable to develop as farmland. Several features that may have been prehistoric were discovered on the Parliament site, such as clusters of stakeholes that may have formed small windbreaks. These were not 
in a concentration that might suggest that an early settlement was located here, but there may have been a settlement nearby, perhaps on top of the ridge where more level ground and better drainage would have contributed to a more attractive location.

It is currently impossible to be sure where the settlements inhabited by the prehistoric people who occupied the area were located, but the foot of the Canongate ridge, with lower, wetter ground on either side, would have been a suitable spot. Although no conclusive evidence for prehistoric remains was identified during the excavation, several isolated features could be described as prehistoric rather than medieval in character. An apparently natural patch of gravel (889) in the subsoil was associated with stone working and was close to a simple hearth (891) located in a shallow scoop. Elsewhere were undated groups of stakeholes, which are more easily interpreted as relating to small shelters or windbreaks rather than fence lines. One group was clustered around a smooth, rounded metre-long stone in the subsoil (890), the only stone of this size noted during the excavation. A section excavated against the stone showed that it might have been set within a cut. The stone was not flat and had a shallow groove running from east to west along its length. If this was not a natural feature, then it was designed for rubbing or grinding rather than supporting something above ground. Both this feature and the hearth could only have functioned if the topsoil around them was very thin, and it could be argued that this supports a prehistoric association.

\subsection{Period 1: 12th-14th-century ditch}

SIMON STRONACH

The most substantial feature in this period was a large ditch (754) cut into subsoil and running from northeast to south-west close to Holyrood Road (fig 3.1). Over $1 \mathrm{~m}$ of fill survived and the ditch had a wide and irregular profile (fig 3.3), which should probably be viewed as the product of erosion and weathering of the sides of an originally much narrower boundary. Certainly the primary fills in the ditch were silts and clays derived from the surrounding natural soil, which suggested that it had been substantially eroded.

Anthropogenic material was rare in the primary weathering accumulations, but some sherds of White Gritty pottery (Pot no. 58), as well as a type of ware used up to the 13th century, and some charred grain seeds were present. One of the sherds of White Gritty (Pot no. 13) was thought to be from a vessel that imitated Yorkshire wares imported in the 13th and 14th centuries. It is difficult to estimate how quickly the weathering fills accumulated, but assuming that the Canongate ridge had been cleared of trees, this amount of material could have washed into the ditch in a very short time and the date of the pottery can be assumed to relate closely to that of disuse.

Further east a deposit of malodorous clay (1646) was noted to lie along the southern edge of excavation, possibly within a cut into subsoil. Unfortunately not enough was exposed on plan to establish that this was a fill within the same ditch, and it could only be excavated to a depth of $0.4 \mathrm{~m}$. However, low amounts

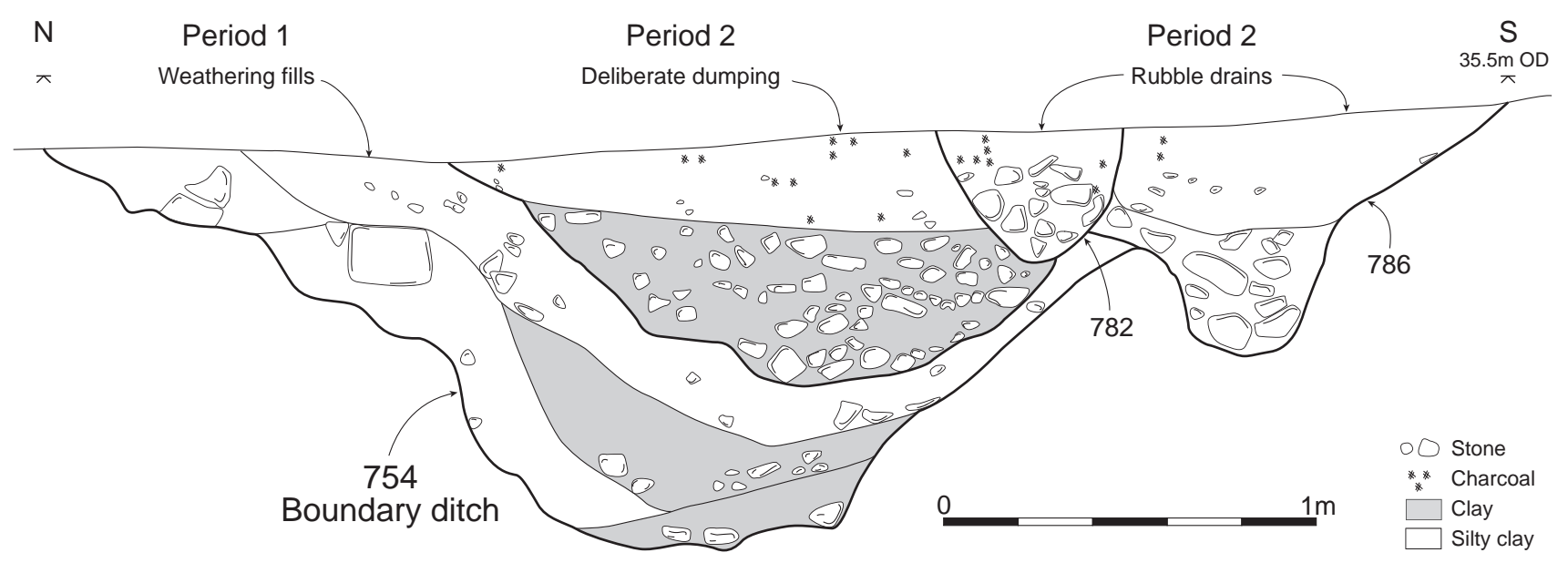

Figure 3.3

Section through the town boundary ditch 
of anthropogenic material (bone, shell, coal/cinders and charred wheat grain) were recovered from samples, and it did run on exactly the same line as the feature further west.

Two further areas (fig 1.3, Trenches $32 \& 33$ ) were excavated roughly on the line of the ditch between the two larger areas of excavation. This was undertaken at a late stage in the project following demolition of Queensberry Lodge, and their positioning was very much constrained by construction work. The southern end of one, which would have been expected to cross the line of the ditch, had been subject to modern disturbance, which extended below the level of subsoil. Although speculative, the location of this disturbance suggested that it may have been occasioned by the need to remove the soft fills of the ditch during construction of Queensberry Lodge to avoid later subsidence. Trench 32 needed to be stepped for safety reasons and consequently the exposed area of subsoil probably did not extend far enough south to encounter the ditch.

\subsection{Period 2: 14th-15th-century burgage plots}

\section{SIMON STRONACH}

Stratigraphically this period comprised three separate sub-periods (fig 3.4). Sub-period 2.1 exclusively comprised features sealed beneath the loam deposit (612) (fig 3.5). Sub-period 2.2 comprised some features beneath the loam, but also some which had been cut from within it, and some cut through it, but thought to be earlier due to stratigraphic relationships to other features. Sub-period 2.3 exclusively comprised features cut into the surface of the loam. The associated artefacts suggested that all should be interpreted as relating to late medieval use of the site.

\subsubsection{Medieval accumulation}

Up to $0.5 \mathrm{~m}$ of homogeneous loam (612, fig 3.5) spread across all of Trench 22 (fig 1.3), except where truncated by later activity. It was evident that this deposit had partly derived from the dumping or accumulation of domestic, building and industrial waste, which had been combined into a homogeneous loam by mixing over a period of time. The soil contained a variety of artefacts including English and German pottery. Other items that suggested a relatively prosperous medieval community in this part of the Canongate were: a copper alloy lace tag (no. 10); a cruciform copper alloy mount (no. 16) possibly originally attached to a waist or sword belt; and a medieval horseshoe (no. 53). There was also evidence for leisure activities with the find of a possible game counter (no. 136); another feature (1506, Period 2, Plot 4) from this period contained a bone die (no. 189).

During excavations in the basement of Queensberry House it became apparent that the exterior loam deposit had formerly spread beneath it $(410=7154,7130$, not illustrated). However, in the east this contained postmedieval artefacts and is likely to have been disturbed during later construction activity, which seemed to have been more intensive here. As ground level rose toward the Canongate it was found that the basement of Queensberry House had been cut into the subsoil, and this must have removed all earlier deposits.

In Period 2, Plots 5 and 6, two equivalent deposits (1634 \& 1684, not illustrated) were identified. These were similar in colour and composition to deposit 612, but were thinner and contained far fewer artefacts, perhaps reflecting much less activity in these plots. In the north of the site, beyond the later (Period 4) terrace wall, three later medieval loams $(652,667 \& 671$, fig 3.5) were preserved. It is thought that these survived here because they were outside the area cultivated in Period 3 and therefore had not been mixed into a homogeneous deposit.

\subsubsection{Boundaries and backlands}

Despite some filling with weathered soil, the large Period 1 ditch (754) must still have been an open and muddy channel by the beginning of Period 2 . Around this time it was filled with a dump of rubble, probably quarried from a local rock outcrop, which was then sealed with silty clay (fig 3.3). This would have functioned as a rubble land-drain and for a while probably helped keep the surrounding area dry. Elsewhere the site was divided into long narrow plots, typical of a medieval town, by the cutting of ditches. The alignment expressed by these was not at right angles to the Period 1 ditch, and the end of one (759), between Period 2, Plots 1 and 2, cut its upper fills (fig 3.4). For these reasons this division of the site is interpreted as part of a reorganisation.

The minimum width of the plots did not vary significantly within the site and appeared to be around $13 \mathrm{~m}$ (Period 2, Plots 1, 2 and 5); as discussed below, a yet thinner strip (between Plots 2.2 and 2.3) may have been a vennel. It would seem that Plots 2.3 and 2.4 had both been amalgamated into double-sized ones, albeit with one (Plot 2.3) generously sized at the expense of the other. The larger plots may merely reflect use 
of a different type of boundary, which has not been identified archaeologically, such as a hedge. However, boundary ditches would have been a sensible option here, given the poor drainage and there are some historical references that have suggested that ditching was common practice (Chapter 4).

\section{Period 2, Plot 1 (Plot 2.1)}

The eastern side of Plot 2.1 was defined by a ditch in the southern part (759), and more formally, toward the frontage, by a drystone wall (004). The western side of the plot was not encountered within the area of excavation but may have been roughly below the eastern side of Reid's Close. The property contained a couple of pits $(336,323)$ dug into subsoil, which was very clayey here. They may have been intended to extract some clay for building or waterproofing, rather than being primarily for rubbish disposal. A rectangular cut (333) was preserved within the plot. It contained stakeholes in its base and impressions of planks in its sides. If the cut originally held a wooden lining, it could have functioned as a trough or something similar. Its backfill was indistinguishable from the surrounding loam and contained an array of artefacts that did not help in any diagnosis of function. A very regular cut (680) was found to have neatly held the base of a barrel (fig 3.6). Presumably this would have held water, perhaps for supplying animals or some craft activity. The wood was in such poor condition that its species could not be identified. The backfill (681) contained many iron nails and fragments, one designed for a horseshoe (no. 57), and a flax seed.

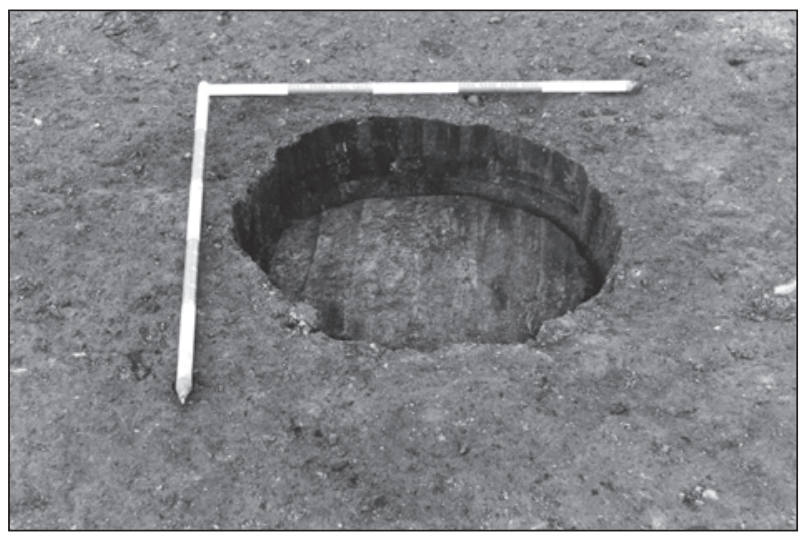

Figure 3.6

Pit containing the base of a barrel
At the south end of Plot 2.1 a rubble drain (786, fig 3.4) was cut on the same alignment as Holyrood Road, perpendicular to the plot boundaries. It contained a red and white clay floor tile (no. 122), which suggests that at least one building of high status had been constructed in the vicinity. The drain suggested that the area remained poorly drained and it fed a sump (767) to the east. The sump had a secondary channel sloping from the south, suggesting that this area was also in need of drainage, although perhaps outside the property. A later rubble drain (782) replaced 786 (fig 3.4) after it had ceased to be effective.

There was a concentration of later rubbish pits (669, 728, 722-4 \& 720) close to the southern edge of the site beside Holyrood Road, on the boundary between Period 2, Plots 1 and 2. Mainly these appeared to contain domestic refuse such as a whetstone (no. 141), pottery and animal bones, but also fragments of Dutch and Maiolica floor tile (nos 127 \& 131), which confirmed the nearby presence of high-status buildings. One of the fills (694) contained grape seeds. Grapes must have been transported to the Canongate dried, and their presence indicated that the inhabitants were wealthy enough to import foreign food as well as building materials.

\section{Period 2, Plot 2 (Plot 2.2)}

Plot 2.2 contained a stone-lined circular feature interpreted as a cistern (764, figs 3.4 \& 3.7), which extended $1.4 \mathrm{~m}$ into subsoil. A stone drain (768) was built into its lip and ran downslope to the south-east toward Holyrood Road, where it extended outside the trench (figs $3.4 \& 3.5 \mathrm{~B}$ ). A shallow post setting (884) lay to the immediate west. Both this feature and the ditch (759), which formed the western boundary of the plot, contained a concentration of metalworking debris, and the ditch also contained a significant amount of magnetic residue (hammerscale). This suggested that part of the plot might have been used for ironworking. The stone-lined cut did not hold water during the excavation, but it would have done so if it had been waterproofed in some way. It is hard to interpret it as anything other than a cistern, since a drain seems to have been designed to carry liquid away from it to the south. As the base had filled with loose rubble, it seems likely that it had some sort of stone structure above the level to which it survived. Above the rubble was a loam, which contained much White Gritty Ware pottery, a stone gaming counter (no. 137) and an iron horseshoe (no. 54). The last is perhaps suggestive of 
the type of smithing activities that could have been undertaken in this rear area of the plot which was safely removed from frontage buildings.

In the south of Plot 2.2, was a large pit (746). The first layers within it contained much midden material. This material had been dumped into the feature from the north and again indicated that metalworking

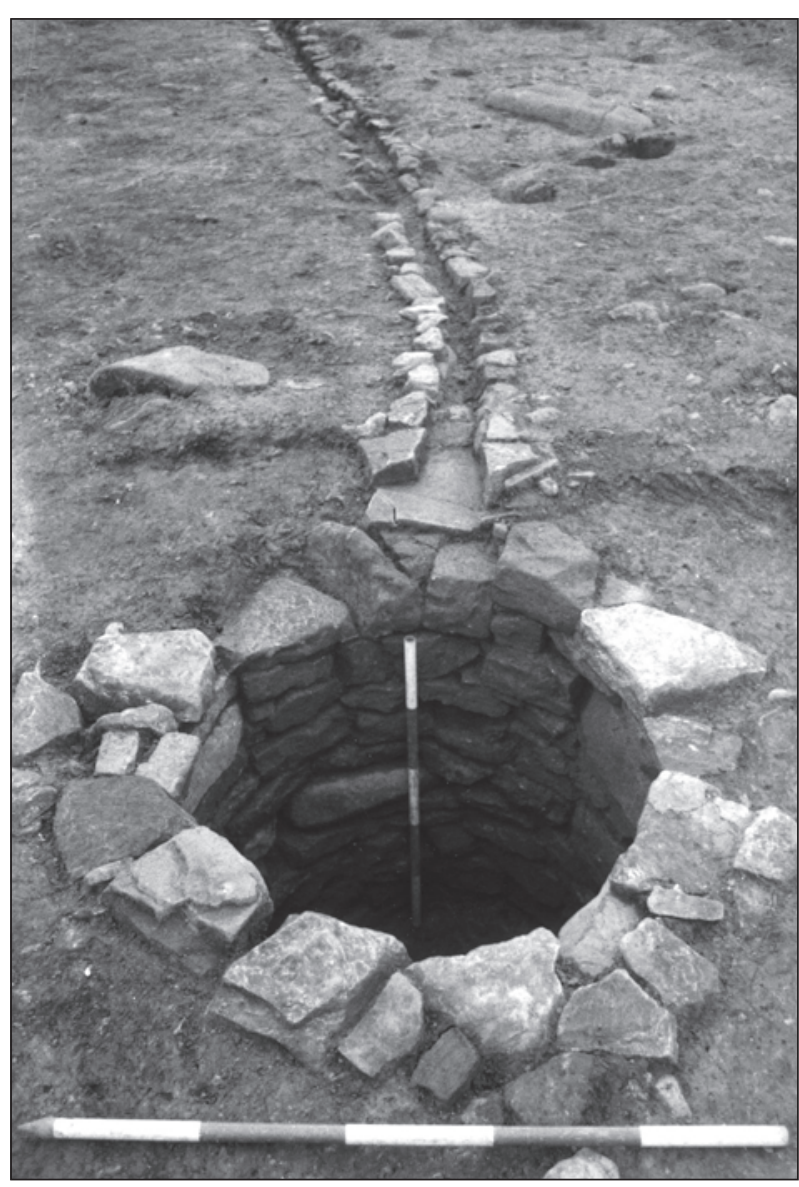

Figure 3.7

Cistern (764) and drain (768), seen from the north (located on fig 3.4)

activity had been undertaken here. The pit was not filled to its brim and the soil that subsequently washed in from the north did not contain metalworking waste, but it included a dog bone with cut marks, which might indicate skinning. It may be that this large disposal pit was excavated to clear the plot following a change in ownership and consequent change of use. A small pit (753) to the north also contained metalworking debris and also seemed to have been for disposal of waste.

\section{POSSIBLE TANNING TANKS}

Plot 2.2 contained two features, which were interpreted as having been designed to hold liquid. One formed a double tank made of roughly shaped slabs bonded with watertight clay in a rectangular cut $(775,775$, figs $3.4,3.5,3.35)$. The base was formed from large flagstones. The fills contained a copper alloy thimble (no. 21), dog bones with cut marks, probably the result of skinning, and an iron knife blade (no. 61). A couple of postholes in the vicinity (817 \& 827) suggested that there may have been some sort of above-ground structure associated with the tank, although this would seem to have been very flimsy and perhaps was just a lean-to shelter.

To the south was a circular double cut (843), of which the northern cut was stone-lined. The southern cut contained a stake thrust hard against its side, and this may indicate the original presence of a wooden lining. The presence of clay at the point at which the two pits were connected confirmed the impression that these tanks were associated with two, presumably different, liquids. The backfilled material in the cuts contained horse bones with skinning marks and the head of a large fork (no. 60). Other domestic refuse was found in the backfill, notably a fragment of rare French Sgraffitto pottery, possibly from a drug jar (Pot no. 58).

These two features have most in common with tanning pits, especially some twinned examples found at Northampton and dated to the 16th century (Shaw 1984). The location of the tanks could be used to argue against an association with tanning, since it was an antisocial activity and they are not located at the very rear of the plot. However, they are at least some distance from the frontage and located in a plot close to the edge of the burgh. In view of the use of alkalis in the tanning process it is probably relevant that a pit (815) neighbouring the rectangular stone tank contained mostly lime. Elsewhere in Plot 2.2 were three pits $(702,706 \& 796)$, all of which contained a mixture of domestic midden and building material.

\section{POSSIBLE VENNEL}

A ditch (810) defined the east side of Plot 2.2. It was post-dated in the middle part of the site by a sandstone culvert (703), leading away from the frontage. It was also earlier than another ditch (772). The fill of ditch 810 (809) was rich in artefacts and included ceramic roof tiles, another indicator of high-status buildings existing on the Canongate frontage, together with pottery that suggests a later medieval date for disuse 
of this boundary. The fill of the later ditch (772) was comparatively very clean. Also located in the vicinity of this boundary were several pits $(411,428,808,851)$, two of which were discovered beneath the basement of Queensberry House. The west side of Plot 2.3 was defined by a drystone wall (figs $3.4 \& 3.8 ; 845 \& 653$ ), which had been reduced by subsequent robbing, and at another time a ditch (913 \& 805). The ditch fill (912) contained a copper alloy buckle and two lace tags, which have been dated to the 15 th/16th century (nos 4, $11 \& 12$ ).

The gap left between the boundaries appeared too small to have accommodated another plot and it may have functioned as a vennel. It did contain a feature (673) which, because of its form, was interpreted as the former location of a tree. This was post-dated by a large pit (fig 3.4; 854), which seemed to have filled gradually with weathered material. The apparent closing of the vennel at this point might suggest that it was designed to provide access to the rear of the plots from Holyrood Road, or as it then was 'The Strand', rather than from the Canongate frontage.

\section{Period 2, Plot 3 (Plot 2.3)}

Plot 2.3 contained a few truncated features $(847,858 \&$ 959). They had been backfilled with domestic refuse, namely fishbone, shell and some building material such as plaster. Two pits (975 \& 994) containing clay and lime mortar were identified below the remnants of a claybonded wall foundation (965). The foundation seemed to represent the south-east corner of a building, which would have extended beyond the northern limit of the excavation trench. This is taken to be the southernmost extent of buildings lining the Canongate.

Within Plot 2.3 a north/south-orientated wall (7060) was discovered around a metre beneath the floor of a room in the east of the Queensberry House basement. At the time of excavation the wall was noted as unusual because it was the only example seen in the basement that did not contain any lime mortar bonding; it predated the large tenement foundations, which had been constructed here during the next period. The wall had been sealed by the dumping of a deposit (7046) containing 15th/16th-century pottery fragments.

\section{Period 2, Plot 4 (Plot 2.4)}

Plot 2.4 contained, at its northern end, the only preserved area of Canongate frontage exposed during the excavation. Although several remnants of claybonded walls survived (195, 1084, 1099 \& 1105),

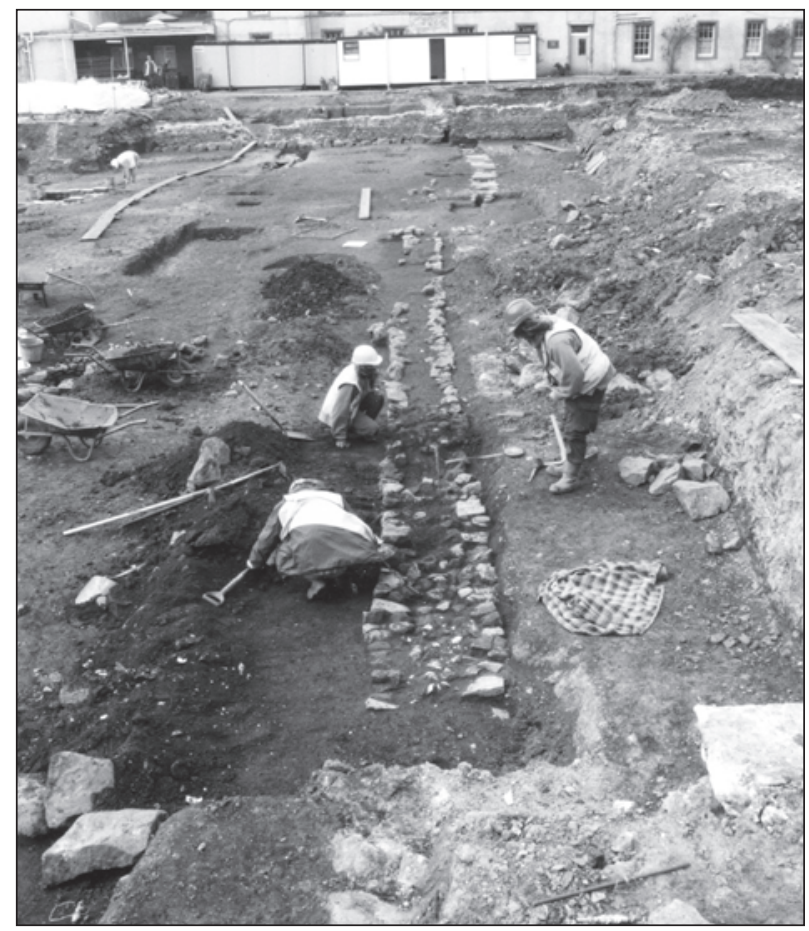

Figure 3.8

Drystone wall defining the western side of Plot 2.3

they were very poorly preserved because of later building activity and probably did not relate to a single structure. Clay (1104 \& 1108) and gravel (1106) surfaces were also preserved; the former contained a complete horseshoe (no. 56) and fragments of 16thcentury jars from Seville, probably used to import olive oil (not illustrated). The surfaces were dominated by a high concentration of metalworking debris, coal and cinders. This and the horseshoe suggested that ironworking was undertaken here, and perhaps even more specifically that it was a farriery. Several other features including hearths (206, 1110 \& 1115) were also recorded.

Further south in Plot 2.4 was a group of channels and backfilled pits to the east of the boundary ditch between Plots 2.3 and 2.4 (1555) and the later drain (983). These were interpreted as a single group of industrial features, which had been replaced or renewed on at least one occasion. They included two stone-lined wells (1567 \& 1571); finds from the backfill of 1567 included a rare sherd of green-glazed Siegburg stoneware (Pot no. 86), dated to the 14th/15th century and one of only three sherds yet found in Scotland, and a decorated stone spindle whorl (no. 140). The 
group was bounded to the north by a badly preserved lime mortar-bonded stone building (1510) containing a cobbled floor (1509), which had been extended (1515) to the west; it is presumed the building and pits were related. The features consisted of three large subrectangular cuts with depths of around $0.4 \mathrm{~m}$ (1522, $1537 \& 1539)$ and several subcircular features with a similar depth (997, 1518, 1527, 1531, 1545 \& 1565). Among them ran at least four linear features (1506, 1520,1541 \& 1574), which may originally have been gullies designed to connect some of the larger features, as was certainly the case between cuts 1518 and 1527 . The backfills within them all appeared to contain midden material, which was not particularly diagnostic as to function. The most common inclusions in samples retrieved from these were hammerscale, small fragments of bone, and coal and cinders. However, none was particularly concentrated and, given the presence of probable metalworking at the front of this plot, could have derived from elsewhere. One of the pits contained impressions that suggested it might have held a stone lining. Both the gullies connecting the features and the nearby presence of the well suggested that, whatever the function of the features, water was involved. If all these features had at one time been lined, they would perhaps fit the bill of the 'steipstanes' mentioned in the documentary sources. These were hollowed stone troughs, possibly used for soaking flax or malt. This can be no more than speculation, however, in the absence of further evidence.

\section{Period 2, Plots 5 and 6 (Plots 2.5 and 2.6)}

The eastern Plots 2.5 and 2.6 were defined not only by boundary ditches (1631, 1695 \& 1698), but possibly also by fences (1692 \& 1712). These slight features may have been preserved here because the loam accumulations were thinner and shallower cuts consequently extended into subsoil. On the boundary was a well (1727), which contained a horse bone that may indicate that skinning had been carried out here. The most varied assemblage of waterlogged plant remains recovered from the excavations was found in the backfill of the well. It contained hazelnut shells, the remains of edible fruits such as pear or apple, blackberry or raspberry, and strawberry. These could have been homegrown, but other species such as fig and grape must have been imported as dried fruits. A poppy seed was also present and may reflect use for flavouring food. The seeds are likely to have found their way into the well as part of faecal material and imply that the well was used as a cesspit toward the end of its life. Also present were considerable numbers of seeds of plants that inhabit damp waste ground.

Several features had been dug within the plots; one was truncated but appeared very regular (1755) and, along with a stone-lined example (1778), seemed likely to have been more than a mere disposal pit. The large cut (1691), resembled the large cut in Plot 2.4 (1522) and might have served the same purpose. Other features may simply have been excavated for waste $(1633,1639,1686,1716,1762 \&$ 1775). Two sections of rubble drain (1655 \& 1759) separated by modern disturbance seem likely to have been part of the same feature. This, taken with a ditch (1725) leading to a couple of sumps (1756 \& 1736), suggests that drainage was a problem, a situation confirmed by two separate finds of amphibian bone from the fills of the rubble drain and sump, as well as the plant remains mentioned above.

The number of artefacts and the quantity of anthropogenic material recovered from samples taken from these features was low. The type of material was typical for medieval midden deposits, including coal, charcoal, metalworking debris, pottery, bone, shell, and charred cereal grains. None was in a concentration to suggest what the plots were predominantly used for; and at least in this part of the site the ground may have been damp and therefore relatively undeveloped.

\subsection{Period 3: 16th-17th-century tenements and gardens}

SIMON STRONACH

At this point in the site's history (fig 3.9) there appeared to have been a major change in the way the backlands were treated. Dark loams rich in artefacts built up across the area (fig 3.5B, 563), although in the eastern part of the site they were both lighter and less substantial (1620 \& 1670, not illustrated). The difference in colour from the lower medieval loam is probably best explained as being a result of manuring with nightsoil and domestic rubbish including coal and ash, and it seems likely that most of the area was turned over to horticulture as depicted on Gordon of Rothiemay's perspective of 1647 (fig 6.1). This period comprises the dark loams and several late features that were sealed below them; it has no sub-periods.

The extensive spread of dark loam (563) contained a large assemblage of artefacts including a post-medieval bone die (no. 188), 17th-century glass and fragments 


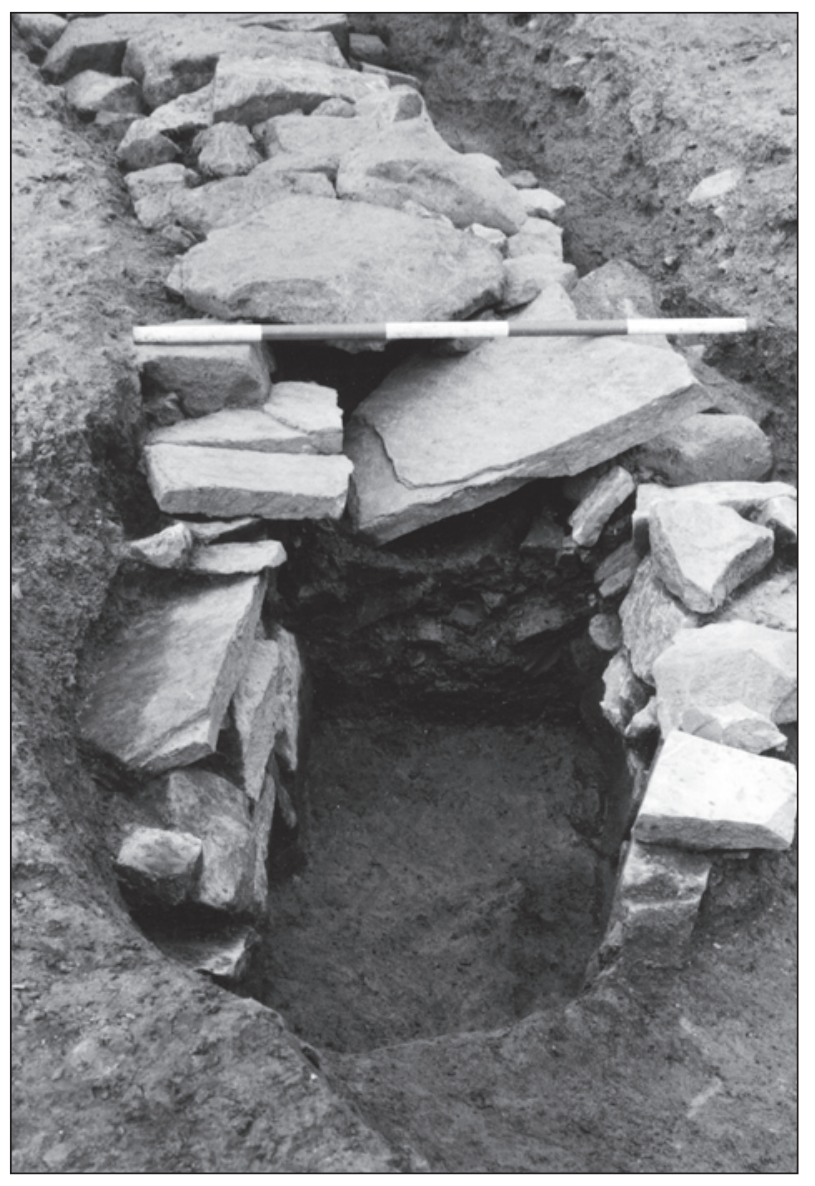

Figure 3.10

Termination of culvert 692

of clay tobacco pipes (nos 73, $268 \& 324$ ), bones from a wide variety of animals, and a range of pottery.

Period 3, Plots 1-3 (Plots 3.1-3) and possible vennel

A rubble drain (665) ran along the boundary between Plots 3.1 and 3.2 (fig 3.9). A large sandstone slab culvert (692, fig 3.11) probably ran along the eastern boundary of Plot 3.2. It might have provided drainage for a frontage building, although there was no evidence that it carried effluent. The culvert appeared designed to drain into the possible vennel established in the previous period, as did a stone culvert (757) on the eastern side. This boundary (between the vennel and Plot 3.3) was also defined by a drystone wall $(750=849$, fig 3.11). These culverts ended midway down the plot, and presumably drainage to the south was left to less formal means, such as open ditches and natural drainage. The possible vennel contained a large pit close to its western boundary at the southern end (804), which seemed primarily designed to bury a large tree stump. This would have been very awkward to move and was probably just disposed of in the hole left when the tree was uprooted. The wood was identified as rowan, which is often used as an ornamental tree, but the fruits and bark also have practical uses. The bark can be used in tanning and for dyeing fabrics black, the berries can be made into jelly and both bark and berries are used in herbal medicine (Grieve 1992, 70). Superstition also held that the rowan provided protection from witches. The location of the tree suggested that the vennel was no longer needed to provide access to the rear of the plots after they were converted into gardens.

The southern part of Plot 3.3 contained no archaeological features that were assigned to this period; however, within the Queensberry House basement several substantial wall foundations that ran under the standing building were preserved beneath the modern

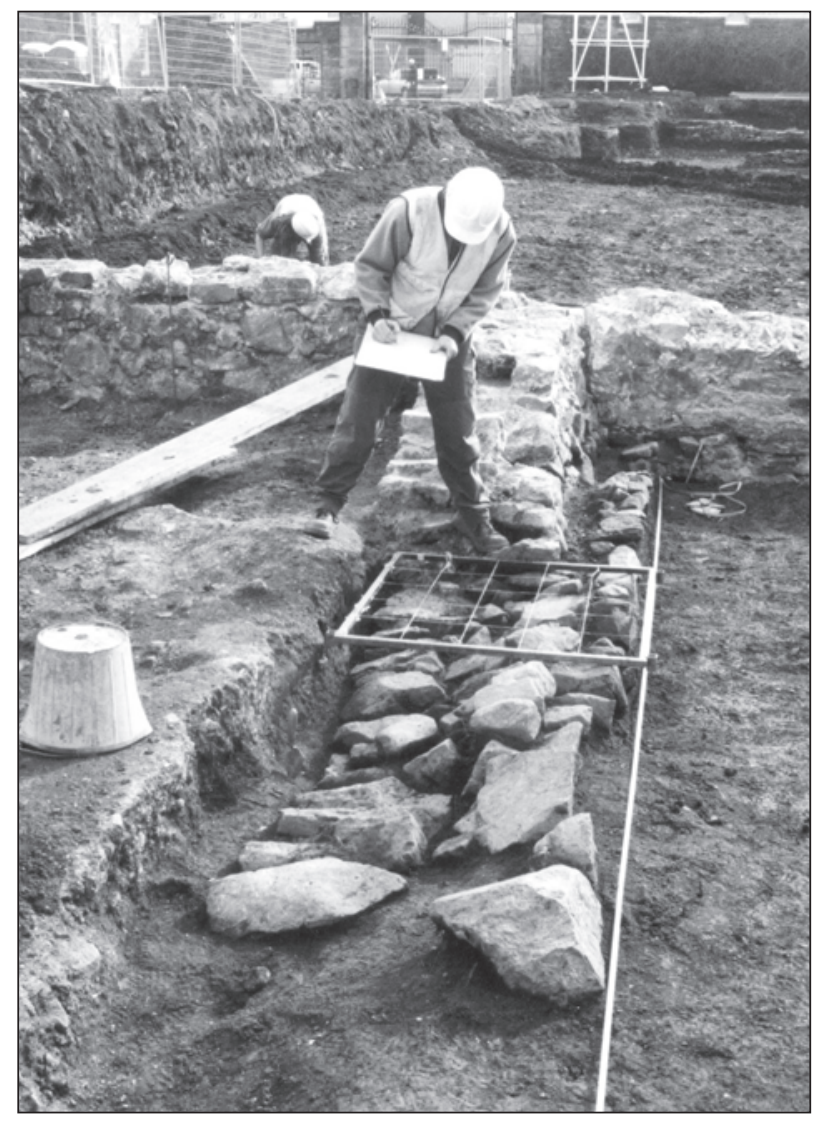

Figure 3.11

Early wall 849 forming the boundary between the vennel and Plot 3.3, preserved under later wall 635 


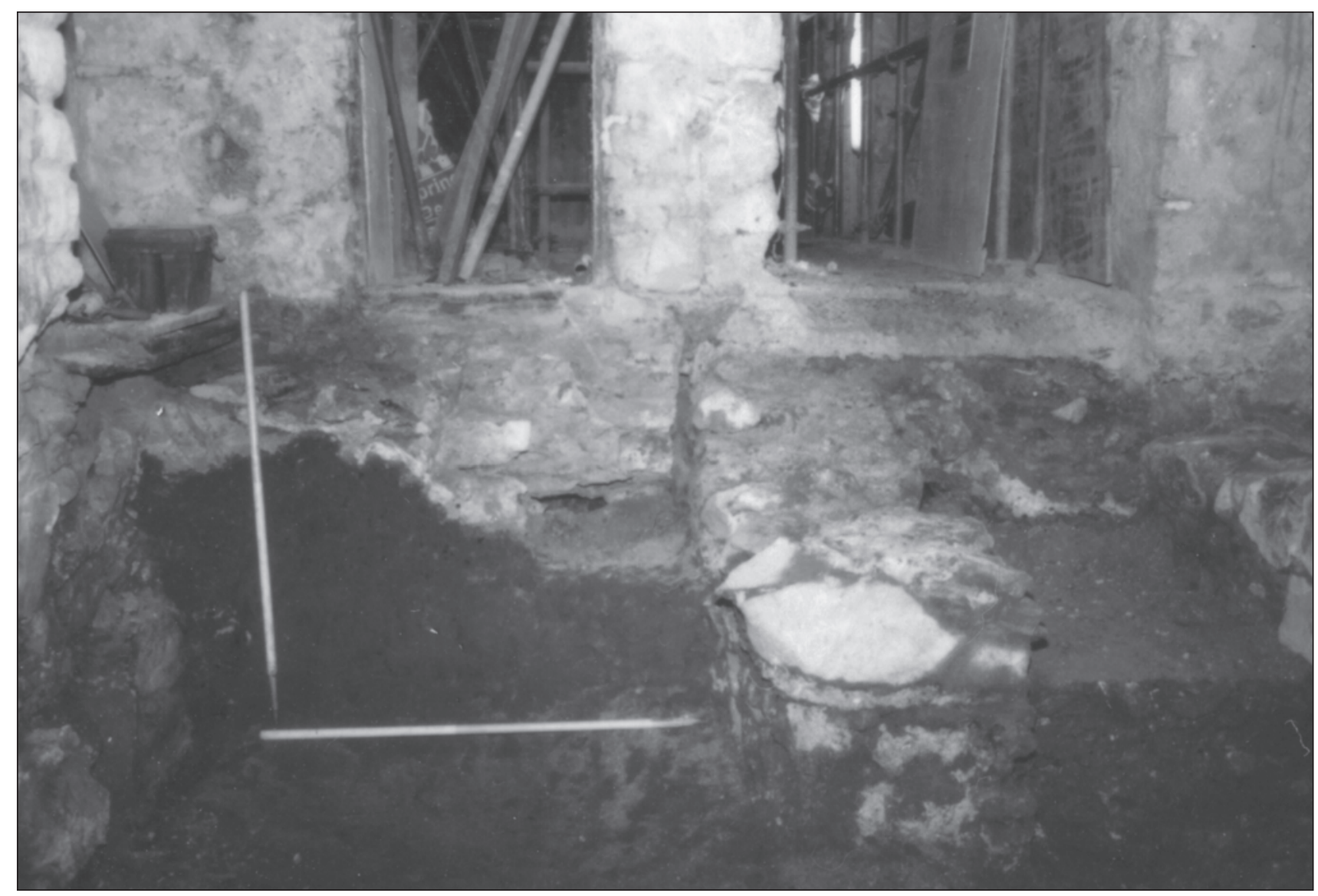

Figure 3.12

Wall of a tenement building surviving under Queensberry House

floor. The east wall of the south-west corner tower (7134) had been built on an earlier foundation, which contained an arch below ground level. A corner (7155) was revealed beneath the doorway of the neighbouring room.

Wall foundations revealed elsewhere indicated the edges of tenement buildings (1230, 7038, 7040 \& 7071-5; figs 3.9 \& 3.12). All these walls had been very disturbed by later construction and demolition, but several observations could be made. Foundation 7071/7106 appeared to be part of the same building, separated by later construction. Otherwise, the foundations were not all built at the same time, but where relations could be identified it was clear that they had functioned together for a spell. The walls usually had faces on the parts exposed above contemporary ground level and their substantial nature suggested that they had supported multi-storey tenements. They frequently used earlier walls for support, and it would seem that construction was something of an ad hoc process, with different sides of buildings often reusing different walls. Little more can be said on the form of the buildings given the limited evidence. Overall they are consistent with the crowded terraces of tenements lining the Canongate on Rothiemay's plan of 1647 (fig 6.1).

Period 3, Plots 4-6 (Plots 3.4-6)

There were no identified plot boundaries further east than the west side of Plot 3.4 during this period. However, given that the boundary between Plots 2.4 and 2.5 was replicated in Period 5, it seems likely that this represents a lack of visibility rather than a temporary amalgamation. Similarly, it seems logical that the amalgamation of Plots 2.5 and 2.6 should be attributed to the documented purchasing of neighbouring properties during the development of the townhouse of Lothian Hut (Chapter 13.2.5) during 
Period 5 rather than this period. Therefore, Plots 3.5 and 3.6 are assumed to have existed and are shown on fig 3.9 using dashed lines.

In Plot 3.4, the drain, which ran along its western boundary in the previous period, was robbed out (1507) and replaced, although much of this structure (1524) had also been robbed later. Several pits, of different form from those of the previous period, were located within this plot $(1512,1534,1553,1561$ \& 1562). They appeared to have been used to dispose of waste, in particular pit 1512, which contained a horse carcass. The bones did not exhibit any butchery marks and it would seem that the horse was a natural casualty. Metal objects and metalworking debris were common in the fills of several of these features and it may be that the association of this plot with metalworking of some description continued into this period. The structure 1510 continued in use and an accumulation of burnt material was preserved over the cobbling and within a niche in the wall. This contained one of the few concentrations of chaff found during the excavation, consisting of barley and oat chaff dominated by culm fragments, which probably originated as straw.

\section{POSSIBLE TANNING PIT}

In the area assumed to have lain within Plot 3.6 one feature extended into the east baulk of the excavated area and consisted of two interconnected subcircular cuts (fig 3.13, 1637 \& 1664). Both were stone-lined. The eastern cut (1664) contained remnants of an inner wood lining and was larger and deeper than 1637. Superficially this feature has much in common with the possible tanning pit 843 (Plot 2.2). No bones with skinning marks were found within either tank but there was a complete small unglazed bowl with a spout on the rim (Pot no. 99). The form of this vessel suggested that it may have been used for measuring out liquid, and its disposal without any evident damage

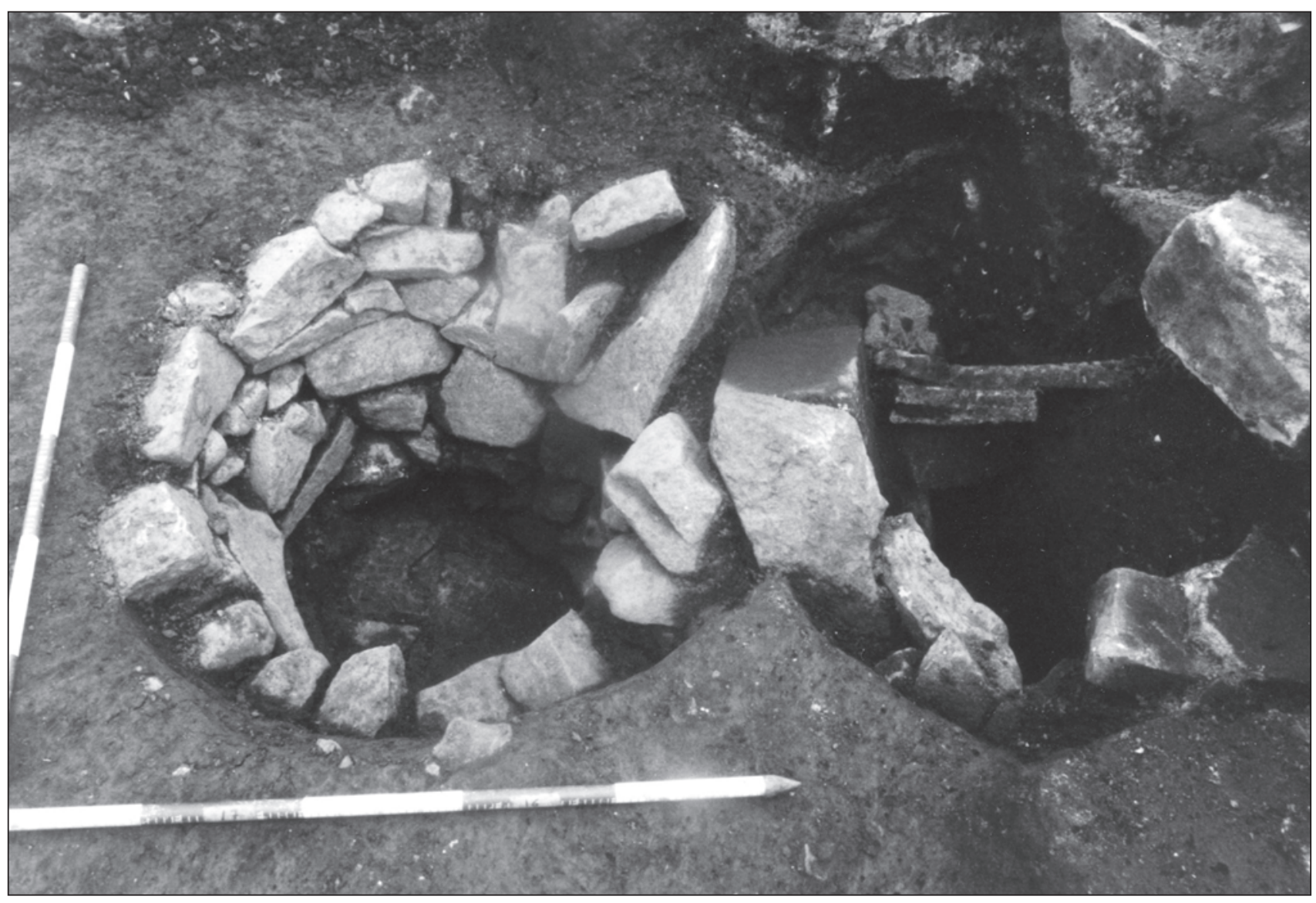

Figure 3.13

Possible tanning pit within Plot 3.6 
may imply that this liquid was unpleasant, rendering the vessel useless after its primary function ceased. Measuring quantities of unpleasant liquids would certainly have been necessary as part of the tanning process. The location of the twin cuts in the backlands, as far away from the frontage as possible and at the edge of the burgh, would also be consistent with use for a noxious process. The stone lining in one of the cuts showed signs of mineralisation, which might have occurred if the pit had held tanning liquor.

Elsewhere in Plots 3.5 and 3.6 only four truncated features (not illustrated) were assigned to this period. Most appeared to be small disposal pits; one (1683) produced a glazed fragment of 16th-century stove tile (no. 74), a very rare find in a Scottish context that indicates the presence of high-status buildings in the vicinity.

\subsection{Period 4: 17th-18th-century townhouses and formal gardens}

SIMON STRONACH

\section{Haddington House}

The previous Plot 3.1 appears to have been subdivided into two properties by the building of a lime-mortared stone wall running north-west/south-east (218, figs $3.14 \& 3.15)$. During the earlier part of this period the new subdivision (Plot 4.1) contained a series of north-east/south-west-aligned slots, each around $2 \mathrm{~m}$ wide and up to $0.4 \mathrm{~m}$ deep. The slots were quite closely

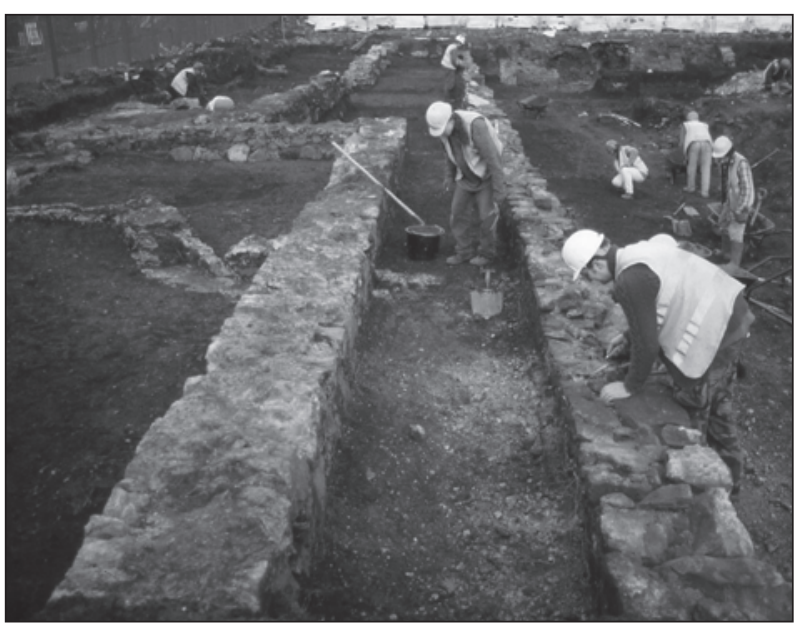

Figure 3.15

Excavation of the surviving walls of Haddington House and garden wall, looking north-west spaced and had steep sides reaching flat bases. All had apparently been backfilled immediately with a mixture of rubble and loam. Their fills contained a variety of finds which suggested that they had been created in the 17 th century. Above the slots was a dark loam (222, not illustrated) which also contained a variety of finds, including a fragment from a small bell (no. 1) and a decorative gilded buckle (no. 2). The lack of disturbance within these slots suggested that they were not used directly as planting beds. It seems more likely that they were intended to provide drainage below the loam, in which were planted formal floral beds and designs.

Later in this period the western subdivision was developed at its southern end, and the first building within the site to be located at the Holyrood Road end of the plots was constructed. This was not apparent on Edgar's plan of 1742 but was by the time of Lizars' survey of 1778 (fig 3.16). Within the excavated area the exterior wall (286, figs $3.14 \& 3.17$ ) was built on a deep, clay-filled foundation trench; an internal wall (284) was also identified. Pottery associated with the foundation trenches confirmed a construction date in the 17 th or 18 th century, which was consistent with an identification of the building as the documented Haddington House. The west and south walls had been incorporated into the perimeter wall of Queensberry House Hospital and survived to a height of around $2 \mathrm{~m}$. Originally the structure had been set back from Holyrood Road and was located between Reid's Close to the west and Haddington's Entry to the east. Its Holyrood Road façade was $8 \mathrm{~m}$ wide (fig 3.17) and contained at least two windows at either end. This side did not appear to have contained the main doorway, and it is more likely that the building was accessed through Haddington's Entry. Later the building was extended to the south, the former façade became an internal wall, a fireplace was inserted, one former window was converted into a door and the other blocked.

To the north of the building was a large well (231, fig 3.18). Historical records relating to 12 Haddington's Entry, built before 1860, mention rights of access to a pump well, which was associated with a nearby malt works. A couple of disposal pits (281 \& 290) were located between the well and the building.

\section{Balmakellie and Queensberry House}

Plot 4.2 was formed from the amalgamation of Period 3, Plots 1 (eastern part), 2, the vennel, 3 and 4. 


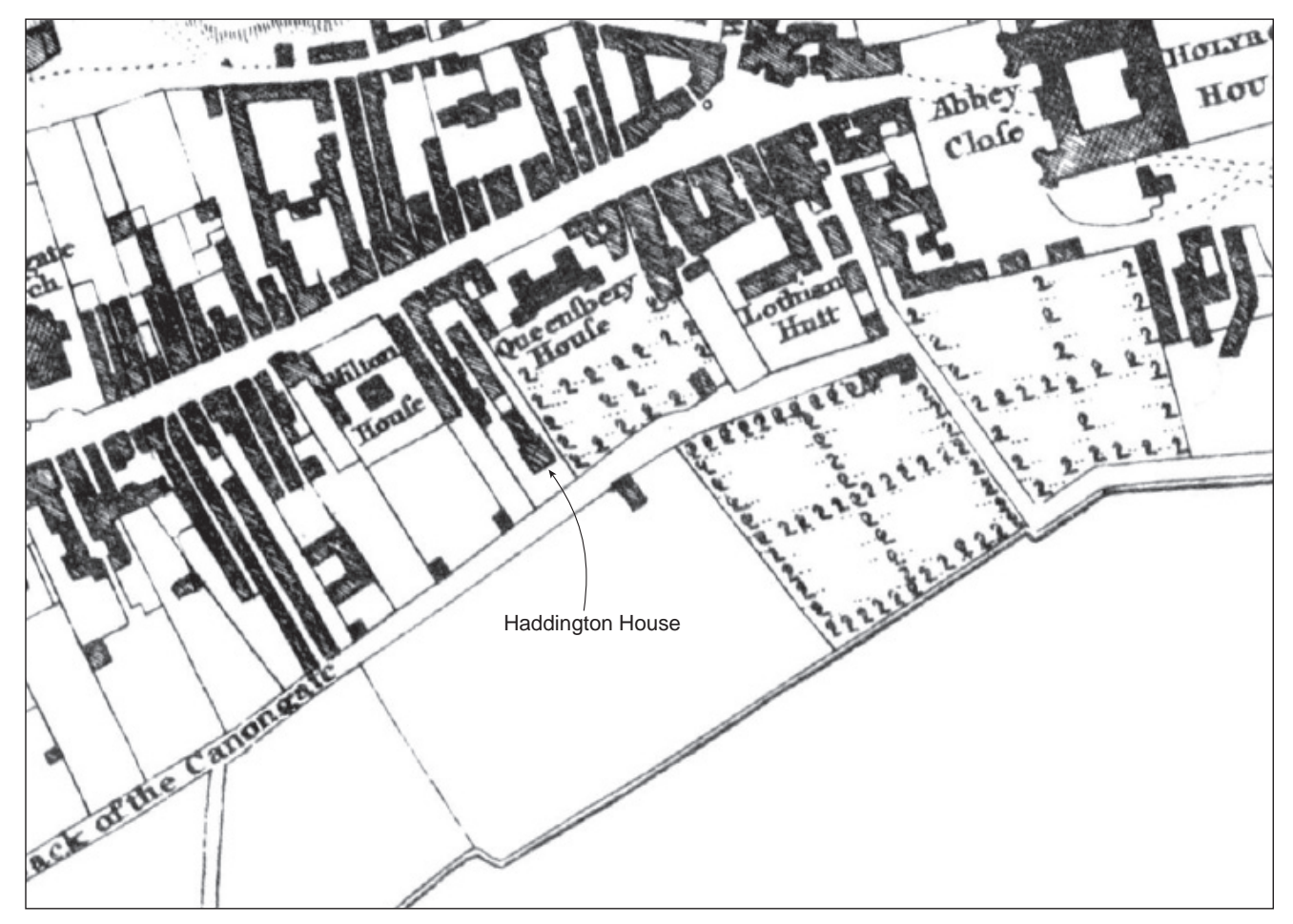

Figure 3.16

Lizars' survey of 1778, showing the presence of Haddington House (C NLS)
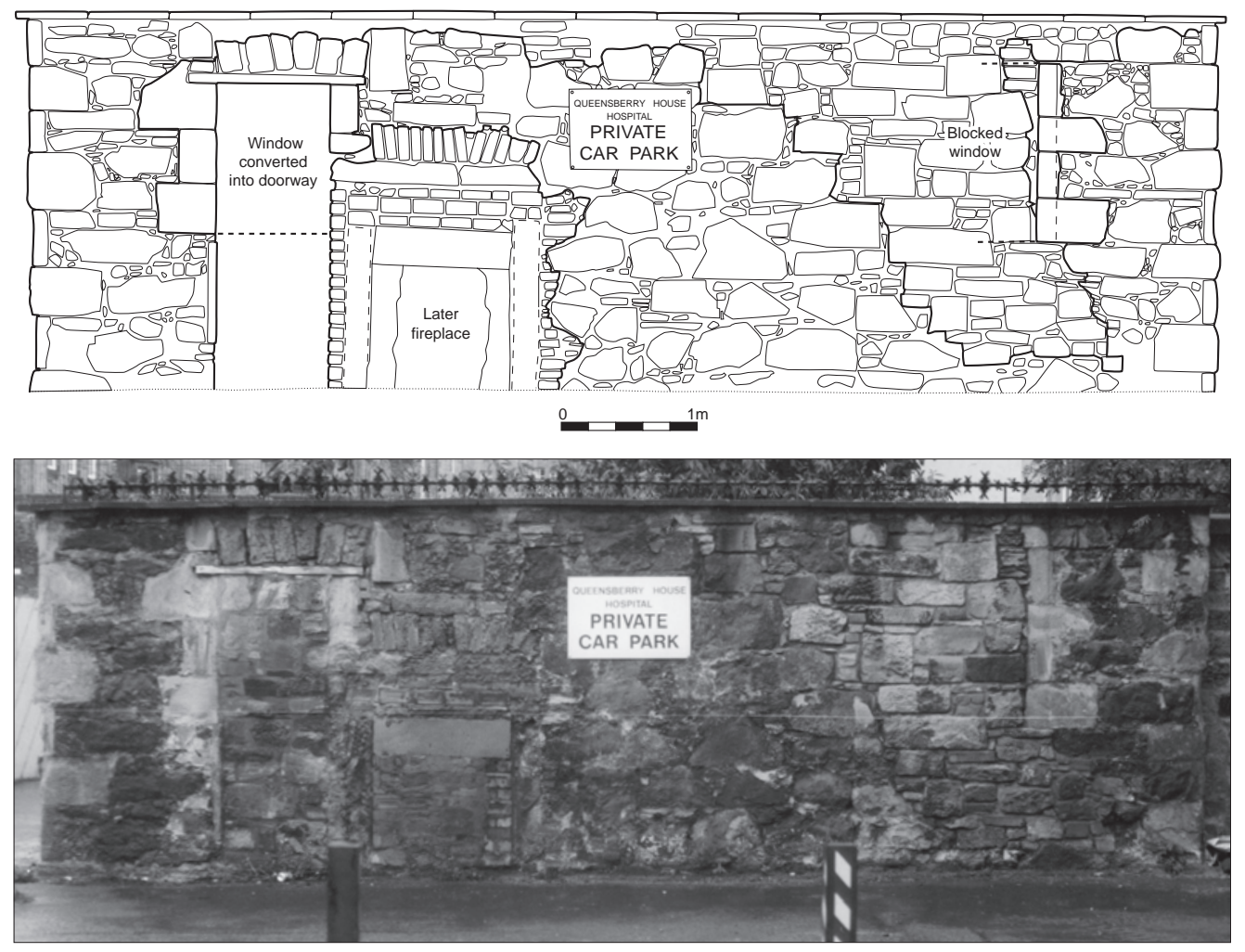

Figure 3.17

The Holyrood Road elevation of Haddington House wall 
In it was a further series of drainage slots, similar to those in the plot containing Haddington House, but distinguished by running from north-west/south-east (fig 3.14). These also contained 17th-century artefacts, many of which indicated an increase in wealth, such as fragments of a decorated glass bottle (no. 85) which was probably Venetian and designed to carry a luxury such as perfume, and an ornate French ceramic bowl (Pot no. 65). A larger cut (618, fig 3.14) on the same orientation and holding more rubble, may have been hardstanding for a path. The very dark loam (540, not illustrated), which sealed these features and functioned as a cultivation soil, contained a variety of finds including an initialled wig curler (no. 121), iron shears (no. 62) and an early 18th-century medicine phial fragment (no. 84).

In the north these garden features appeared to respect a south-west/north-east-aligned wall (635, fig $3.14)$; the wall returned to the north along the line of the presumed property boundaries associated with the Balmakellie phase of building. The wall had later been extended east and west (629 \& 988). The wall was likely to have formed a raised terrace overlooking the formal gardens. The extensions clearly reflected the expansion of the Canongate property, such as was carried out from the Balmakellie phase to that of the 2nd Duke of Queensberry. A gap in the centre of the wall accommodated a set of steps leading down from the terrace.

Layers of loam were dumped to raise the ground level within the terrace (643, 888, 974 \& 992). One of these sealed a large pit (935), which appeared to have been created to dispose of surplus construction or demolition material such as rubble, both sandstone and true roof slates, glazed tiles and mortar. One of the fills contained a coin (no. 199) dating to the reign of James II or III (1437-88). Due to the underlying topography of the site the terrace did not need to be created in the west, as the ground level was already high enough. Here the retaining wall had been cut into the underlying loams. A small regular gully (650) filled with stone in this area may represent the base of a garden feature.

Immediately to the south of the terrace wall in its western extension was a very large, shallow scoop (717), filled with crushed sandstone, which may have been mason's debris from the construction of the extension. Adjacent to the wall to the east were two pits (674 \& 922) filled mainly with lime mortar, and these may also have been related to construction.

Some irregular features (916, 923 \& 927) were present to the south of these pits. All were fairly irregular and had fills similar to the neighbouring drainage features. For this reason they are interpreted as features within the formal gardens. A linear spread of lime mortar (708) was located close by, and seems likely to have represented another feature within the gardens. To the east were several irregular features (943, $950 \&$ 960). These were not very well preserved but exhibited a similar fill and alignment to those in

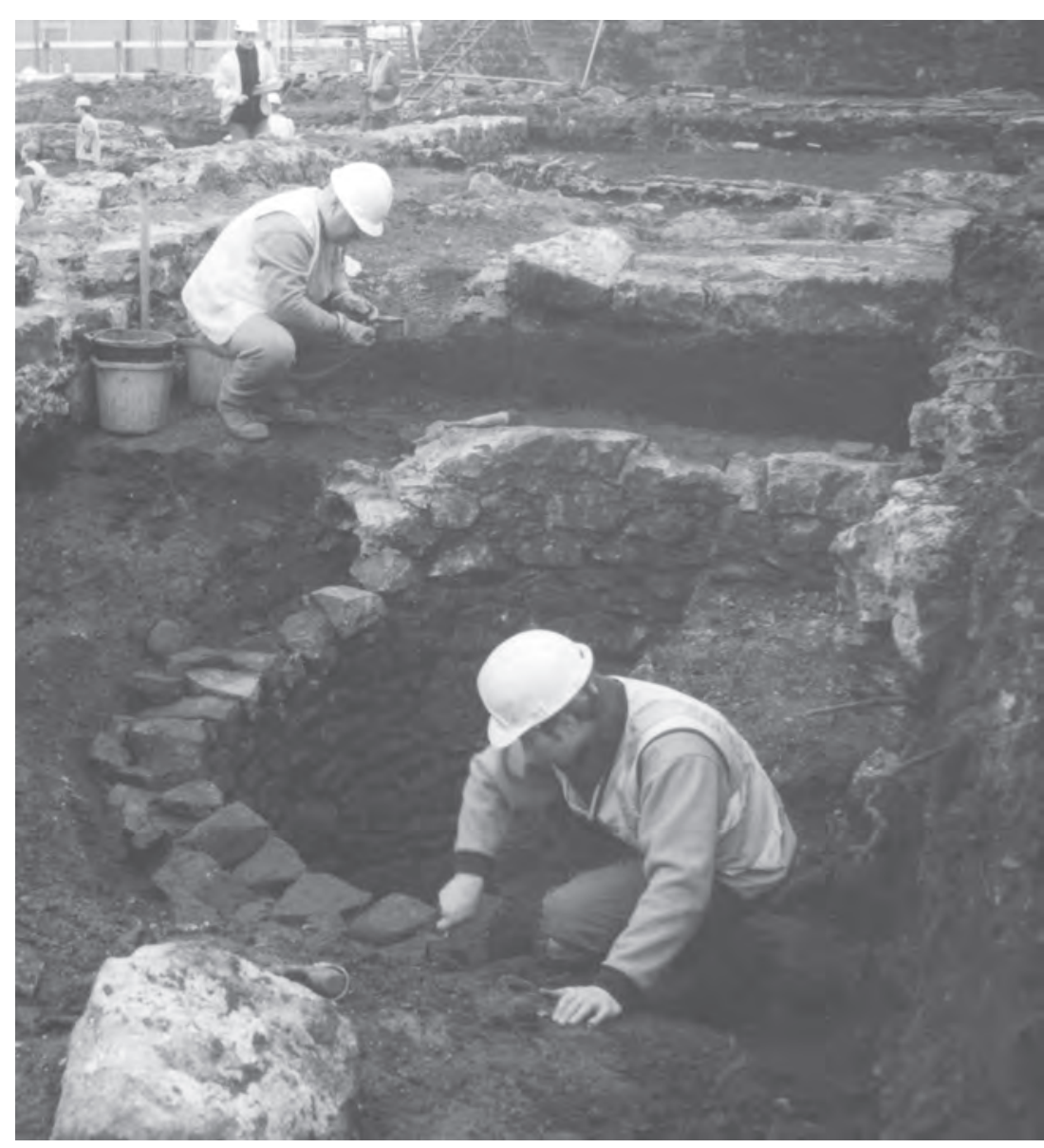

Figure 3.18

Excavation of a well behind Haddington House 
the west, and are also interpreted as garden features. Later in this period two simple rubble-filled landdrains (666 \& 670) were created to the immediate south of the terrace wall.

The terrace was remodelled towards the end of this period. A robber trench (644) removed part of the original wall 635 , and several layers of rubble and earth (623-5) were dumped to raise the level of the terrace by around $0.5 \mathrm{~m}$. A wall $(610=127$, not illustrated $)$ was then built on an east/west alignment within the raised terrace. This was a very crude structure built from roughly dressed stones loosely bonded with lime mortar. It suggested a much less formal garden, perhaps as a result of the decline in the Canongate's prestige toward the end of this period.

Close to the southern boundary with Holyrood Road was a truncated drain (601) leading to a sump (633), which must have drained the area to the south of a possible boundary ditch (661).

\section{Sunken-floored kitchen and culverts}

Two culverts discovered within the basement of Queensberry House may have related to two interconnected culverts outside. In a sunken-floored room identified as the kitchen a capped sandstone drain (7096) was of the same build as culvert 919 outside to the south and one seen between the two in an evaluation trench (132); these have all been interpreted as part of the same drainage system, which was joined by culvert 928, which was of the same build and seemed to be heading toward culvert 7017 , discovered beneath the floor of a room in the east of the basement. Culvert 7096 ran beneath the south wall of the standing building, while 7017 had been cut by the construction of the wall. It is assumed that this wall was constructed during development of the site in the later half of the 17th century by Dame Balmakellie, and culvert 7096 must have functioned as part of this. Culvert 7017 must relate to a late phase of tenement use. However, both appear to have functioned within the same drainage system. Adaptation and retention of an existing system fits in well with the way in which Balmakellie's construction work reused existing foundations rather than clearing them and starting afresh.

A brass jeton from Nuremberg dated to 1490-1550 (no. 215) was retrieved from the backfill around culvert 919, while some silt (921) within it contained four copper pins (nos 24 \& 25). Additionally, two pins came from a levelling deposit into which this drain was cut, and another from the deposit overlying its stone capping. The entire excavation only yielded a total of 11 pins, which makes this concentration appear very significant. It was recorded that one of the properties in the area acquired as part of development by Lord Hatton (around 1680) was that of a tailor (Hume \& Boyd c 1984, 57) and the pins may have derived from his premises. Culvert 919 had been constructed to pass through the terrace wall 635, while in the west culvert 628 was truncated by the wall's extension (629).

The level of the old tenement foundations immediately below the floor of Queensberry House Hospital indicated that the floor level of Balmakellie's building could not have been very different. Between and around the foundations were dumps of rubble and loam, deliberately used for levelling and composed of waste from the demolition process. Clay pipe fragments from these deposits fell within the date range 1630 to 1660 , immediately prior to Dame Balmakellie's development.

The room identified as the kitchen had been created with a sunken floor lower than the rest of the basement, and later levelling had led to the preservation of early surfaces and features. The room was originally larger and incorporated what had later become part of a corridor to the immediate north. Here one of the capstones of culvert 7096 was a stone basin set within a cobbled surface 7138 (fig 3.14). The basin sloped northward, where it had a spout that extended beneath the north standing wall of the room. On the other side of the wall, on what was the exterior of the early building, the top of a culvert could be seen some half a metre higher, and this may have fed the kitchen culvert. Practical reasons for making this room sunken-floored would include having a ready supply of water flowing through its culvert. Silt within the culvert (7105) contained the waterlogged remains of apple or pear and some grape pips, which probably arrived as sewage and suggested that, at least latterly, the culvert was probably not used for supplying fresh water.

A socket discovered set into the cobbling in the east of the room might have been connected to a stairway or entrance. Further south in the room, beyond the later wall used to create a corridor and at the same level, a handmade brick and flagstone surface (7088) was used instead of cobbling. Presumably the cobbling or brick had originally stretched over the rest of the room. The bricks had also been used to form two rectangular features (7097 \& 7092). Analysis of some 
metalworking waste, which had accumulated in the base of 7097 and in the culvert in the same room, has indicated that precious metals were being assayed or refined in the room. The brick features may have been the foundation of a rectangular assaying furnace. The likely historical implications of this are explored in Chapter 9.4, but it would appear that the furnace is most likely to have been built during Lord Hatton's period of ownership.

Later in this period the brick, flagstone and cobble surfaces were partially robbed out and the room was decreased in size by building a wall to form a corridor in the northern part. This must indicate that the building had now been extended to the west. Within the room, demolition debris (7087), containing pottery dated to the 18th or 19th century, was dumped to raise the floor level, although it remained below that elsewhere in the basement. The floor was surfaced with flagstones set in lime mortar (7080, not illustrated), most of which had been robbed later. In the north-east corner some of the bricks robbed from the earlier surface were used to make a small structure (7079, not illustrated). A corresponding gap in the newly built wall confirmed an impression that this had been the base of a short staircase providing access to the room. In several other rooms flagged surfaces survived and it appears that this surface was used throughout the basement.

Several other culverts were identified during watching briefs in the basement (7158, 7162, $7167 \&$ 7168). These frequently used handmade brick alongside sandstone. They seem likely to have all functioned together, flowing generally from north to south. Probably later in this period an exterior sandstone culvert (954) and an interior one (7004) were added. The interior culvert contained some strawberry seeds and probably carried cess.

\section{Canongate frontage}

The Canongate frontage to the north-east of Queensberry House remained occupied by tenements and associated vennels. It appears that the street had a kerb (188) formed from large rounded stones set into a cut. To the south was a remnant of a clay surface (1081), which contained a simple scoop (1057) used as a hearth at least once. To the south was a cobbled surface (1017) overlain by a compact trampled deposit (1087, not illustrated), which contained material common in domestic waste such as pottery, clay pipe fragments and oyster shell. Several substantial wall foundations were also discovered. Wall 1075 was likely to have been the foundation for the back wall of a tenement fronting the street. To the rear (south) was a foundation at right angles (1205). Further north a small fragment of wall (1032) had survived redevelopment. Several post or stakeholes were located, although no real pattern could be discerned.

\section{Lothian Hut}

The property to the east, Plot 4.3, was formed from the amalgamation of Plots 3.5 and 3.6. There were no surviving features in the northern half of the property. In the south there were two different kinds of features. To the west was a set of drainage slots which, like those farther to the west in Plot 4.2, were filled with rubble and midden. They contained finds such as pieces of diamond-shaped lead window cames (nos $39 \& 40)$ and fragments of glass vessels, which again suggested that the features were created in the 17th century. A circular stone-lined well (1715) was also present in this property. Clay pipes recovered from its backfill suggested the well was disused after 1630-50. It may have provided water for use within these formal gardens or it may have been backfilled when they were created.

All of these features were located to the west of the line of a north-west/south-east-aligned ditch (1627). An amphibian bone was recovered from the fill, which suggested that it had provided drainage. On the other side were two more features (1601 \& 1603), which were on a similar alignment, and were filled with lime mortar. These may also have provided drainage.

A number of features $(1737,1776,1781,1785$ \& 1786) were interpreted as relating to a townhouse called Lothian Hut, built in the middle of the 18th century (Chapter 13.2.5). The building is shown on Lizars' plan of 1778 (fig 3.16), although it possibly had a genesis earlier in the century as some buildings shown in the same area on Edgar's plan of 1742 may have been reused. The features all contained material relating to construction or demolition such as rubble and lime mortar. A north/southaligned cut feature (1781) was interpreted as a robber trench for an earlier wall. A regular subrectangular feature (1776) contained mortar, sandstone fragments and oyster shell and was interpreted as a lime mortar preparation pit. The former position of Lothian Hut was believed to be immediately to the east of the excavated area. 


\subsection{Period 5: 19th-century military barracks and modern features}

SIMON STRONACH

\section{Haddington House}

In the building identified as Haddington House a very disturbed brick feature (282) appeared to have formed the base of a rectangular structure. A drain (265, fig 3.19) with a pronounced bend sloped away from this and exited the building through a gap in wall 222, which was the only place where any fill was preserved in the drain. This contained many fish bones, which suggested that the building might have been domestic. However, the next most common inclusion was metalworking debris and fragments of slag. This contrast may represent a change in use from a domestic building into an industrial one, perhaps when taken over by the military early in the 19th century (Chapter 14.3). Further north along Reid's Close a structure (213) was constructed, and then extended to the south (212), up to Haddington House.

\section{Quartermaster's store and military features}

Further east was a rectangular building with dividing walls, which corresponded to the location of a quartermaster's store (figs 3.19 \& 3.20) constructed during military use of the site and planned by Kirkwood in 1817 (fig 3.21) but not by Lizars in 1778. The quartermaster's store was converted into a canteen late in its history. A number of internal walls, surfaces, drains and an extension were added in order to achieve this. Also as part of military use, rubble and hard standing (622, not illustrated) were dumped over the terraced gardens to create a parade ground, and two large conduits (952 \& 957) were constructed to service barracks. The excavation revealed foundations likely to have been for the western gatehouse depicted on Kirkwood's plan adjacent to Holyrood Road.

\section{Tenement and Queensberry House}

The tenement immediately to the east of Queensberry House, still standing as no. 60 Canongate at the start of the project, was built around this time (fig 3.19, inset). To the rear were foundations (1097 \& 1098), which were interpreted as relating to a slightly later building. Several features associated with these were preserved, including a stone cesspit (1094), several flagged surfaces $(1026,1046,1096 \& 1210)$ and a well-laid cobble floor (1006). Less substantial internal walls (1013 \& 1068) were also recorded.

Within Queensberry House, material was dumped within the sunken-floored kitchen in the 19th century to bring the floor level into conformity with the rest of the basement. A range of crockery fragments from this make-up is thought to have related to the building's use as a House of Refuge from 1853 (Chapter 14.4). They have provided a valuable insight into conditions within the institution.

\subsection{Conclusions}

SIMON STRONACH

This section considers how the archaeological excavations have contributed to answering the research questions set out at the beginning of the project (Chapter 1).

\section{Pre-burghal settlement, pre-1128}

The area was exploited from the earliest times; did pre-burghal settlement remains survive below medieval accumulations?

Some possible prehistoric features were recorded and a small assemblage of lithics recovered. The remains are not really substantial enough to suggest that a long-lived prehistoric settlement once existed on the site. However, their presence implies that the site was perhaps peripheral to a settlement, located on the level surface of the ridge, which would have remained well drained all year.

\section{The medieval period, 1128-1580}

Was there continuity of settlement from the pre-burghal to the medieval period?

Some early features were discovered during the excavations but cannot be securely dated to any period. It is possible that they are pre-burghal, but they could date to many centuries earlier. In any event, the activity they represent would seem to be transient rather than settled. The cutting of the Period 1 ditch represented the earliest division of the site. This matched the alignment of Holyrood Road in the eastern part of the site, but not in the west because of a kink in the road. This can be readily seen on an aerial photograph of the area (fig 1.5). The ditch did not form a right-angled end to the property boundaries identified in Period 2. Nor did it line up with a ditch discovered during excavations to the west (Gooder 1999), which was likely to have defined the southern limits of medieval burgage plots extending back from the Canongate. The ditch seems to have returned, presumably to the north, somewhere on the line of Reid's Close, and reflected a layout at odds with the extant plots. The excavations suggested that this layout pre-dated the medieval division of this part of the Canongate into plots.

The alignment of the ditch is closer to that expressed by gardens within the abbey, or as it then was palace, grounds as shown on Lizars' plan (1778; fig 3.16) and Kirkwood's plan (1817; fig 3.21). On balance, the feature is probably best interpreted as defining an abbey 
enclosure and, moreover, the edge of the monastic precinct itself, which was later divided into individual properties. The ditch should probably not be thought of as truly defensive, although it would have made an impressive boundary, especially when combined with a bank, as well as helping to drain higher ground to the north. Given the absence of archaeological features that would have suggested more intensive use, it seems likely that the putative enclosure defined a cultivated area. The limited number of artefacts within the ditch's primary fills offered some support for this interpretation.

It is likely that the ditch had been maintained by cleaning for many years before it became redundant in the 13 th or 14 th century. Unfortunately, the archaeological deposits were only relevant to abandonment and did not suggest when the feature was first created. However, the earliest pottery from the loam that covered the site was made in the 12th century. The pottery recovered from the soil probably reflected use of waste from the abbey for manuring and, significantly, a fragment of inlaid floor tile (no. 122) from the ditch fill was of a type that might have come from a religious building. In all probability the enclosure was created around the time of David I's foundation of the Augustinian priory in 1128. To conclude, the excavations did not recover any evidence for continuity of settlement from pre-burghal to medieval times. It should be noted however, that although no supporting evidence was found in this part of the medieval precinct, this does nothing to challenge suggestions that the priory occupied the site of an earlier church.

\section{What was the relationship between the abbey and the} burgh?

From the abbey's point of view, the conversion of ecclesiastical land into plots for sale or rent must have represented one of the quickest and easiest ways to obtain funds. Urban encroachment onto former abbey grounds has been noted in Coupar Angus (O'Sullivan 1995, 1056), where the demand for space must have been much less.

To judge by the date of pottery fragments in the infilled early ditch, the conversion into plots occurred during the 13 th or 14 th century. A similar date was suggested for the infilling of a ditch within the abbey precinct discovered during earlier excavations (Bain 1998, 1074). This was interpreted as reflecting a major reordering of the abbey as a result of increasing royal patronage in the 14th century. The presence of the monarch in the abbey would have created a need for nearby townhouses of suitable rank for the attendant court and perhaps a demand for new plots.

It is possible that conversion into plots was a piecemeal process. The possibility that the abbey precinct may once have extended onto the site has been suggested previously (Dennison \& Ewart 1998, 44) because of the position of the girth cross as marked on Rothiemay's plan (fig 6.1). This marked the edge of the Abbey Sanctuary and implied that the boundary was some distance further west than Horse Wynd and within the Parliament site. There was no evidence from the relative plot widths to suggest that those on the east were created later than those in the west. However, a contrast becomes apparent between east and west of the vennel in Period 2 when considering the number of finds that the plots contained: the plots to the west (Plots $2.1 \& 2.2$ ) contained more artefactual material and may have been created first. This conclusion is supported by the presence of the vennel itself, as a thoroughfare can often mark a temporary edge of plot development.

A second contrast becomes apparent when considering the depth of deposits across the site, and this may suggest another temporary edge of plot development between Plots 2.4 and 2.5, corresponding to a marked drop in the amount of accumulated material. This conclusion is also supported by a decrease in the amount of artefactual material to the east, within Plots 2.5 and 2.6. If we assume that Plots 2.3 and 2.4 were created with a double width, as would seem to be the case, then the abbey may have been responding to quite specific demands. Given that the plots were being laid out on land that the abbey was in all probability already using, this approach is understandable.

What did the early burgh look like and how did the natural topography of the surrounding area influence the layout?

As noted in Chapter 4.2, it is likely that the abbey created the first burgage plots next to the Holyrood precinct. If the interpretation offered above is correct, the earliest plots are likely to be those immediately west of the excavated area. As shown by Spearman (1988a) in Perth, corroboration of different dates of plot creation can be sought by examining their relative widths, which should be standardised within each contemporary block. Measurements taken from the 1st Edition (1854) Ordnance Survey plan of the area suggested a plot width of around $7 \mathrm{~m}$ to the west and further upslope in the Canongate. The later 
plots on the Parliament site would seem to have been almost twice as wide, at around $13 \mathrm{~m}$. Presumably the area remained as a cultivated part of the abbey precinct until plots occupied all the available space on the ridge between it and the burgh boundary with Edinburgh. The evidence from the excavations suggested that this part of the precinct began to be developed into plots around the 14th century and it would seem that the Canongate's main period of growth, from the precinct to the Netherbow Port, was completed by this time.

With regard to topography, the tail of the Canongate ridge becomes rather constricted as it descends toward the abbey and the area may not have been ripe for plot development until demand led to exploitation of the growing town's margins. The conversion of an area of abbey grounds into plots suggests pressure on, or at least demand for, land. However, the archaeological evidence from within the properties on the site did not suggest that they were subdivided. On the contrary, the backlands of some of the plots appeared to have been amalgamated from the earliest period of division (Plots 2.3 \& 2.4). The lack of buildings in the backlands is apparent on Rothiemay's plan of 1647 (fig 6.1) and contrasts starkly with the burgh of Edinburgh. Excavations within Edinburgh have shown the presence of substantial stone buildings in the backlands from at least the 14th century (Schofield 1976).

This apparent contradiction is not readily explained by any intensive industrial use of the backlands, which would have precluded building. On the contrary, the archaeological evidence suggested that these backlands might only have seen small-scale craft or subsistence activities (a reconstruction of the site during the medieval period is shown in fig 4.2). Certainly, considering that the time span expressed by the features and deposits in Period 2 may have lasted 200 years, it is the lack of features in comparison to other burghs, such as Perth and Aberdeen, that is surprising.

There is some evidence to suggest that the amalgamation of backlands may not necessarily have meant that the corresponding frontages were a single property. Certainly, the tenement wall foundations discovered below Queensberry House (Period 3) suggested divisions where none was evident outside, to the south, in the backlands. It was perhaps the nature of these properties, and the special status of the Canongate, which led to a lack of development in the backlands. They may have been a rather peripheral concern in comparison with the social status to be gained by owning a highly visible frontage, or near-frontage, property. Keeping the backlands as gardens rather than selling them for development may also have been part of expressing status. The artefacts recovered from the plots complement this interpretation, suggesting an increasing level of wealth and conspicuous consumption.

Although in general there was a lack of backland activity within the site, there were significant variations between the plots that should not be ignored. In Period 2 two plots ( $\& 4$ ) were much 'busier' in terms of archaeological features than the others. With Period 2, Plot 2, this distinction was reinforced by a concentration of artefactual remains. This seems likely to have reflected the occupation of the owners. It seems that craftworking was concentrated in these plots, with much less evidence of activity in the others, which also tended to be wider, presumably as a result of amalgamation.

Ironworking waste was concentrated at one time during Period 2 in Plot 2 and suggested that both smithing and smelting were undertaken here. Perhaps this activity was the impetus behind the creation of the vennel providing access from the rear, although an alternative explanation is offered above. There may also have been another craft undertaken in this plot, with some evidence for small-scale skinning. Two twin-tank features located within the plot have been interpreted as tanning tanks (fig 3.35). The tanning process involves both the long-term soaking of hides in a solution of water and vegetable matter (for example, bark) and their daily agitation in an acid or alkaline solution (for example, water with urine, stale beer, lime or dung). The twin tanks could have been used for both. As noted above, the tanks could also have been used to steep barley or flax; neither of these uses is preferred as an interpretation because it is difficult to see why either would require twinned tanks. Dyeing is not considered likely because it usually seems to require some kind of heating.

A medieval tannery has been identified in St Andrews where a series of pits was identified side by side (Lewis 1996). Several tanning pits discovered in Aberdeen had similar dimensions to those identified on the Parliament site and were also rectangular or circular (Cameron \& Stones 2001, 108). However, in contrast to these examples, the small number of tanks on the Parliament site suggested that only a small number of hides could have been processed at any one time. The remains are difficult to interpret 
as any kind of commercial tannery and they may represent tanning to meet specific needs. The animal bones with cut marks indicative of skinning were consistent with this idea, for they came from foxes, dogs, cats and horses, rather than animals commonly used in commercial ventures. Also the presence of bones with cut marks suggested that the animals were skinned here, rather than at the professional skinners of the medieval burgh. Whether these were being processed as part of some kind of specialised leatherworking or for household requirements is difficult to say.

In general, Plot 2.4/Plot 3.4 was the most intensively used for industrial processes throughout the medieval period. Ironworking waste was found toward the front of Plot 2.4. The nature of the metalworking seems to have involved primary smelting and smithing, a surprising discovery given its location on the crowded frontage. Part of this activity may have involved farriery. Horses were probably more common than usual because of the high concentration of nobles in the area. The burial of a horse and also the presence of burnt straw in a structure within Plot 3.4 could even suggest the presence of a stable.

Further to the south, to the rear of the frontage buildings in Plot 2.4, were several large, probably lined, pits joined by channels whose function was not elucidated by any artefactual or environmental remains. The process appeared to have required a nearby source of water. It is possible that the pits were used to steep barley or flax, although it is not clear why this would require more than one pit joined by channels.

The contrast between the plots emphasised the mixed nature of land use in the medieval burgh. Canongate may have contained high-status dwellings, with open back gardens, but these were scattered amongst the workshops and yards of craftworkers. However, as royal patronage of Holyrood continued to rise, the tendency toward high-status properties with gardens became more pronounced.

This leaves an impression of the Canongate as a rather unusual burgh, with a very crowded and grand frontage with relatively open uncluttered space to the rear. Comparison with the width of plots in other towns, from $5 \mathrm{~m}$ in Perth to $10 \mathrm{~m}$ in St Andrews, bears this out, for those excavated on the Parliament site were significantly wider. It is also worth noting that the earlier plots outside the excavated area to the west are comfortably within the expected range. This difference suggests that transformation of the Canongate into an atypical burgh can be traced to around the 14th century, when the site was divided into plots. The process seems likely to reflect increasing royal patronage of Holyrood. It should, of course, be remembered that the Canongate did not operate in isolation, and what became greater Edinburgh evolved out of the growth of three separate settlements (Edinburgh, Canongate and Leith). It was thus possible for Canongate to become the burgh of choice for the wealthy, with the other settlements serving complementary roles: Edinburgh as the commercial centre and Leith as a busy port.

\section{The post-medieval period, 1580-1707}

What was the nature of the buildings and gardens associated with the urban precinct that developed around the Palace of Holyroodhouse?

Canongate's prestige reached its zenith in the early 16th century with the construction of Holyrood Palace. The archaeological remains suggest that this had a rapid and radical impact on the surrounding townscape. Neighbouring properties were purchased and tenements on the frontage were cleared to make space for the grand townhouse that evolved into Queensberry House. The Holyrood Road frontage was developed for the first time with the construction of Haddington House.

What was to become Queensberry House had its genesis in 1667 as Dame Margaret Balmakellie began to buy up neighbouring properties in order to create her 'great lodging'. Although obscured by later alterations, this structure still survives in remarkably wellpreserved form within the later house. This T-shaped building was cleverly designed to maximise the impact both of the Canongate façade and the open views to Holyrood Park at the rear. Expressing aristocratic status amongst the crowded buildings that sprang up around Holyroodhouse was a competitive business and prompted major renovations and extensions of the structure carried out by Lord Hatton from 1679 and the second Duke of Queensberry from 1695. Hatton's most notable addition was the viewing tower or belvedere, the remains of which were discovered in the attic of the building. Queensberry gave the building much of its current appearance, notably the addition of closet towers.

To the rear, archaeological remains of the formal gardens that accompanied these buildings were discovered. A large raised terrace with central 


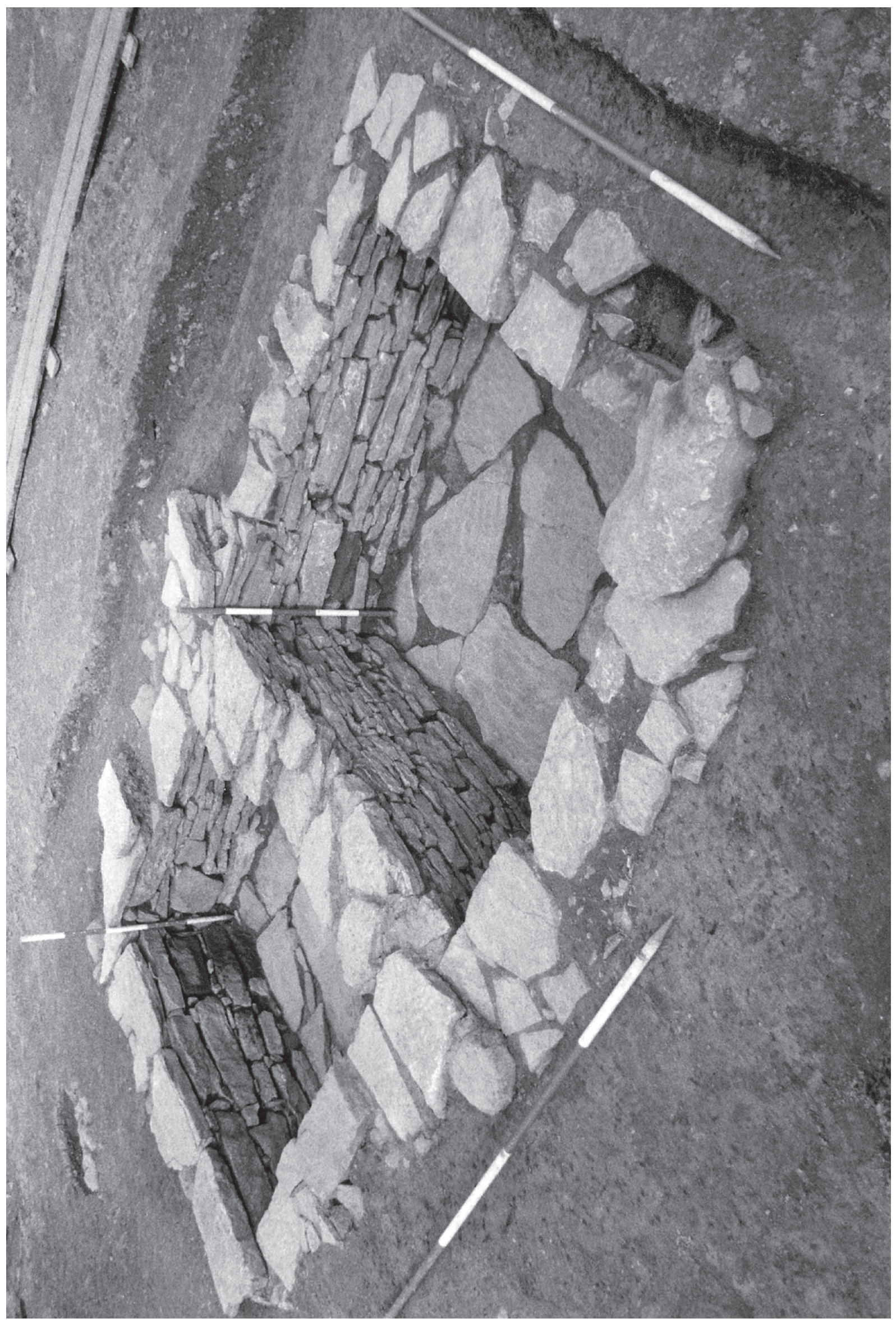

Figure 3.35

Twin tanks that may have been tanning pits 
staircase was constructed to the rear of Balmakellie/ Queensberry House. This would have afforded the owners and their guests a fine panorama over the patterned hedges and plants in the garden, and would have elevated them above neighbouring properties. The artefacts found within the garden included items that reflected importation of luxury items such as wine and perfume, as well as personal items associated with the nobility, especially a wig curler.

Even though the townscape had been dramatically altered, it still retained some medieval character. In particular, it is worth noting the line of a garden path on the route of a vennel during Periods 2 and 3, and the location of Balmakellie House within what had been Plots 2.3 and 3.3, a seemingly amalgamated area of backlands from the earliest phase of plot division.

The remains from Period 4 included a remarkable discovery that allowed a glimpse beyond the nature of the buildings to that of one of the owners. Within the basement of the predecessor of Queensberry House were the surviving remnants of a floor, made somewhat eclectically from handmade brick, sandstone flags and cobbles. It is rare to be able to associate any group of archaeological finds with a particular individual, but it is known from documents that Lord Hatton, the owner from 1679, paid for a cobbled floor to be laid in the kitchen. The excavation revealed metalworking remains likely to relate to the assaying and refining of silver and other precious metals and what appeared to have been the base of an assaying forge associated with this cobbled floor. Lord Hatton was a Master of the Scottish Mint (Chapter 9.4) and refining the quality of silver and other metals would have been relevant to such a position. Given that the room was recorded as a kitchen during Hatton's tenure, it can be questioned whether this was a bona fide workshop. The evidence might be interpreted to suggest that Hatton, on purchasing the house, converted the erstwhile kitchen into a workshop illegally to cream off money from the Royal Mint. The dumps of levelling material that sealed these remarkable remains contained pottery consistent with the date of Queensberry's acquisition of the house following Hatton's disgrace.

\section{The early modern period, 1707-1825}

Did the archaeological evidence reflect the decline in status of the Canongate during this period?

The opening of the New Town, and consequently the availability of more fashionable places to live, seems to have caused an exodus of the wealthy and a decline in the Canongate's prestige. During this period, Queensberry House ceased to be the principal residence of the dukes and became rented accommodation, albeit initially for the upper echelons of society. Very little below-ground archaeology from this period was identified, presumably because very little disturbance or development was carried out. Queensberry House did not undergo major renovations and the most significant, and somewhat poignant, event was the stripping of the interior by William Aitchison after he bought it in 1801. In this sense the absence of all the interior fittings, such as wooden panelling and fine fireplaces, provided the most marked reflection of this decline.

\section{The modern period, 1825-present day}

What remains relating to the site's early development as a brewery survived, and was there any continuity in the use of wells from the medieval period?

The eastern half of the site became a brewery in the second half of the 19th century. The archaeological remains showed, for the first time, extensive development of the old medieval backlands in the form of large structural plinths and foundations. These related to 19th- and 20th-century buildings, but no surfaces or other above-ground elements survived. The medieval and post-medieval wells that survived on the site had not been used in the modern period. The modern brewery wells were large and must have removed completely any medieval predecessors that might have existed. Therefore there was no evidence for any continuity in the use of wells.

In the western part of the site the transformation of the Canongate was typified by the conversion of Queensberry House to a barracks and later to a House of Refuge. Analysis of the finds from the House of Refuge allowed a glimpse into the impoverished lives of the inhabitants, in stark contrast to their privileged post-medieval antecedents. 


\section{REFERENCES}

Aliaga-Kelly, C 1997 'Metal objects', in E Proudfoot \& C Aliaga-Kelly 'Excavations at Niddry Castle, West Lothian, 1986-90', Proc Soc Antiq Scot 127, 821-7.

Allan, J P 1984 Medieval and Post-Medieval Finds from Exeter 1971-80. Exeter.

Ambros, C \& Muller, H-H 1980 Frühgeschichtliche Pferdskelettfunde aus dem Gebiet der Tschechoslowakei. Bratislava.

Ambrosiani, K 1981 Viking Age Combs, Comb Making and Comb Makers in the Light of Finds from Birka and Ribe. Stockholm Studies in Archaeology Series 2. Stockholm.

Andrews, A \& Noddle, B 1975 'Absence of premolar teeth from ruminant mandibles found at archaeological sites', J Archaeol Sci 2, 137-44.

Anson, P 1950 Scots Fisherfolk. Edinburgh.

Armitage, P L 1982 'A system for ageing and sexing the horn cores from British post-medieval sites (17th to early 18th century) with special reference to British Longhorn cattle', in B Wilson; C Grigson \& S Payne (eds) Ageing and Sexing Animal Bones from Archaeological Sites, 255-61. Oxford: BAR Brit Series 109.

Atkinson, D R \& Oswald, A 1969 'London Clay Tobacco Pipes', J Brit Archaeol Assoc 32, 171-227.

Atkinson, D R 1975 Tobacco Pipes of Brosely. Saffron Waldon.

Atkinson, J A \& Photos-Jones, E 2000 " "Brave at heart": clanship and the work of the Highland smith', in S M M Young; A M Pollard; P Budd \& R A Ixer (eds) Metals in Antiquity, 271-9. Oxford: BAR Int Series 792.

Baker, J \& Brothwell, D 1980 Animal Diseases in Archaeology. London.

Ballin, T B 1999 'Bipolar Cores in Southern Norway: classification, chronology and geography', Lithics (Newsletter of the Lithic Studies Soc) 20,13-22.

Barker, T C 1977 The Glassmakers, Pilkington 1826-1976. London.

Black, M 1992 The Medieval Cookbook. London.

Boessneck, J 1969 'Osteological differences between sheep (Ovis aries Linné) and goat (Capra hircus Linné)', in Brothwell \& Higgs (eds) 1969, 331-58.

Bogdan, N Q \& MacGregor, A forthcoming The Perth High Street Archaeological Excavation. The worked bone. Unpublished Historic Scotland Report.

Bogdan, N Q; Hodgson, G W I; Smith, C; Jones, A; Fraser, M; Heppel, D; Clarke, A S; Jones, A K G; Smart, I H M; Longmore, R B; Cerón-Carrasco, R \& MacKay, D forthcoming The Perth High Street Archaeological Excavation. Fascicule IX. The environmental evidence. Historic Scotland Report.

Brothwell, D \& Higgs, E S (eds) 1969 Science in Archaeology. London. Second edn.

Bullock, P; Federoff, N; Jongerius, A; Stoops, G \& Tursina, T 1985 Handbook for Soil Thin Section Description. Wolverhampton.

Caldwell, D H 1991 'Tantallon Castle, East Lothian: a catalogue of the finds', Proc Soc Antiq Scot 121, 335-57.

Caldwell, D H 1996a 'Small finds', in J H Lewis, 'Excavations at St Andrews, Castlecliffe, 1988-90', 635-45, Proc Soc Antiq Scot 126, 605-88.

Caldwell, D H 1996b 'A note on the finds from the palace', in D Caldwell \& J H Lewis 'Linlithgow Palace: an excavation in the west range and a note on the finds from the palace', 632-67, Proc Soc Antiq Scot 126, 823-69.

Caldwell, D H \& Dean, V E 1992 'The pottery industry at Throsk, Stirlingshire, in the 17th and early 18th century', Post-Medieval Archaeol 26, 1-46.

Cameron, A S \& Evans, D 2001 'Pottery', in A S Cameron \& J A Stones (eds) Aberdeen: an in-depth view of the city's past, 153-92. Edinburgh: Soc Antiq Scot Monog 19.

Carter, S P 2001 'A reassessment of the origin of the St Andrews "Garden Soil", Tayside \& Fife Archaeol J 7, 87-92.

Chambers, R 1858 Domestic Annals of Scotland. Volume 1. Edinburgh \& London.

Charleston, R J 1984 'The glass', in Allan 1984, 337-48.

Clark, J (ed) 1995 The Medieval Horse and its Equipment. London.

Clark, J 1986 Medieval Horseshoes. Finds Research Group 7001700, Datasheet 4.

Clarke, P V \& Hurst, J 1978 'German Stoneware', in J Schofield 1976, 206-11.

Coad, J \& Streeten, A D 1982 'Excavations at Castle Acre Castle, Norfolk, 1972-77’, Archaeol J 139, 138-301.

Cochran-Patrick, R W 1892 Medieval Scotland. Glasgow.

Coull, R J 1996 The Sea Fisheries of Scotland: a historical geography. Edinburgh.

Cox,A 1995 'The finds', in DW Hall 'Excavations at St Nicholas Farm, St Andrews', Tayside E Fife Archaeol J 1, 63-7.

Cox, A 1996a 'Post-medieval dress accessories from recent urban excavations in Scotland', Tayside \& Fife Archaeol J 2, 52-9.

Cox, A 1996b 'Copper alloy objects', in R Coleman 'Excavations at the Abbot's House, Dunfermline', Tayside \& Fife Archaeol J 2, 91-4.

Cox, A 1996c 'Backland activities in medieval Perth: excavations at MealVennel and Scott Street', Proc Soc Antiq Scot 126, 733-821.

Cox, A 1998 ‘Artefacts', in DW Hall;A D S MacDonald; D R Perry \& J Terry 'The archaeology of Elgin: excavations on Ladyhill and in the High Street, with an overview of the archaeology of the burgh', Proc Soc Antiq Scot 128, 790-6.

Cox, A 1999 'The artefacts', in C Smith; D Hall; A Cox \& R Cerón-Carrasco, Report on the Medieval Finds Assemblages from Urquhart Castle. Unpublished Historic Scotland Report.

Cox,A 2000a 'The artefacts', in D R Perry Castle Park, Dunbar: two thousand years on a fortified headland. Edinburgh: Soc Antiq Scot Monogr Series 16, 113-67.

Cox, A 2000b 'The artefacts', in G Brown \& M Roy 'Excavations at 27-35 Panmure Street/72-78 Murraygate, Dundee', Tayside \& Fife Archaeol J 6, 82-3. 
Cox, A forthcoming 'The artefacts', in D Perry; M Middleton \& S Farrell 'Excavations at Pullars Works, Mill Street and Curfew Row, Perth, 1999'.

Cox, A and King, M 1997 'Recent medieval metalwork finds from East Fife', Tayside E Fife Archaeol J 3, 188-203.

Crossley, D 1987 'Sir William Clavell's glasshouse at Kimmeridge, Dorset: the excavations of 1980-81', Archaeol J 144, 340-82.

Crossley, D \& Aberg, F 1972 '16th-century glass-making in Yorkshire: Excavations at Hutton and Rosedale, North Riding 1968-71', Post-Medieval Archaeol 6, 125-59.

Crummy, N 1988 The Post-Roman Small Finds from Excavations in Colchester 1971-85. Colchester Archaeological Trust Ltd, Colchester.

Cunnington, CW \& Cunnington, P 1969 Handbook of English Medieval Costume. London: Faber \& Faber.

Cunnington, C W; Cunnington, P \& Beard, C 1960 A Dictionary of English Costume 900-1900. London: Barnes \& Noble.

Davey, P (ed) 1987 Archaeology of the clay tobacco pipe 10. Oxford: BAR Brit Ser, 178.

Davey, P J 1992 'Dutch clay tobacco pipes from Scotland', in D Gaimster \& M Redknap (eds) Everyday and Exotic Pottery from Europe c 650-1900. Studies in honour of John Hurst, 279-89. Oxford.

Davidson, J \& Gray, A 1909 The Scottish Staple at Veere. London.

Dawson,J 1999 'A report on crockery at the Royal Edinburgh Asylum c 1857-77', Scottish Pottery 20th Historical Review, $18-30$.

Dawson, J 2000 Crockery from Craiglockhart Poorhouse, Edinburgh. Unpublished MA dissertation. Also available on the internet on www.poorhouse.org.uk.

Dawson, J forthcoming Ceramics from the Royal Edinburgh Asylum.

de Neergaard, M 1987 'The use of knives, shears, scissors and scabbards', in J Cowgill; M de Neergaard \& N Griffiths, Knives and Scabbards, 51-61. London.

Dearn, M \& Branigan, K 1995 'The use of coal in Roman Britain', Antiq J 75, 71-105.

Donnelly, M;Atkinson, J A \& Photos-Jones, E 1999 Letterewe Phase 1: Survey and Archaeological Research. GUARD Report 537/SASAA Report 12.1.

Duco, D H 1981 'De Kleipijp in de Zeventiende Eeuwse Nederlanden', in P Davey (ed) The Archaeology of the Clay Tobacco Pipe. V, 111-468. Oxford: BAR Int Series 106.

Duco, D H 1987 De Nederlandse kleipijp: handbook voor dateren en determineren. Leiden.

Dyer, J 1974 'The excavation of two barrows on Galley Hill, Streatley', Bedfordshire Archaeol J 9, 13-34.

Eames, E 1983 'Floor Tiles', in J Wordsworth 'Friarscroft and the Trinitarians', in D E Easson (ed) 1947 Charters of the Abbey of Coupar Angus. Edinburgh.

Egan, G \& Pritchard, F 1991 Dress Accessories. London: HMSO.

Egan, G 1996 'Some archaeological evidence for metalworking in London c 1050-1700 AD', J Hist Metall Soc 30(2), 83-94.

Ewan, E 1990 Townlife in Fourteenth-century Scotland. Edinburgh.

Ewart, G \& Baker, F 1998 ‘Carrick Castle: symbol and source of Campbell power in south Argyll from the 14th to the 17th century', Proc Soc Antiq Scot 128, 937-1016.

Fabian-Baddiel, S 1994 Miller's Golf Memorabilia. London.

Fenton, A 1963 'The Rural Economy of East Lothian in the 17th and 18th centuries', Trans E Lothian Antiq Fld Natur Soc 9, 1-23.

Ford, B \& Walsh, A 1987 'Horseshoe nails', in Holdsworth (ed), 137.

Ford, B 1987a 'Copper alloy objects', in Holdsworth (ed), 121-30.

Ford, B 1987b 'Stone objects', in Holdsworth (ed), 147-50.

Ford, B 1995 'Artefacts', in D Bowler; A Cox \& C Smith 'Four excavations in Perth, 1979-84', Proc Soc Antiq Scot 125, 959-79.

Frank, S 1982 Glass and Archaeology. London.

Gaimster, D \& Hughes, M 1999 'The earliest maiolica stove in north-west Europe: reanalysis of the Dissolution finds from the Abbey of St Mary Graces, London', in D Gaimster (ed) Maiolica in the North:The Archaeology of TinGlazed Earthenware in North-West Europe c 1500-1600, 185-8. London.

Gaimster, D 1988 'Lower Rhine Slipware found in Britain', in J Naumann Keramik vom Niederrhein und ihr internationales Umfeld, 167-78. Dusseldorf: Beitrage zur Keramik 3.

Gaimster, D 1990 'The Continental stove tile fragments from St Mary Graces, London, in their British and European context', Post-Medieval Archaeol 24, 1-49.

Gaimster, D 1997 German Stoneware 1200-1900. Archaeology and Cultural History. London.

Gallagher, D B 1984 'Scottish three-letter basal stamps', Soc Clay Pipe Research Newsletter 3, 9-11.

Gallagher, D B 1987a 'Pipes for the Company of Scotland: the documentary evidence', in Davey 1987, 233-8.

Gallagher, D B $1987 b$ 'Edinburgh pipemakers in the seventeenth century: the documentary evidence', in Davey 1987, 1-13.

Gallagher, D B 1987c 'The 1900 price list of the Pipe-makers' Society', in Davey 1987, 142-63.

Gallagher, D B 1987d'Thomas White, tobacco pipe manufacturer of Canongate, Edinburgh', in Davey 1987, 26-8.

Gallagher, D B 1998 'Holyrood Abbey: the disappearance of a monastery', Proc Soc Antiq Scot 128(2), 1079-99.

Geddes, J \& Carter, A 1977 'Objects of non-ferrous metal, amber and paste', in $\mathrm{H}$ Clarke \& A Carter, Excavations in King's Lynn, 1963-70, 287-91. Leeds: Soc Med Archaeol Monogr Series 7.

Gerrard, C M; Gutierrez, A \& Vince, A 1995 Spanish Medieval Ceramics in Spain and the British Isles. Oxford: BAR Int Series 610.

Gerrard, F 1977 Meat Technology. London.

Gibson, W M 1994 Fishing in Old East Lothian (Cockenzie, Port Seaton, Fisherrow and Prestonpans). Edinburgh.

Godfrey, E S 1975 The Development of English Glassmaking 1560-1640. London.

Good, G L \& Tabraham, C J 1981 'Excavations at Threave Castle, Galloway, 1974-78', Medieval Archaeol 25, 90-140.

Goodall, A R 1984 'Objects of non-ferrous metal', in J P Allan Medieval and Post-medieval Finds from Exeter 197180, 337-48. Exeter: Exeter Archaeol Rep 3.

Goodall, I H 1975 'Metalwork from Goltho', in G Beresford, 
The Medieval Clay-land Village: excavations at Goltho and Barton Blount, 79-98. Leeds: Soc Med Archaeol Monogr Series 6.

Goodall, I H 1983 'Iron objects', in P Mayes \& L A S Butler Sandal Castle Excavations 1964-73. Wakefield.

Gooder, E 1984 'Glass', in E Gooder 'Finds from the cellar of the Old Hall, Temple Balsall', Post-Medieval Archaeol $18,149-249$.

Gooder, E; Woodfield, C \& Chaplin, R E 1964 'The walls of Coventry', Trans Proc Birmingham Archaeol Soc 81, 88-139.

Gooder, G 1999 'Archaeological Excavation at Plot N, Holyrood North Development Area, Edinburgh: Data Structure Report'. Unpublished AOC Archaeology Group Report.

Graham, P 1980 Angling in the Lothians: A Commentary and Guide to Freshwater Fishing. Edinburgh.

Grant, A 1982 'The use of tooth wear as a guide to the age of domestic ungulates', in Wilson et al (eds) 1982, 55-71.

Griffiths, N 1995 'Harness pendants and associated fittings', in J Clark (ed) The Medieval Horse and its Equipment, 6171. London.

Grove, D 2000 'Animal bone, 1983-85', in P Dixon; J O’Sullivan \& I Rogers Archaeological Excavations at Jedburgh Friary 1983-89, 64-7. Edinburgh: Scot Trust Archaeol Res Monogr 5.

Guy, I 1982 The Scottish Export Trade, 1460-1599, from the Exchequer Rolls. University of St Andrews, MPhil thesis.

Haggarty, G 1980 'The pottery', in G Ewart 'Excavations at Stirling Castle 1977-78', Post-Medieval Archaeol 14, 36-46.

Haggarty, G 1984 'Observations on the ceramic material from phase 1 pits BY and AQ', in C Tabraham 'Excavations at Kelso Abbey', Proc Soc Antiq Scot 114, 395-7.

Haggarty, G 1999 'The pottery from St Nicholas Farm, St Andrews', in J Hamilton \& R Toolis 'Further excavations at the site of a medieval leper hospital at St Nicholas Farm, St Andrews', Tayside E Fife Archaeol J 5, 97-101.

Haggarty, G 2006 'A gazetteer and summary of French pottery imported into Scotland c 1150-c 1650', Tayside $\mathcal{E}$ Fife Archaeol J 12, ceramic resource CD.

Haggarty, G forthcoming 'The pottery', in 'Excavations at Calton Road, Edinburgh'. Unpublished AOC Archaeology Ltd Report.

Hall, A J \& Photos-Jones, E 1998 'The bloomery mounds of the Scottish Highlands: Part 2 - a review of iron mineralization', J Histl Metall Soc 32(2), 54-66.

Hall, D W 1989 'Ceramic Objects', in J Stones A (ed) Three Scottish Carmelite Friaries: Excavations at Aberdeen, Linlithgow \& Perth 1980-86, Microfiche 12, 9.3.3. Edinburgh: Soc Antiq Scot Monogr Series 6.

Hall, D W 1996a 'Blind date - Scottish medieval pottery industries', Tayside \& Fife Archaeol J 2, 126-8.

Hall, D W 1996b 'The pottery', in D Bowler; A Cox \& C Smith (eds) 'Four excavations in Perth 1980-84', Proc Soc Antiq Scot 125, 952-9.

Hall, D W 1997 'The pottery', in M Rains \& D W Hall (eds) Excavations in St Andrews 1980-88: A Decade of Archaeology in a Historic Scottish Burgh. Glenrothes: Tayside \& Fife Archaeol Com Monogr 1, 40-63.

Hall, D W 1998 'The Scottish medieval pottery industry - a pilot study', Tayside \& Fife Archaeol J 4, 170-8.
Hall, D W \& Haggarty, G 2006 'The Pottery', in M Collard; $\mathrm{J}$ A Lawson \& N Holmes Archaeological Excavations in St Giles Cathedral Edinburgh 1981-93. SAIR 22.

HAPT, Holyrood Archaeology Project Team 2008 Scotland's Parliament Site and the Canongate. Edinburgh: Society of Antiquaries of Scotland Monograph.

Harcourt, R 1974 'The dog in prehistoric and early historic Britain', J Archaeol Sci 1, 151-75.

Harvey, Y 1975 'The small finds', in C Platt \& R ColemanSmith (eds) Excavations in Medieval Southampton, 1953-69. Volume 2: The finds, 254-313. Leicester.

Hastie, M \& Holden, T G 2000 'The plant remains', in G Brown \& M Roy (eds) 'Excavations at 27-35 Panmure Street/728 Murraygate, Dundee', Tayside \& Fife Archaeol J 6, 63-7.

Henderson, IT \& Stirk, D I 1982 Golf in the Making. London, second edition.

Henkes, H 1994 Glas Zonder Glans. Rotterdam: Rotterdam Papers 9.

Hodgson, G W I, Smith, C \& Jones, A forthcoming 'The mammal bone', in Bogdan et al.

Holden, T G \& Hastie, M 2001 'The plant remains', in Moloney \& Baker, 77-9.

Holden, T G 1998 'The charred plant remains', in J R Mackenzie (ed) 'Excavations at Green's Playhouse, 106110, Nethergate, Dundee', Tayside \& Fife Archaeol J 4 198-9.

Holdsworth, P (ed) 1987 Excavations in the Medieval Burgh of Perth 1979-81. Edinburgh: Soc Antiq Scot Monogr Series 5 .

Holmes, E F 1988 Sewing Thimbles. Finds Research Group 700-1700, Datasheet 9.

Horton, M C, Higgins, D A \& Oswald, A 1987 ‘Clay tobacco pipes from the Scottish Darien colony (1698-1700)', in Davey 1987, 239-52.

House of Refuge 1835 House of Refuge for the Destitute. Second Report by the Committee of the House of Refuge for the Destitute, July 1835. Edinburgh.

Hume Brown, P 1891 Early Travellers in Scotland. Edinburgh.

Hume, I N 1961 'The glass wine bottles of ColonialVirginia', J Glass Studies 3, 91-117.

Hume, M \& Boyd, S C 1984 Queensberry House Hospital: A History. Edinburgh.

Hurst, J; Neal, D S \& Van Beuningen, H J E 1986 Pottery Produced and Traded in North-West Europe 1350-1650. Rotterdam: Rotterdam Papers VI.

Innes, C \& Thomson, T (eds) 1854 Acts of the Parliament of Scotland. 12 vols. London.

Janssen, H 1981 'Later medieval pottery production in the Netherlands. Appendix 1', in P Davey \& R Hodges 1981 Ceramics and Trade. Sheffield.

Jones, R; Will, R; Haggarty, G \& Hall, D W 2003 'Sourcing Scottish White Gritty Ware', Medieval Ceramics 26-7 (2002-3), 45-84.

Keene, D 1996 'Metalworking in medieval London: an historical survey', J Hist Metall Soc 30(2), 94-103.

Kelly, H 1999 Scottish Ceramics. Pennsylvania.

Kenworthy, J B 1982 'The flint', in J C Murray (ed) Excavations in the Medieval Burgh of Aberdeen 1973-81, 200-15. Edinburgh: Soc Antiq Scot Monogr Series 2.

Laing, L 1999 'The finds', in I MacIvor \& D Gallagher 'Excavations at Caerlaverock Castle, 1955-66', Archaeol J 156, 196-239. 
le Cheminant, R 1982 'The development of the pipeclay hair curler - a preliminary study', in P Davey (ed) The Archaeology of the Clay Tobacco Pipe, VII, 102-26. Oxford: BAR Brit Series 100.

Legge, A J \& Rowley-Conwy, P A 1988 Star Carr Revisited. London.

le Patourel, H E J 1973 The Moated Sites of Yorkshire. Leeds: Soc Med Archaeol Monogr Series 5.

Lemmen, H van 1998 Delftware Tiles. Buckinghamshire.

Lindsay, W J 1983 ‘Appendix 1:The pottery', in D Hall \& W J Lindsay 1983 'Excavations at Scalloway Castle, 1979 and 1980', Proc Soc Antiq Scot 113, 565-77.

Lockhart, GW 1997 The Scots and their Fish. Edinburgh.

Logan, J C 1972 'The operation of a glassworks in the Industrial Revolution', Industrial Archaeology 9 (2), 177-87. Newton Abbot: David and Charles.

Lynch, M, Spearman, M \& Stell, G (eds) 1988 The Scottish Medieval Town. Edinburgh.

Macadam, W I 1887 'Notes on the ancient iron industry of Scotland', Proc Soc Antiq Scot 21, 89-131.

MacAskill, N L 1987 ‘Ceramic building material', in P Holdsworth (ed) 1987, 156-7.

MacCormick, A 1996 'Metalworking in medieval Nottingham 1100-1641', J Hist Metall Soc 30(2), 103-110.

MacGregor, A 1982 'Bone, antler and ivory objects', in J C Murray (ed) Excavations in the Medieval Burgh of Aberdeen 1973-78, 180-4. Edinburgh: Soc Antiq Scot Monogr Series 2 .

Marshall, J S 1986 The Life and Times of Leith. Edinburgh.

Martin, C J M 1987 'A group of pipes from Mid Shore, Pittenweem, Fife', in Davey 1987, 183-209.

Maxwell, R 1997a 'Copper alloy objects', in Hall \& Rains (eds) 1997, 64-74.

Maxwell, R 1997b 'Ceramic roof tile', in Hall \& Rains (eds) 1997, 90-2.

McCarthy, M \& Brooks, C M 1988 Medieval Pottery in Britain AD 900-1600. Leicester.

McGowran, T 1985 Newheaven on Forth: Port of Grace. Edinburgh.

McGreggor, M; Lee, G W \& Wilson, GV 1920 The Iron Ores of Scotland. Tansfield: Special Reports on the Mineral Resources of Great Britain.

McNeill, P G B \& MacQueen, H L 1996 Atlas of Scottish History to 1707. Edinburgh:The Scottish Medievalists and Department of Geography, University of Edinburgh.

Miller, G 1991 'Classification and Economic Scaling of 19thCentury Ceramics', in G Miller (ed) Approaches to Material Culture Research for Historical Archaeologists, 37-58. Pennsylvania: The Society for Historical Archaeology.

Moloney, C \& Baker, L M 2001 'Evidence for the form and nature of a medieval burgage plot in St Andrews: an archaeological excavation on the site of the Byre Theatre, Abbey Street, St Andrews', Tayside E Fife Archaeol J 7, 49-86.

Mowat, S 1994 The Port of Leith: Its History and Its People. Edinburgh.

Murdoch, K R 1997 'Glass', in E Proudfoot \& C Aliaga-Kelly 'Excavations at Niddry Castle, West Lothian, 1986-90', Proc Soc Antiq Scot 127, 783-842.

Murdoch, K R 2001 'The glass and window-lead', in K L Mitchell; K R Murdoch \& J R Ward, Fast Castle: Excavations 1971-86, 81-8. Edinburgh.
Murdoch, K R 2002 'Vessel glass', in J Lewis Spynie Palace and the Bishops of Moray. History, Architecture and Archaeology, 137-40. Edinburgh: Soc Antiq Scot Monogr Series 21.

Murphy, C P 1986 Thin Section Preparation of Soils and Sediments. Berkhamsted.

Murray, H K \& Murray, J C 1993 'Excavations at Rattray, Aberdeenshire. A Scottish deserted burgh', Medieval Archaeol 37, 109-218.

NAS National Archives of Scotland.

New Statistical Account of Scotland (NSAS), volume 1: List of Parishes: Edinburgh. 1845.

Nicholson, R 1991 An Investigation into Variability within Archaeologically Recovered Assemblages of Faunal Remains: The Influence of Pre-depositional Taphonomic Processes. University of York, DPhil thesis.

Norton, C 1994 'Medieval floor tiles in Scotland', in J Higgitt (ed) Medieval Art and Architecture in the Diocese of St Andrews. Brit Archaeol Assoc Conf Trans 1986, 137-73.

O’Sullivan, J 1995 'Abbey, market and cemetery: topographical notes on Coupar Angus in Perthshire, with a description of archaeological excavations on glebe land by the parish church', Proc Soc Antiq Scot 125, 1045-68.

Oakley, G E 1979 'The copper alloy objects', in J H Williams, St Peter's Street Northampton: excavations 1973-76, 24864. Northampton.

Payne, S 1973 'Kill-off patterns in sheep and goats - the mandibles from A van Kale', J Anatolian Stud 23, 281-303.

Photos-Jones, E 1997 The Technical Examination of Two Artefacts (Billet and Bloom) from the Stidriggs Hoard, Dumfries and Galloway. SASAA Internal Report 7.

Photos-Jones, E 1999a The Metallurgical Characterization of the Tarras Farm, by Forres, Bloomery Iron Furnace and Industrial Waste: Scotland's Earliest Dated Bloomery Furnace? SASAA Internal Report 40.

Photos-Jones, E 1999c 'The Calderbank Project: a research design'. SASAA Internal Report 37.

Photos-Jones, E 2000 The Technical Characterization of Industrial Waste from the Excavations at the High Street, Rothesay, Isle of Bute, with a View to Establishing Possible Industrial Activities Associated with the Castle. SASAA Internal Report 47.

Photos-Jones, E 2001 The Technical Characterization of the Caerlaverock 'Old' Castle, Dumfrieshire Industrial Waste. SASAA Internal Report 30.1.

Photos-Jones, E; Atkinson, J A; Hall, A J \& Banks, I 1998 ‘The Bloomery Mounds of the Scottish Highlands. Part I: The archaeological background', J Hist Metall Soc 32(1), 15-32.

Photos-Jones, E \& Atkinson, J A 1998 'Ironworking in Perth: a case of town and country', Proc Soc Antiq Scot 128, 887-904.

Purmer, D \& van der Wiel, H J 1996 Handboek van het Nederlands Kopergeld 1523 1797.Vriezenveen.

Ray, A 1973 English Delftware Tiles. London.

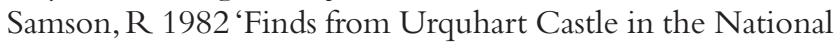
Museum, Edinburgh', Proc Soc Antiq Scot 112, 465-76.

Samuel, A M 1918 The Herring: Its Effects on the History of Britain. London.

Saville, A 1994 'Exploitation of lithic resources for stone tools in earlier prehistoric Scotland', in N Ashton \& A David (eds) Stories in Stone, 57-70. Lithic Studies Society Occasional Papers 4. London. 
Schofield, J 1976 'Excavations south of Edinburgh High Street, 1973-74', Proc Soc Antiq Scot 107 (1975-6), 155-241.

Schubert, H R 1957 History of the British Iron and Steel Industry from c $450 B C$ to $A D$ 1775. London.

Sexton, A H 1902 An Outline of the Metallurgy of Iron and Steel. Manchester.

Silver, I 1969 'The ageing of domestic animals', in Brothwell \& Higgs (eds) 1969, 283-302.

Smith, A M 1995 The Nine Trades of Dundee. Dundee:Abertay Historical Society.

Smith, C 1996 'The animal bone', in A Cox 'Backland activities in medieval Perth: excavations at Meal Vennel and Scott Street', Proc Soc Antiq Soc 126, 792-4 \& 812-3.

Smith, C 1998 'Dogs, cats and horses in the Scottish medieval town', Proc Soc Antiq Scot 128, 859-85.

Smith, C 2000a 'The animal bone', in D R Perry Castle Park, Dunbar: Two Thousand Years on a Fortified Headland, 194279. Edinburgh: Soc Antiq Scot Monogr Series 16.

Smith, C 2000b 'A grumphie in the sty: an archaeological view of pigs in Scotland, from their earliest domestication to the agricultural revolution', Proc Soc Antiq Scot 130, 705-24.

Smith, C 2001 'The animal bone', in Moloney \& Baker 2001, 71-3.

Smith, C 2003 'The animal bone from Briggait, Peebles', in P J Dixon; J R MacKenzie; D R Perry \& P Sharman (eds) The Origins of the Settlements at Kelso and Peebles, Scottish Borders. Scottish Archaeological Internet Reports (SAIR) 2.

Smith, C \& Clark, A S forthcoming 'The bird bones', in N Q Bogdan, G W I Hodgson, C Smith, A Jones, M Fraser, D Heppel, A S Clarke, A K G Jones, I H M Smart, R B Longmore, R Céron-Carrasco \& D MacKay The Perth High Street Archaeological Excavation. The environmental evidence. Historic Scotland Report.

Smith, C S \& Forbes, R J 1957 'Metallurgy and assaying', in C Singer; E J Holmyard; A R Hall \& T Williams (eds) $A$ History of Technology, Volume 3. From the Renaissance to the Industrial Revolution c 1500-1750. Oxford.

Smythe, R H \& Goody, P C 1975 The Horse. Structure and Movement. London.

Snodgrass, C P 1953 Statistical Account of Scotland - The County of East Lothian. Edinburgh.

Spearman, R M 1988 'Workshops, materials and debris: evidence of early industries', in Lynch et al (eds) 1988, 134-47.

Stevenson S, Simpson, A T \& Holmes N 1981 Historic Edinburgh, Canongate and Leith: the archaeological implications of development. Scottish Burgh Survey.
Stones, J A 1989 'The small finds: summary report', in J A Stones (ed) Three Scottish Carmelite Friaries, 147-63. Edinburgh: Soc Antiq Scot Monogr Series 6.

Teichert, M 1975 'Osteometrische Untersuchungen zur Berechnung der Widerristhöhe bei Schafen', in A T Clason (ed) Archaeozoological Studies, 51-69. Amsterdam.

Thompson, A; Grew, F \& Schofield, J 1984 'Excavations at Aldgate, London, 1974', Post-Medieval Archaeol 18, $1-148$.

Turner Simpson, A \& Holmes, N 1981 History of a Great Hospital. Edinburgh Royal Infirmary, 1729-1929. Edinburgh.

Tylecote, R F 1976 The History of Metallurgy. London.

Tylecote, R F 1986 The Prehistory of Metallurgy in the British Isles. London.

Verhaege, F 1983 'Low Countries medieval pottery imported into Scotland: notes on a minor trade', Medieval Ceramics 7, 3-44.

von den Driesch,A 1976 A Guide to the Measurement of Animal Bones from Archaeological Sites. Peabody Museum Bulletin 1. Massachussets.

Vose, R H 1994 'Excavations at the 17th-century glasshouse at Haughton Green, Denton, near Manchester', PostMedieval Archaeol 28, 1-71.

Watson, W 1956 Flint Implements. An Account of Stone Age Techniques and Cultures. London.

Watt, D E R (ed) 1987 Scotichronicon by Walter Bower. Aberdeen.

Watters, B 1998 Where Iron Runs Like Water! A New History of Carron Iron Works 1759-1982. Edinburgh.

Wheeler, A \& Jones, A K G 1989 Fishes. Cambridge Manuals in Archaeology. Cambridge.

Whittington, G, Edwards, K J \& Cundill, P R 1991 'Late and post-glacial vegetational change at Black Loch, Fife, eastern Scotland - a multiple core approach', New Phytologist 118, 147-66.

Whyte, I D 1976 'Grain production in East Lothian in the seventeenth century', Trans E Lothian Antiq Fld Natur Soc $15,39-47$.

Will, R 1999 Tarras by Forres. Unpublished Glasgow University Archaeology Research Division (GUARD) Report 567.

Wilson, B, Grigson, C \& Payne, S (eds) 1982 Ageing and Sexing Animal Bones from Archaeological Sites. Oxford: BAR Brit Series 109.

Wood, E S 1982 'A 16th-century glasshouse at Knightons, Alfold, Surrey’, Surrey Archaeol Collect 73, 1-47.

Yeoman, P 1995 Medieval Scotland. London: Batsford.

Yonge, C M 1960 Oysters. London. 